\author{
Sanderson César Macêdo Barbalho
}

\title{
Modelo de referência para o desenvolvimento de produtos mecatrônicos: proposta e aplicações
}

Tese de doutoramento apresentada à Escola de Engenharia de São Carlos, como parte dos requisitos para a obtenção do título de doutor em engenharia mecânica.

ORIENTADOR: Prof. Tit. Henrique Rozenfeld

São Carlos

Maio / 2006 



\section{DEDICATÓRIA}

Esse trabalho é dedicado a Rennê e Jade, esposa e filha. E companheiras. Para minha madrinha Mundoca (in memoram). 



\section{AGRADECIMENTOS}

Ao Professor Titular Henrique Rozenfeld pela orientação e pelas oportunidades de desenvolvimento profissional e aprendizado.

Aos colegas do NUMA. Especialmente Savi, o primeiro com quem troquei idéia sobre essa cidade tão diferente de minha terra Natal. A Elaine e Kamarão, pela amizade e companheirismo. Ao colega e Professor Sérgio vai minha gratidão por diversos momentos nos quais pus à prova sua paciência em escutar meus devaneios.

Ao longo do trabalho diversos alunos de Iniciação Científica contribuíram com o resultado final da pesquisa. Deixo meu agradecimento especial a Cláudia, Felipe, André, Artur e Lucas pela dedicação no trabalho conjunto que fizemos com o Cenário de Integração. Deixo meu agradecimento também a Vinícius e Renan que foram os alunos de graduação que mais contribuíram com o MRM.

Agradeço à equipe de administração do NUMA. Cristiane foi fantástica em diversos momentos, em especial na impressão do trabalho final. Fernandinho, pela amizade, as peladas no CEFER e a paciência em resolver meus problemas computacionais. Francis, sempre disposta a ajudar os desorganizados com a força do São Longuinho. À Thelma pelo trabalho artístico que fez desta tese algo bonito de se ver.

Ao Prof. e amigo Telésforo, pela confiança no meu trabalho e pelo apoio dado ao início dessa jornada São Carlense. Espero ter honrado seu nome.

Ao amigo Erasmo pela paciência em ler o texto de minha tese e pela força dada sempre que nos encontrávamos.

Ao Eng. Mário Stefani, diretor da OPTO ELETRÔNICA S.A., a quem devo a oportunidade de ter realizado uma série de atividades que não tiveram paralelo quanto à contribuição para minha formação profissional.

Aos colegas Alexandre e Daniel que me ajudaram a desenvolver os questionários de levantamento de dados. A Fabiano pela contribuição amiga. A Paula pelo empenho em desenvolver as telas do site do MRM. A todos os que integram o P\&D da OPTO ELETRÔNICA S.A.

À Rennê, esposa, amiga, conselheira: me aturou nos momentos mais críticos do trabalho, transcreveu todas as entrevistas, corrigiu texto etc. etc. À Jade, por torcer para termos mais tempo para brincar. Ao Seu Lincoln por ter sido companheiro. A minha família, em especial minha avó Alice, agradeço a torcida. 



\section{ÍNDICE}

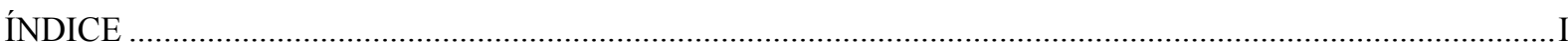

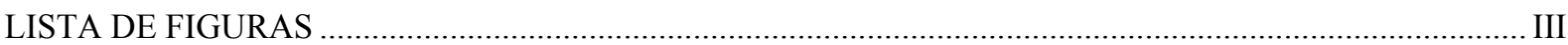

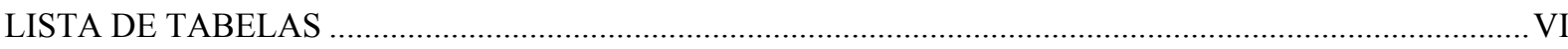

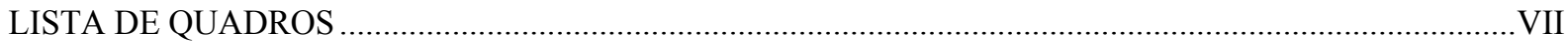

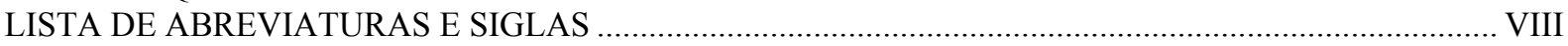

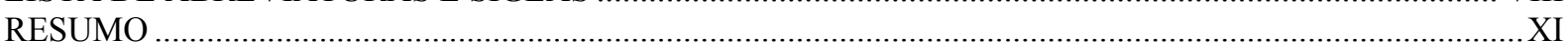

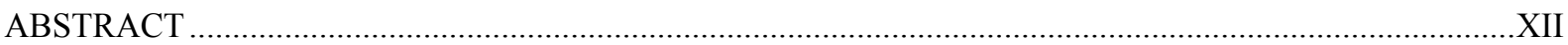

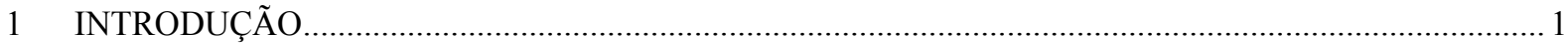

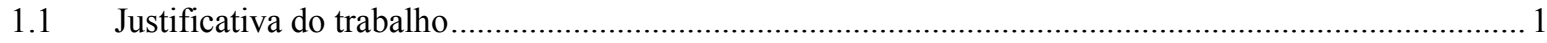

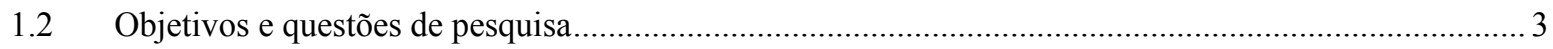

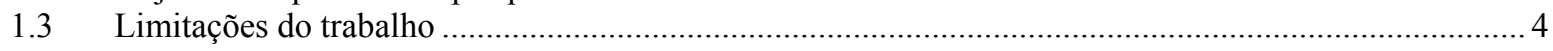

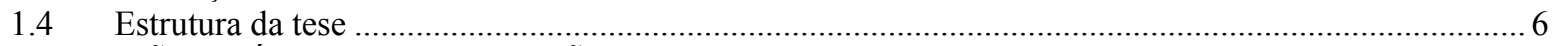

2 REVISÃO TEÓRICA - INTRODUÇÃO AOS TEMAS PRINCIPAIS DO TRABALHO ............................... 7

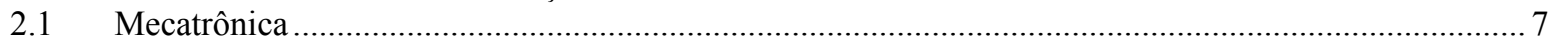

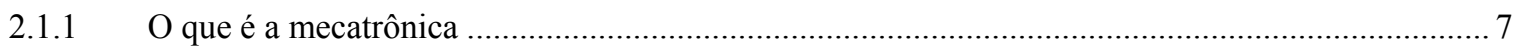

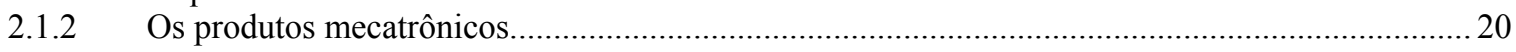

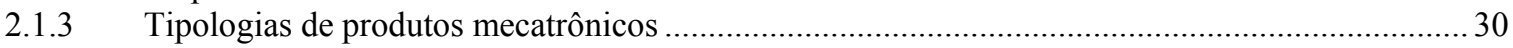

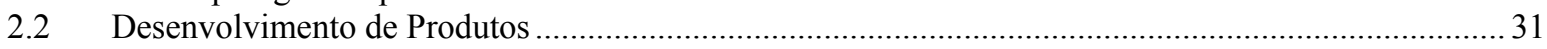

2.2.1 Abordagens para o entendimento do desenvolvimento de produtos................................................ 31

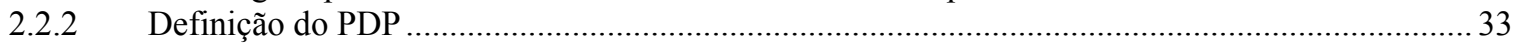

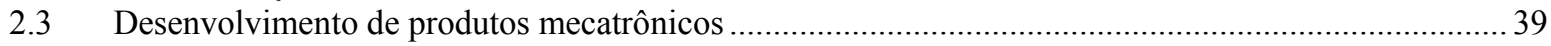

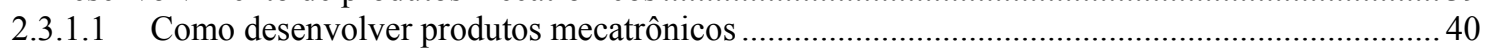

2.3.1.2 Problemas potenciais do desenvolvimento de produtos mecatrônicos ....................................... 58

2.3.1.3 Desenvolvimento de processo e fabricação de produtos mecatrônicos ………………………........... 63

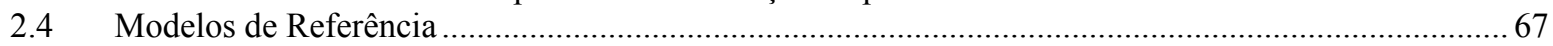

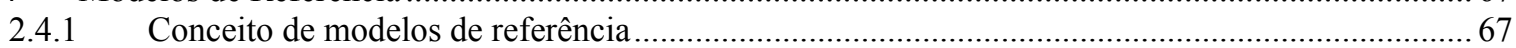

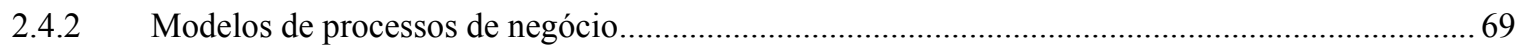

2.4.3 Tipos de conteúdo necessários em modelos de referência............................................................... 73

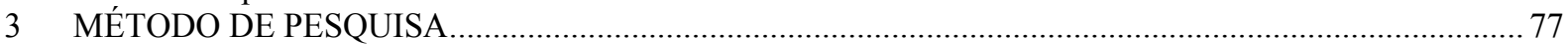

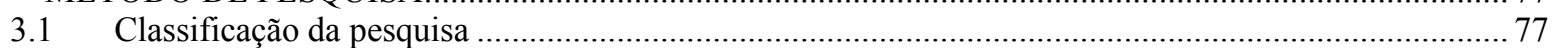

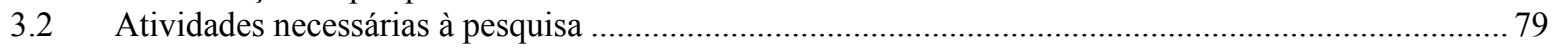

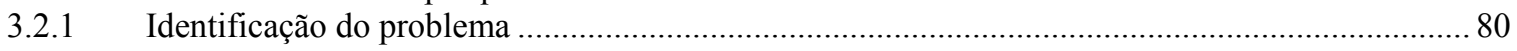

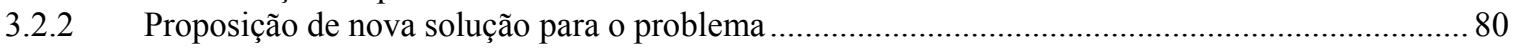

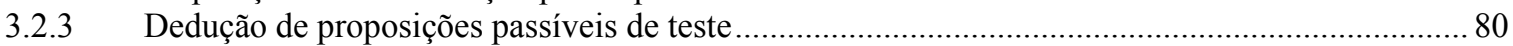

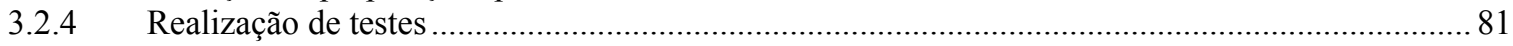

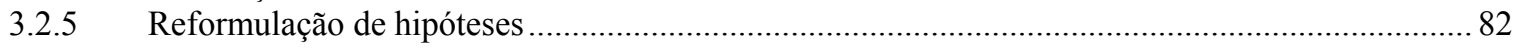

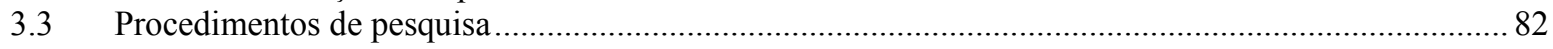

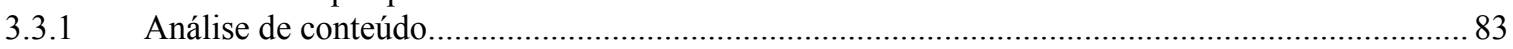

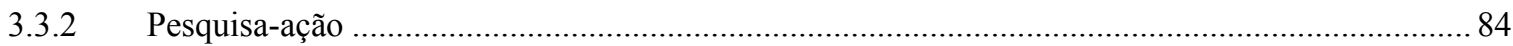

3.4 Utilização dos procedimentos de pesquisa para produzir os resultados esperados da pesquisa e validar a

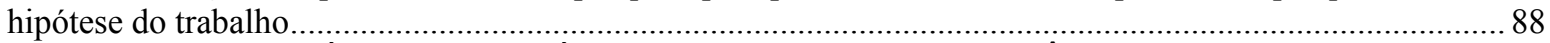

4 TIPOS DE CONTEÚDOS NECESSÁRIOS AO MODELO DE REFERÊNCIA PARA O

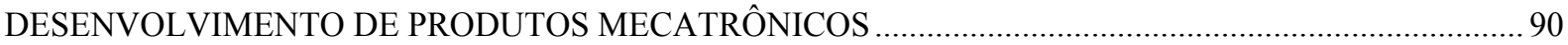

4.1 Tipos de conteúdo de modelos de referência para processos de negócio ................................................. 90

4.2 Tipos de conteúdo identificados na bibliografia de PDP e mecatrônica..................................................92

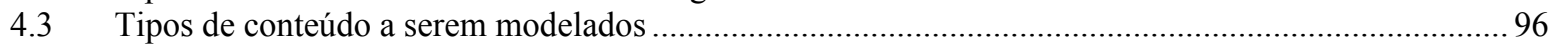

4.4 Método de modelagem e forma de representação...................................................................................97

4.4.1 Método de modelagem ............................................................................................. 98

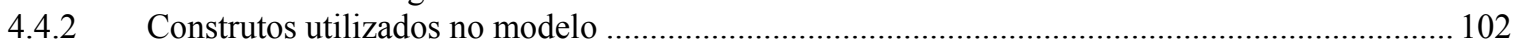

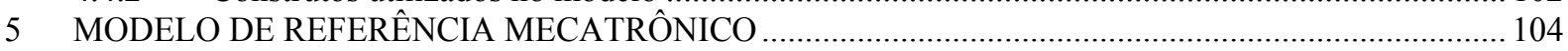

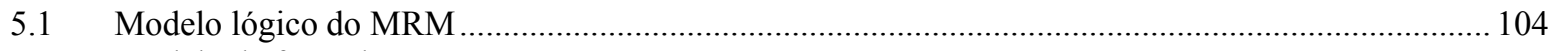

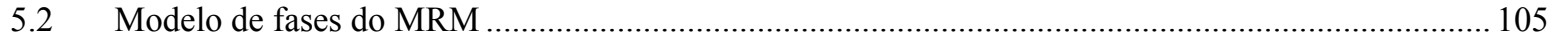

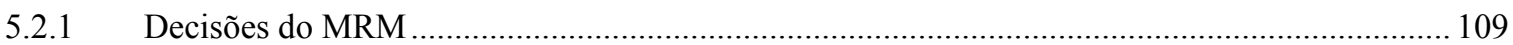

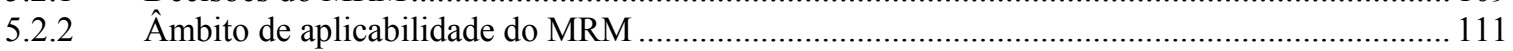

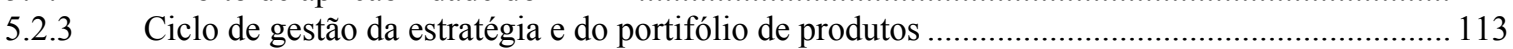

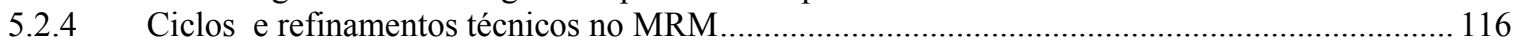

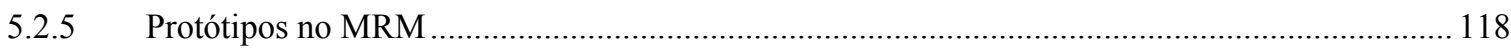




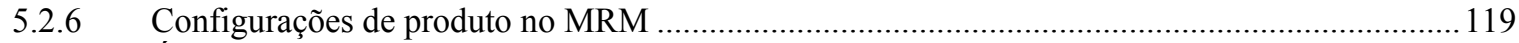

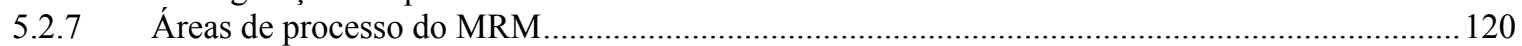

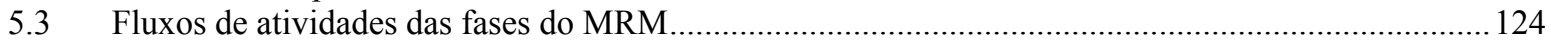

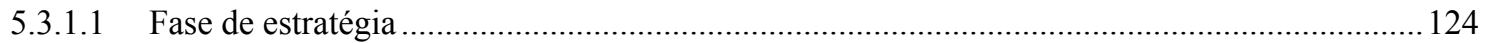

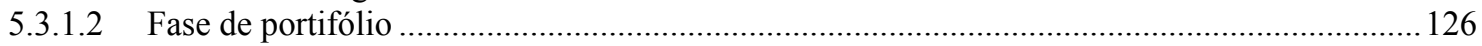

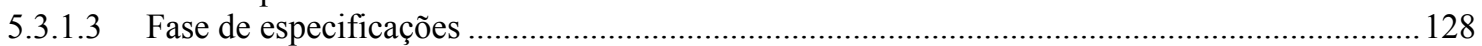

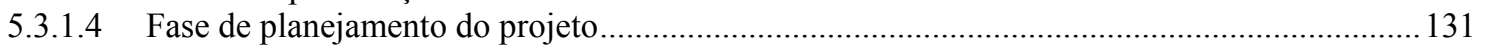

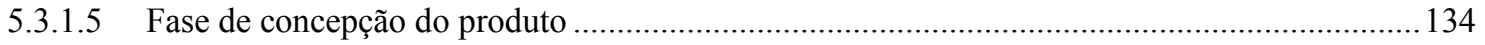

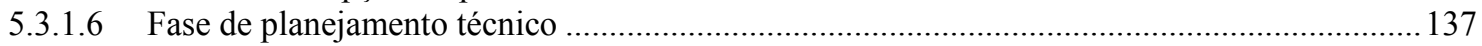

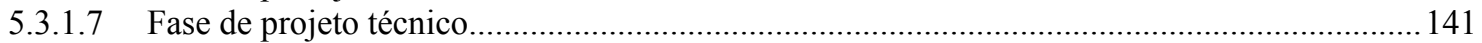

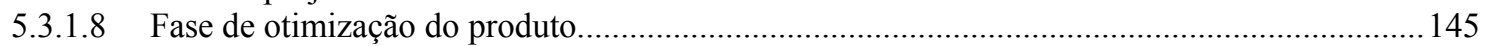

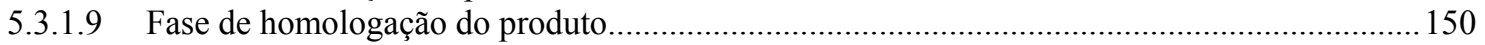

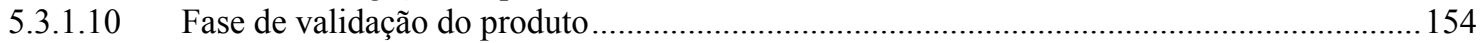

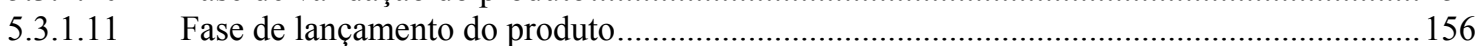

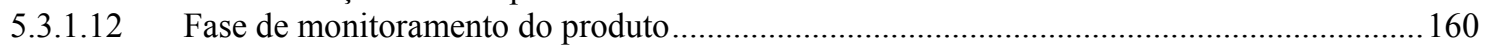

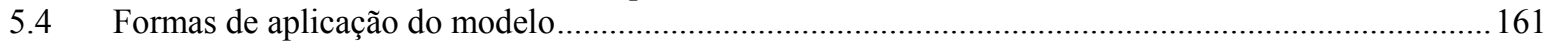

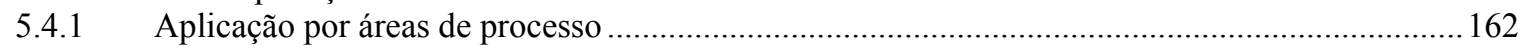

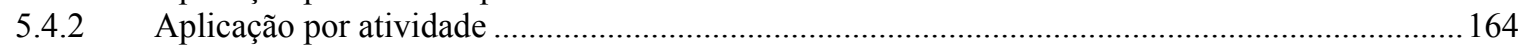

5.4.3 Método sugerido de uso do MRM por áreas de processo e por atividades ........................................ 165

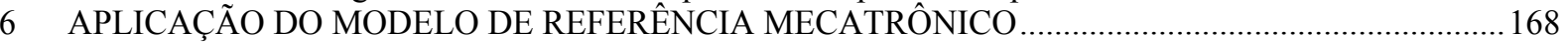

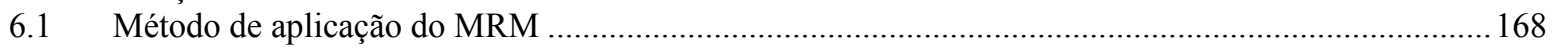

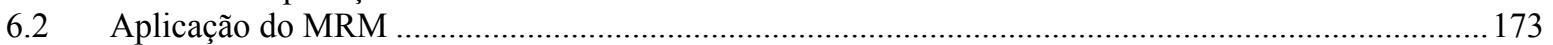

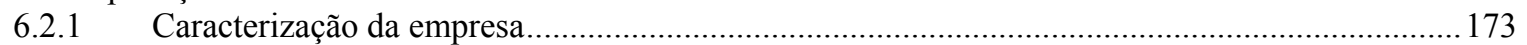

6.2.2 Caracterização dos projetos nos quais o MRM foi aplicado ........................................................ 175

6.2.3 Caracterização do PDP na empresa no início do trabalho de aplicação do modelo ........................178

6.2.4 Nível de capabilidade das áreas de processo do PDP no início do trabalho de aplicação do modelo 186

6.2.5 Aplicações do modelo de referência mecatrônico na empresa........................................................ 188

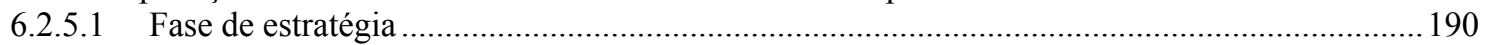

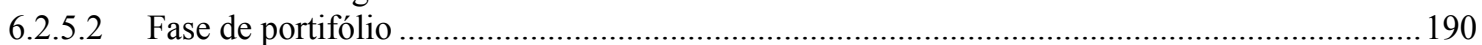

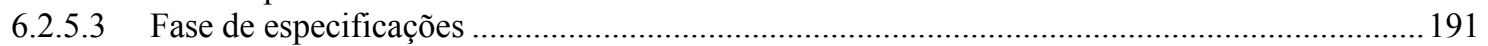

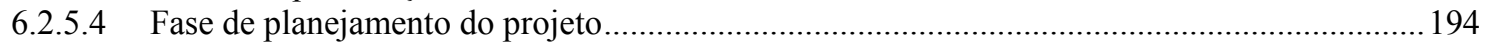

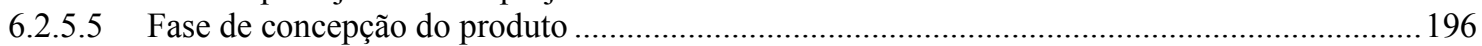

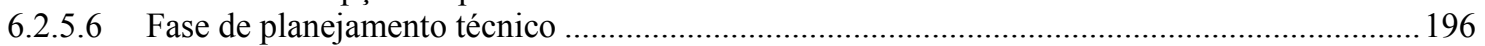

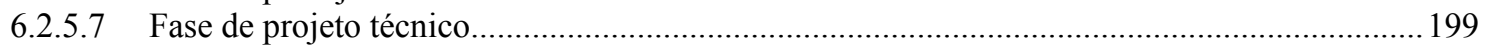

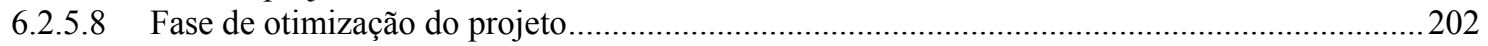

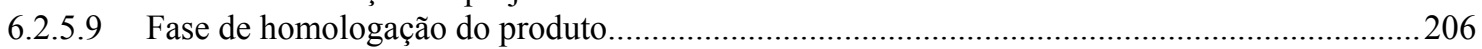

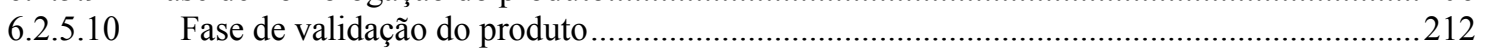

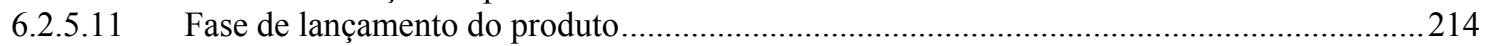

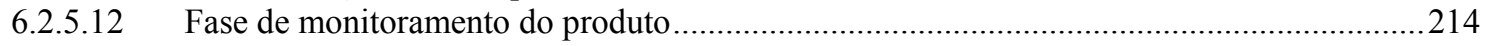

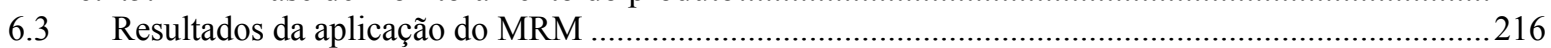

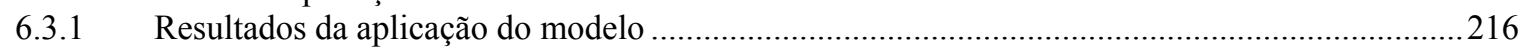

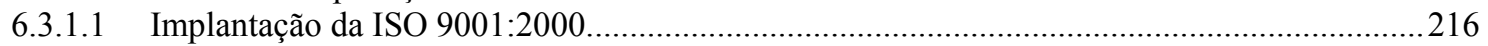

6.3.1.2 Registro do retinógrafo em órgãos reguladores .....................................................................220

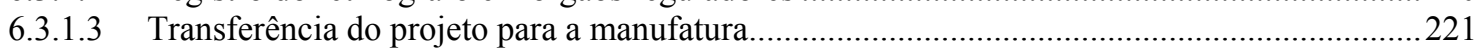

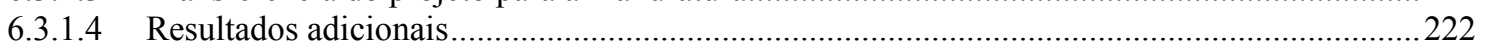

6.4 Situação do PDP da empresa após aplicado o MRM .....................................................................223

6.4.1 Nível de capabilidade das áreas de processo do PDP no final do trabalho de aplicação do modelo 223

6.4.2 Graus de melhoria da capabilidade do PDP ...................................................................................22

6.4.3 Validação da melhoria das áreas de processo do MRM...............................................................22

6.4.4 Melhoria de indicadores de desempenho do PDP ...................................................................228

6.4.5 Discussão com os entrevistados da ETAPA 2 sobre a aplicação do MRM …………………….....2.23

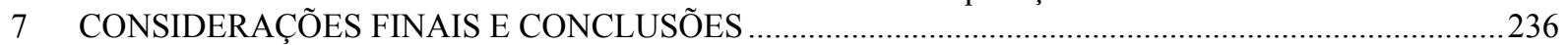

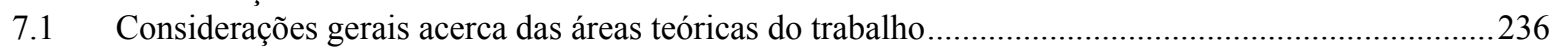

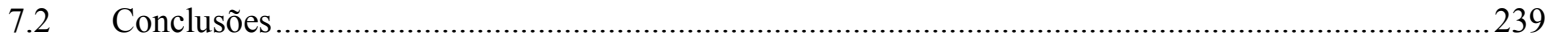

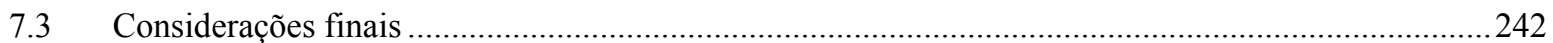

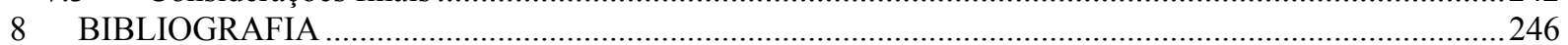




\section{LISTA DE FIGURAS}

Figura 1 - Impacto (a) e evolução (b) da utilização da eletrônica em produtos industrais (Fonte: MOORE, 2003,

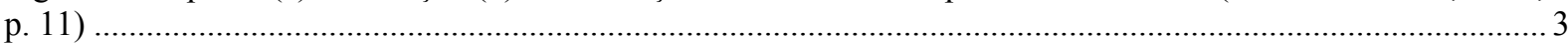

Figura 2 - Áreas de aplicação da mecatrônica. (Fonte: www.rpi.edu/ craigk, acesso em 21/05/2005) ..............4 Figura 3 - Elementos tecnológicos de sistemas de manufatura mecatrônicos (Adaptado de: HUNT, 1988, p. 29) 8 Figura 4 - Projetos mecânicos convencionais e mecatrônicos (Fonte: HORIKAWA, 2000) ............................. 9 Figura 5 - Máquina ferramenta manual e de comando numérico (Fonte: HUNT, 1988, p. 41)........................ 11 Figura 6 - Uma ilustração do desenvolvimento da eletrônica automotiva (Fonte: ADAMSSON, 2005, p. 13).... 12 Figura 7 - Arquitetura funcional básica de: (a) um produto eletrônico (televisão); e (b) um produto mecatrônico (mouse mecânico)

Figura 8 - Sistemas de controle malha fechada e malha aberta (Fonte: DORF e BISHOP, 2001) .....................17

Figura 9 - Exemplos de relação entre sistemas de controle e produtos mecatrônicos:teclado - produto mecatrônico como sistema de controle malha aberta. .......................................................................... 18 Figura 10 - Exemplos de relação entre sistemas de controle e produtos mecatrônicos: unidade de disco rígido produto mecatrônico como sistema malha fechada. ................................................................................ 19 Figura 11 - Exemplos de relação entre sistemas de controle e produtos mecatrônicos: sistema malha fechada que

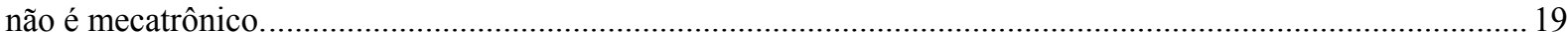

Figura 12 - Elementos de um sistema mecatrônico

Figura 13 - Descrição de uma câmara reflex a partir dos elementos de sistemas mecatrônicos. (Adaptado de BRADLEY, 1991, p. 444)

Figura 14 - Descrição de um mouse sem fio a partir dos elementos de sistemas mecatrônicos . (Adaptado de: http://www.uniqueics.com/htmls/od_optical_mouse.htm, acesso em 23/11/2005).

Figura 15 - Descrição de uma unidade eletrônica de controle de motores (Adaptado de

http://members.rennlist.com/pbanders/ecu.htm, acesso em 21/11/2005) .............................

http://mars.jpl.nasa.gov/mer/mission/spacecraft rover antennas.html, acesso em 22/11/2005) .26

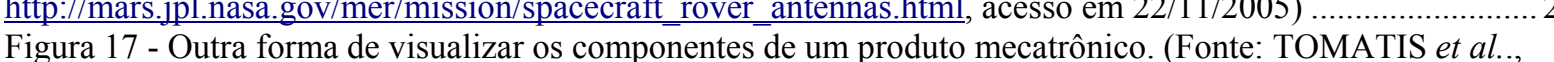
2001, p. 3).....

Figura 18 - Projetos distintos resultantes de um mesmo processo. (Fonte: ROZENFELD et al. 2006, p. 42) ... 36

Figura 19 - Visão geral do processo de projeto e desenvolvimento do produto. (Fonte: PRASAD, 1996, p. 418)38 Figura 20 - Fluxo principal de atividades de projeto mecânico, eletrônico e de software (Fonte: BERNARDI et al.., 2002, p.2) .

Figura 21 - Blocos funcionais de um telefone para seus diferentes estados (BUUR, 1990, p. 76)....................44

Figura 22 - Modelo DeMarco utilizado por BRADLEY et al.., 2000 (p. 103).................................................45

Figura 23 - Diagrama de contexto e nível 0 de uma máquinha de lavar (Fonte: BRADLEY et al.., 2000, P. 104-

105)

Figura 24 - Diagrama de fluxo de dados da função "usar máquinha de lavar". Fonte: BRADLEY et al.., 2000, p.

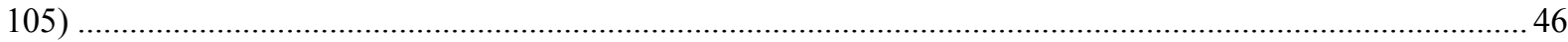

Figura 25 - Processo de desenvolvimento clássico e nova abordagem de projeto mecatrônico (Fonte:

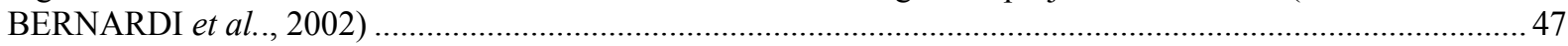

Figura 26 - Processo de projeto de sistemas de controle (DORF e BISHOP, 2000, p. 20) ................................49

Figura 27 - Processo de projeto da interface humano-máquina (Fonte: BRADLEY, et al., 2000, p. 214) ...........51

Figura 28 - Árvore função-meio de um aparelho telefônico (Fonte: BUUR, 1990, p. 78) .................................53

Figura 29 - Parte do fluxo para registro de equipamento eletromédicos. (Fonte: RDC $\mathrm{n}^{\mathrm{o}} 185,2001, \mathrm{p} .15$ )........55

Figura 30 - Problema de projeto submetido a recém-contratados do departamento de engenharia mecânica da

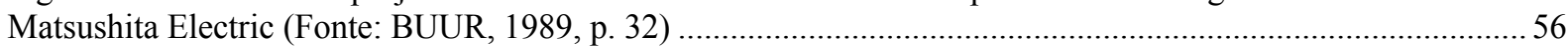

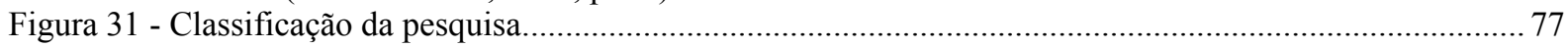

Figura 32 - Tipos de conteúdo modelados nas normas QS-9000: APQP e GSQA (a) e nos autores de

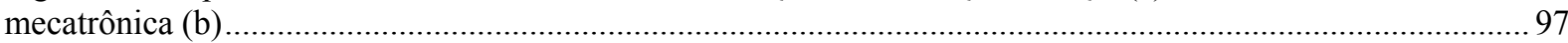

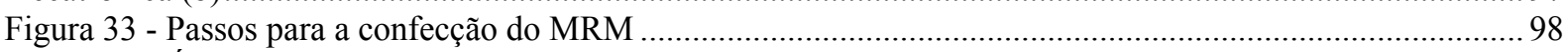

Figura 34 - Árvore de função para a atividade "modelar e sistematizar a concepção"..................................... 100

Figura 35 - Fluxo de informações da atividade "modelar e sistematizar a concepção".................................... 100

Figura 36 - Template do documento "especificações do produto": modelo sugerido. ...................................... 101

Figura 37 - Exemplo do documento "especificações do produto": aplicação para um retinógrafo digital. ........ 101

Figura 38 - Forma de representação do MRM........................................................................................ 102

Figura 39 - Fichas de atividade (a) e documento (b) de "modelar e sistematizar a concepção" e de "projeto da concepção do produto", respectivamente. ............................................................................................ 103

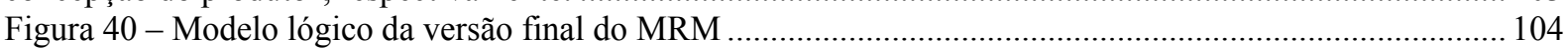

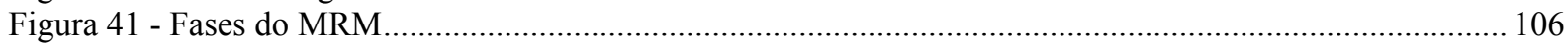

Figura 42 - Atividades centrais e paralelismo entre fases do MRM ....................................................... 108

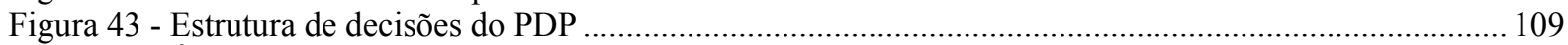

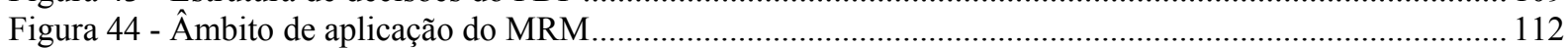


Figura 45 - Ciclo de gestão da estratégia e do portifólio em uma LDP ...................................................... 113

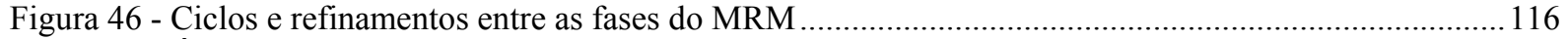

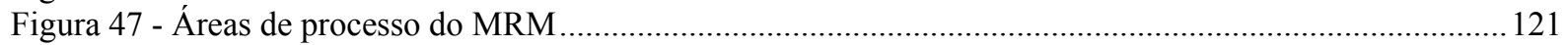

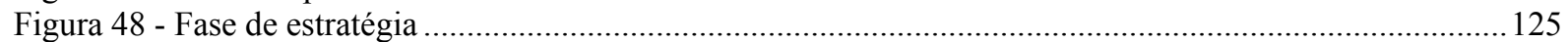

Figura 49 - Fase de portifólio ........................................................................................................ 126

Figura 50 - Exemplo de integração do planejamento de portifólio com a estratégia de produtos...................... 127

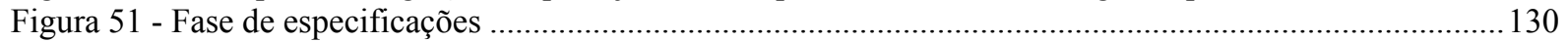

Figura 52 - Fase de planejamento do projeto...................................................................................... 132

Figura 53 - Estrutura analítica (EAP) de um projeto mecatrônico: satélite de monitoramento ambiental.

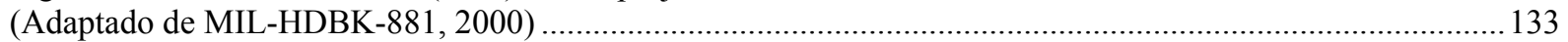

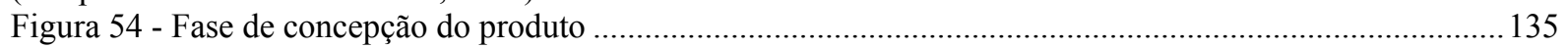

Figura 55 - Fase de planejamento técnico.......................................................................................... 139

Figura 56 - Arquitetura do produtos: equipamento de fotografia da retina (Fonte: OPTO ELETRÔNICA S.A.,

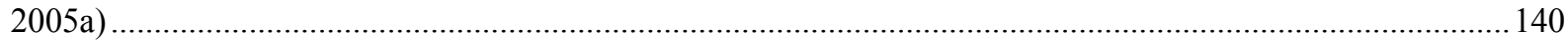

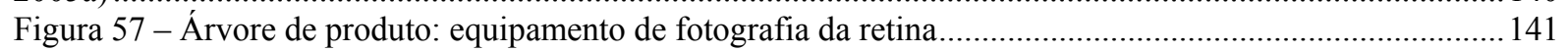

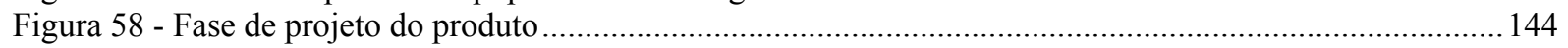

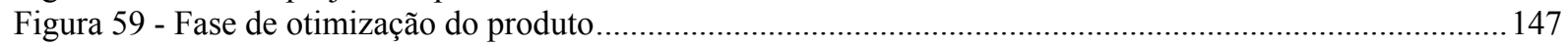

Figura 60 - Ilustrativo de equipamentos de suporte para produtos mecatrônicos: (a) rack de unidade de medição

de circunferência; (b) mesa elevatória de retinógrafo digital....................................................................... 148

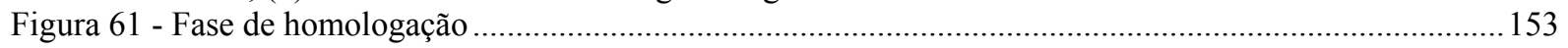

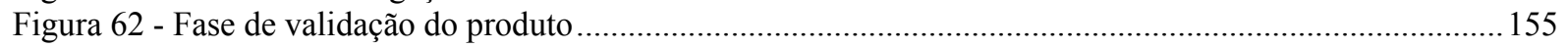

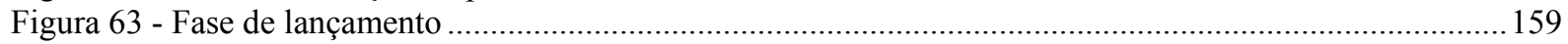

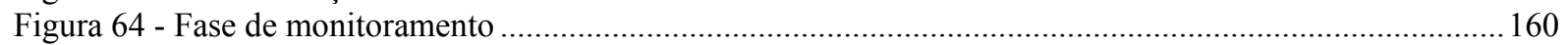

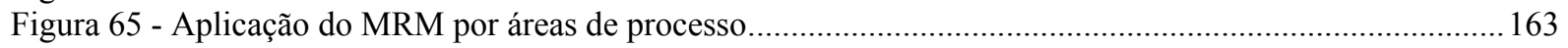

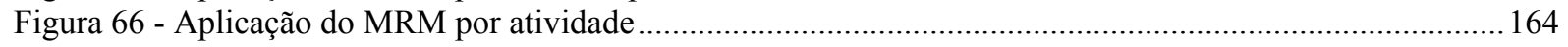

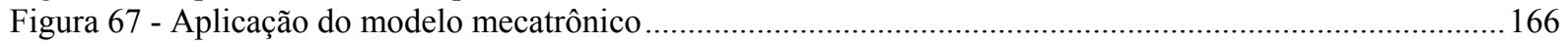

Figura 68 - Escala de aferição da capabilidade das áreas de processo do PDP .............................................. 166

Figura 69 - Utilização do método sugerido para a aplicação do MRM para o teste das proposições de validação

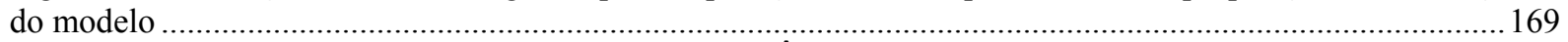

Figura 70 - Retinógrafo ADS1.5 (Fonte: OPTO ELETRÔNICA S.A., 2005b)........................................... 175

Figura 71 - Microscópio oftálmico (Fonte: http://www.opto.com.br/divmedica/produtos/opto-SM2002.htm,

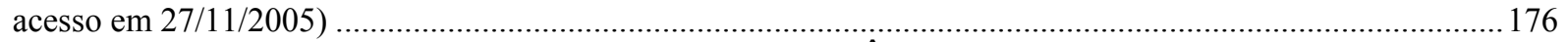

Figura 72 - Fotocoagulador desenvolvido pela OPTO ELETRÔNICA S.A. (Fonte: http://www.opto.com.br/

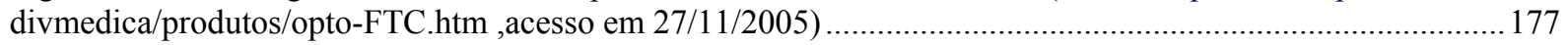

Figura 73 - Sumário da arquitetura funcional da câmera multiespectral ..................................................... 178

Figura 74 - Organograma da empresa no início da aplicação do MRM ....................................................... 179

Figura 75 - Processo de desenvolvimento típico de um produto considerado inovador para a empresa .............180

Figura 76 - Nível de capabilidade das áreas de processo do MRM no início de sua aplicação $\left(\mathrm{N}_{\mathrm{ci}}\right)$.................. 187

Figura 77 - Aplicações do MRM na empresa pesquisada............................................................................. 189

Figura 78 - Especificações do produto: (a) parte do software i-MP; (b) parte dos requisitos do projeto MUX.. 192

Figura 79 - Matriz de verificação do projeto retinógrafo: (a) capa; (b) folha de medidas de segurança............. 193

Figura 80 - Registro de especificação do produto do projeto retinógrafo .................................................... 193

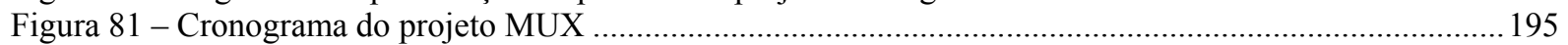

Figura 82 - Cronogramas de atividades no projeto microscópio-Can......................................................... 195

Figura 83 - Concepção do projeto retinógrafo ..................................................................................... 196

Figura 84 - Arquitetura do retinógrafo e seu vínculo com tópicos do relatório técnico do equipamento (Fonte:

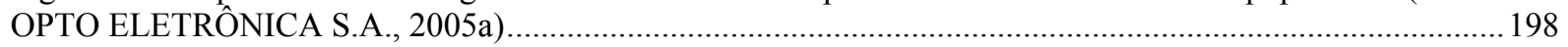

Figura 85 - Níveis 01 e 02 da árvore de produtos da MUX .......................................................................... 198

Figura 86 - Documentação técnica: (a) retinógrafo; e (b) microscópio-Can. ...............................................200

Figura 87 - Registros de configuração do projeto técnico........................................................................2201

Figura 88 - Ilustrativo de engenharia básica do equipamento de fotografia da retina - sistema óptico de

iluminação. (Fonte: OPTO ELETRÔNICA S.A., 2005a)........................................................................201

Figura 89 - Ilustrativo do sistema de controle do equipamento (Fonte: OPTO ELETRÔNICA S.A., 2005a)....202

Figura 90 - Arquitetura do software de alto nível projetado (Fonte: OPTO ELETRÔNICA S.A., 2005b) ........202

Figura 91 - Registros de análise de riscos do projeto Retinógrafo............................................................203

Figura 92 - Formulário FMEA preenchido para análise de riscos através da identificação de modos e efeitos de

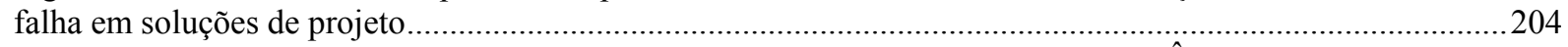

Figura 93 - Experimentos de software do projeto retinógrafo (Fonte: OPTO ELETRÔNICA S.A., 2004b)......205 Figura 94 - Documentação de montagem: (a) mecânica; (b) eletrônica. (Fonte: OPTO ELETRÔNICA S.A. (2004a; OPTO ELETRÔNICA S.A. (2005d).... 
Figura 95 - Parte do fluxograma de montagem do retinógrafo digital 208

Figura 96 - Parte da análise de falhas de processo de montagem e fabricação da mesa elevatória do retinógrafo

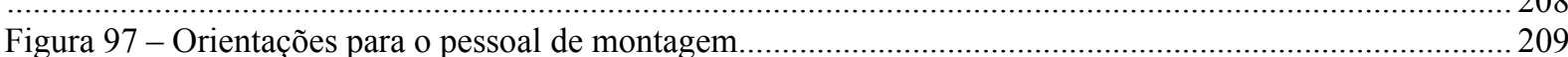

Figura 98 - Parte de termo de contrato de fornecimento desenvolvido para o projeto retinógrafo ....................210

Figura 99 - Checklist de montagem de parte do retinógrafo devidamente preenchido. ...................................210

Figura 100 - Treinamento da fonte de alimentação do retinógrafo: (a) foto ilustrativa; (b) registro no livro de projetos.

Figura 101 - Registro de homologação de processo de montagem

Figura 102 - Documentação técnica do projeto retinógrafo: (a) relatório técnico; (b) análise de riscos; e (c) validação de software .

Figura 103 - Registros de testes de validação com protótipos piloto: (a) retinógrafo e (b) fotocoagulador i-MP.

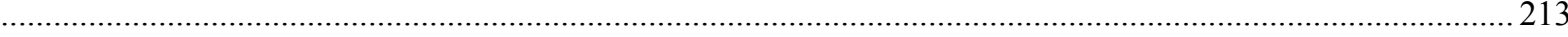

Figura 104 - Exemplo da forma de gerenciamento de mudanças de produto utilizado na empresa ..................2215

Figura 105 - Certificado ISO 9001:2000 _..................................................................................... 217

Figura 106 - Comunicação formal da ANVISA sobre a documentação gerada para o retinógrafo ADS (a) e

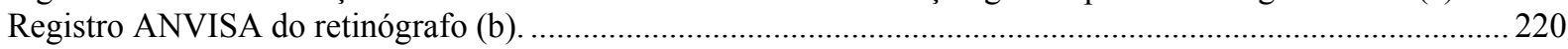

Figura 107 - Nível de capabilidade das áreas de processo no final da aplicação do MRM $\left(\mathrm{N}_{\mathrm{cf}}\right)$.....................223

Figura 108 - Melhoria dos níveis de capabilidade das áreas de processo do MRM ........................................2224

Figura 109 - Grau de concordância com o aumento do nível de capabilidade do PDP da empresa ..................226

Figura 110 - Grau de concordância quanto ao aumento de capabilidade das áreas de processo do MRM .........227

Figura 111 - Grau de concordância com o aumento de capabilidade por área funcional ................................227

Figura 112 - Grau de concordância com aumento de capabilidade das áreas de processo por unidade

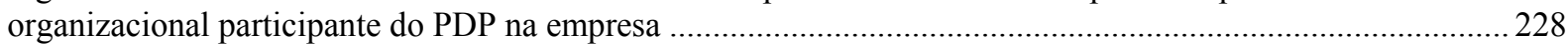

Figura 113 - Graus de melhorias dos indicadores de desempenho pesquisados..........................................2230

Figura 114 - Graus de melhorias dos indicadores de desempenho estratificados em função do papel do respondente no PDP

Figura 115 - Graus de melhorias dos indicadores de desempenho estratificados para os entrevistados com maior tempo de empresa 


\section{LISTA DE TABELAS}

Tabela 1 - Conteúdos necessários em modelos de referência de processos de negócio segundo autores de

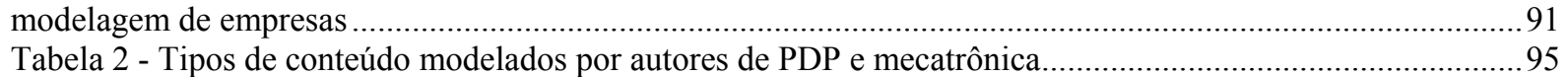

Tabela 3 - Quantidade de ações de PDP analisadas em cada área de processo do MRM.....................................186 


\section{LISTA DE QUADROS}

Quadro 1 - Tipos de inteligência de máquina (Fonte: BRADLEY et al.., 2000, p. 43)..................................... 14

Quadro 2 - Comparação de aplicações para microprocessadores (Fonte: BRADLEY, 1991, p. 210).................. 14

Quadro 3 - Evolução do portifólio de uma LDP hipotética ................................................................... 115

Quadro 4 - Sumário das aplicações do MRM na fase de estratégia................................................................ 190

Quadro 5 - Sumário das aplicações do MRM na fase de portifólio ............................................................... 191

Quadro 6 - Sumário das aplicações do MRM na fase de especificações ........................................................ 191

Quadro 7 - Sumário das aplicações do MRM na fase de planejamento do projeto ......................................... 194

Quadro 8 - Sumário das aplicações do MRM na fase de concepção .............................................................. 196

Quadro 9 - Sumário das aplicações do MRM na fase de planejamento técnico ................................................ 197

Quadro 10 - Sumário das aplicações do MRM na fase de projeto técnico ...................................................... 199

Quadro 11 - Sumário das aplicações do MRM na fase de otimização ..........................................................203

Quadro 12 - Sumário das aplicações do MRM na fase de homologação ........................................................206

Quadro 13 - Sumário das aplicações do MRM na fase de validação................................................................2 212

Quadro 14 - Sumário das aplicações do MRM na fase de lançamento...........................................................2 214

Quadro 15 - Sumário das aplicações do MRM na fase de monitoramento do produto ....................................215

Quadro 16 - Perfil dos entrevistados na segunda etapa de validação do MRM quanto à área funcional.............225 


\section{LISTA DE ABREVIATURAS E SIGLAS}

\begin{tabular}{|c|c|}
\hline $\mathrm{AD}$ & Alta Direção \\
\hline ADS1.5 & Retinógrafo digital \\
\hline ANATEL & Agência Nacional de Telecomunicações \\
\hline ANEEL & Agência Nacional de Energia Elétrica \\
\hline ANTT & Agência Nacional de Transportes Terrestres \\
\hline ANVISA & - Agência Brasileira de Vigilância Sanitária \\
\hline APQP & Advanced Product Quality Planning e Control Plan \\
\hline ARIS & Architecture of Integrated Information Systems \\
\hline ASIC & Aplication Specific Integration Circuit \\
\hline ATO & - assembly to order \\
\hline ATO & Assembly to Order \\
\hline BCG & Boston Consulting Group \\
\hline BOM & Bill of Materials \\
\hline CACE & Computer Aided Control Engineering \\
\hline CAD & Computer Aided Design \\
\hline CAE & Computer Aided Engineering \\
\hline CAM & Computer Aidem Manufacturing \\
\hline CAPP & Computer Aided Process Planning \\
\hline CASE & ComputerAided Software Engineering \\
\hline $\mathrm{CCD}$ & Charge-coupled device \\
\hline $\mathrm{CDOV}$ & Concept, Design, Optimization, Verification \\
\hline CEP & Controle Estatístico de Processo \\
\hline CFR & Critical Functional Response \\
\hline CGI & Capability Glocal Index \\
\hline CIMOSA & - Computer Integrated Manufacturing Open System Architecture \\
\hline CIs & Circuitos Integrados \\
\hline CMM & Capability Maturity Model \\
\hline CMMI & -Capability Maturity Model Integration \\
\hline $\mathrm{Cp}$ & Capability Index \\
\hline Cpk & Process Capability \\
\hline DFD & Diagrama de Fluxo de Dados \\
\hline DFM & Design for Manufacture \\
\hline DFMA & Design for Manufacture and Assembly \\
\hline DFMA & Design for Manufacture and Assembly \\
\hline DFMEA & Design FMEA \\
\hline DFSS & Design for Six Sigma \\
\hline DMRI & Degeneração Macular Relacionada à Idade \\
\hline DoD & Defense Department \\
\hline DOE & Design of Experiments \\
\hline DSP & Digital Signal Processing \\
\hline EAP & Estrutura Analítica do Projeto \\
\hline $\mathrm{E}-\mathrm{CAD}$ & Electronic CAD \\
\hline ECM & Engineering Change Management \\
\hline ECSS & European Cooperation for Space Standardization \\
\hline ECU & Electronic Control Unit \\
\hline $\mathrm{ECV}$ & Eaned Commercial Value \\
\hline EKD & Enterprise Knowledge Development \\
\hline EMM & Engenharia, Manufatura e Marketing \\
\hline EMMP & Engenharia, Manufatura, Marketing e Planejamento \\
\hline EMMPQ & Engenharia, Manufatura, Marketing, Planejamento e Qualidade \\
\hline EP & Especificações de Projeto \\
\hline EPC & Event-driven process chain \\
\hline EPP & Escritório de Planejamento e Projetos \\
\hline EPROM & Erasable Programmable Read-only memory \\
\hline EEPROM & Electrically-Erasable Programmable Read-Only Memory \\
\hline ERP & Enterprise Resource Planning \\
\hline ESA & European Space Agency \\
\hline ETO & - engineering to order \\
\hline ETO & Engineering to Order \\
\hline $\mathrm{F} 1$ & Fase 1: estratégia \\
\hline $\mathrm{F} 2$ & Fase 2: portifólio \\
\hline F3 & Fase 3: especificações \\
\hline F4 & Fase 4: planejamento do projeto \\
\hline
\end{tabular}




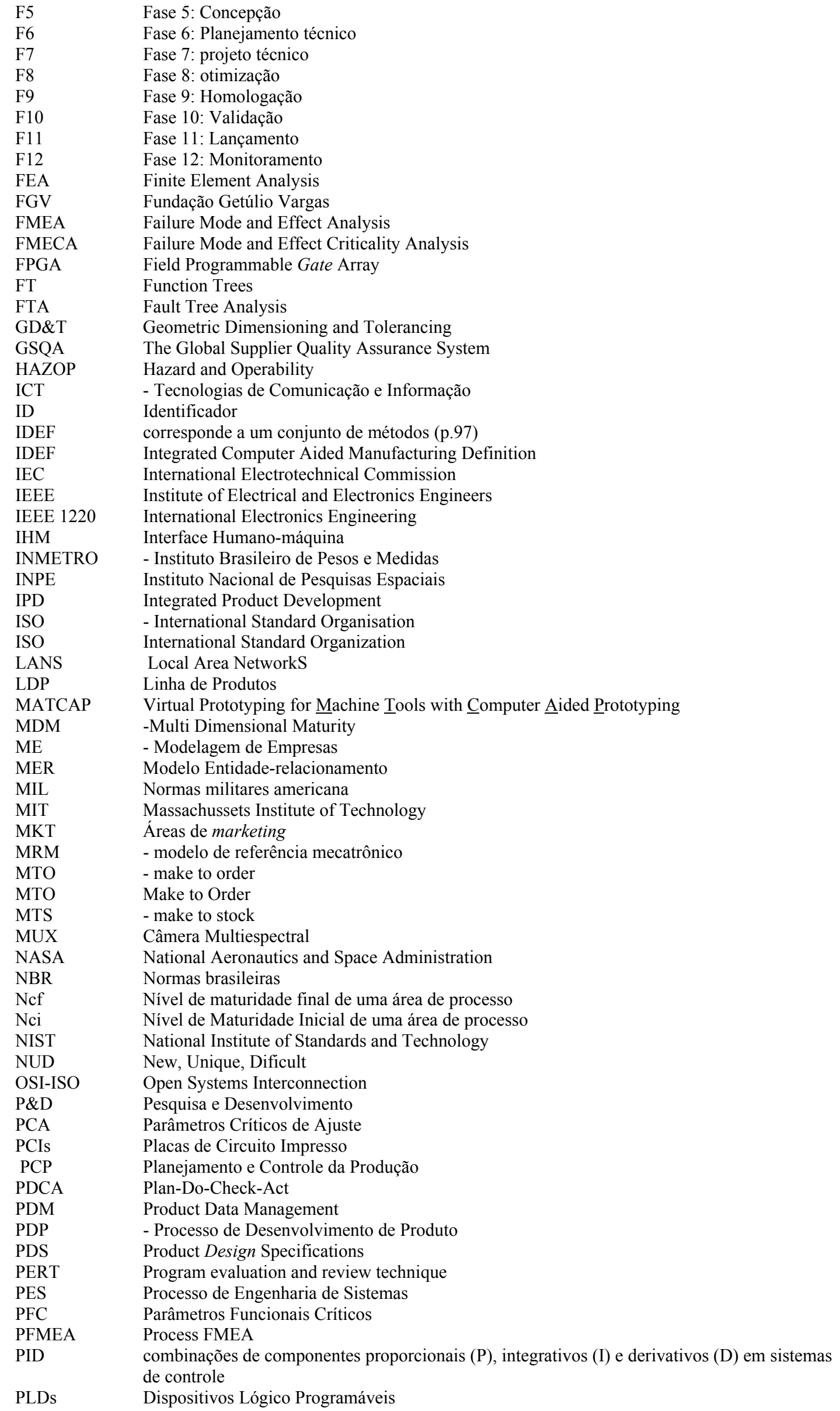




$\begin{array}{ll}\text { PM } & \text { Project Manager } \\ \text { PMBOK } & \text { Project Management Body of Knowledge } \\ \text { PMI } & \text { Project Management Institute } \\ \text { PPAP } & \text { Production Part Approval } \\ \text { Ppk } & \text { Potencial Process Capability } \\ \text { PPM } & \text { Partes-por-milhão } \\ \text { PPO } & \text { Product and Process Organization } \\ \text { QFD } & \text { Quality Function Deployment } \\ \text { QS-9000 } & \text { Quality System Requirements } \\ \text { RF } & \text { Rádio freqüência } \\ \text { RFC } & \text { Respostas Funcionais Críticas } \\ \text { RPN } & \text { Risk Priority Number } \\ \text { SADT } & \text { Structured AnalysisDesign Technic } \\ \text { SAPP } & \text { Solicitação de Alteração de Produto ou Processo } \\ \text { SCPF } & \text { Soluções Críticas por Função } \\ \text { SEI } & \text { Software Engineerign Institute } \\ \text { SIP/SOP } & \text { Signal Input/Signal Output } \\ \text { SISU } & \text { Swedish Institute for Systems Development } \\ \text { TPQ } & \text { Total Product Quality } \\ \text { UML } & \text { Unified Modeling Language } \\ \text { UOB } & \text { Units of Behaviour } \\ \text { VAC } & \text { Value Added Chain } \\ \text { VE } & \text { Value Engineering } \\ \text { VPL } & \text { Valor Presente Líquido } \\ \text { WBS } & \text { Work Breakdown Structure } \\ \text { WI-FI } & \text { Wireless Fidelity } \\ \text { WP } & \text { Work Package } \\ \text { www } & - \text { World Wide Web } \\ & \end{array}$




\section{RESUMO}

BARBALHO, S.C.M. (2006) Modelo de referência para o desenvolvimento de produtos mecatrônicos: proposta e aplicações. São Carlos, 2006. 256p. Tese (Doutorado) - Escola de Engenharia de São Carlos, Universidade de São Paulo, São Carlos, 2006.

Propõe o modelo de referência para o processo de desenvolvimento de produtos mecatrônicos, denominado MRM, que consiste em um conjunto de melhores práticas sistematizadas das bibliografias de desenvolvimento de produtos, eletrônica, engenharia de software e projeto de engenharia. Discute o conceito de mecatrônica propondo um conjunto de componentes que caracterizariam esses produtos. Utiliza conceitos de modelagem de empresas para apresentar o MRM. Estrutura o desenvolvimento de produtos mecatrônicos em doze fases intercaladas por pontos de decisão e caracterizadas pelos documentos gerados no final de cada uma. Elabora uma metodologia de aplicação do modelo com base no conceito de capabilidade de áreas de processo. Descreve a aplicação do MRM em uma empresa que desenvolve produtos mecatrônicos. A aplicação abrange todas as fases do modelo e é avaliada por meio de entrevistas com os principais usuários das melhorias aplicadas na empresa. O trabalho utiliza dois procedimentos básicos de pesquisa: a análise de conteúdo no estudo da bibliografia utilizada na pesquisa; e a pesquisa-ação como método de aplicação do modelo. $\mathrm{O}$ uso do MRM permitiu à empresa a consecução da certificação ISO 9000 para seu processo de desenvolvimeto de produtos (PDP), assim como o registro de produtos mecatrônicos em órgãos regulatórios nacionais e internacinais. A avaliação realizada ao final da aplicação do trabalho mostra que o modelo melhorou indicadores de custo dos projetos, controle de prazos ao longo dos projetos, assim como reduziu as reclamações dos setores de manufatura com relação às especificações geradas pela engenharia. Os entrevistados consideraram que a capacidade de integração de pessoas novas aos projetos em desenvolvimento é a melhoria mais significativa conseguida com a aplicação do MRM na empresa. Os resultados permitem considerar o modelo coerente com a bibliografia de PDP, indicam que a utilização de modelos de referência podem melhorar o PDP de uma empresa e demonstram haver uma relação entre o aumento da capabilidade de um processo e a melhoria de seus indicadores de desempenho.

Palavras-chave: Processo de desenvolvimento de produtos; mecatrônica; modelos de referência. 


\begin{abstract}
BARBALHO, S.C.M. (2006) Reference model for mechatronic product development: proposal and applications. São Carlos, 2006. 256p. Tese (Doutorado) - Escola de Engenharia de São Carlos, Universidade de São Paulo, São Carlos, 2006.

This thesis proposes the reference model for the mechatronic product development process, called MRM, i.e. a set of best practices about product development, engineering design, electronics and software engineering. It discusses the concept of mechatronic and proposes a set of elements that characterize this kind of products. It takes into account enterprise modeling techniques to present MRM. MRM framework is composed by twelve phases with well defined checkpoints and outputs. The work describes a methodology to apply MRM based on process areas capability indexes. It presents a MRM application in a company that develops mechatronic products. The application is evaluated based on interviews with model users. Research methods are content analysis and action research. The skilled results are ISO 9000 certification and product registration. Inteviews show that cost and schedule control were improved by MRM use. Manufacture disfuctions based on bad engineering specifications were decresed. The evaluation suggests that new engineers and technician integration is the best result of model application. These results allow to verify the effectiveness of reference models to improve product development and demonstrate that there is a relationship between increments of process capability and improvements critical succes factors rates.
\end{abstract}

Palavras-chave: Product development; mechatronics; reference models. 


\title{
1 INTRODUÇÃO
}

\author{
A ciência não nos oferece cópias do \\ real. Ela nos dá apenas modelos \\ hipotéticos e provisórios do mesmo. $R$. \\ ALVES.
}

Criação e pragmatismo. Essas palavras poderiam, por si só, definir o processo de desenvolvimento de produtos (PDP). O que estaria envolvido no processo de criação de produtos tão complexos como os que hoje existem? Produtos esses que têm no conceito de mecatrônica uma possível explicação para a confluência de tecnologias que estão hoje envolvidas em carros, TVs, aparelhos de som, brinquedos etc. Como transformar o resultado de mentes criativas em produtos comercialmente viáveis? Como uma empresa deve estruturar seu processo de desenvolvimento para que a tecnologia que desenvolva se transforme em sucessos comerciais?

Em qual medida o pragmatismo deve ser usado para que aqueles que criam não se deixem levar pelo prazer de buscar o resultado técnico perfeito na sua criação sem atentar para o resultado econômico que ela pode gerar?

Atualmente são propostos os chamados modelos de referência (reference models, mas também roadmaps, baseline e planos integrados) para estabelecer diretrizes, procedimentos e critérios considerados necessários ao sucesso das atividades de desenvolvimento de produtos. Esses modelos visam fornecer um caminho viável para os que desejam introduzir produtos de grande potencial de sucesso mercadológico.

\subsection{Justificativa do trabalho}

Empresas como Xerox, TRW, Delphi, Multibrás, Eaton, Phillips, Samsung, Springer Carrier, Ford, General Motors, Volkswagem etc. desenvolvem seus próprios modelos de referência para desenvolver novos produtos nas suas matrizes. Os modelos são distribuídos às 
suas filiais ao redor do mundo. Situações específicas, em termos de recursos disponíveis e condições mercadológicas, pelas quais as filiais dessas grandes organizações passam, não são normalmente previstas nos modelos.

Pequenas empresas que desenvolvem produtos não dispõem de condições financeiras para contratar grandes e demoradas consultorias de processo. Além disso, o caráter de curto prazo que permeia o ambiente econômico dessas empresas faz com que aspectos gerenciais sejam considerados de secundária importância ante à necessidade de chegar a uma solução tecnicamente eficaz no projeto de novos produtos.

Esse trabalho busca desenvolver uma solução de tecnologia gerencial que, tornada pública, permita a empresas brasileiras e estrangeiras que operam no Brasil realizar atividades de benchmarking acerca de procedimentos, métodos e processos decisórios relacionados com o desenvolvimento de produtos. Pequenas e médias empresas que desenvolvem produtos poderão utilizar a tecnologia para orientar decisões relativas a prioridades de alocação de recursos e definir métodos de gestão adaptados ao seu processo de desenvolvimento.

Recentes estudos demonstram a revolução em custos e prazos para o lançamento de novos produtos permitidos pela introdução da micro-eletrônica em uma ampla variedade de setores industriais (MOORE, 2003). A Figura 1(a) apresenta um quadro ilustrativo do impacto da microeletrônica nos custos e no grau de inovação de produtos que podem ser denominados mecatrônicos, enquanto na Figura 1 (b) é ilustrada a evolução do uso de dispositivos microeletrônicos no setor automotivo.

Segundo o autor, atualmente, a indústria eletrônica é líder no que concerne à agregação de valor a seus insumos; seu mercado é estimado em 800 bilhões de dólares, maior até mesmo que a indústria automobilística. Como pode ser visto na Figura 1(a), os produtos 
ilustrados como relacionados à indústria eletrônica exigem integração com soluções ópticas, mecânicas, de comunicação etc., o que permite caracterizá-los como mecatrônicos.

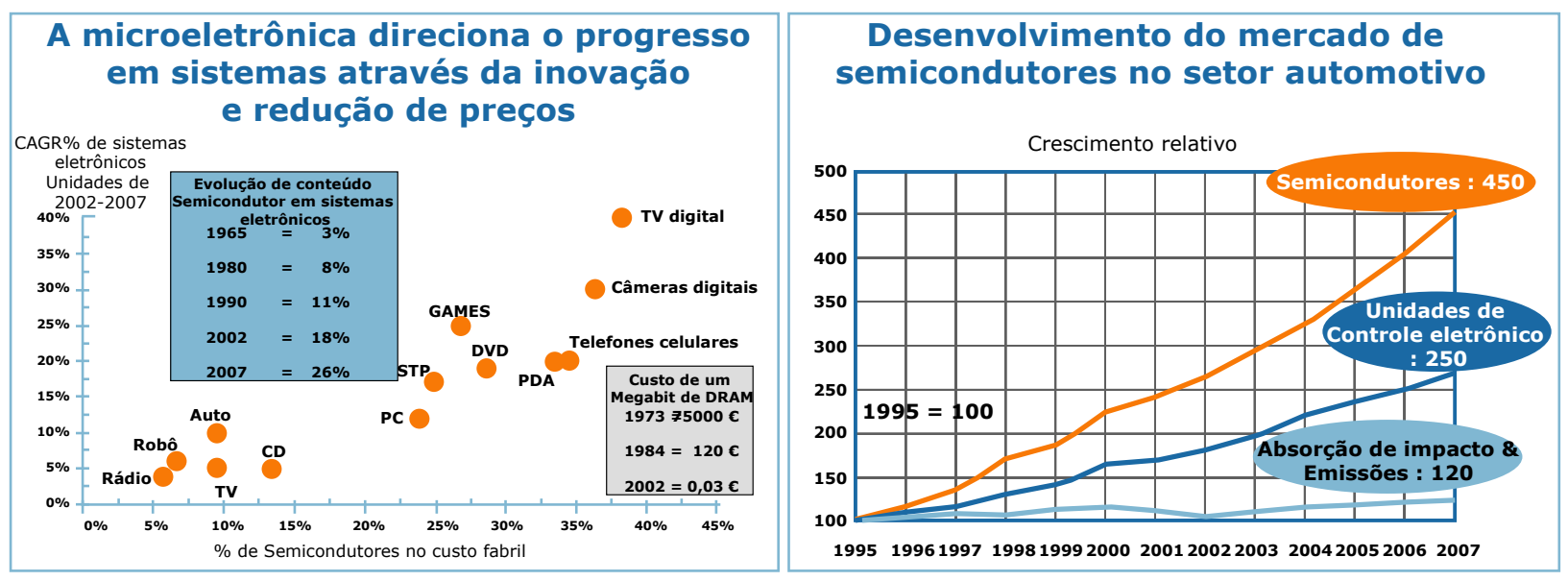

Figura 1 - Impacto (a) e evolução (b) da utilização da eletrônica em produtos industrais (Fonte: MOORE, 2003, p. 11)

$\mathrm{O}$ estudo acima citado adverte para a importância da indústria européia se manter competitiva no desenvolvimento de produtos que utilizem fortemente a eletrônica como habilitadora da introdução de novas funcionalidades e como potencializadora da redução de custos. O presente trabalho é fruto do desejo de contribuir para que a indústria brasileira possa se alinhar com esse tipo de estratégia.

Além disso, a análise da bibliografia de PDP e mecatrônica realizada nesse trabalho, conforme pode ser visto no APÊNDICE C (CD-ROM) permitiu identificar a seguinte lacuna:

A inexistência de um modelo de referência que contemple as melhores práticas da teoria de PDP e que seja adaptado ao contexto tecnológico dos produtos mecatrônicos.

\subsection{Objetivos e questões de pesquisa}

A pesquisa ora relatada tem como motivação a busca de um objetivo geral:

Desenvolver um modelo de referência para o desenvolvimento de produtos mecatrônicos (MRM).

Na busca deste objetivo, o trabalho busca responder a três questões básicas: 
Q1) qual modelo de referência para o PDP pode ser aplicado em empresas cujos produtos são mecatrônicos?

Q2) como o modelo de referência mecatrônico (MRM) deve ser utilizado em uma empresa para o desenvolvimento de um produto real?

Q3) quais os resultados que uma empresa pode esperar da aplicação do modelo de referência mecatrônico?

Uma vez que o trabalho apresentado trata da confecção de um modelo de referência, e modelos são sempre hipóteses provisórias do real (ALVES, 1994), a hipótese de pesquisa é:

HIP1) Os resultados da aplicação do modelo devem estar respaldados na bibliografia especializada em PDP. A melhoria de indicadores de desempenho no PDP da empresa na qual o MRM é aplicado determina a validade das melhores práticas contidas no modelo ou sua refutação.

\subsection{Limitações do trabalho}

A Figura 2 apresenta as áreas de aplicação da mecatrônica conforme o grupo de pesquisa em mecatrônica da Universidade de Resseler.

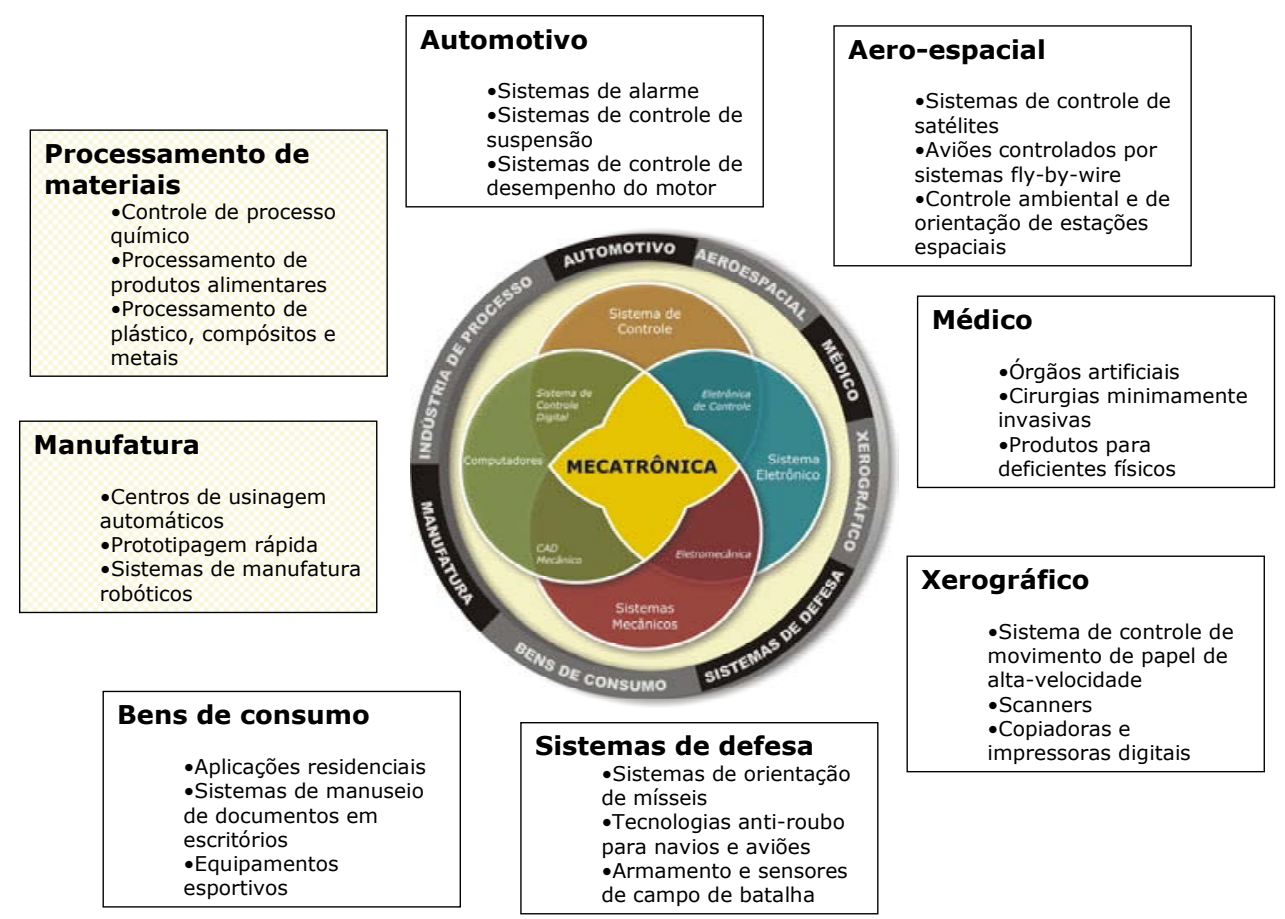

Figura 2 - Áreas de aplicação da mecatrônica. (Fonte: www.rpi.edu/ craigk, acesso em 21/05/2005)

De acordo com a Figura 2 a mecatrônica comportaria sistemas mecânicos, eletrônicos, de software e de controle em igual dimensão. Essa concepção não condiz com o conceito 
discutido no item 2.1.1 uma vez que se entende que os sistemas de controle não têm peso similar às partes mecânica, eletrônica e de software que caracterizariam os produtos mecatrônicos. O conceito, entretanto, é importante para delimitar o espectro de aplicação do MRM.

As áreas de aplicação hachuradas indicam setores não abrangidos pelo MRM. Os sistemas mecatrônicos a serem utilizados na indústria de processos, tal como química, alimentos etc., e na indústria de equipamentos de manufatura, como robôs, sistemas flexíveis de manufatura e similares, não são abrangidos no presente trabalho pelo fato de pressuporem um alto grau de integração com o sistema de produção já existente na unidade fabril, e, portanto, um tipo de relacionamento cliente-fornecedor não previsto no trabalho.

Outra limitação do trabalho tem relação com o escopo de utilização do modelo confeccionado. Nesse sentido, o principal recorte teórico do trabalho está relacionado com a estratégia de manufatura de quem deseje utilizar o modelo. Ele é pensado para empresas que desenvolvem novos produtos para vender no mercado através de estratégias make to order (MTO), make to stock (MTS) ou assembly to order (ATO). O modelo não está adaptado a empresas que desenvolvem por encomenda em sistemas engineering to order (ETO). Portanto, embora esteja indicado na Figura 2 que o modelo pode ser utilizado na indústria aeroespacial, essa aplicação é limitada uma vez que há atividades específicas de projetos ETO não abrangidas pelo modelo, tais como participação em concorrências e licitações, efetivação de contratos, instalação do equipamento e treinamento do corpo técnico do cliente etc. Nesse sentido, ROZENFELD et al. (2006), BARBALHO e ROZENFELD (2004a) e BRADLEY et al. (2001) podem complementar o presente trabalho e apresentar diretrizes para a generalização dessa pesquisa no que concerne à estratégia de manufatura ETO. 


\subsection{Estrutura da tese}

O presente texto está dividido em sete capítulos. No segundo é apresentada a revisão bibliográfica acerca das três temáticas básicas do trabalho: a mecatrônica, o processo de desenvolvimento de produtos e a modelagem de empresas. No capítulo três é discutida a metodologia de pesquisa do trabalho. No capítulo quatro são analisados e identificados os tipos de conteúdo necessários ao modelo mecatrônico e sua forma de representação. $\mathrm{O}$ capítulo cinco apresenta os conceitos básicos do MRM e sumariza seu conteúdo, o qual consta na íntegra no APÊNDICE A. No capítulo seis é apresentada a aplicação do modelo em uma empresa que desenvolve produtos mecatrônicos. O capítulo sete discute as conclusões do trabalho e sugestões para seu desdobramento.

Todos os apêndices citados ao longo do trabalho constam no CD-ROM anexo. 


\section{REVISÃO TEÓRICA - INTRODUÇÃO AOS TEMAS PRINCIPAIS DO TRABALHO}

Esse capítulo tem como objetivo contextualizar o leitor quanto às áreas teóricas dentro das quais o presente texto transita. O tema principal do trabalho se encontra no campo do processo de desenvolvimento de produtos. É acerca dessa temática que a tese se justifica e para a qual pretende contribuir. A abordagem pela qual o desenvolvimento de produtos é estudado, analisado e modelado está dentro do escopo da modelagem de empresas. Utiliza-se conceitos e técnicas de modelagem de empresas para analisar o PDP e para construir uma referência para esse processo. Em função da grande abrangência das possíveis aplicações de uma ferramenta similar à desenvolvida nesse trabalho, optou-se por restringir sua área de aplicação aos produtos que possam ser considerados mecatrônicos.

Sendo assim, o capítulo apresenta uma introdução aos principais temas relacionados a essa tese. Na seqüência: mecatrônica, PDP e modelos de referência.

\subsection{Mecatrônica}

Nesse tópico discute-se o que é a mecatrônica, o que são produtos mecatrônicos e de que consistem eles.

\subsubsection{O que é a mecatrônica}

Um importante aspecto relacionado com a produção de teoria relacionada com a mecatrônica é explicitado por ADAMSSON (2005): "... a engenharia mecatrônica é um tópico de pesquisa com múltiplas origens teóricas". A diversidade de entendimento relacionado com a mecatrônica é ilustrada ao longo desse tópico. Nele estão elencadas definições de mecatrônica que acompanham a evolução do conceito na bibliografia científica desde seu surgimento no final da década de oitenta. 
HUNT (1988) define mecatrônica como “[...] um termo cunhado pelos japoneses para descrever a integração das engenharias mecânica e eletrônica”. Embora havia já na década de 70 diversos equipamentos e dispositivos que utilizavam ambas as tecnologias, a especificidade da mecatrônica é definida pelo autor como “...uma abordagem multidisciplinar e integrada para o projeto de produtos e sistemas de manufatura". HUNT (op. cit.) menciona a importância da utilização de times multidisciplinares no projeto de produtos mecatrônicos, porém enfatiza o caráter integrador de tecnologias de grupo, computer aided process planning (CAPP), computer aided engineering (CAE), computer aided design (CAD), computer aided manufacturing (CAM) e robôs como impulsionador da integração entre os diferentes grupos funcionais envolvidos no projeto de novos produtos. O uso dessas tecnologias nos processos de desenvolvimento e entrega de produtos é ilustrada na Figura 3.

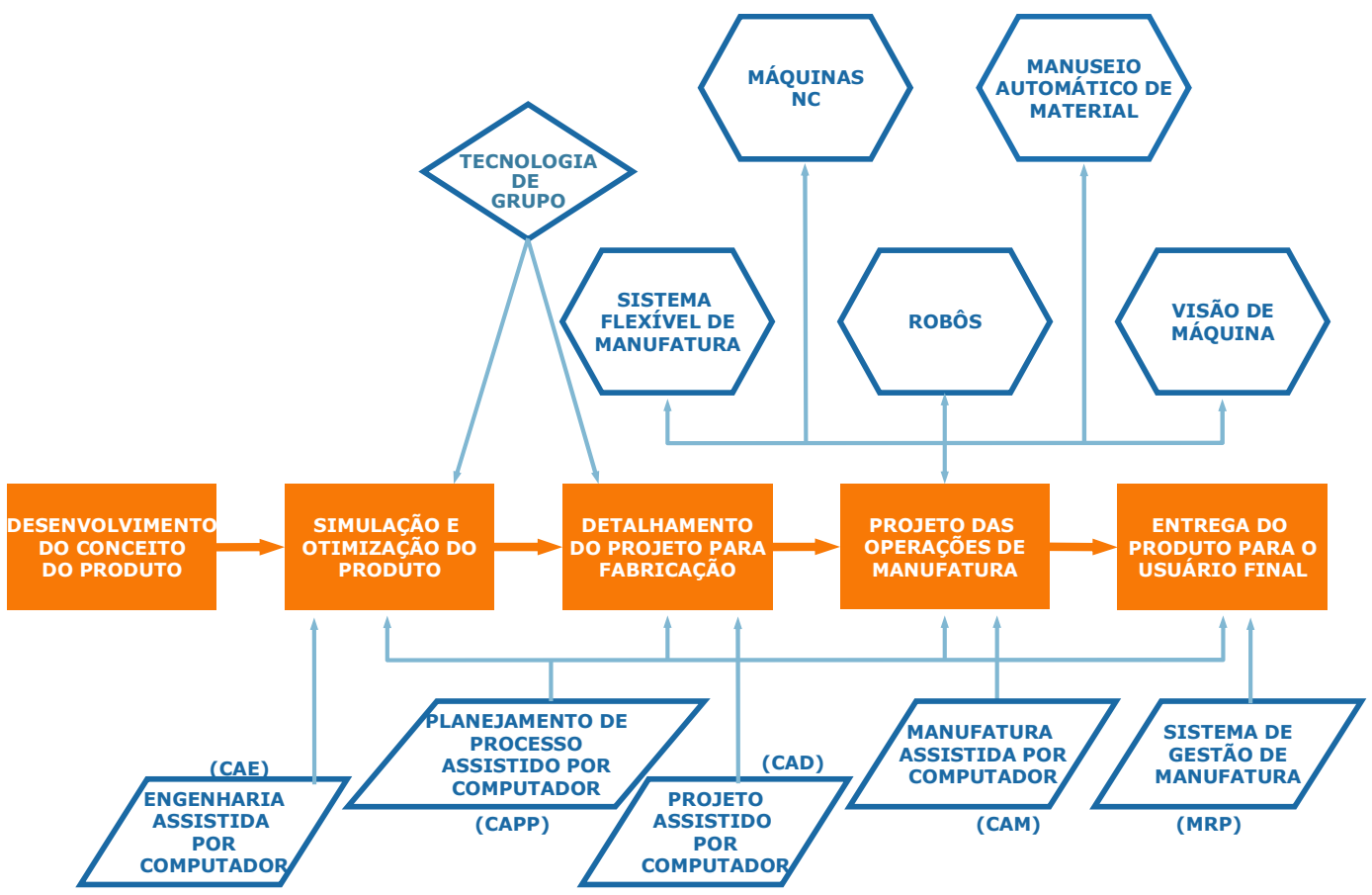

Figura 3 - Elementos tecnológicos de sistemas de manufatura mecatrônicos (Adaptado de: HUNT, 1988, p. 29)

O horizonte vislumbrado por HUNT (op. cit.), para indicar como o conceito de mecatrônica deveria evoluir na época da publicação do referido texto, é ilustrado no trecho abaixo: 
"A Mecatrônica não é, ainda, uma tecnologia especifica que pode ser comprada, mas uma abordagem para a automação de tecnologias, organização e gerenciamento. Esta integração é parte de um movimento geral para criar a fábrica mecatrônica do futuro, uma facilidade totalmente automatizada com elementos de marketing e manufatura trabalhando em harmonia..." (idem ibidem, p. 48)

HUNT (op. cit.) representa um conjunto de autores que entendiam a mecatrônica sob o enfoque do sistema de produção proporcionado pelas tecnologias que permitiam integrar projeto e manufatura. Esse enfoque não se adapta ao propósito de entender em que consistem os produtos mecatrônicos.

HORIKAWA (2000) aborda a mecatrônica sob o aspecto de projeto. Segundo ele, a mecatrônica pode ser definida como um sistema mecânico com realimentação elétrica. O autor classifica projetos mecânicos como convencionais (passivos ou ativos) e mecatrônicos, os quais são ilustrados na Figura 4.

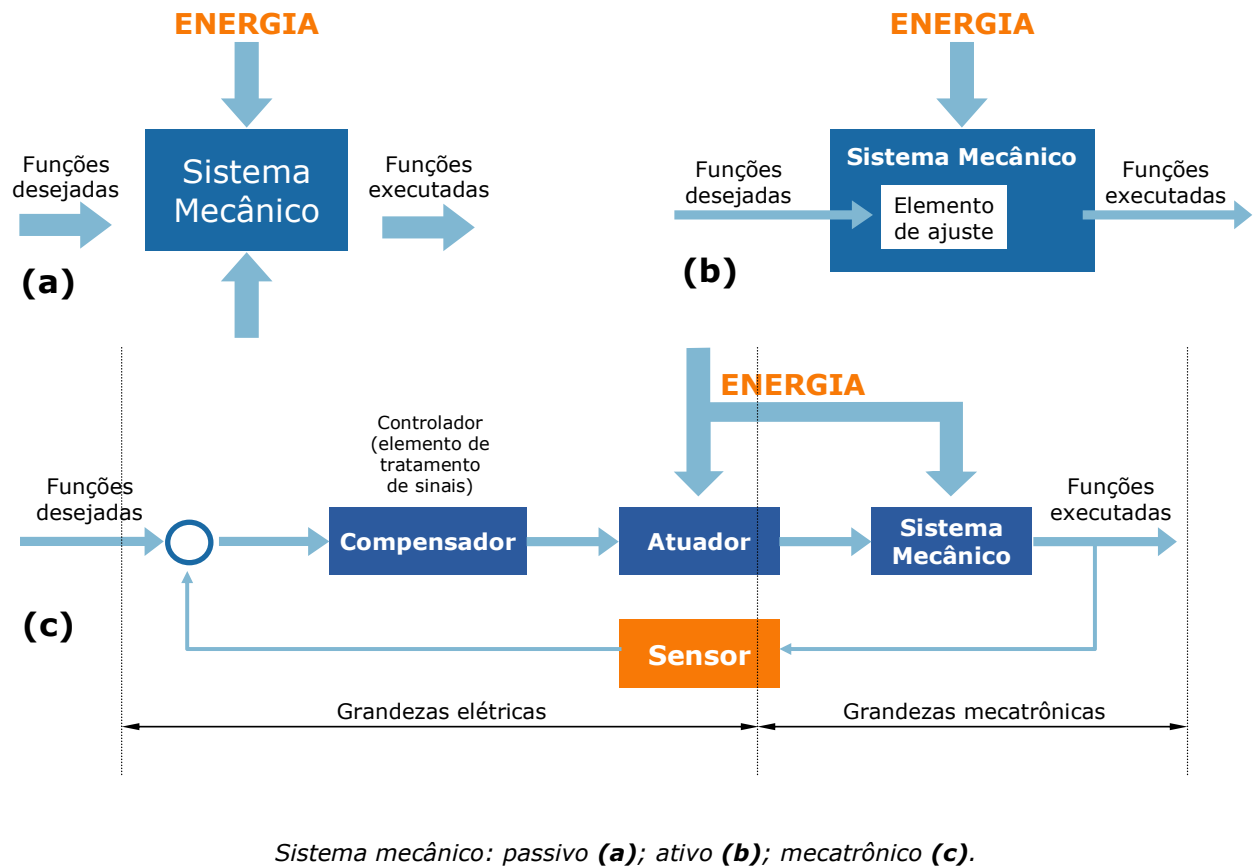

Figura 4 - Projetos mecânicos convencionais e mecatrônicos (Fonte: HORIKAWA, 2000)

Projetos mecânicos passivos e ativos são totalmente baseados nos princípios físicos das chamadas "ciências mecânicas". Em projetos passivos, o processo de adaptação do produto a uma nova necessidade é integralmente dependente da intervenção humana. Novas 
funções são conseguidas apenas por meio do reprojeto do produto. Os projetos mecânicos ativos incorporam o conceito de controle através de uma malha de realimentação baseada em princípios mecânicos. A malha de controle introduz elementos de ajuste que corrigem parâmetros internos do sistema.

O controle realizado por realimentação baseada em princípios mecânicos apresenta sérias limitações: (1) quanto à precisão do monitoramento do processo; (2) quanto à precisão no tratamento do sinal de controle; e (3) quanto à complexidade do projeto, fabricação e montagem da malha de realimentação. Os sistemas mecatrônicos, mediante a introdução de componentes eletrônicos na malha de controle, permitiriam o aumento da precisão do controle dos parâmetros de projeto, uma maior rapidez de resposta e um aumento na capacidade de implementação de algoritmos de controle mais complexos. Dessa forma, a mecatrônica permitiria "...transferir a complexidade do sistema mecânico para a eletrônica ou o software" (WALTERS et al., 2000).

Um típico sistema mecatrônico que segue o conceito de projeto mecatrônico definido acima é representado por uma máquina operatriz de comando numérico com relação a suas predecessoras tipicamente mecânicas.

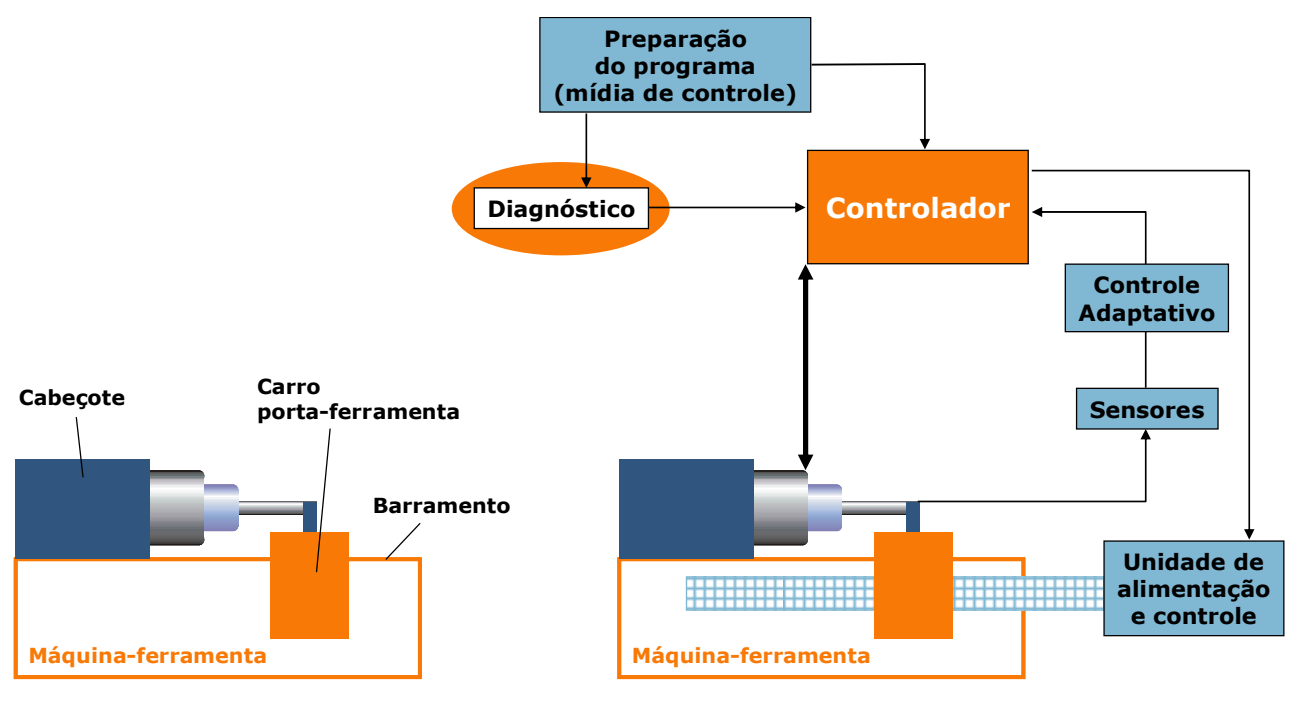

(a)

(b) 
Figura 5 - Máquina ferramenta manual e de comando numérico (Fonte: HUNT, 1988, p. 41)

Dado um programa de usinagem, um dispositivo controlador compara o posicionamento atual do sistema cabeçote-carro com o programa e envia um sinal de posicionamento para a unidade de alimentação e controle. Atuadores ajustam o sistema cabeçote-carro para que os parâmetros de processo se mantenham conforme definido no programa de usinagem.

O enfoque da mecatrônica como incorporação da eletrônica na malha de realimentação de produtos tipicamente mecânicos apresenta como fragilidade o fato de não explicar a existência de produtos eminentemente mecatrônicos tais como o vídeo cassete, o aparelho de som equipado com tocador de discos compactos (CD-Player), um grande conjunto de periféricos da indústria de computadores, tais como equipamento de leitura de discos compactos de memória fixa (CD-ROM), mouses, scanners, impressoras laser e jato de tinta etc. Além disso, o enfoque da mecatrônica com base na engenharia mecânica não daria conta de explicar possíveis evoluções de equipamentos tipicamente eletrônicos como televisores, aparelhos de microoondas etc, abertas por tecnologias de sensoriamento ambiental.

Apesar das limitações causadas pelo enfoque eminentemente mecânico, o entendimento da mecatrônica como aplicação da eletrônica na engenharia mecânica explica um número considerável de aplicações da mecatrônica. Como ilustração, reproduz-se a evolução da eletrônica em automóveis, segundo ADAMSSON (2005). Tal evolução, apresentada na Figura 6, justifica o fato de a indústria automobilística investir fortemente na integração de sistemas de suporte ao projeto de componentes eletrônicos, mecânicos e de engenharia de controle ao longo de seu ciclo de projeto, incluindo sistemas de suporte ao diagnóstico de falhas na operação do produto (STRUSS et al., 2005).

BUUR (1990) faz uma distinção entre tecnologia mecatrônica e engenharia mecatrônica. Esta última, segundo o autor, não se trata de uma nova especialização, mas de 
uma disciplina de integração cujo projeto é orientado com base no estado-da-arte quanto às “tecnologias de produção e montagem”. Esse aspecto da mecatrônica é bastante perceptível nas indústrias de telefones celulares, nas quais as novas famílias de produtos estão intrinsecamente relacionadas com as tecnologias de manufatura de circuitos integrados e montagem eletrônica automatizada, assim como com novos materiais utilizados na confecção da mecânica estrutural.

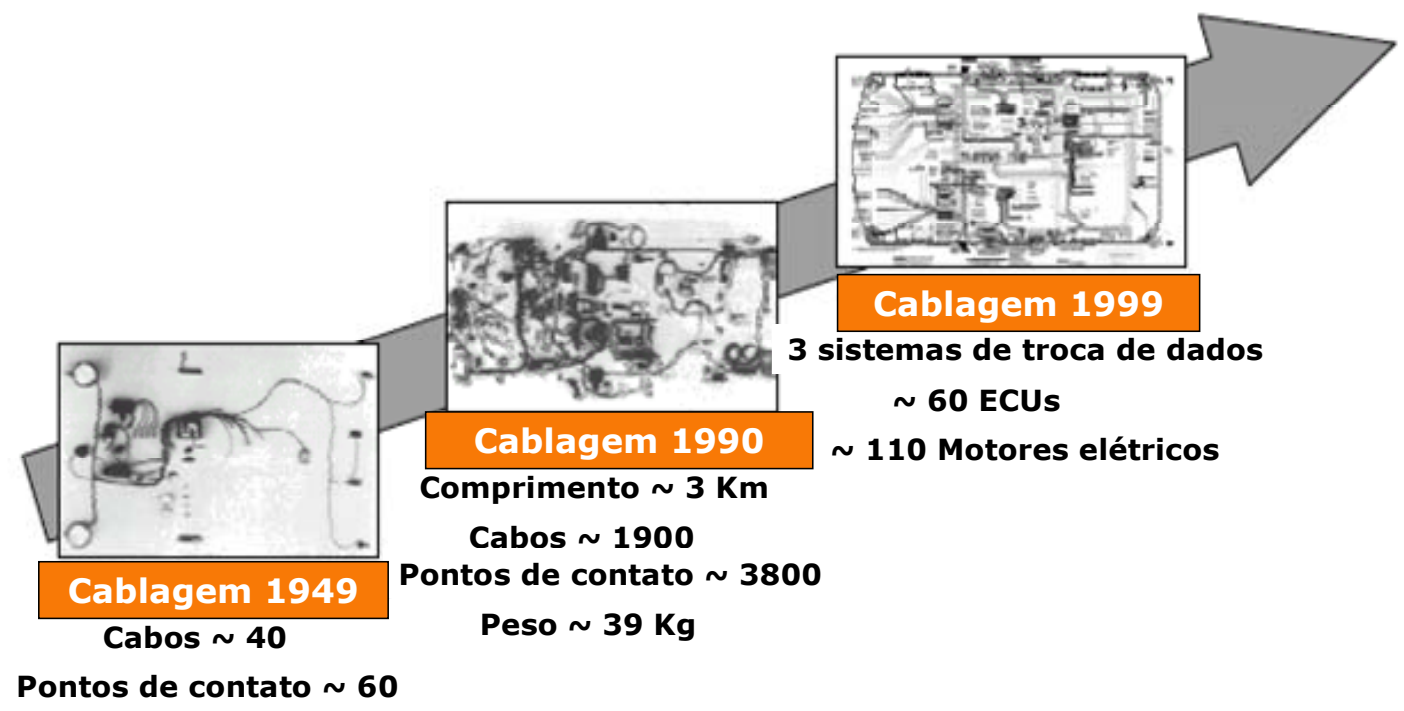

Figura 6 - Uma ilustração do desenvolvimento da eletrônica automotiva (Fonte: ADAMSSON, 2005, p. 13)

Por tratar-se de uma disciplina baseada no estado-da-arte das tecnologias incorporadas nos produtos a ela relacionados, a mecatrônica traz como demanda a constante atualização dos profissionais das diferentes áreas técnicas. A engenharia mecatrônica deve estar apta a prover as demandas tecnológicas que os diferentes campos de aplicação da mecatrônica necessitam. Por exemplo, no campo dos equipamentos de segurança, a mecatrônica foi aplicada através do uso de acionamento de motores por controle eletrônico remoto; no campo do esporte profissional através da introdução de controle eletrônico em malha fechada para compensar vibrações em raquetes de tênis; no campo da tecnologia de celulares, pela miniaturização da eletrônica, pela introdução de novos protocolos de comunicação e pela 
pesquisa em novos materiais e processos de fabricação; no campo da siderurgia, através de novos sensores que permitam digitalizar imagens para monitoramento da fabricação.

Essa discussão sugere que, mais do que o aspecto formal, ou seja, das disciplinas que são combinadas para o desenvolvimento de tecnologia mecatrônica - mecânica, eletrônica, software etc. - é mais importante adotar uma perspectiva funcional da mecatrônica, ou seja, um entendimento do tipo de funcionalidade provida por um produto mecatrônico. A abordagem funcional é descrita por GRIMHEDEN e HANSON (2005) como forma de demonstrar a evolução do conceito de mecatrônica. Segundo os autores, do ponto de vista funcional, a mecatrônica pode ser entendida como uma abordagem pela qual é possível prover produtos munidos de:

- inteligência: habilidade para utilizar um conjunto de parâmetros para o controle de funções. A inteligência do sistema está relacionada com a adaptabilidade a variações nos parâmetros, programabilidade, comunicação, autodiagnóstico, auto-reparo etc; e

- $\quad$ flexibilidade: facilidade com a qual o produto pode ser ajustado a um novo ambiente durante o seu ciclo de vida.

RZEVSKI (2003) discute o que chama de "inteligência emergente" que seria a capacidade de sistemas mecatrônicos distribuídos, cada qual com um grau de inteligência inerente, interagirem criando um comportamento mais complexo. Segundo o autor, a tecnologia de programação orientada a objetos permite a criação desse tipo de estrutura.

BRADLEY et al. (2000) discute os tipos de inteligência de máquina alcançados atualmente (vide Quadro 1). O grau de inteligência aplicado a um sistema mecatrônico tem forte relacionamento com o tipo de dispositivo micro-eletrônico utilizado. O Quadro 2 apresenta uma típica distribuição da eletrônica aplicada a produtos mecatrônicos, segundo BRADLEY (1991). Observa-se a identificação do potencial de processamento de dados 
representado pela quantidade de bits que são capazes de processar os dispositivos utilizados em cada aplicação descrita.

Quadro 1 - Tipos de inteligência de máquina (Fonte: BRADLEY et al.., 2000, p. 43)

\begin{tabular}{|c|c|c|}
\hline Descrição & Exemplo & Característica \\
\hline Função simples & Furadeira & Capaz de apenas uma operação \\
\hline Automático & Braços robóticos de movimentação & Realiza uma seqüência fixa de operações \\
\hline Programável & Máquina ferramenta $\mathrm{CNC}$ & $\begin{array}{l}\text { Realizar uma seqüência de operações sob controle } \\
\text { programável incluindo decisões no fluxo de execução }\end{array}$ \\
\hline Adaptativo & Aviões do tipo fly-by-wire & $\begin{array}{l}\text { Adapta-se de forma autônoma a mudanças nas condições } \\
\text { ambientais através de sensores de realimentação }\end{array}$ \\
\hline Buscador de metas & Veículos autoguiados & $\begin{array}{l}\text { Adapta-se a mudanças no ambiente em relação a uma } \\
\text { meta definida }\end{array}$ \\
\hline Autônomo avançado & $\begin{array}{l}\text { Equipamentos mecatrônicos que } \\
\text { processam dados }\end{array}$ & $\begin{array}{l}\text { Capacidade de planejamento e tomada de decisão } \\
\text { estratégica }\end{array}$ \\
\hline
\end{tabular}

Quadro 2 - Comparação de aplicações para microprocessadores (Fonte: BRADLEY, 1991, p. 210)

\begin{tabular}{|c|c|c|}
\hline Aplicação & Microprocessador & Requisitos \\
\hline Máquinas de lavar & Microcontrolador de 4 ou 8 bits & Baixo custo; imune a ruído elétrico \\
\hline Transdutores inteligentes & Microcontrolador de 8 bits & $\begin{array}{l}\text { I/O analógico; baixo consumo de potência; } \\
\text { comunicações }\end{array}$ \\
\hline Câmera autofocus & Microcontrolador de 8 bits & Alto nível de integração \\
\hline $\begin{array}{l}\text { Unidade de gerenciamentc } \\
\text { de motores } \\
\text { Processamento de voz }\end{array}$ & $\begin{array}{l}\text { Microprocessador ou microcontrolador } \\
\text { de } 8 \text { ou } 16 \text { bits } \\
\text { Processador digital de sinais de } 16 \text { ou } \\
32 \text { bits }\end{array}$ & $\begin{array}{l}\text { I/O analógico; processamento de sinais; imune ao ruído } \\
\text { elétrico; alta corrente de saída } \\
\text { Operações de multiplicação e acumulação rápidas }\end{array}$ \\
\hline Sistema de controle de vố & Microprocessador de 16 ou 32 bits & Alta confiabilidade; comunicações \\
\hline Controlador de robôs & Microprocessador de 16 ou 32 bits & Alta velocidade de cálculo; comunicações \\
\hline
\end{tabular}

A abordagem funcional procura definir elementos que demonstrem como os produtos mecatrônicos se diferenciam dos equipamentos desenvolvidos com tecnologias mecânica, eletrônica e de software. O primeiro autor a desenvolver uma perspectiva funcional na definição da mecatrônica foi BUUR (1990):

\begin{abstract}
"Mecatrônica é uma tecnologia que combina mecânica com eletrônica e tecnologia da informação para compor tanto uma interação funcional como uma integração espacial de componentes, módulos, produtos e sistemas".(BUUR, 1990, p.18, grifos nossos)
\end{abstract}

A definição de BUUR (op. cit.) tem viés nas áreas tecnológicas que caracterizam os produtos mecatrônicos, portanto, embora explicite aspectos funcionais, se mantém dentro de um paradigma formal. Além disso, não parece ser necessário haver integração espacial para 
que um determinado produto seja mecatrônico. Em um mouse, por exemplo, a função do produto só vem à tona quando o ícone representativo do mouse é apresentado e se movimenta no monitor do computador sem que seja necessária integração espacial do mouse com o monitor. A definição é importante para deixar clara a necessidade de haver interação funcional entre as diferentes áreas do conhecimento relacionadas com projetos de produtos mecatrônicos. Uma televisão, por exemplo, apresenta uma carenagem mecânica e um detalhado projeto estrutural para suportar os componentes eletrônicos responsáveis pela recepção e apresentação da imagem, porém essa função não influi no cumprimento da funcionalidade principal da TV. A Figura 7 apresenta uma visão simplificada da arquitetura funcional de um mouse e uma TV comparando-as enquanto produtos mecatrônicos segundo o conceito de BUUR (op. cit.).

Observa-se que a função básica da TV é realizada totalmente por dispositivos eletrônicos e eletromagnéticos. No mouse mecânico não há efetiva manipulação dos ícones dispostos no monitor sem que o sensor mecânico indique, pelo movimento de rolagem, a posição do mouse na sua superfície de contato. O movimento é captado por chaves de contato elétrico que geram sinais a serem codificados e enviados ao computador no qual um software interpreta a movimentação a ser realizada no monitor. $\mathrm{O}$ mesmo princípio de interação funcional se aplica às funções de "click" executadas pelas hastes mecânicas, chaves e o software "driver".

HISTAND e ALCIATORE (2006, p. 11) definem mecatrônica como:

"Mecatrônica é um campo interdisciplinar da engenharia que lida com o projeto de produtos cujas funções são realizadas por uma integração sinergética entre componentes mecânicos, eletrônicos e elétricos conectados por uma arquitetura de controle". (Grifos nossos) 


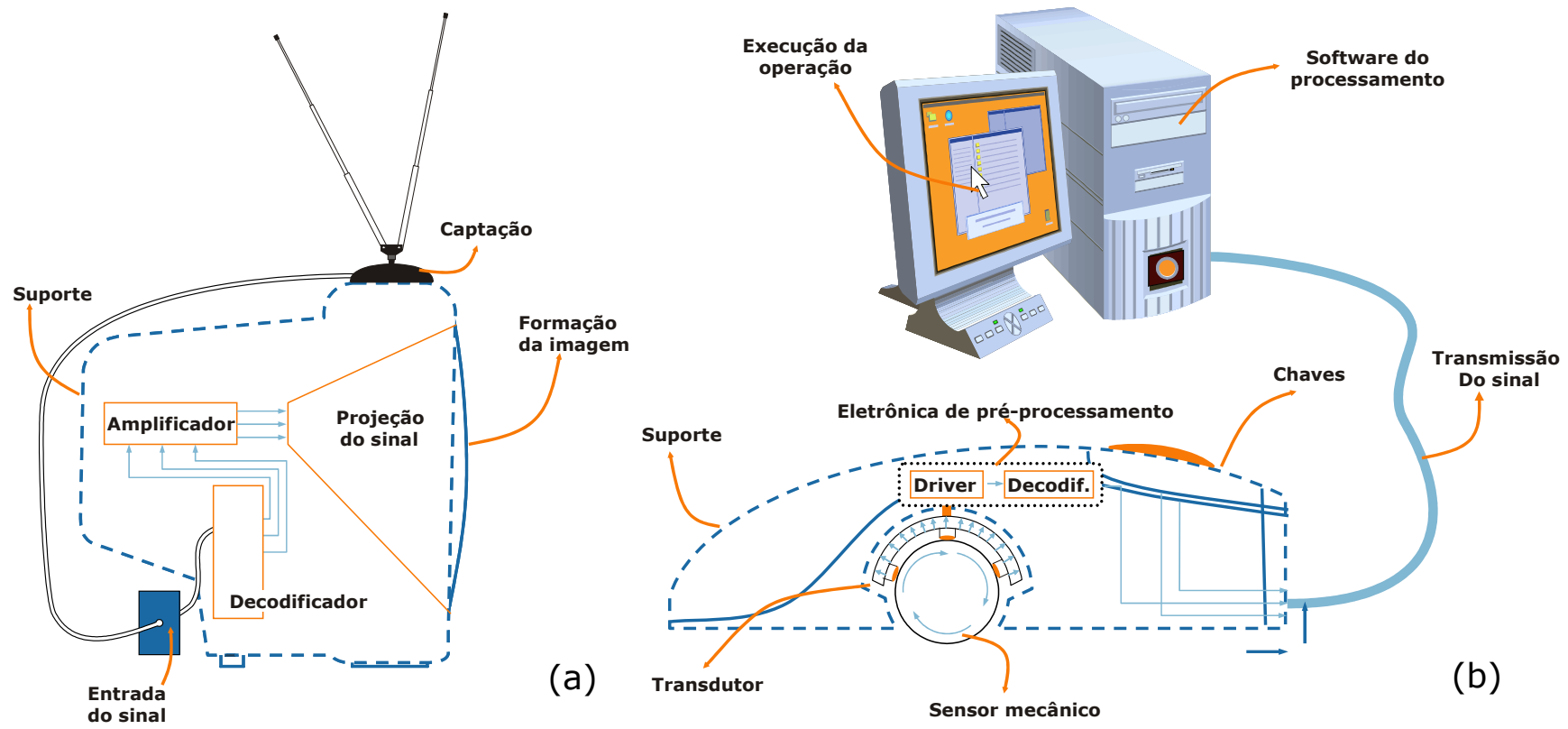

Figura 7 - Arquitetura funcional básica de: (a) um produto eletrônico (televisão); e (b) um produto mecatrônico (mouse mecânico).

O conceito de interação funcional descrito por BUUR (op. cit.) é aqui identificado como "integração sinergética" e ao invés de tecnologias, os autores mencionam componentes. A definição de HISTAND e ALCIATORE (op. cit.) acrescenta um importante elemento ao conceito de mecatrônica: os sistemas de controle. A relação entre sistemas de controle e mecatrônica é discutida a seguir.

Segundo DORF e BISHOP (2001, p.2), “[...] um sistema de controle é uma interconexão de componentes formando uma configuração que provê uma resposta desejada". Os sistemas de controle, em linhas gerais, podem ser de malha aberta ou de malha fechada. Sistemas malha-aberta utilizam dispositivos atuadores para controlar o processo diretamente sem o uso de sinais de realimentação. O uso de sinais de realimentação caracteriza os sistemas de controle de malha fechada, nos quais uma medida da saída do sistema é utilizada para comparar com a saída desejada de forma a melhorar a resposta. A Figura 8 apresenta uma comparação entre os sistemas de controle malha aberta e malha fechada. 


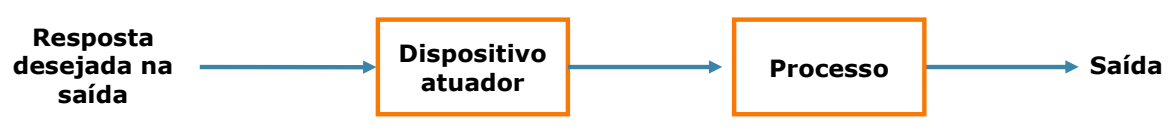

(a)

(b)

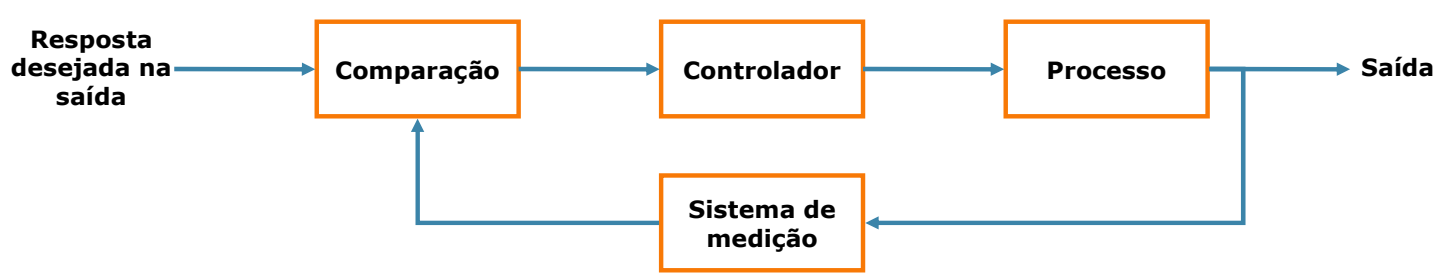

Figura 8 - Sistemas de controle malha fechada e malha aberta (Fonte: DORF e BISHOP, 2001)

Pode-se considerar que todo produto mecatrônico comporta ao menos um sistema de controle, muito embora a teoria de controle não seja suficiente para dar conta do projeto de equipamentos mecatrônicos, uma vez que é dedicada à identificação de parâmetros e valores que otimizem o funcionamento de um determinado sistema em regime permanente, e portanto, não prescreve métodos para o projeto do sistema a ser controlado. Pode-se dizer que o projetista de equipamentos mecatrônicos deve ter sólida formação em sistemas de controle, sendo capaz de utilizar seus conhecimentos em mecânica, eletrônica e software para implementar os sistemas de controle necessários ao correto funcionamento do produto.

Por outro lado, há um grande número de sistemas de controle que não são mecatrônicos, uma vez que utilizam apenas um tipo de tecnologia: mecânica, eletrônica, hidráulica, pneumática etc. A Figura 9 apresenta um esquema simplificado de um teclado, um produto mecatrônico entendido como um sistema de controle malha aberta no qual a palavra a escrever é digitada pelo usuário do computador e sua exatidão é observada na tela do computador sem que haja uma malha automática de realimentação. 


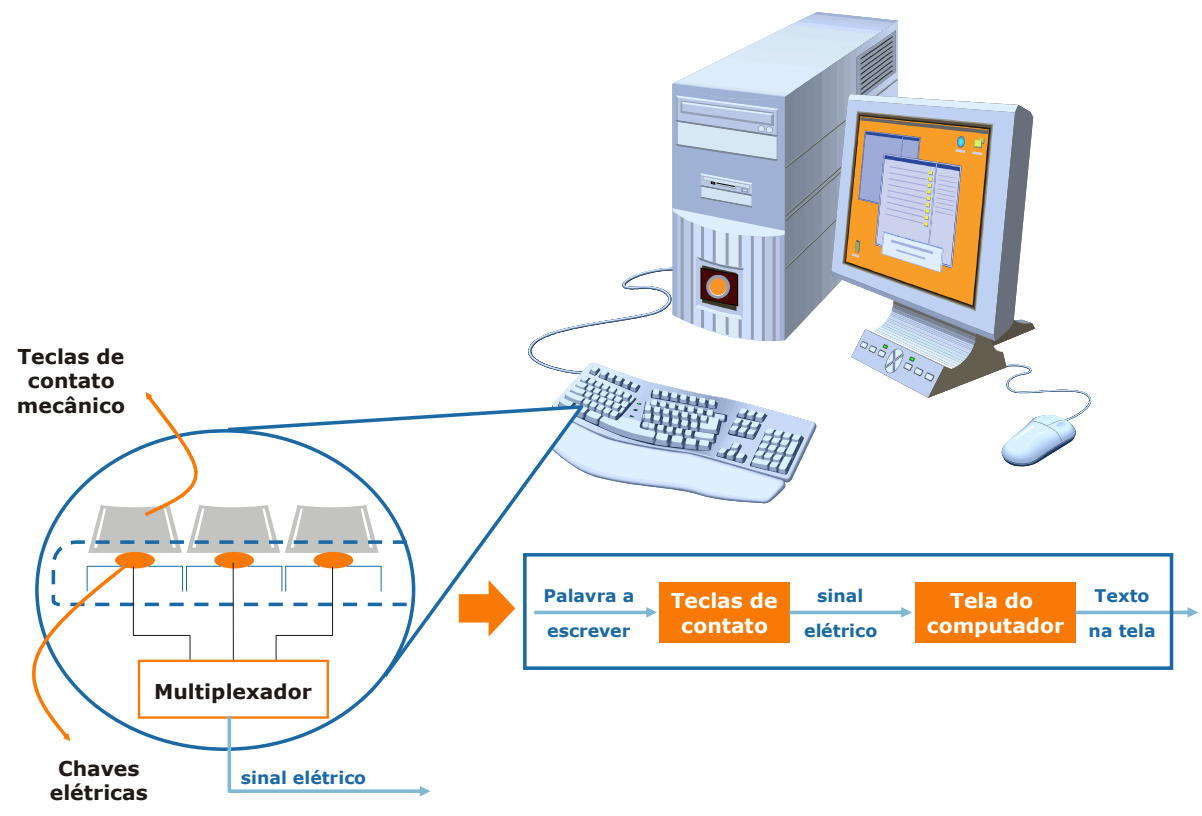

Figura 9 - Exemplos de relação entre sistemas de controle e produtos mecatrônicos:teclado - produto mecatrônico como sistema de controle malha aberta.

A Figura 10 apresenta um esquema simplificado de um sistema de leitura de uma unidade de disco rígido em um computador pessoal. O diagrama implementa o conceito descrito em AMERONGEN (2005) onde há controle malha fechada da posição do cabeçote de leitura e da velocidade de rotação do motor do disco rígido, ambos controlados a partir dos dados de leitura interpretados pelo decodificador de trilha. Enquanto o sistema de controle da velocidade do motor age no sentido de manter a taxa de transferência constante entre disco rígido e memória dinâmica, o controle de posição do cabeçote apenas verifica o perfeito posicionamento deste. Adicionalmente, se houver apenas uma posição para cada valor de velocidade do motor, é possível simplificar o sistema de controle utilizando apenas a malha de realimentação do motor.

A Figura 11 apresenta o sistema de controle de uma caixa d'água encontrada nas mais comuns residências e construções comerciais. Observa-se que o sistema de controle é totalmente hidráulico. No sistema representado pela caixa d'água, a bóia funciona como sensor e atuador simultaneamente. 


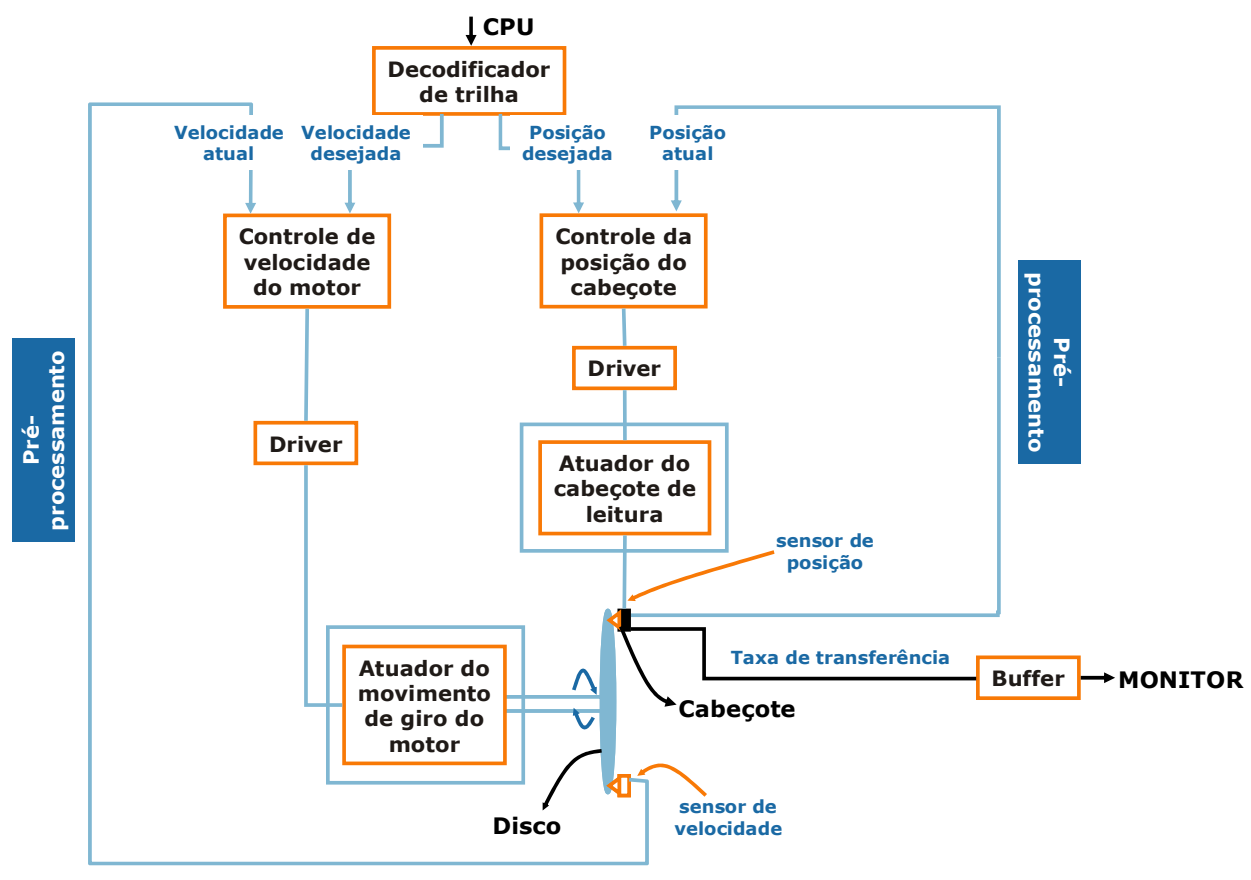

Figura 10 - Exemplos de relação entre sistemas de controle e produtos mecatrônicos: unidade de disco rígido produto mecatrônico como sistema malha fechada.

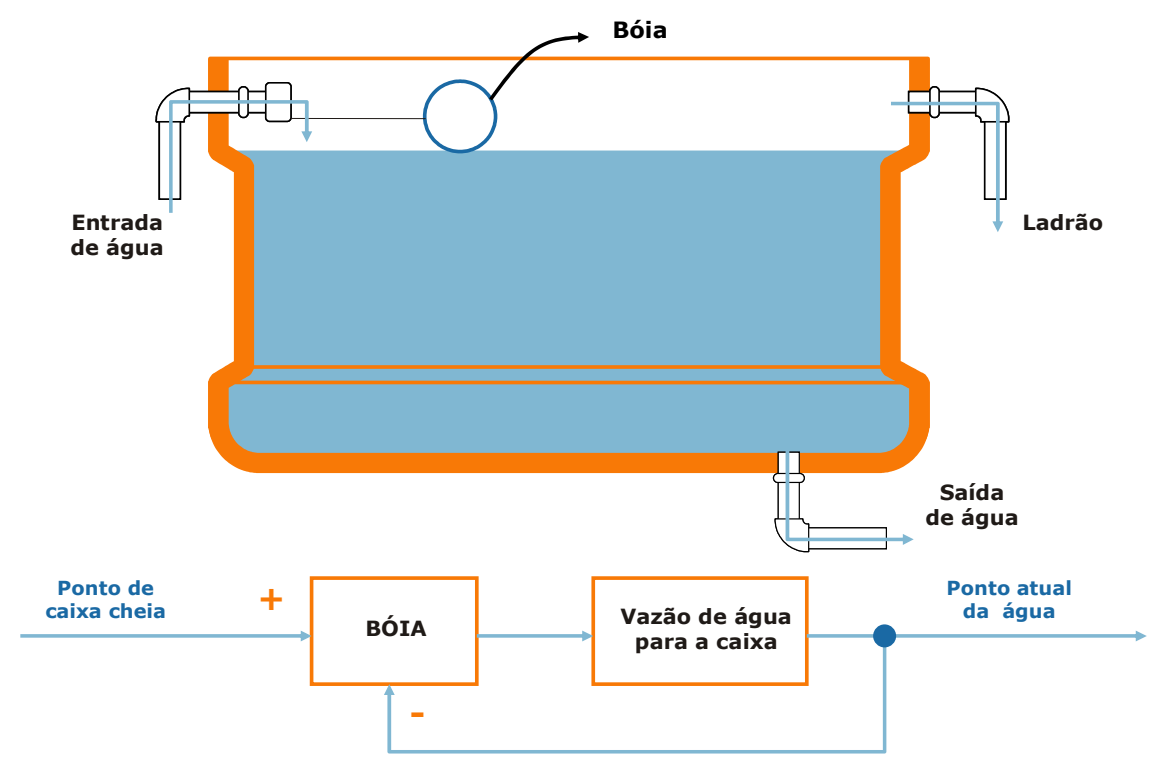

Figura 11 - Exemplos de relação entre sistemas de controle e produtos mecatrônicos: sistema malha fechada que não é mecatrônico.

RIZZONI apud GROVE (2001) apresenta uma definição de mecatrônica que engloba os elementos básicos de sistemas de controle. Segundo o autor, a mecatrônica é:

"[...] a confluência de métodos de projeto tradicionais com sensores e tecnologia de instrumentação, atuadores e sistemas de alimentação, sistemas microprocessados embarcados e software de tempo real." 
Na definição apresentada por RIZZONI (op. cit.) o foco da discussão sai totalmente do aspecto formal representado pelas disciplinas que caracterizam os produtos mecatrônicos e se fundamenta nas tecnologias relacionadas com as funções desempenhadas por esse tipo de produto: atuadores, sensores, instrumentação, microprocessadores, sistema de alimentação e software em tempo real. BRADLEY (1991) apresenta uma extensa discussão em torno dessas tecnologias. No tópico seguinte essa discussão será retomada para conceituar os produtos mecatrônicos.

\subsubsection{Os produtos mecatrônicos}

Segundo BERNARDI et al.. (2002), "... o amplo espectro de produtos que utilizam a mecatrônica torna difícil chegar a uma definição universalmente válida para o que seriam os produtos mecatrônicos." Nesse tópico será sistematizada uma concepção genérica para um produto mecatrônico com base na discussão anteriormente realizada. Em linhas gerais um produto mecatrônico deve basicamente obedecer aos seguintes critérios:

- de integração de tecnologias mecânica, eletrônica e de software;

- de que as funções básicas do produto sejam providas pela interação entre as tecnologias que o compõem;

- $\quad$ de que o produto possa ser entendido como um sistema de controle malha aberta ou malha fechada.

Os principais componentes desse tipo de produto são, segundo BRADLEY (1991):

- $\quad$ sensores e instrumentação: sistema de mensuração utilizado no produto para controlar condições de operação e/ou ambientais. Os sensores são os componentes do sistema de medição que respondem a um parâmetro físico que se deseja medir. Algumas vezes os sensores são acompanhados de transdutores que são componentes que convertem um 
determinado tipo de energia em um outro que possa ser melhor processado pelo sistema. Instrumentação é o projeto do tratamento do sinal interfaceando-o com o sistema microprocessado de controle e reduzindo o ruído oriundo do ambiente de medição.

- $\quad$ software de processamento/controle: É o principal componente lógico do sistema. Nele são armazenadas e comandadas as principais funções do produto. As informações oriundas dos sensores e transdutores utilizados são processadas e rotinas são executadas de maneira a comandar a operação do produto. Esse componente pode ser central ou distribuído, podendo comportar soluções em software de baixo nível (assembly) armazenado em memórias removíveis por ultra-violeta (EPROM) ou microcontrolador dedicado, ou em programação de alto nível utilizando $\mathrm{C}++$, Delphi etc., opção normalmente utilizada quando o sistema exige uma interface mais elaborada com o usuário do produto. Em casos nos quais sejam exigidas altas confiabilidade e robustez do sistema de controle, o software pode ser substituído por projeto de lógica digital discreta ou circuitos baseados em programação por portas pré-programadas (field programmable gate array - FPGA). O componente de software comporta também funcionalidades de processamento de sinais, tais como processamento de imagens, armazenamento de dados etc. É importante observar que o componente de software em um produto mecatrônico pode comportar apenas as funções de processamento de sinais sem implementar qualquer função de controle.

- $\quad$ atuadores e drives: os atuadores são componentes robustos utilizados para corrigir o funcionamento do sistema. São comumente soluções mecânicas ou eletromecânicas que agem diretamente sobre o mecanismo que realiza a operação básica do produto. Os drives são tipos de circuitos eletrônicos que realizam a interface com os sinais de controle gerados pelo sistema microprocessado atribuindo-lhes a potência (normalmente por amplificação de corrente) necessária à alimentação dos atuadores. 
- $\quad$ projeto de engenharia: é o projeto básico do mecanismo ou solução de engenharia para o propósito ao qual o produto deve atender. Quando integrado em equipamentos mecatrônicos, é necessário que o projeto básico leve em consideração os demais componentes mecatrônicos desde sua concepção. Essa solução, diferentemente da abordagem tradicional, deve observar os requisitos dos sensores e atuadores a serem utilizados, e estes normalmente influenciam a escolha do microprocessador a ser usado no projeto. O grau de interação humano-máquina, os níveis de flexibilidade necessários às diferentes configurações de produto e a severidade dos requisitos de segurança devem ser cuidadosamente analisados de forma a gerar as especificações para o projeto dos demais componentes do sistema mecatrônico.

- $\quad$ sistema de comunicação: os sistemas de comunicação não estão necessariamente presentes em todos os produtos mecatrônicos, mas são fundamentais no projeto de sistemas de controle distribuído como é o caso dos sistemas flexíveis de manufatura, de sistemas de controle à distância, a exemplo dos robôs de exploração interplanetária, ou mesmo de sistemas mais comuns, como é o caso dos aparelhos de telefonia celular. Sistemas de comunicação são os meios físicos ou eletromagnéticos através dos quais os sinais produzidos e utilizados por sensores, microprocessadores e atuadores transitam através do sistema mecatrônico. Entre os meios de comunicação mais presentes temos as redes locais (Local Area NetworkS- LANS) que utilizam tecnologia de fibra óptica e protocolos de comunicação de sistemas abertos (Open Systems Interconnection - OSI/ISO) e ultimamente os sistemas sem fio (Wireless Fidelity - WI-FI).

A Figura 12 apresenta um esquema genérico para um produto mecatrônico com os componentes definidos acima. O fluxo principal é exemplificado pelas setas cheias na horizontal. Essas setas representam, basicamente, um fluxo de informações, à exceção das identificadas com um asterisco $\left(^{*}\right)$. Entre atuador e projeto de engenharia e entre esse e a 
aplicação, o fluxo principal pode ser também de energia ou materiais. As setas tracejadas na vertical identificam os possíveis fluxos de informação realizados através dos sistemas de comunicação. As aplicações identificadas na Figura 12 demonstram as possibilidades de introdução de componentes e módulos mecatrônicos na indústria de processos (petróleo), de produtos de massa (carros) ou defesa (aviões militares). O sistema mecatrônico é, entretanto, na maioria da vezes, comercializado como produto final.

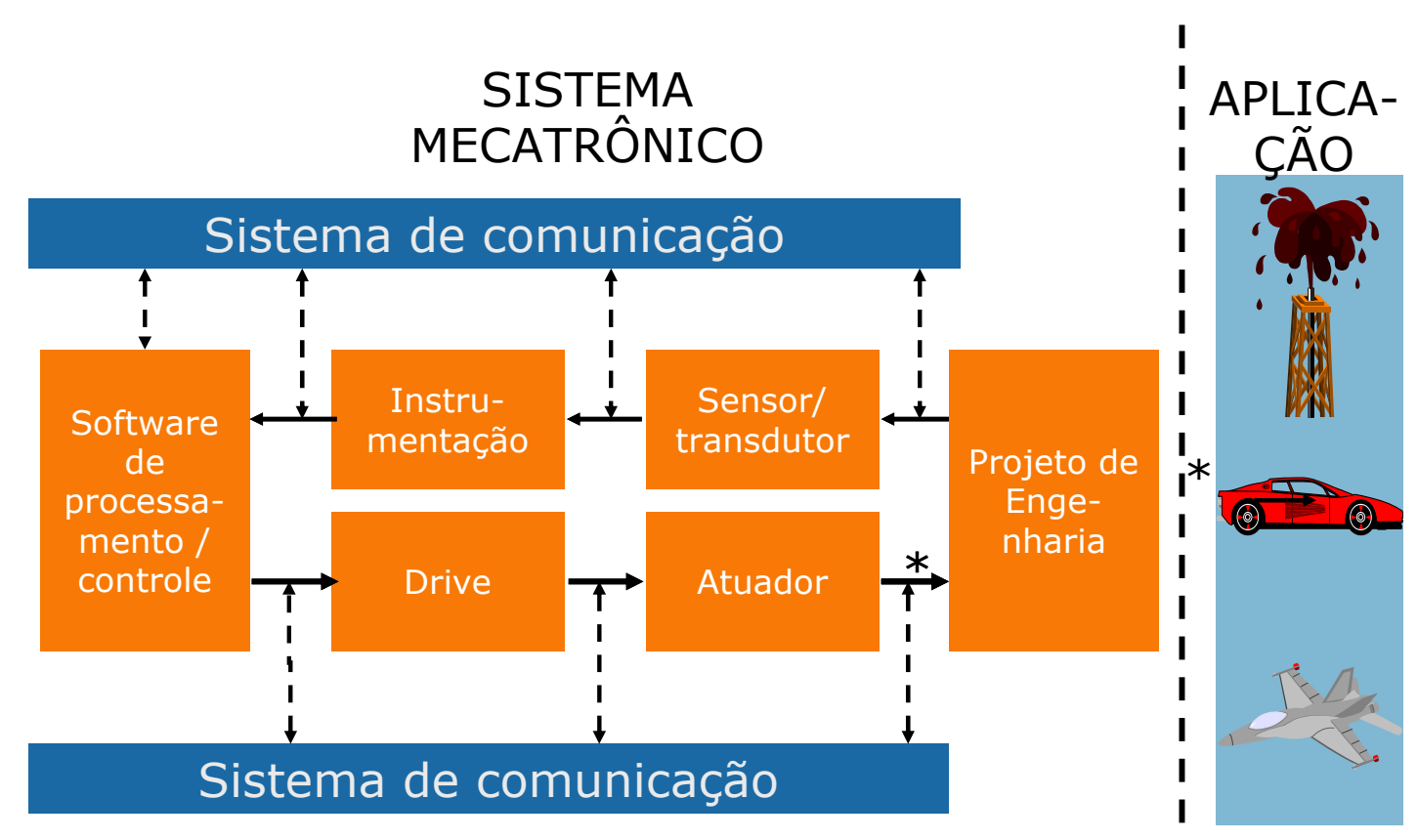

Figura 12 - Elementos de um sistema mecatrônico

A Figura 13 apresenta um esquema de uma câmara reflex descrita conforme os elementos identificados na Figura 12. O software de controle é distribuído em dois microprocessadores de 8 bits equipados com memórias removíveis eletricamente (EEPROM), um localizado no corpo da câmera e um outro na objetiva. O projeto básico de engenharia da câmera é representado na figura pelo conjunto de lentes e o filme localizado na parte traseira da câmera. Através da regulação de abertura e tempo de exposição, a imagem é formada no filme químico. A objetiva comporta um conjunto de atuadores com função de ajuste de foco e de abertura. Há um conjunto de sensores que interpretam o padrão de iluminação em posições diferentes da imagem captada (central, adjascente e periférica) e também há sensores que 
identificam a posição relativa das lentes e a enviam para o controlador central e deste para o display (ver BRADLEY et. Al., 1991).

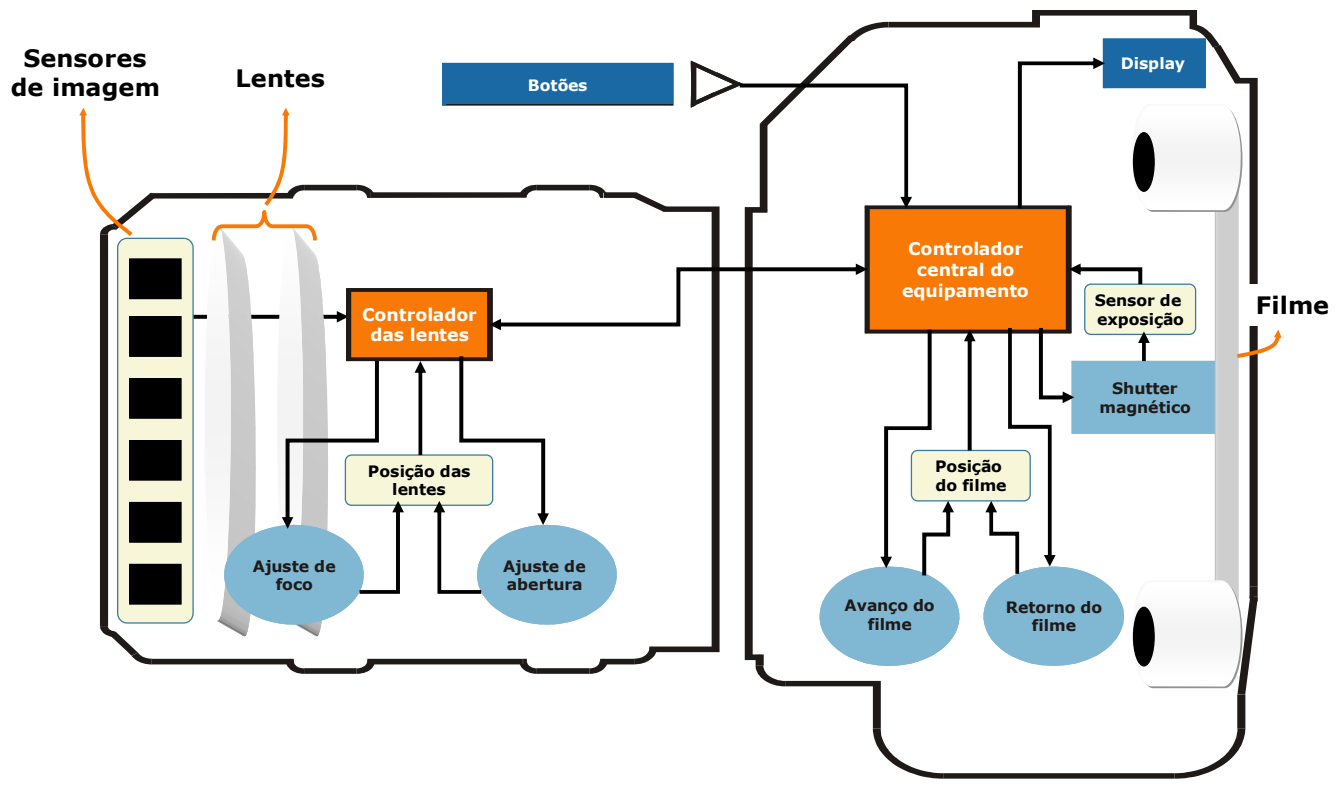

Figura 13 - Descrição de uma câmara reflex a partir dos elementos de sistemas mecatrônicos. (Adaptado de BRADLEY, 1991, p. 444)

$\mathrm{Na}$ parte central do equipamento encontram-se sensores e atuadores que regulam o tempo de exposição da câmera para uma determinada condição de imagem, movimentam o filme e indicam a quantidade de fotos ainda nele disponível. Os botões e displays fazem parte do projeto da interface humano-máquina, assunto retomado no item 5.3.1.8.

A Figura 14 apresenta a descrição de um mouse sem fio como produto mecatrônico. Observa-se a introdução do sistema de comunicação como elemento fundamental do projeto. A engenharia básica do mouse óptico consiste na utilização de um diodo emissor de luz (light emmiting diode - LED) como fonte de luz. A luz incide sobre a superfície na qual o mouse se encontra, é refletida e atravessa uma lente que converge em um fotosensor. O fotosensor comporta uma câmera de semicondutor de metal-óxido complementar (complementary metaloxide-semiconductor - CMOS) que faz fotos de uma pequena área na superfície, montando um quadro de pixels, que é interpretado pelo processador de sinais digitais (digital signal 
processing - DSP) quanto à direção e velocidade do movimento e transformado em coordenadas enviadas por radio freqüência (RF) ao computador.

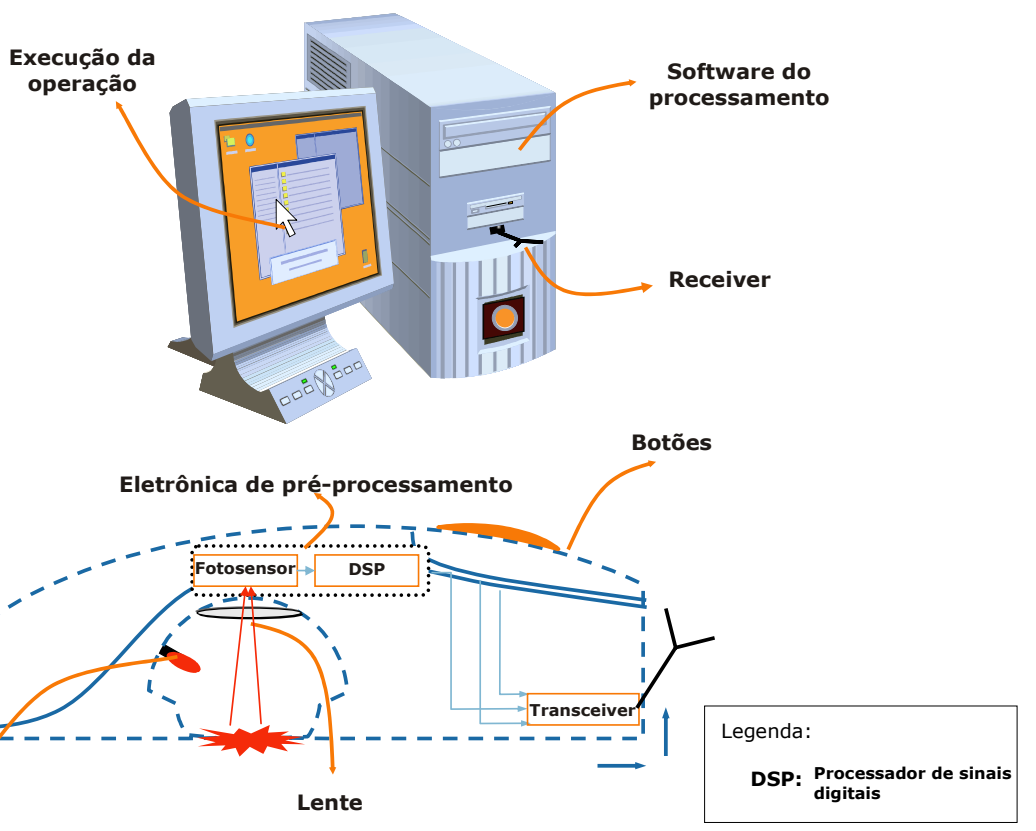

Figura 14 - Descrição de um mouse sem fio a partir dos elementos de sistemas mecatrônicos . (Adaptado de: http://www.uniqueics.com/htmls/od optical mouse.htm, acesso em 23/11/2005)

O atuador do mouse óptico é representado pelo ícone que aparece na tela do computador. Uma vez que o sistema é malha aberta, não há correção automática do posicionamento do dispositivo. Há sistemas com mouse óptico se comunicando com o computador através de interfaces para sistemas pessoais (Personal System/2 - PS/2), entretanto, na figura é representado um sistema com interface serial universal (Universal Serial Bus - USB) no qual há um receiver em série com um controlador de RF. O sistema de comunicação é determinado pela freqüência de oscilação do fotosensor. Ambos, tranceiver e receiver, são sintonizados nessa freqüência. A transmissão e a recepção do sinal é realizada por antenas de ciclo (loop antennas) projetadas como sistema indutivos-capacitivos (LC) de superfície (PCB loop antenna), conforme descrito em MOTOROLA (2004, p. 41) fazendo parte dos próprios circuitos transceiver e receiver, respectivamente. Entre as especificações principais desse tipo de dispositivo constam a freqüência de trabalho e a distância de operação. 
A Figura 15 apresenta um sistema mecatrônico desenvolvido para ser integrado em um produto final. Trata-se de uma representação simplificada de uma unidade de controle eletrônico de motores de automóveis (ECU).

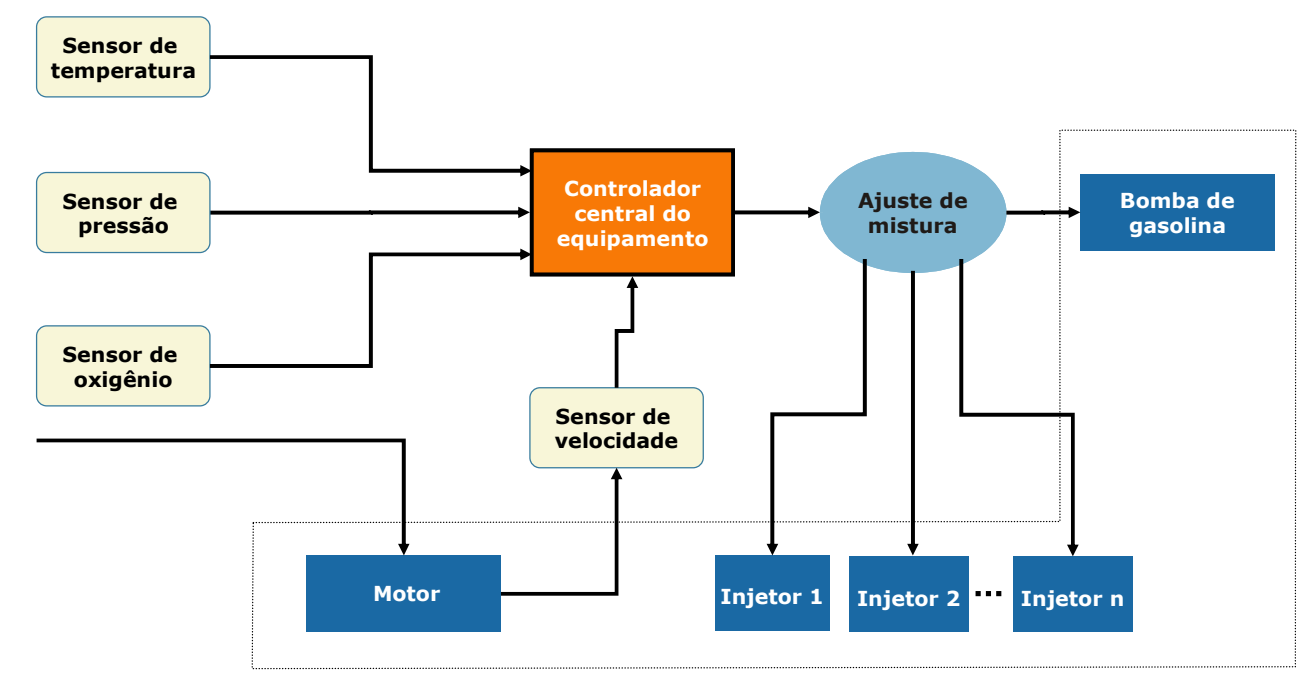

Figura 15 - Descrição de uma unidade eletrônica de controle de motores (Adaptado de http://members.rennlist.com/pbanders/ecu.htm, acesso em 21/11/2005)

A ECU controla o momento e a duração do pulso de tensão imposto aos injetores, assim como a operação do sistema de disparo do motor quando o automóvel é ligado. O conjunto motor-injetores-bomba de gasolina representa o projeto básico do motor à combustão interna. Um conjunto de sensores analógicos permite o monitoramento das condições de temperatura, pressão, quantidade de oxigênio disponível para a queima e velocidade do motor. Esses parâmetros são utilizados para estabelecer a quantidade mínima de combustível necessária à manutenção da velocidade do motor em condições de operação normal. Portanto, os atuadores básicos são válvulas que regulam a concentração de combustível e ar na mistura introduzida nos injetores. Considerando as altas potências de operação de motores automotivos, os projetos dos circuitos de instrumentação e driver tornam-se bastante complexos.

Uma descrição detalhada do funcionamento da ECU e dos sistemas automotivos de injeção eletrônica pode ser encontrado no site http://www.autoshop101.com/autoshop15.html 
(acesso em 23/12/2005), cujos artigos são assinados pela Toyota Motor Company dos Estados Unidos.

Um robô de exploração interplanetária pode ser visto como um produto mecatrônico cuja função principal é exercida apenas com a intensa utilização do componente "sistema de comunicação", conforme ilustrado na Figura 16.

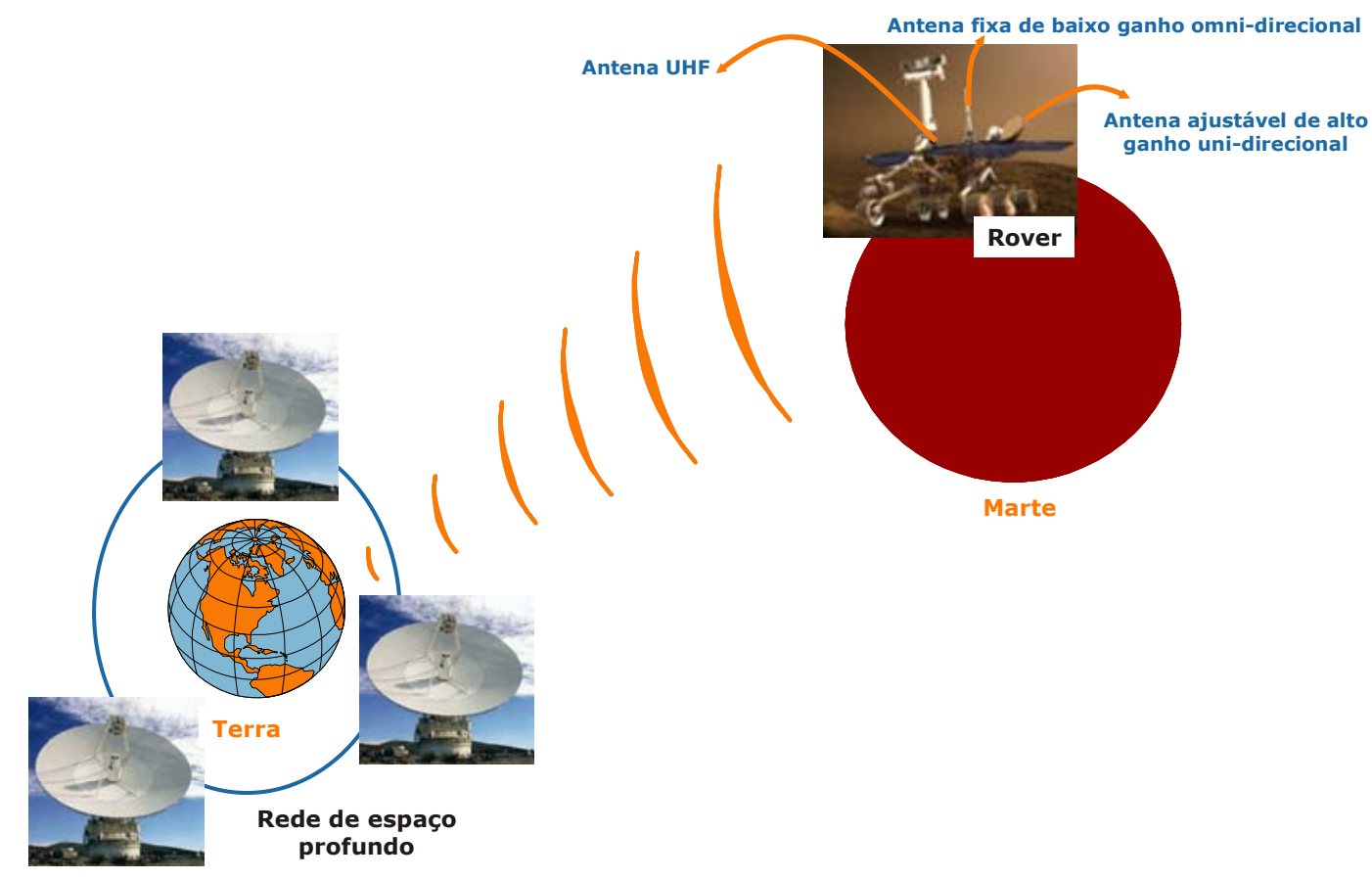

Figura 16 - Esquema de comunicações da missão "robô exploratório de marte". (Fonte: http://mars.jpl.nasa.gov/mer/mission/spacecraft rover antennas.html, acesso em 22/11/2005)

O veículo robótico remotamente controlado (rover) contém um conjunto de antenas cujo objetivo é manter comunicação com a base em terra. Para isto foram projetadas três antenas denominadas "rede de espaço profundo" (Deeep Space Network - DSN) que estão localizadas a aproximadamente $120^{\circ}$ entre si (California, Madri e Camberra) de maneira a manter comunicação com veículos em missões espaciais independente do movimento de rotação do planeta. No rover, há duas antenas com capacidade de transmissão e recepção de sinais direto da DSN. Uma das antenas é fixa e envia dados a baixas taxas de transmissão em todas as direções. Essa antena é de baixo ganho e sua alta robustez e confiabilidade visam garantir a recepção de dados da missão. A outra antena com capacidade de envio de dados 
para Terra é unidirecional, porém conta com capacidade de ajuste de direção. Essa antena é capaz de enviar grandes pacotes de dados.

A terceira antena visa a comunicação do rover com veículos espaciais que estejam em missão próximos à sua órbita. É uma antena de freqüência ultra alta (ultra high frequency UHF) de baixa capacidade de transmissão de dados (bit rate) se comparada com as anteriores. Embora o exemplo da missão de exploração do solo marciano seja extremo na necessidade de uso de sistemas de comunicação, sistemas de manufatura comumente exigem um forte aporte nesse componente, assim como equipamentos de uso geral que impliquem em comunicação através de computadores, tais como aparelhos celulares, sistemas Palm com Wi-Fi etc.

Atualmente há grande esforço de pesquisa e desenvolvimento em uma área que tem sido chamada de adaptrônica, a qual daria conta de "estruturas adaptativas" ou "estruturas inteligentes", sendo basicamente "... a integração de atuadores, sensores e controladores com materiais e componentes estruturais." (GIURGIUTIU et al., 2002). Em outras palavras um componente adaptrônico contém sensores, atuadores e controladores em seu interior. Muitas das aplicações desse conceito faz uso de propriedades piezoelétrica de diferentes tipos de materiais, conforme descrito em LETTY et al.. (2005).

Uma outra forma de compreender os produtos mecatrônicos é apresentada por TOMATIS et al.. (2001), a qual é ilustrada na Figura 17. 


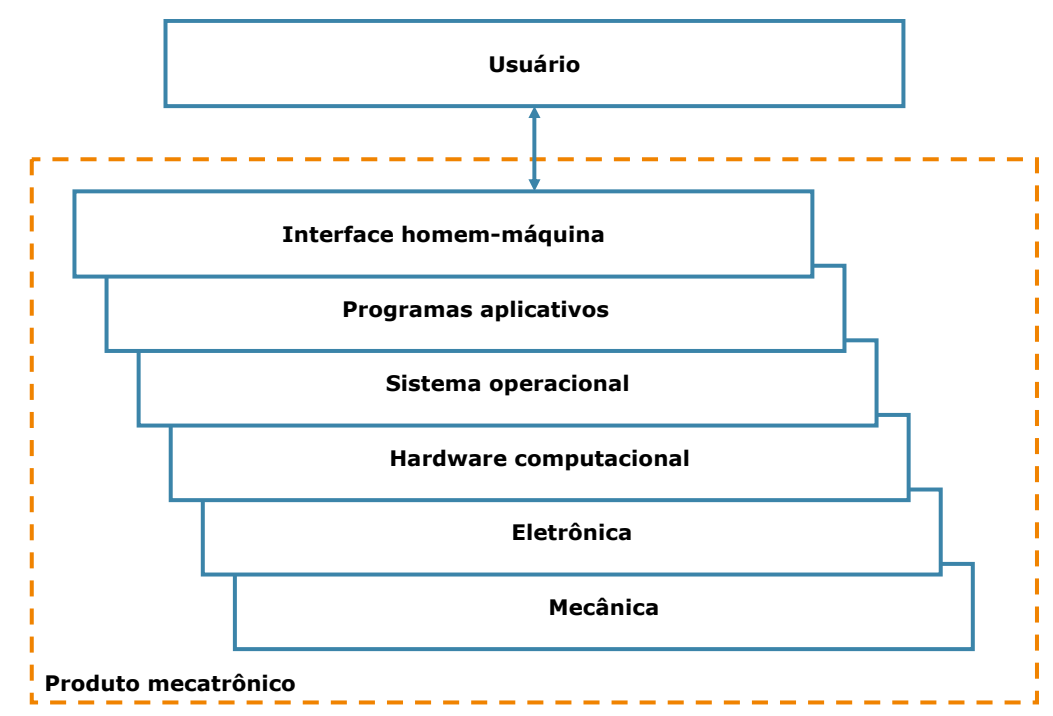

Figura 17 - Outra forma de visualizar os componentes de um produto mecatrônico. (Fonte: TOMATIS et al.., 2001, p. 3)

A forma de representação proposta por TOMATIS et al. (op. cit.) é baseada no conceito de camadas (layers). Segundo o autor todo produto mecatrônico é formado de camadas que se iniciam com a mecânica do sistema, passa pela eletrônica e pelo hardware computacional, e através do software utilizado com seu sistema operacional dedicado se comunica com o usuário mediante uma interface humano-máquina bem definida. Cada camada atinge o desempenho esperado apenas quando a camada inferior está operando a contento. Para o autor o grande número de interfaces necessárias entre as camadas explicaria a alta complexidade dos produtos mecatrônicos.

A representação sugerida por TOMATIS et al. (op. cit.) tem como principal ponto positivo o fato de permitir um melhor entendimento do componente "software de controle" apresentado na Figura 12, uma vez que esse software pode assumir um grau de complexidade tal que seja necessária a utilização de sistemas operacionais específicos para o projeto do equipamento (ver Figura 17), especialmente quando se desenvolve robôs. Um outro aspecto positivo é deixar clara a existência de uma camada entre o projeto eminentemente eletrônico e o software de controle representada pelo hardware computacional. Enfim, ao explicitar a camada de "interface humano-máquina", o autor demonstra a importância desse elemento 
para o projeto de equipamentos mecatrônicos, os quais, comumente, são mais complexos de operar que sistemas baseados em apenas uma área de conhecimento.

\subsubsection{Tipologias de produtos mecatrônicos}

RZEVSKI (2003) propõe uma classificação para os produtos mecatrônicos em função de suas características comportamentais. Para o autor, os produtos mecatrônicos poderiam então ser:

- $\quad$ sistemas mecatrônicos automáticos - sistemas mecatrônicos mais comuns que são capazes de manusear materiais e energia, comunicarem-se com seu ambiente e apresentar comportamentos de auto-regulação, ou seja, de resposta pré-programada a mudanças previstas em seu ambiente;

- sistemas mecatrônicos inteligentes - sistemas capazes de atingir objetivos sob condições de incerteza. Esses sistemas são projetados para responderem a mudanças em seu ambiente de operação sem que seja necessário reprogramá-los. Esses sistemas são desenvolvidos através do uso de lógica fuzzy, redes neurais e inteligência artificial;

- $\quad$ redes mecatrônicas inteligentes - são sistemas mecatrônicos capazes de decidir seu próprio comportamento por meio de negociação entre suas unidades constituintes, cada uma das quais é um "sistema mecatrônico inteligente". A mais interessante característica desse tipo de sistema é a capacidade de melhorar seu desempenho através da auto-organização.

A classificação de RZEVSKI (op. cit.) tem relação com o nível de sofisticação tecnológica do sistema mecatrônico. O modelo desenvolvido no presente trabalho orientou-se por atender a sistemas mecatrônicos de mais baixa sofisticação, portanto, sistemas mecatrônicos automáticos. Todos os exemplos e aplicações desenvolvidos nesse trabalho enfocam esse tipo de equipamento. 


\subsection{Desenvolvimento de Produtos}

Nesse tópico serão discutidas as abordagens existentes para o entendimento do processo de desenvolvimento de produtos (PDP). Adotada uma abordagem, são apresentadas definições para esse processo. Essa discussão é complementada com o texto que consta no APÊNDICE B com uma revisão teórica detalhada acerca do PDP.

\subsubsection{Abordagens para o entendimento do desenvolvimento de produtos}

É possível encontrar discussões acerca do processo de desenvolvimento em literaturas relacionadas às disciplinas tradicionais da engenharia, da qualidade, da administração geral, administração da produção e administração de marketing, assim como da engenharia de produção.

No trabalho de PAHL e BEITZ (1995) é possível encontrar uma detalhada descrição de princípios de projeto mecânico, os quais deveriam ser utilizados na etapa de projeto preliminar (embodiment design). BOOTHROYD et al.. (1994) desenvolveram todo um método de adequação do projeto à estrutura de fabricação de uma empresa mapeando os principais processos de fabricação em diferentes tipos de indústrias.

Em eletrônica há recente desenvolvimento de procedimentos prescritivos para o projeto, principalmente vinculados às técnicas de construção eletrônica como a utilização de breadboards, de protótipos em wire-wrap, ao processo de soldagem e defluxo, assim como à utilização de técnicas de roteamento e simulação de circuitos através de sistemas CAD que permitem a produção de código CAM automaticamente (HOROWITZ e HILL, 1999). HOROWITZ e HILL (op. cit.) apresentam ainda uma série de elementos relacionados com segurança, resfriamento e proteção de circuitos impressos, os quais devem ser considerados quando da realização do projeto de equipamentos eletro-eletrônicos. 
Em software, a engenharia de software prescreve ações bastante similares às abordagens dos autores clássicos de projeto de engenharia (engineering design), seja quando adotado um viés relacionado com metodologias de análise estruturada (PRESSMAN, 2001), seja quando a metodologia de projeto é baseada no paradigma de orientação a objeto (PAULA FILHO, 2001). O uso de ferramentas de apoio à engenharia de software (Computer Aided Software Engineering - CASE) e as técnicas de prototipagem têm possibilitado às casas de software a realização de um esforço concentrado de análise e projeto reduzindo proporcionalmente o tempo com a codificação e teste do produto.

Em administração geral o PDP é tratado como um dos principais processos de negócio da empresa, freqüentemente utilizado para exemplificar o modus operandi dos processos em contraposição às atividades funcionais (DAVENPORT, 1994). A abordagem do PDP como processo de negócio está na origem das proposições de CLARK e FUJIMOTO (1991), WHEELWRIGHT e CLARK (1993), COOPER (1993) e outros autores abordados no presente texto. Em administração da produção o PDP é tratado como etapa essencial do processo de gestão da manufatura no qual são definidos produtos/serviços e processos de produção (SLACK et al., 2002). Em marketing o desenvolvimento de produtos é tratado sob o enfoque das atividades mercadológicas necessárias à garantia da eficácia do produto quanto ao atendimento de seu mercado-alvo: geração de idéias, triagem de idéias, desenvolvimento e teste de conceito, desenvolvimento da estratégia de marketing, suporte ao projeto do produto, teste de mercado e comercialização (KOTLER, 2000).

A abordagem da engenharia de produção tem origem nos trabalhos de projeto de engenharia (engineering design). Nestes estudos, pesquisadores de origem alemã, inglesa e americana discutiam a adoção de metodologias de projeto que permitissem maior produtividade das equipes de engenharia. Esse trabalho culminou nos estudos que defendiam a engenharia simultânea como prática de projeto cujo potencial seria de gerar produtos a custo 
reduzido, em menor tempo e com maior qualidade. Os trabalhos de PRASAD (1996), PRASAD (1997), CLAUSING (1994) e RIBENS (2000) têm esse viés. PAHL e BEITZ (1995) e PUGH (1990) são pioneiros nessa abordagem.

Algumas normas aplicáveis ao PDP podem ser classificadas nas interfaces dessas abordagens. A ISO 9001:2000 (ASSOCIAÇÃO BRASILEIRA DE NORMAS TÉCNICAS, 2000a) e derivadas agregam contribuições da administração geral e da engenharia de produção. Os padrões INSTITUTE OF ELECTRICAL AND ELECTRONICS ENGINEERS (1998a - IEEE 1220) e da Agência Espacial Européia (European Space Agency - ESA), a exemplo do padrão (EUROPEAN COMMISSION FOR SPACE STANDARDIZATION, 1996a) alicerçado no conceito de engenharia de sistemas (systems engineering), têm origem nas interfaces entre engenharia de produção e engenharia de software.

As duas principais vertentes do estudo do processo de desenvolvimento de produtos são representadas pelos estudos cujo enfoque é a administração geral e naqueles focados no projeto de engenharia. A partir da análise do PDP sob o enfoque da gestão por processos foram estabelecidos os fundamentos do próprio estudo do desenvolvimento de produtos (product development). Por outro lado, a exploração do conceito de engenharia simultânea permitiu aos pesquisadores de projeto de engenharia se aproximarem da abordagem por processos. A aproximação entre esses dois campos se dá por vezes tendo como fundamento a abordagem por processos, como é o caso de CLARK e FUJIMOTO (1991), e por outras, tendo como fundamento o conceito de engenharia simultânea (CLAUSING, 1994). Essas duas vertentes, e especialmente os temas convergentes nelas, formam o alicerce teórico básico desse trabalho.

\subsubsection{Definição do PDP}

PUGH (1990) apresenta a seguinte definição para o PDP: 
"[...] É atividade sistemática necessária, da identificação de necessidades de mercado / usuário até a venda do produto que atenda com êxito àquela necessidade - uma atividade que abrange produto, processo, pessoas e organização".

PUGH (op. cit.) pode ser considerado o primeiro clássico do PDP, pois, embora originalmente vinculado às teorias de projeto de engenharia, explicitamente discute as diferenças entre o que chama de projeto parcial (partial design) e projeto total (total design), este último sendo o próprio processo de desenvolvimento de produtos. O projeto parcial seria o enfoque dado nas diferentes áreas da engenharia que interagem no projeto técnico de um novo produto. Por outro lado, o projeto total seria um processo vinculado à identificação, projeto e atendimento das necessidades de mercado.

CLARK e FUJIMOTO (1991) sugerem a seguinte definição para o processo de desenvolvimento de produtos:

\section{"[...] é o processo pelo qual uma organização transforma dados sobre oportunidades de mercado e possibilidades técnicas em informações de valor para a produção comercial."}

Essa definição do PDP enfatiza o caráter informacional desse processo, ou seja, o fato de os insumos e resultados básicos do desenvolvimento de produtos serem informações, em contraposição à manufatura, cujos resultados são bens e/ou serviços (SLACK et al., 2002). A definição sugere ainda que os dados de entrada do PDP provêm de duas fontes básicas: mercado e tecnologia. Abstrai-se daí que o PDP é um processo que requer um monitoramento sistemático do mercado e da tecnologia relativos a uma dada empresa. Note-se que ao demonstrar a necessidade de analisar a variável tecnológica para entender o PDP de uma empresa, CLARK e FUJIMOTO (op. cit.) ampliam o conceito de PUGH (1990).

COOPER (1993) introduz o chamado modelo stage-gate, para o qual o PDP é:

"[...] um modelo formal, mapa, template ou processo pensado para orientar um projeto de novo produto do estágio de idéias até depois do seu lançamento." 
A definição de COOPER (op. cit.) estabelece em linhas gerais o que poderia ser compreendido como um escopo temporal para o PDP: um processo que se inicia na geração da idéia do produto e vai além de seu lançamento no mercado. Aspecto fundamental do conceito de COOPER (op. cit.) é a identificação do PDP como algo que pode ser mais formal ou mais informal dentro de uma dada empresa, mas que de fato existe mesmo que apenas como "processo pensado". O modelo stage-gate advoga que o PDP deve ser entendido como um balanceamento adequado de atividades realizadas nos estágios (fases) com decisões efetivas realizadas entre eles (gates).

No início do século XXI tem amadurecido o entendimento de que a gestão do desenvolvimento de produtos deve ocorrer ao longo de todo o ciclo de vida dos produtos comercializados por uma empresa. CHRISSIS et al. (2003) apresentam uma definição de PDP que contempla essa discussão. Segundo os autores, o PDP é:

\section{"[...] Uma abordagem sistemática que busca uma colaboração de stakeholders relevantes ao longo da vida do produto para satisfazer necessidades dos consumidores, expectativas e requisitos".}

A idéia de stakeholders proposta por CHRISSIS et al.(op. cit.) significa a necessidade de englobar todos os atores organizacionais que participam do desenvolvimento de produtos nas demais áreas funcionais de uma empresa, tais como marketing, desenho industrial ou finanças, conceito similar ao "projeto total" de PUGH (op. cit.). Enfatiza-se que em CHRISSIS et al.(op. cit.) o PDP corre ao longo da "vida do produto". Essa idéia, amplia o “escopo do PDP” (AMARAL, 2001) abrangendo, por um lado, atividades relacionadas com o planejamento das estratégias de produto e de mercado da empresa, e por outro, atividades relacionadas com a retirada de produtos do mercado e o descarte de produtos que chegaram ao fim de sua vida útil. 
Em recente publicação, ROZENFELD et al. (2006) argumenta que o processo de desenvolvimento de produtos é operacionalizado através de projetos distintos, conforme apresentado na Figura 18.

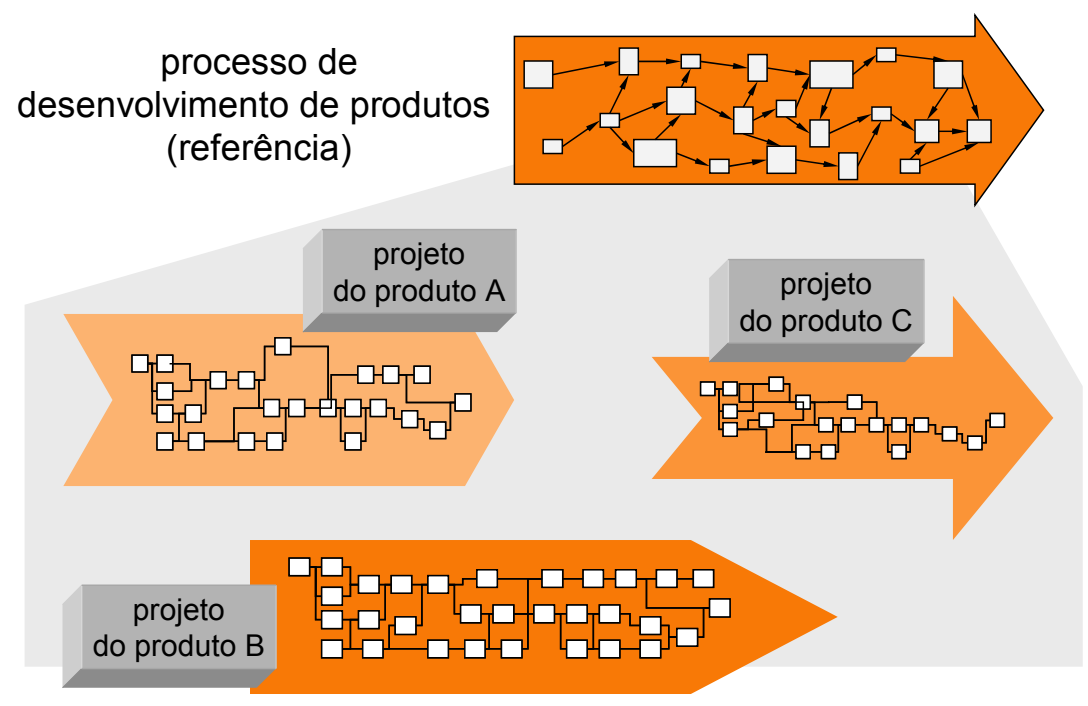

Figura 18 - Projetos distintos resultantes de um mesmo processo. (Fonte: ROZENFELD et al., 2006, p. 42)

Segundo os autores, que buscam formular um modelo de referência genérico para o PDP, um processo "... sistematizado e documentado permite que as particularidades de cada projeto e equipe de desenvolvimento sejam atendidas...". O trecho abaixo ilustra o entendimento dos autores sobre a relação entre o PDP e os projetos de novos produtos:

\footnotetext{
"[...] imagine que uma empresa possua na documentação de seu processo 50 atividades [...] No inicio de um novo projeto, pode-se adotar essas 50 atividades $e$, depois, eliminar algumas que não estão diretamente relacionadas com o produto em questão e, ao mesmo tempo, adicionar outras atividades[...] A partir desse momento, o desenvolvimento de um produto particular é gerenciado como um projeto" (idem ibidem., p. 41).
}

Vale observar, entretanto, o fato de que o ciclo de vida de um produto comporta um grande conjunto de ciclos de projetos: projetos para confeccionar especificações para o produto, para projetá-lo tecnicamente, para certificá-lo em órgãos regulatórios, para lançá-lo, para retirá-lo do mercado etc. Cada um desses ciclos de projeto é diferente do outro, porém todos são vinculados a um processo, seja ele documentado ou apenas pensado, conforme ressalta COOPER (op. cit.). 
PUGH (1990, p. 5) enfatiza que o PDP deve ser projetado como tendo um conjunto central de atividades, denominado "cerne do projeto" (design core) que são "[...] imperativas para qualquer projeto, independente da área de aplicação”. O cerne do projeto consite no que o autor chama de "fluxo de projeto principal" (main design flow), um processo altamente iterativo. O autor ilustra o conceito de iteratividade no fluxo de projeto através de um exemplo:

"[...] você pode estar no projeto detalhado de um produto quando um novo conceito emerge (que possa ser adequado ao atendimento das especificações do produto). Se ele parece ser uma solução altamente atrativa às especificações, e os prazos permitam, você retornará à fase de concepção e possivelmente reprojetará a solução”. (op. cit., p. 6)

PRASAD (1996) entende o PDP como um processo de fluxos ${ }^{1}$ e ciclos (tracks and loops) interativos. Para o autor "[...] cada ciclo representa uma interação entre um ou mais fluxos do desenvolvimento de produtos" (op. cit., p. 421). Os fluxos essenciais (tracks) do PDP seriam: missão, planejamento, projeto, processo, produção, manufatura/montagem e entrega/serviços. Segundo o autor:

“[...] em situações reais, interações entre dois ou mais destes fluxos paralelos ocorrem... Um ciclo com designação 1-T indica interações que ocorrem dentro de um mesmo fluxo. Uma designação 2-T indica que ciclos e interações ocorrem entre dois fluxos paralelos. Similarmente, uma designação 3-T significa que existem interações entre ao menos três fluxos paralelos. Dependendo do tipo de produto, sua complexidade e a condição organizacional da empresa, uma série destes ciclos $2 T$ e $3 T$ podem ser executados para que se chegue ao produto final". (op. cit., p. 421)

A Figura 19 ilustra o conceito discutido por PRASAD no trecho acima. Os fluxos são as barras horizontais no centro da figura.

\footnotetext{
${ }^{1}$ É importante observar que ao invés de um fluxo principal de projeto, conforme ilustra PUGH (op. cit.), a proposta de PRASAD (op. cit.) identifica no PDP uma série de fluxos paralelos cuja interatividade seria função da aplicação do conceito de engenharia simultânea no PDP de uma dada empresa. As atividades centrais seriam apenas um dos fluxos do PDP.
} 


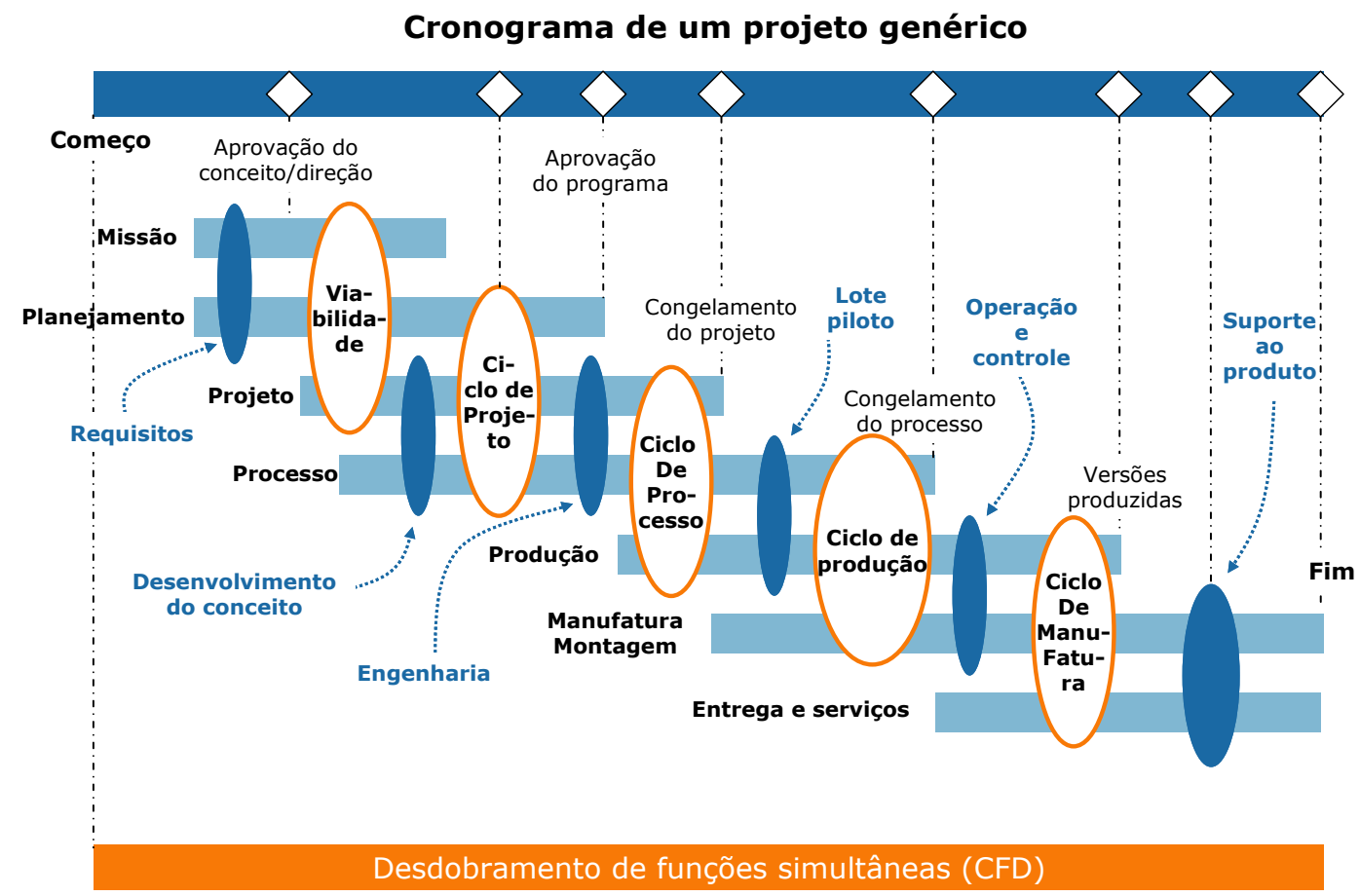

Figura 19 - Visão geral do processo de projeto e desenvolvimento do produto. (Fonte: PRASAD, 1996, p. 418)

Os ciclos $2 \mathrm{~T}$ são ilustrados como círculos ovais que englobam conjuntos de duas barras horizontais paralelas, enquanto os ciclos $3 \mathrm{~T}$ são representados por círculos maiores que abrangem conjuntos de três barras paralelas. Por exemplo, o ciclo de "engenharia" ocorre quando há interação entre atividades relacionadas com os fluxos de "projeto" e de "processo". De maneira similar, o "ciclo de projeto" ocorre nas interações entre planejamento, projeto e processo.

Em suma, o PDP pode ser entendido como um processo definido pelas seguintes caraterísticas:

- $\quad$ é um processo cujo cerne é definido pela identificação, projeto e atendimento das necessidades do mercado;

- $\quad$ é um processo que transforma informações de mercado e tecnologia em produtos que atendam às demandas dos consumidores; 
- $\quad$ é um processo cujo resultado é constituído por informações importantes para a produção comercial do produto;

- $\quad$ é um processo no qual há fases interligadas por decisões que direcionam o fluxo de atividades a serem realizadas em cada projeto.

- $\quad$ é um processo cujo escopo temporal é delimitado pelo ciclo de vida de um produto;

- $\quad$ é um processo no qual um grande conjunto de atores organizacionais interage para a realização das atividades que o caracterizam;

- $\quad$ é um processo operacionalizado através de projetos;

- $\quad$ é um processo que comporta um conjunto de atividades centrais sem as quais não é possível projetar um novo produto;

- $\quad$ é um processo no qual ocorrem ciclos de interação entre atividades de fluxos distintos;

No APÊNDICE B há uma extensa discussão acerca desses itens. No tópico seguinte será discutido o processo de desenvolvimento de produtos mecatrônicos.

\subsection{Desenvolvimento de produtos mecatrônicos}

Nenhum autor pesquisado no presente trabalho abordou o desenvolvimento de produtos mecatrônicos em todo o espectro definido pelo "ciclo de vida do produto", conforme discutido no item 2.2.2. A abordagem mais abrangente foi a do dinamarquês Jacob Buur considerando seus dois livros (BUUR, 1989 e BUUR, 1990). O citado autor discute a influência da mecatrônica sobre o PDP desde a definição do portifólio de produtos da empresa até o projeto do produto propriamente dito. 
BRADLEY (1991) apresenta uma descrição das atividades relacionadas com o desenvolvimento de produtos mecatrônicos do tipo ETO, tais como máquinas para automação de linhas de produção. O autor dá ênfase às atividades de projeto e instalação do equipamento desenvolvido. Em BRADLEY (2000) há uma extensa discussão em torno de métodos de gestão do desenvolvimento de produtos mecatrônicos.

Os demais títulos pesquisados dão ênfase nas atividades técnicas de projeto do produto mecatrônico propriamente dito.

Esse tópico está organizado da seguinte forma: inicialmente é apresentada uma sistematização de melhores práticas da bibliografia de desenvolvimento de produtos mecatrônicos, são então discutidos os principais determinantes e os problemas relacionados com o projeto dos produtos mecatrônicos e, enfim, são apresentadas discussões sobre o projeto do processo de produção desses produtos.

\subsubsection{Como desenvolver produtos mecatrônicos}

Dificilmente uma empresa nasce mecatrônica, ou quando o faz, geralmente há uma área dominante em termos de tecnologia de produto. A área dominante tende a determinar o fluxo principal de projeto da empresa. A Figura 20 apresenta um quadro com as etapas genéricas do projeto mecânico, de software e eletrônico, segundo BERNARDI et al. (2002). 

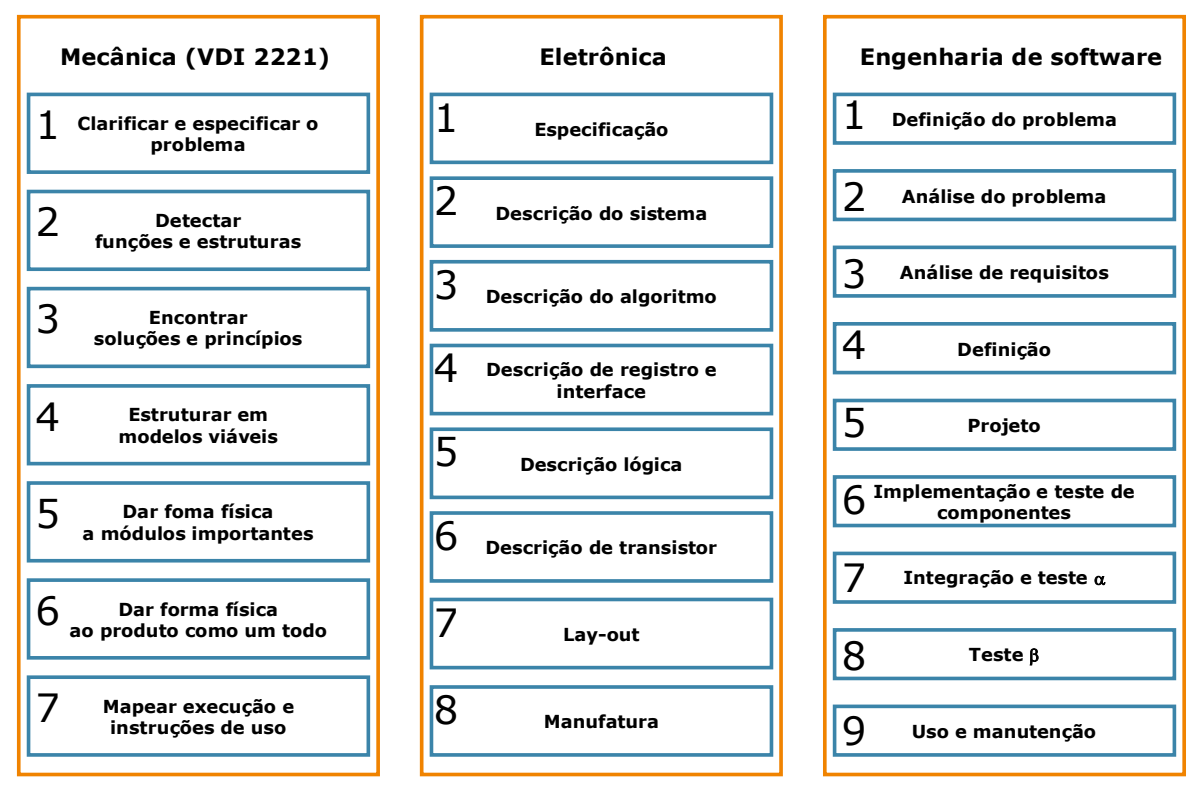

Figura 20 - Fluxo principal de atividades de projeto mecânico, eletrônico e de software (Fonte: BERNARDI et al.., 2002, p.2)

BERNARDI et al. (op. cit.) consideram haver uma forte diferenciação entre os projetos eletrônico e de software se comparados com o projeto mecânico quanto à questão dos testes necessários ao produto. A mecânica é baseada em um sólido procedimento de cálculo estrutural e de mecanismos e utiliza simulações por elementos finitos para definir margens de segurança para o produto. Em software e eletrônica, procedimentos de testes com protótipos físicos são normalmente necessários uma vez que há problemas relacionados com o nível de ruído ou carregamento térmico dos circuitos eletrônicos que dificilmente se consegue detectar por simulação. Adicionalmente, o nível de rigorosidade dos testes é função das exigências por segurança e confiabilidade, as quais são estabelecidas por órgãos governamentais e muitas vezes precisam ser realizados em áreas especialmente projetadas para tal.

WALTERS et al. (2000) enfatizam a necessidade de que o responsável pelo projeto, tão logo seja definido o conceito do produto, particione o sistema em domínios tecnológicos. O autor identifica então como atividade principal do projeto eletrônico a escolha de estratégias de solução para o problema de projeto. As diferentes estratégias podem afetar as soluções encontradas em outros domínios. Exemplos de estratégias de projeto podem incluir a 
utilização de microprocessadores ou microcontroladores, uso de processadores de sinais digitais (DSP), a utilização de um circuito integrado para aplicações específicas (Application Specific Integrated Circuit - ASIC), o uso de conjuntos de portas de campo programável (Field Programable Gate Arrays - FPGA) ou o uso de comunicadores de linhas de energia (Power Line Communications - PLC). Cada escolha determinará um conjunto de ferramentas de projeto e simulação específico que será necessário para a realização de testes eletrônicos e de integração.

BUUR (1990) descreve algumas diferenças importantes entre o projeto mecânico, eletrônico e de software. Essas diferenças são sumarizadas abaixo:

- $\quad$ quanto às funções principais: em eletrônica e software a função principal é a transformação de informações, através de sinais elétricos (eletrônica) ou funções lógicas (software), enquanto que em engenharia mecânica é possível transformar materiais e energia, além de informações;

- quanto ao projeto conceitual: em mecânica, os problemas podem ser sempre caracterizados como novos havendo muitas alternativas de solução disponíveis. Já em eletrônica utiliza-se componentes padronizados e soluções de projeto sugeridas por fabricantes. Em software há um conjunto pré-estabelecido de operações pelas quais o projeto pode ser implementado, sendo a priori, incomum a possibilidade de usar algoritmos padrão;

- $\quad$ quanto ao projeto detalhado: há uma grande quantidade de tecnologias de manufatura mecânica havendo alto grau de liberdade para o projetista especificar dimensões, formas, materiais e acabamentos. Em eletrônica há uma quantidade menor de tecnologias de produção sendo que os componentes são normalmente comprados. Em software não há uma fase de produção propriamente dita, uma vez que a própria codificação gera o produto final. 
Pensando no ciclo de projeto propriamente dito, tem-se uma etapa de projeto conceitual que resulta em uma "... descrição diagramática dos relacionamentos entre blocos conceituais, conhecida como arquitetura do sistema" (RZEVSKI, 2003, p. 1034). Chegar à arquitetura do sistema exige um forte esforço em descrever tecnicamente o que deve ser projetado. Os autores pesquisados no presente trabalho concordam quanto à necessidade de descrever o produto em termos de árvores de funções, entretanto, discordam nas formas de desdobrá-la em especificações a serem seguidas pela equipe de projeto.

SADAUNE e PHILIPPE (2002) sugerem a utilização do Structured Analysis Design Technic SADT/IDEF0 (discutido no item 2.4.3) como método de descrição funcional do produto a ser desenvolvido. Esse método é também discutido por BUUR (1990) e BRADLEY et al. (2000) sendo considerado por ambos bastante complexo quando detalha as transformações primárias, além de não deixar clara a influência dos controles sobre a operação das funções a eles relacionadas.

BUUR (1990) sugere o uso de diagramas funcionais em conjunto com diagramas de transição de estado para especificar o funcionamento requerido do sistema mecatrônico. A Figura 21 apresenta um bloco funcional desenvolvido pelo autor para o funcionamento de um aparelho telefônico.

BRADLEY et al. (2000) utiliza o método de análise estruturada (discutido no item 2.4.3) para descrever o funcionamento de produtos mecatrônicos. A Figura 22 apresenta o método básico, enquanto a Figura 23 apresenta diagramas de contexto e de nível 0 de uma máquina de lavar e a Figura 24 apresenta o fluxo de dados de nível 1 da função "uso da máquina de lavar".

HÖHNE (2001) sugere o estabelecimento de uma classificação sistemática de elementos funcionais mecânicos em sistemas mecatrônicos. Segundo o autor, a mecânica teria 
as seguintes funções em produtos mecatrônicos: (1) arranjar os elementos através de suporte ou isolação; (2) fornecer energia mecânica para o sistema, armazenando-a ou transformandoa; (3) adaptar a energia mecânica para uma dada condição de uso, transmitindo-a, ampliandoa, reduzindo-a, bloqueando-a ou comutando-a; e (4) transmitir a energia mecânica por meio de acoplamentos, condutores ou distribuidores de energia.

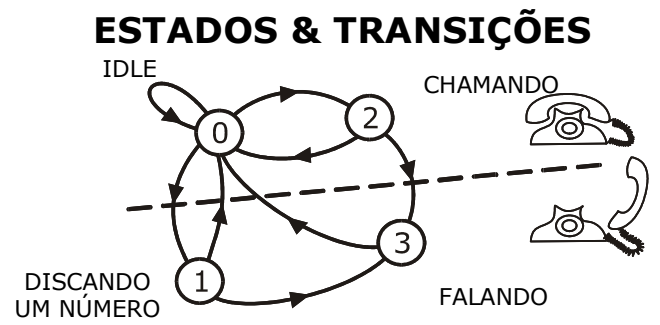

\section{FUNÇÕES DE TRANSFORMAÇÃO}

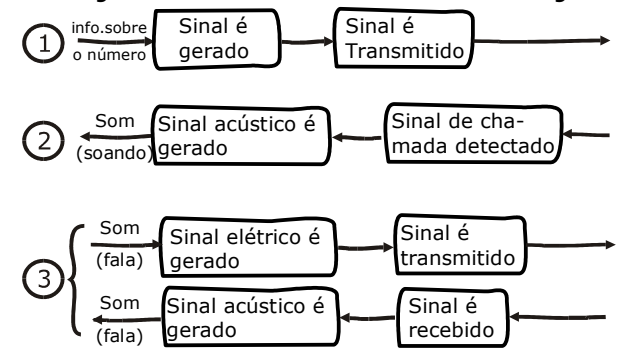

ESTRUTURA FUNCIONAL

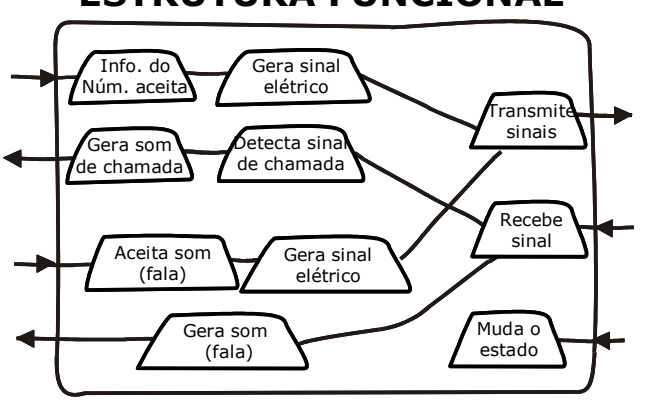

FUNÇÕES ATIVAS
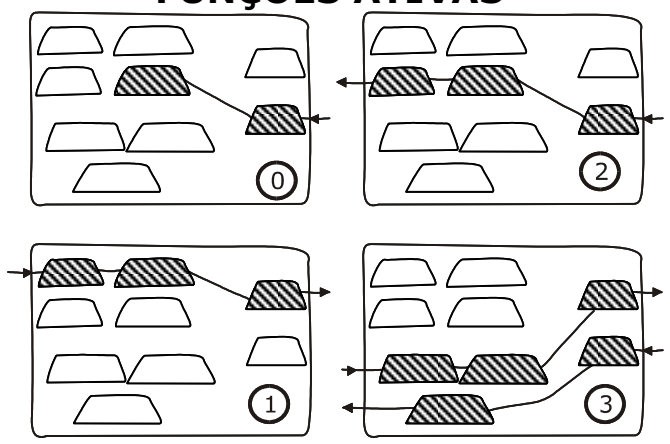


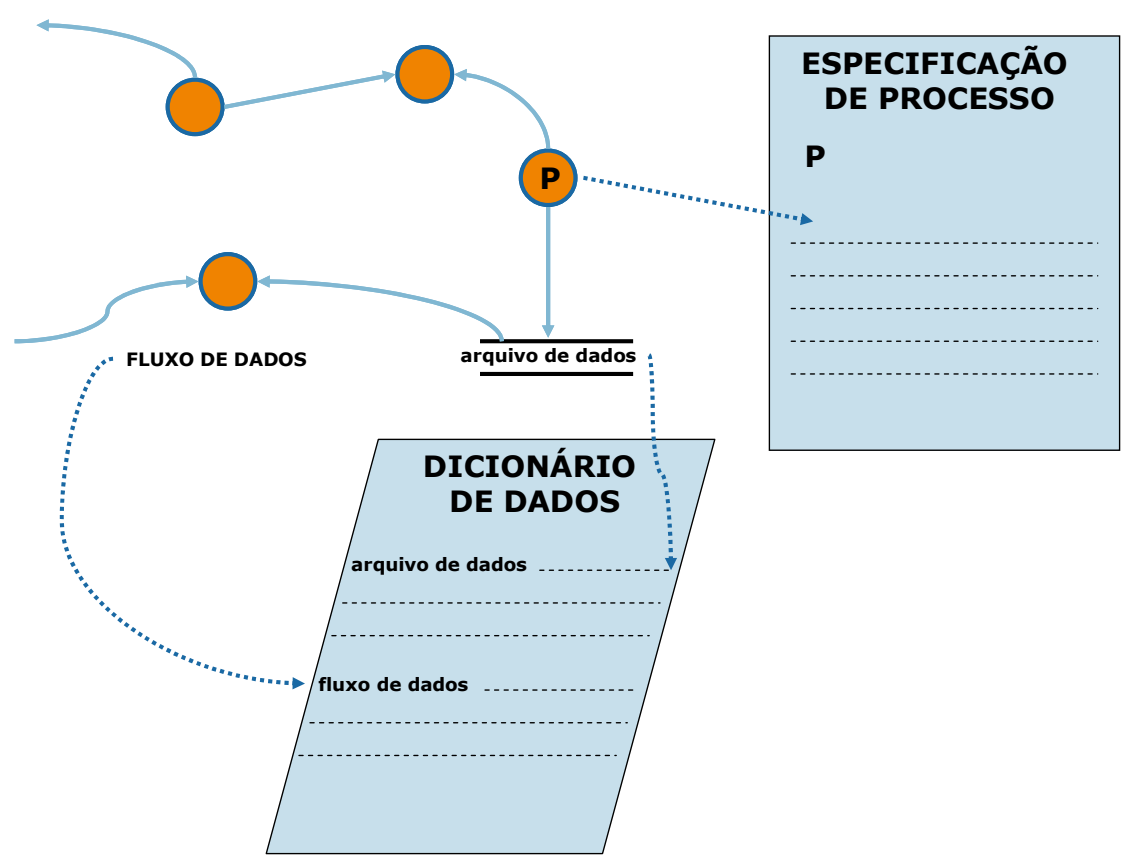

Figura 22 - Modelo DeMarco utilizado por BRADLEY et al.., 2000 (p. 103)

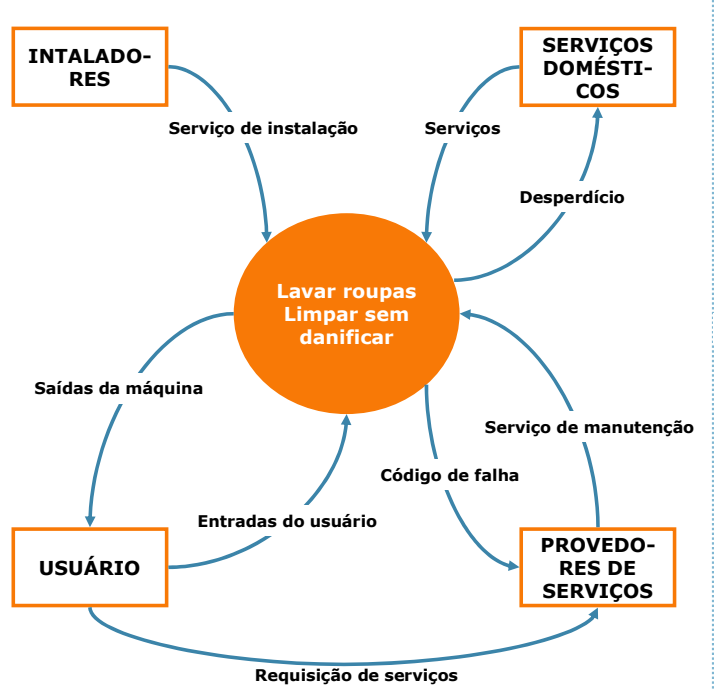

(a)

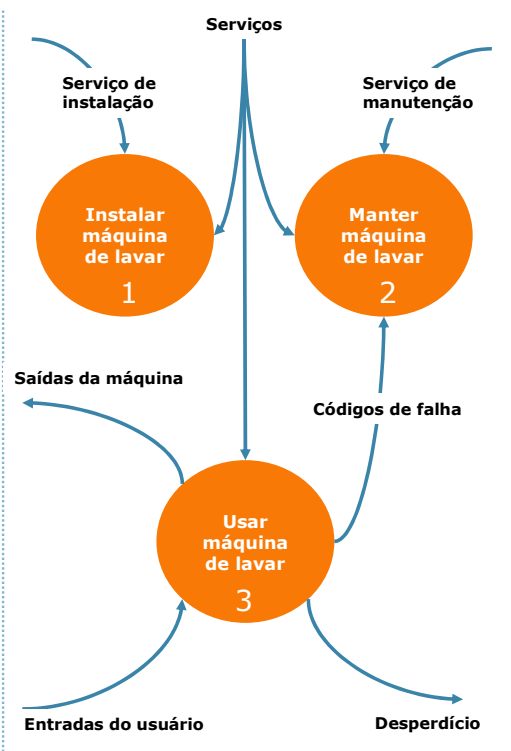

(b)

Figura 23 - Diagrama de contexto e nível 0 de uma máquinha de lavar (Fonte: BRADLEY et al.., 2000, P. 104-105) 


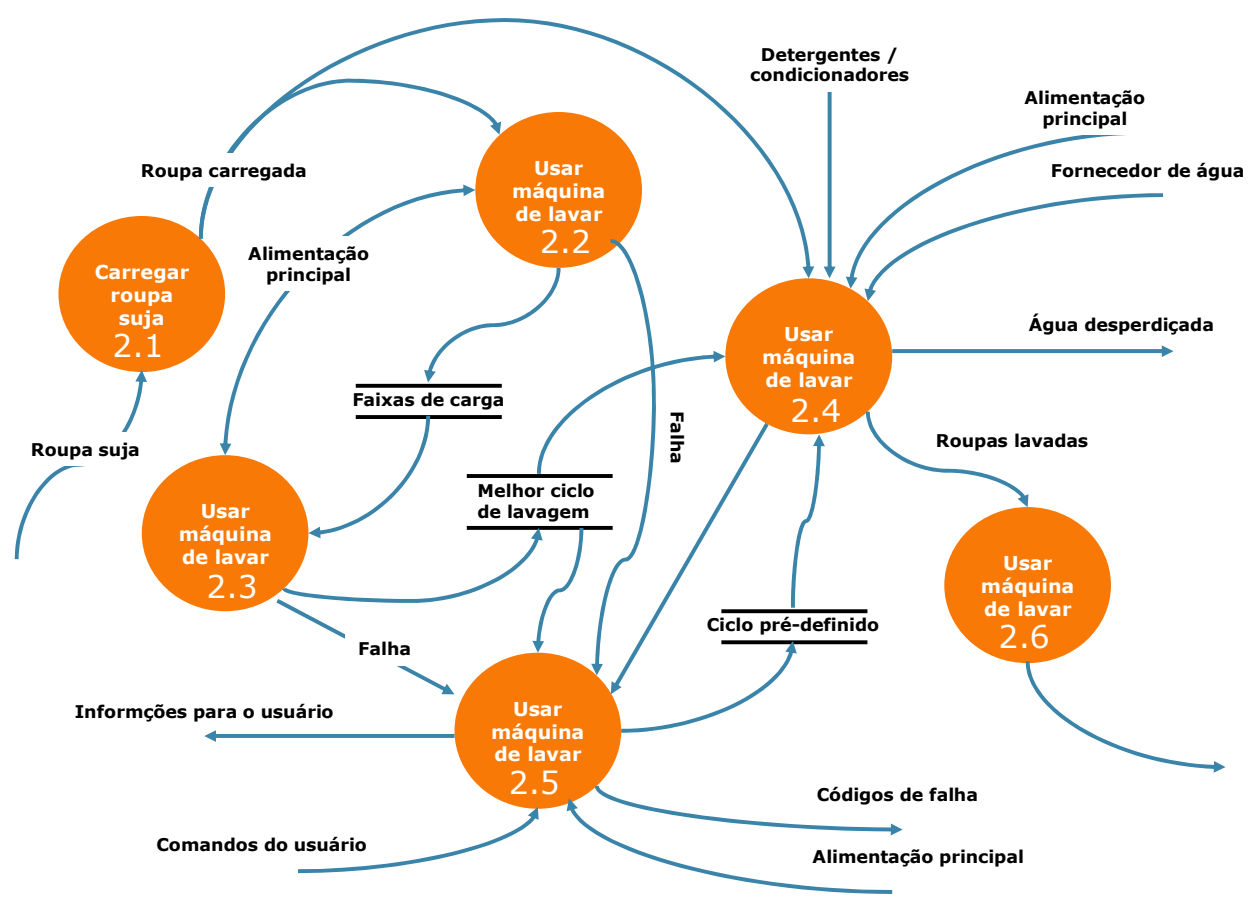

Figura 24 - Diagrama de fluxo de dados da função "usar máquinha de lavar". Fonte: BRADLEY et al.., 2000, p. 105)

BERNARDI et al. (2002) apresentam o que chamam de "... procedimentos tradicionais de projeto mecatrônico". Esses procedimentos tradicionais são contrapostos por uma nova abordagem para o PDP desses produtos baseada no uso de ambientes virtuais para a simulação de todo o sistema. O ambiente virtual seria basicamente um sistema de informações que permitisse a manipulação de informações de projeto mecânico, eletrônico e de software de maneira conjunta. Toda uma bateria de testes virtuais seria possível através desse sistema. Adicionalmente, o produto seria integrado e otimizado com base em conhecimentos registrados em uma base de dados central. Os procedimentos tradicional e a nova abordagem proposta são apresentados na Figura 25. 

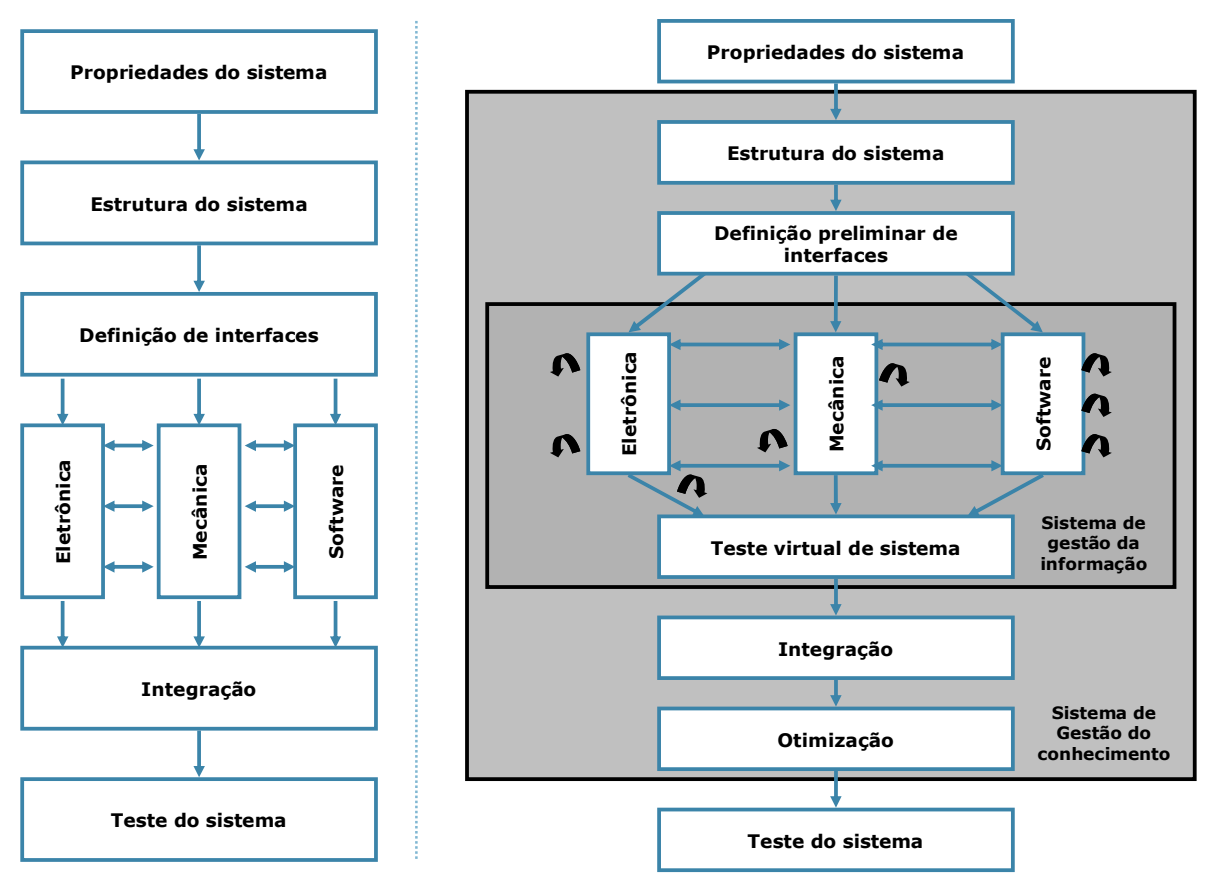

Figura 25 - Processo de desenvolvimento clássico e nova abordagem de projeto mecatrônico (Fonte: BERNARDI et al.., 2002)

Seja sob uma abordagem baseada em sistemas de informação ou através de uma sistemática tradicional, é comumente necessário particionar o sistema em áreas técnicas no início das atividades de projeto detalhado, conforme mencionado anteriormente (WALTERS et al., 2000; BUUR, 1990). BRADLEY et al. (2000) apresentam uma série de boas práticas de projeto que uma empresa deve prover para o desenvolvimento de sistemas mecatrônicos:

- $\quad$ é necessário que a empresa adote uma abordagem generalista e, portanto, aberta às possibilidades de solução técnica dos vários campos da engenharia envolvidos no projeto;

- $\quad$ é necessário que a empresa estabeleça meios que facilitem a busca por soluções de projeto, como por exemplo através dos sistemas de gestão do conhecimento;

- a empresa precisa manter disciplinada valorização do novo conhecimento gerado e da criatividade em busca de novas soluções mesmo que elas corram no sentido contrário às melhores práticas de projeto existentes na sua base de conhecimentos; 
- $\quad$ é necessário facilitar a aplicação de soluções existentes para as tarefas que estão sendo realizadas;

- $\quad$ é necessário permitir uma avaliação objetiva das soluções apontadas para os problemas de projeto, o que, muitas vezes só pode ser conseguido através de modelagem dinâmica e simulação, ou através do uso de protótipos;

- é necessário utilizar um pensamento gerencial moderno, especialmente no que concerne à adoção de técnicas de gestão de projetos e de engenharia de sistemas.

WALTERS et al. (2000) analisam o projeto eletrônico em sistemas mecatrônicos e identificam o seguinte comportamento por parte dos projetistas:

- há baixo grau de reutilização de projetos prévios;

- $\quad$ normalmente o projetista constrói blocos construtivos de partes específicas do projeto;

- há uma grande variedade de estratégias de projeto, frequentemente baseadas em preferências pessoais e experiências anteriores dos projetistas;

- $\quad$ a redução de ruído é "uma arte", ou seja, embora fundamental no projeto eletrônico, é uma atividade geralmente não-documentada.

HORIKAWA (2000) apresenta uma "metodologia de projeto de um sistema mecatrônico" que parte da idéia de que é possível realizar paralelamente o projeto mecânico e do sistema de controle e que, quando da realização de testes, há duas possibilidades de reprojeto: da mecânica ou do sistema de controle.

DORF e BISHOP (2000) sugerem um método de projeto para a engenharia de sistemas de controle. Esse método é apresentado na Figura 26. 


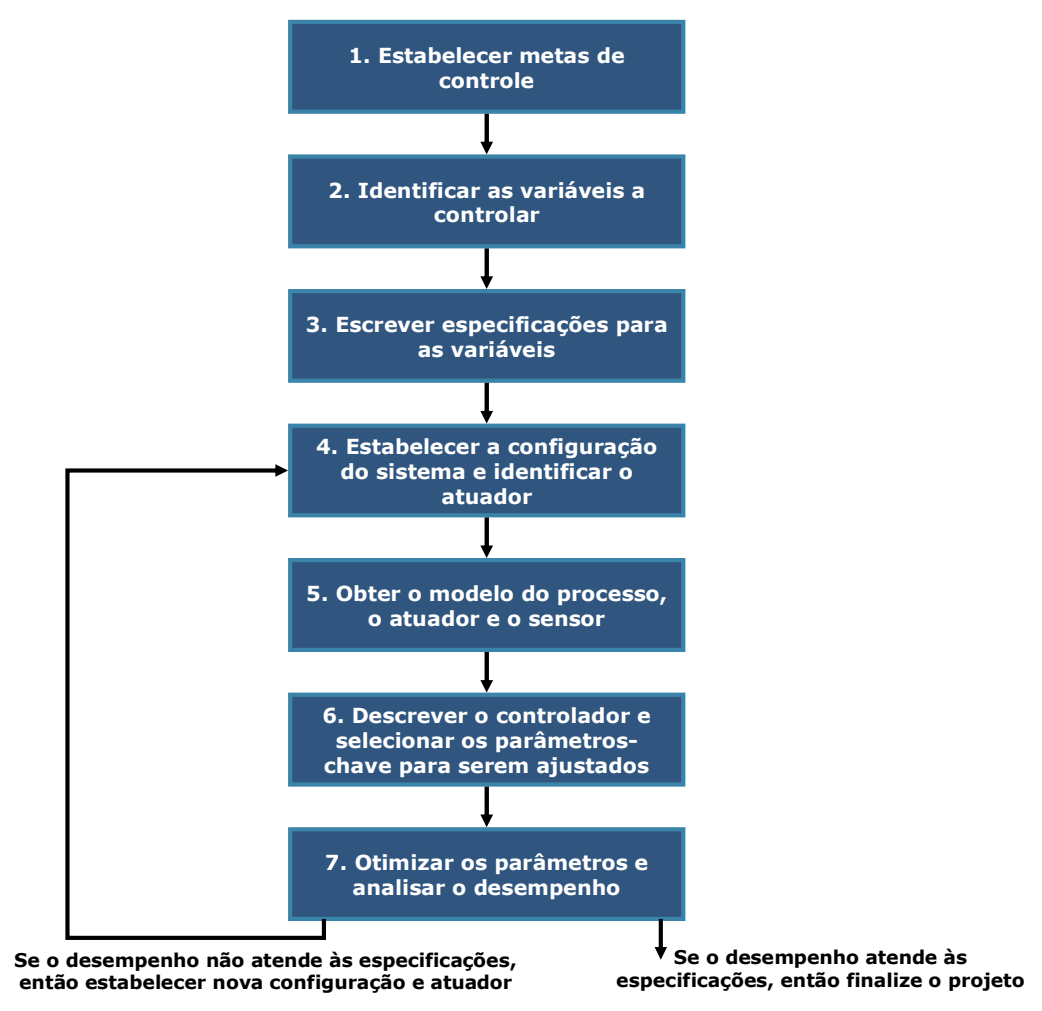

Figura 26 - Processo de projeto de sistemas de controle (DORF e BISHOP, 2000, p. 20)

As metas do sistema de controle podem ser, por exemplo, o controle de velocidade de um motor DC. Nesse caso, a variável a ser controlada é a velocidade do motor. As especificações a serem utilizadas no projeto vão determinar a acurácia requerida para o sistema de controle, o que permitirá a identificação do sensor a ser utilizado. A configuração do sistema pode ser primeiramente definida consistindo basicamente de um sensor, o processo sob controle, um atuador e um controlador, conforme ilustrado na Figura 8. Identificado o atuador, é possível utilizar suas informações técnicas e o princípio de funcionamento do processo a ser controlado e do sensor para estabelecer um modelo matemático com a função transferência do sistema.

O passo seguinte é definir um controlador que permita comparar a resposta desejada com a mensurada pelo sensor e tomar as medidas adequadas para ajustar a saída do sistema. Em seguida é realizado o teste e ajuste do sistema para atingir o desempenho desejado. Se o 
ajuste resulta no desempenho desejado, o projeto é finalizado e documentado. Caso negativo, uma nova configuração é estabelecida e um novo ciclo de projeto é realizado.

BUUR (1990) sugere a utilização de sistemáticas de especificação de interfaces entre componentes eletrônicos e mecânicos dentro de sistemas mecatrônicos e prescreve o uso do conjunto de passos descritos abaixo:

- determinação da qualidade e quantidade de fluxo de informação entre sistemas mecânico e eletrônico;

- $\quad$ agrupamento de partes do fluxo de informação em blocos de interface designados como tarefas;

- $\quad$ escolha de sensores e atuadores apropriados para cada tarefa;

- estabelecimento de subsistemas independentes para cada grupo de sensores e atuadores que sob o ponto de vista do sistema de controle possam ser interrelacionados.

Do ponto de vista das interfaces humano-máquina, em BRADLEY (1991) e em BRADLEY et al. (2000) há uma interessante discussão acerca dos aspectos antropomórficos utilizados para especificar as interfaces necessárias. Alguns produtos mecatrônicos, tais como jogos digitais, têm na interface humano-máquina o principal fator de satisfação do cliente. A Figura 27 apresenta o processo sugerido por BRADLEY et al. (2000) para o projeto da interface do sistema mecatrônico. 


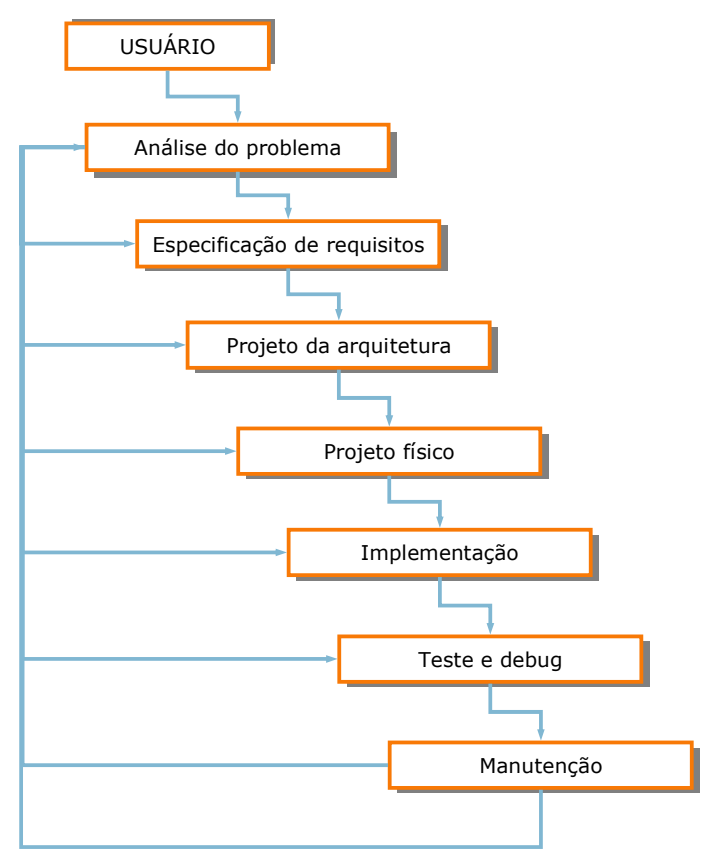

Figura 27 - Processo de projeto da interface humano-máquina (Fonte: BRADLEY, et al., 2000, p. 214)

A segurança para operadores, usuários ou pessoas que mantém contato não-intencional com o produto em seu local de uso é um fator fundamental em diversos sistemas mecatrônicos. BRADLEY et al. (op. cit.) menciona a necessidade de utilização de técnicas de redução de riscos em projetos mecatrônicos, como por exemplo:

- $\quad$ HAZOP - estudos de operabilidade e riscos (Hazard and Operability): desenvolvido para análise de possíveis falhas e suas conseqüências na indústria química;

- $\quad$ análise da criticalidade e efeitos dos modos de falha (Failure Mode, Effect and Criticality Analysis - FMECA): é uma abordagem bottom-up utilizada para identificar níveis de criticidade de falhas potenciais e investigar formas de reduzí-las;

- $\quad$ análise de árvore de falhas (Fault Tree Analysis - FTA): é uma abordagem top-down utilizada para identificar as causas potenciais de falhas no equipamento que eventualmente impactem na saúde do operador ou de pessoa que mantenha contato com o produto. 
Qualquer equipamento elétrico ou eletrônico, deve adicionalmente, estar de acordo com normas de segurança elétrica que prescrevem estratégias de desenho e montagem eletrônica. O objetivo dessas normas é evitar riscos relacionados com choque por correntes de fuga, sobretensões eventualmente decorrentes da instalação elétrica local, resistência de aterramento incapaz de proteger operadores e usuários em casos de descargas eletrostáticas e um grande número de situações de risco relacionadas com grandezas mecânicas, térmicas e químicas (INTERNATIONAL ELECTROTECHNICAL COMMISSION, 1988) (IEC 606011). Aparelhos eletrônicos em geral precisam ser imunes a campos eletromagnéticos induzidos ou conduzidos (INTERNATIONAL ELECTROTECHNICAL COMMISSION, 2003) (IEC 60601-1-2). Equipamentos que utilizam tecnologia laser passam por uma série de critérios normativos relacionados com o controle da geometria e do tempo de exposição de usuários e operadores a essa tecnologia (INTERNATIONAL ELECTROTECHNICAL COMMISSION, 1994) (IEC 60825).

Embora haja generalidades, em linhas gerais os requisitos relacionados com a segurança do manuseio de equipamentos mecatrônicos são bastante específicos para a indústria na qual a empresa atua, e ainda, para o produto desenvolvido, além de ter forte relação com o mercado que a companhia deseja atingir.

BUUR (1990) e BRADLEY et al. (2000) sugerem a utilização de árvores função-meio para relacionar as soluções de projeto com a árvore funcional do produto. Um exemplo dessa ferramenta é apresentado na Figura 28 que consiste na descrição sistemática de um aparelho telefônico.

Finalmente, os produtos mecatrônicos abrangidos pelo modelo aqui apresentado (ver tópico 1.3) devem atender a normas e/ou padrões de qualidade de produto e de processo conforme a indústria à qual se direcionem. As normas de produto aplicáveis são muito dependentes de cada produto, entretanto há generalidades que precisam ser consideradas, 
representadas principalmente pelas normas IEC 60601-1 e complementares, conforme acima discutido.

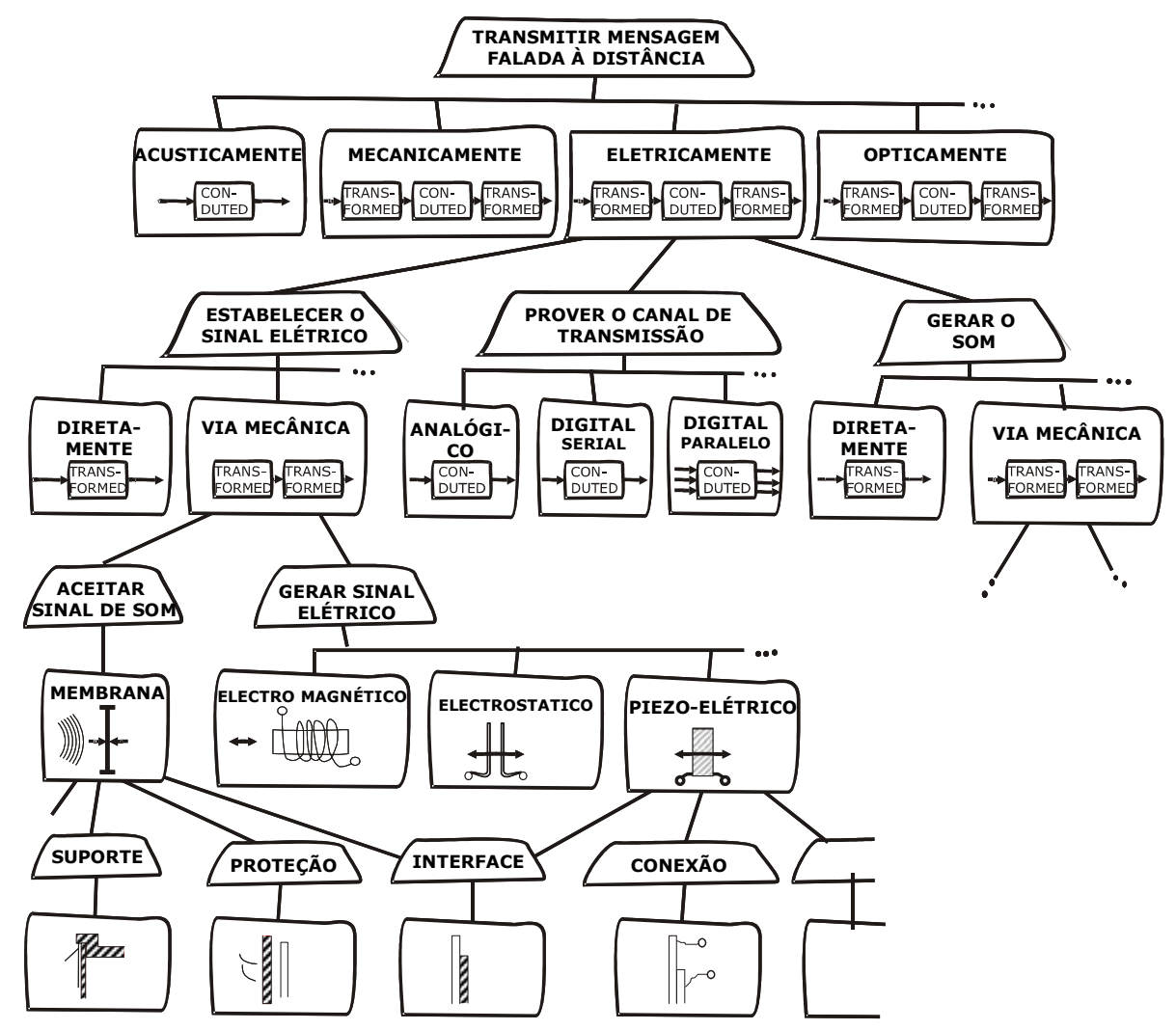

Figura 28 - Árvore função-meio de um aparelho telefônico (Fonte: BUUR, 1990, p. 78)

Quanto às normas que estabelecem diretrizes para o processo de desenvolvimento de produtos mecatrônicos é importante observar os seguintes requisitos na confecção de um modelo de referência:

- NBR ISO 9001:2000 (ASSOCIAÇÃO BRASILEIRA DE NORMAS TÉCNICAS, 2000b) - a norma trata o desenvolvimento de produtos como um requisito do processo de "realização do produto", denominado "projeto e desenvolvimento" (requisito 7.3) cuja definição é: “[...]conjunto de processos que transformam requisitos em características especificadas ou na especificação de um produto, processo ou sistema" (ASSOCIAÇÃO BRASILEIRA DE NORMAS TÉCNICAS (2000a). Há outras cláusulas da NBR ISO 9001:2000 relacionadas com o processo de desenvolvimento de produtos, principalmente 
quanto à documentação do processo (cláusula 4.2.3) e quanto ao acompanhamento dos objetivos de desempenho estabelecidos para o processo: 8.2.2 - auditoria interna, o 8.2.3 medição e monitoramento de processos - e 8.4 - análise de dados.

- $\quad$ NBR ISO 13485:2003 (ASSOCIAÇÃO BRASILEIRA DE NORMAS TÉCNICAS, 2003) - é uma norma colateral à NBR ISO 9001:2000 que é direcionada à regulação das especificidades do sistema de gestão da qualidade para empresas que desenvolvem produtos médicos, dentre os quais equipamentos para uso na medicina. $\mathrm{O}$ principal requisito adicionado por essa norma ao projeto dos produtos mecatrônicos é a necessidade de haver um rigoroso processo de prevenção de riscos de segurança impostos pelo produto em uso, assim como a necessidade de realizar processos de validação de softwares eventualmente desenvolvidos.

- $\quad$ conjunto de padrões da área espacial/militar - consistem em normas MIL (padrão militar americano) e ESA (padrão aeroespacial europeu) cujo objetivo é manter forte controle sobre os procedimentos técnicos e gerenciais de empresas que forneçam produtos para esses mercados. Os padrões impõem uma série de requisitos para o gerenciamento do ciclo de vida dos produtos desenvolvidos, tais como árvores de produto e estrutura da divisão do trabalho (WBS); assim como para as formas de organização a serem adotadas, a estrutura de gerenciamento de custos e tempo, a gestão da configuração, de documentos e os requisitos para o suporte logístico integrado;

Finalmente, os mercados abrangidos por produtos mecatrônicos são comumente regulados por órgão públicos que mantém controle sobre os equipamentos disponíveis ao consumidor final. O processo de certificação de um produto mecatrônico passa por um procedimento burocrático que, se não obedecido, pode implicar em multas e restrições de funcionamento da companhia. A Figura 29 apresenta o processo de registro de produtos médicos. A figura mostra que há forte integração entre o processo de registro de 
equipamentos no Brasil e em países estrangeiros. Equipamentos com registro na Europa, Japão e EEUU têm sua documentação acolhida no órgão regulatório brasileiro. Os equipamentos são registrados mediante ensaios realizados em organismos de certificação do equipamento (OCP) a partir dos quais são confeccionados relatórios para análise da qualidade e da certificação do equipamento - RAQCEs.

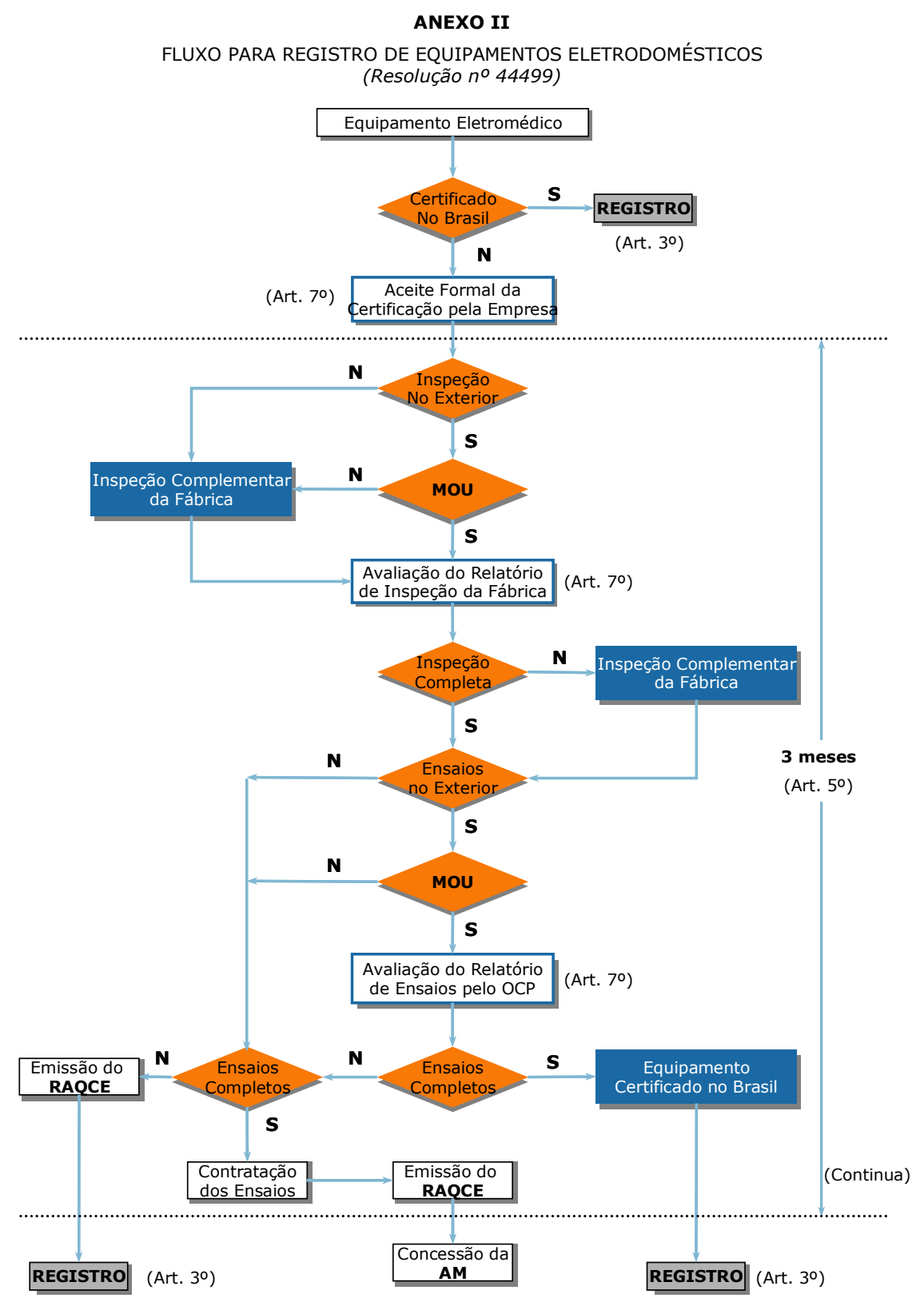

Figura 29 - Parte do fluxo para registro de equipamento eletromédicos. (Fonte: $\left.\operatorname{RDC} \mathbf{n}^{0} 185,2001, p .15\right)$ 
Nos setores automotivo e de eletro-eletrônicos de linha branca, a maioria dos requisitos agregados pelas normas de qualidade estão relacionados com os processos de fabricação e montagem e serão apresentados no item 2.3.1.3.

BUUR (1989) relata um extenso estudo sobre as práticas japonesas de projeto mecatrônico e enfatiza a importância das questões organizacionais sobre o andamento do projeto desse tipo de produto. $\mathrm{O}$ autor registra que "... os japoneses não desenvolveram métodos específicos para o projeto mecatrônico. Eles confiam na educação generalista e na cooperação do time de projeto". A partir dessa constatação, BUUR identifica uma série de aspectos organizacionais que, em hipótese, impulsionam o projeto de sistemas mecatrônicos no Japão.

O treinamento no trabalho foi identificado por BUUR como uma prática consolidada nas empresas mecatrônicas japonesas. Dentre as responsabilidades da alta gerência, a educação de seus novos subordinados é considerada fundamental. Normalmente, um experiente projetista é responsabilizado por acompanhar grupos de recém-contratados na solução de problemas de projeto propostos dentro de programas de treinamento. Um exemplo é apresentado na Figura 30. Nesse caso, os treinandos podiam dedicar duas horas diárias à solução do projeto. A empresa dispunha recursos de manufatura para a fabricação e teste de protótipos.

MOVIMENTADOR DE FITAS DE VÍDEO:

Projete um mœanismo para mover o bastão da posição

A para B, usando o motor fornecido. Todas as peças devem estar contidas dentro das dimensões especificadas.

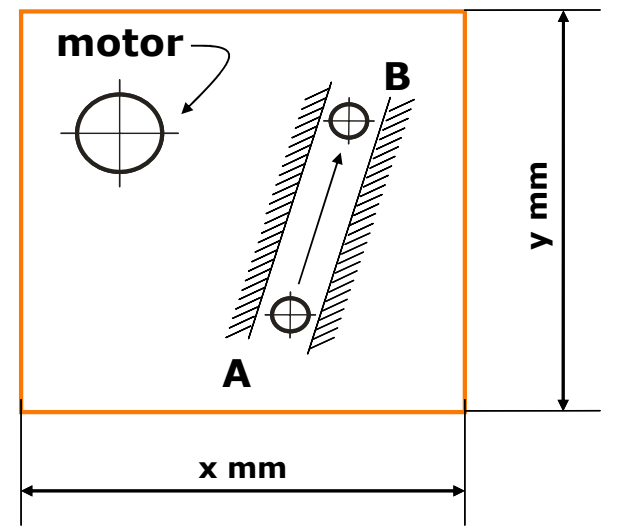


Ainda segundo BUUR (1989), o sistema de rotação dos novos engenheiros através de diferentes setores da empresa é fundamental para desenvolver pessoal com conhecimento generalista. Enquanto nas empresas européias uma transferência de setores é apenas aceita se acompanhada por promoções, no Japão, a rotação de setores é empregada até mesmo com gerentes.

O treinamento de engenheiros mecânicos em eletrônica e vice-versa é bastante presente nas empresas pesquisadas pelo autor que, entretanto, identificou práticas de treinamento bastante relacionadas com o perfil tecnológico básico da empresa. Empresas com tradição em mecânica, normalmente preferem educar engenheiros mecânicos em práticas de projeto eletrônico e de software. Similarmente, quando o perfil da empresa é associado com o projeto de hardware, há preferência por educar os engenheiros mecânicos e eletrônicos no projeto de software que contratar engenheiros de computação (BUUR, 1989, p. 35).

Segundo o autor, o projeto do trabalho nas empresas japonesas é cuidadosamente desenhado para que a cooperação seja estimulada entre o pessoal técnico. Isso abrange desde as baixas diferenças salariais entre jovens e experientes engenheiros, assim como entre gerentes e pessoal técnico de mesmo tempo de carreira, até o arranjo físico do escritório e dos postos de trabalho. Adicionalmente, estimula-se o compartilhamento de documentos de um mesmo projeto através de arquivos de grupo e de seção. A meta é que um membro de projeto ao invés de ter seu próprio arquivo de documentos, utilize um sistema de arquivamento comum que seja indexado de forma a facilitar o arquivamento e a busca de material. Essa prática, aliada ao fato de não haver funções de suporte, tais como secretárias, desenhistas, técnicos etc., estimula a comunicação, uma preocupação de manter registros facilmente comunicáveis, uma visão sistêmica e o aumento da produtividade das equipes de projeto. 


\subsubsection{Problemas potenciais do desenvolvimento de produtos mecatrônicos}

Segundo BUUR (1990) a contrapartida da inteligência e flexibilidade provida pela mecatrônica aos produtos que a utilizam é o aumento da complexidade desses produtos, seja em seu projeto, seja na sua interface com o usuário quando em operação. Esse aumento da complexidade é o principal diferencial de projeto dos produtos mecatrônicos em relação a outras tipologias de produto. Segundo MOULIANITIS et al. (2004), a complexidade dos produtos mecatrônicos está relacionada com os seguintes fatores:

- $\quad$ quantidade de componentes e subsistemas: aumenta a árvore de projeto aumentando o número de interconexões necessárias e de decisões técnicas a serem tomadas. Há, conseqüentemente, um aumento na possibilidade de falhas de projeto.

- complexidade e escolhas relacionadas com a arquitetura do sistema: o número de interconexões afeta a arquitetura do produto e quando um componente é trocado todas as conexões precisam ser verificadas quanto à compatibilidade com o novo item.

- $\quad$ quantidade de caminhos alternativos para o projeto de componentes: embora os caminhos alternativos aumentem o grau de liberdade do projeto, eles tornam as escolhas mais complexas e aumentam a árvore de projeto.

- $\quad$ quantidade de atividades necessárias a um reprojeto do produto: se há uma falha de projeto detectada em uma etapa adiantada, há um caminho longo a ser novamente percorrido pelos projetistas.

- a variedade das áreas de conhecimento envolvidas no projeto: quanto maior o número de áreas de conhecimento necessárias ao projeto, maior a complexidade da integração do produto. 
- grau de customização de componentes: quanto mais específicas as condições de uso do produto, maior a complexidade do projeto.

- $\quad$ extensão do uso de sistemas embarcados: quanto maior a necessidade de software embarcado, mais complexo o projeto.

A complexidade do produto a ser desenvolvido, pode, portanto, gerar maior complexidade no projeto do produto. Da mesma forma, um aumento na flexibilidade desejada do produto, assim como no grau de inteligência a ele imputado, amplia a complexidade do produto, e portanto a de seu projeto. Em suma, projetos de produtos mecatrônicos tendem a ser mais complicados de serem realizados que projetos de produtos mecânicos, eletrônicos etc.

BUUR (1989) demonstra que o método empregado pelas empresas japonesas para a integração de suas novas contratações às equipes de projeto pressupõe a necessidade de desenvolver uma cultura generalista no seu corpo técnico, sendo porém, um enfoque generalista direcionado ao tipo de produto que a empresa desenvolve. Isso significa que é importante que a empresa tenha capacidade de aculturar suas novas contratações em torno da cultura generalista orientada ao produto da companhia. Portanto, tanto o perfil especialista formado pela maioria das faculdades de engenharia, quanto um perfil generalista formado por alguns cursos de mecatrônica apresentam limitações quanto à introdução do novo engenheiro em um time de projeto.

No item 2.1.1 é apresentada a mecatrônica como uma disciplina da engenharia baseada na idéia de que o projeto mecatrônico é a aplicação das tecnologias de produção e montagem mais modernas na solução de problemas. Isso exige alto grau de especialização do pessoal de projeto, o que tende a gerar times de desenvolvimento fortemente focados em desempenho técnico. Entretanto, a mecatrônica, como qualquer outra atividade de engenharia, só se 
justifica na medida em que atende aos objetivos estratégicos da empresa. A empresa que deseja utilizar a mecatrônica como diferencial competitivo deve, portanto, estabelecer claramente:

"... as propriedades que são apenas pré-condições necessárias para vender o produto (o estado-da-arte) e aquelas pelas quais o produto pode realmente aumentar sua competitividade". (BUUR, 1990, p.13)

Portanto, a empresa deve estabelecer com clareza as especificações do produto e identificar as funções nas quais o uso da mecatrônica pode gerar diferencial competitivo.

Do ponto de vista do projeto técnico propriamente dito, as diferentes especialidades geram formas diversas de ver o mesmo problema (ADAMSSON, 2005). Engenheiros mecânicos vêem o projeto sob o aspecto espacial, eletrônicos vêem o processamento de sinais e comunicação, engenheiros de software vêem o projeto sob o ponto de vista lógico e de algoritmos de operação. Adicionalmente, cada disciplina tende a fazer seus próprios modelos de forma isolada.

A modelagem dos sistemas mecatrônicos é um tema recorrente. AMERONGEN (2003) sugere a utilização de modelos baseados no fluxo de energia para representar a integração das diferentes disciplinas no projeto de sistemas mecatrônicos. Utilizando conceitos de engenharia de controle, seria possível modelar sistemas mecânicos através de equivalentes capacitivos, indutivos e resistivos, e portanto, modelar o fluxo de energia através de variáveis proporcionais, derivativas ou integrativas com relação à energia ou sua derivada. Esse método é utilizado pelo autor para modelar o projeto de um robô de usinagem. Há um software desenvolvido para suportar essa modelagem através do formalismo conhecido como bond graph.

REINHART e HAGEN (2001) relatam o projeto Machine Tools with Computer Aided Prototyping (MATCAP) como solução computacional para a integração do projeto eletrônico e mecânico. Esse tipo de solução, entretanto, dá uma forte ênfase à integração espacial do 
projeto através de sistemas CAD ampliados com funcionalidades de importação de partes padronizadas(features) de projeto eletrônico, como cabos, conectores, placas etc. A integração funcional, entretanto, não pode ser conseguida apenas pela solução sugerida pelo autor, além do que, as features seriam válidas apenas para projetos com alto grau de similaridade. Entretanto, para empresas com projetos bastante similares entre si, a alternativa é uma excelente forma de reduzir custos com prototipagem.

BERNARDI et al. (2002) sugerem a utilização da equivalência elétrica já mencionada para que sejam gerados modelos das diferentes áreas técnicas que possam ser discutidos pelo time de projeto. Adicionalmente, o autor introduz a necessidade de utilização de sistemas de gestão do conhecimento para que o aprendizado de projetos anteriores possa ser utilizado na solução de problemas de projetos atuais.

JAMES (2004) discute o uso dos softwares Simulink e MATLAB para o projeto de unidades de controle eletrônico automotivas. Como o aspecto da segurança desse tipo de produto é crítico, há estudos que defendem o uso de redes de petri para determinar cenários de risco no uso de produtos mecatrônicos, especialmente automotivos. DEMMOU et al. (2004) advoga o uso conjunto de redes de petri para analisar a dinâmica da transição de estado dos equipamentos mecatrônicos aliada ao uso de funções de transferência modeladas por equações diferenciais para estudar as variáveis contínuas do sistema.

O uso de redes de petri aliadas a equações diferenciais é proposto também por MIYAGI et al. (2002) para o projeto de sistemas de automação predial. HILLER e HIRSCH (2006) discutem o projeto de sensores a equipar sistemas de segurança automotivos. Os autores advogam o uso da abordagem de multicorpos para entender as situações mais críticas relacionadas a sistemas de airbag, cintos de segurança etc. 
ADAMSSON (2005) relata os resultados de projetos de pesquisa-ação realizados com empresas suecas da área automotiva. $\mathrm{O}$ autor enfoca os problemas organizacionais que surgem quando são desenvolvidos produtos mecatrônicos. Sua abordagem enfoca a questão da integração entre os membros de um projeto de desenvolvimento. O autor parte do pressuposto de que há três dimensões básicas de integração: baseada em atividades e métodos (processual), baseada na forma como a empresa organiza seu pessoal de projeto (organizacional) e baseada na utilização de tecnologias de integração, tais como ferramentas CAD, CAE, computer aided control engineering (CACE) etc. Suas conclusões são sumarizadas a seguir:

- $\quad$ alguns conceitos de projeto necessários a todos os envolvidos são entendidos de forma diferente - seria necessário investir tempo para permitir aos engenheiros o entendimento profundo de métodos para a integração dos sistemas que compõem o produto.

- há uma grande demanda por coordenação das atividades das diferentes disciplinas. A alocação dos requisitos do sistema para cada subsistema componente é crucial para a integração do projeto e pode ser realizada utilizando-se o conceito de arquitetura.

- nas empresas pesquisadas foi detectado que a integração do software ao projeto mecatrônico se dava dentro da área funcional da eletrônica. Esse comportamento também é relatado por BUUR (1989).

- não há sistema comercial especialmente projetado para a gestão de dados de sistemas mecatrônicos, isso faz com que a empresa precise decidir por investir no desenvolvimento de softwares para a integração das áreas do projeto ou em realizar a integração através de métodos organizacionais. 
- $\quad$ quando a empresa é baseada na expertise técnica em determinada área, é difícil realizar o trabalho de integração necessária à mecatrônica. Se os engenheiros dedicam muito tempo às atividades necessárias à integração entre grupos funcionais, eles podem perder sua expertise, assim como o foco no trabalho do projeto.

- a complexidade do produto é um importante elemento a ser analisado para determinar o quanto a empresa precisará despender em esforço de integração e coordenação do projeto.

- $\quad$ habilidades técnicas e de cooperação são fundamentais para a produtividade do pessoal de engenharia. Quanto mais experientes os engenheiros alocados aos projetos, mais rapidamente acontece a integração entre as soluções às quais chegam os diferentes profissionais de projeto.

A seguir são apresentados requisitos de projeto do processo de fabricação e montagem de equipamentos mecatrônicos.

\subsubsection{Desenvolvimento de processo e fabricação de produtos mecatrônicos}

A norma Quality Systems Requirements, ou QS-9000 (AUTOMOTIVE INDUSTRY ACTION GROUP, 1995), consiste nos requisitos do sistema de qualidade exigidos pelas grandes montadoras do setor automobilístico para "... prover melhoria contínua enfatizando a prevenção de defeitos e a redução da variabilidade e do desperdício na sua cadeia produtiva". Essa norma é confeccionada sobre a base estabelecida pela ISO 9000:1994, tendo sido recentemente ampliada pela TS 16949. Seu enfoque, porém, não foi alterado. As empresas que desenvolvem produtos mecatrônicos para a cadeia automotiva devem adotar um conjunto de métodos de gestão em seu processo de desenvolvimento que são consolidados no "Planejamento Avançado da Qualidade do Produto e Plano de Controle" (Advanced Product Quality Planning e Control Plan - APQP, ver AUTOMOTIVE INDUSTRY ACTION 
GROUP, 1994), consistindo basicamente na utilização de um cronograma formal de projeto, na utilização de análise de modos e efeitos de falha (failure mode and effect analysis FMEA) de projeto e de processo, em um rigoroso controle de configurações e mudanças de produto, e no projeto de um rigoroso sistema de controle de qualidade da manufatura e montagem.

A GSQA - significa Sistema de Garantia da Qualidade de Fornecedores Globais (The Global Supplier Quality Assurance System, ver ELECTROLUX HOME PRODUCT EUROPE, 2002), sendo o padrão utilizado pela ELECTROLUX para a seleção e desenvolvimento de fornecedores. As empresas que desenvolvem produtos mecatrônicos, não só para a ELECTROLUX, mas também para outras empresas que trabalham com eletroeletrônicos de linha branca devem seguir um rigoroso sistema que permita a identificação e rastreabilidade do produto, a adoção de práticas de produção limpa (housekeeping), além de requisitos contemplados na norma QS-9000.

O conjunto dos requisitos específicos dos processos de manufatura e montagem aplicáveis a produtos mecatrônicos direcionados a esses setores é elencado abaixo:

- $\quad$ informações necessárias à aquisição - o fornecedor deve assegurar que restrições governamentais relacionadas com o uso de substâncias tóxicas, perigosas e de uso restrito são satisfeitas para os componentes comprados e o processo de manufatura.

- $\quad$ controle do processo - o fornecedor deve projetar o processo de manufatura de maneira a assegurar conformidade com regulamentos de segurança e ambientais relacionadas com manuseio, reciclagem, eliminação ou disposição de materiais perigosos. Deve, ainda, estar conforme com requisitos para designação, documentação e controle de características especiais do processo. A norma denomina como características especiais aquelas cuja 
variação excessiva pode afetar a segurança, conformidade com regulações governamentais, função, aparência ou qualidade de operações subseqüentes.

A QS-9000 apresenta requisitos genéricos para o desempenho de processos em operação contínua: processos estáveis com dados em distribuição normal devem ser controlados utilizando $\mathrm{Cpk} \geq 1.33$; processos instáveis cronologicamente com saídas dentro das especificações e obedecendo padrões pré-definidos devem ser controlados com Ppk $\geq$ 1.67; processos que não obedecem a distribuição normal devem ser controlados usando partes-por-milhão (PPM) ou outras técnicas de controle. Eventos significativos, tais como mudança de ferramenta ou reparo na máquina, devem ser registrados em gráficos de controle.

Deve haver um planejamento detalhado do set-up de máquinas que preveja documentação de set-up e seu registro histórico para comparação por parte do pessoal de fábrica.

- $\quad$ rastreabilidade do produto - o fornecedor deve especificar procedimentos de inspeção de recebimento com registro de dados históricos, avaliação de terceira parte e auditoria no estabelecimento de subcontratados, certificados de garantia ou de laboratórios credenciados. O fornecedor deve utilizar laboratórios de testes credenciados, quando solicitado pelo contratante. Os produtos finais devem ser monitorados sob condições definidas estatisticamente.

- manufatura - o fornecedor deve estabelecer um sistema de gestão de estoques que garanta disponibilidade e minimização dos níveis de estoque trabalhando com a perspectiva de redução dos lotes de entrega ao contratante. Além disso, é necessário garantir $100 \%$ de entregas no prazo acordado, caso contrário, deve implementar ações corretivas para melhorar o desempenho da entrega. Um sistema computadorizado que permita o disparo de pedidos em tempo real deve ser disponibilizado pelo fornecedor. 
- plano de controle de processo baseado na FMEA de processo que contenha fluxograma de processo indicando identificação de etapas, caracterísitcas de controle, formas de levantamento de dados, método de controle, freqüência de inspeção e planos de reação a não-conformidades.

- $\quad$ processos especiais devem ser ensaiados para que sejam definidos parâmetros de processo que permitam a definição de especificações do produto com baixa variabilidade. Processos especiais incluem soldas, tratamentos superficiais e coatings.

- estudos de capabilidade devem ser realizados e documentados abrangendo "capabilidade de processo potencial" (Ppk) no qual são removidas as causas de variação potencial do processo projetado e "capabilidade de processo executado" (Cpk) no qual os dados são coletados com todo o processo correndo em escala comercial e com todas as variações possíveis. A GSQA estabelece amostra de 50 resultados para ambos os estudos e meta de 2,0 Ppk e 1,67 Cpk.

- $\quad$ testes e amostras de qualificação devem ser realizados e documentados em pelo menos três diferentes níveis: (1) "teste de amostra sem ferramenta", objetiva demonstrar que a combinação de material e conceitos de produção resultam em peças que estão conformes com as especificações; (2) "amostras técnicas" objetivam ser testadas para verificar a adequação da peça aos requisitos técnicos e regulatórios; e (3) teste de corrida completa que objetiva demonstrar que a capabilidade e capacidade do processo está conforme as especificações. As peças resultantes dessa terceira amostra são usadas como "amostras iniciais" (initial samples) e para testes de validação, inclusive cálculos de Ppk.

Revisão de amostras iniciais que consiste na realização de medidas dimensionais, testes de materiais e demais requisitos do produto. A amostra inicial deve ser submetida a 
variações na peça, no processo, nas ferramentas, moldes e equipamentos, nos materiais e na planta fabril. Essas amostras devem ser devidamente identificadas e acondicionadas.

\subsection{Modelos de Referência}

Nesse tópico são discutidos a definição de um modelo de referência, as especificidades apresentadas pelos modelos a serem aplicados em processos de negócio e alguns métodos e ferramentas de modelagem.

\subsubsection{Conceito de modelos de referência}

BARBALHO e ROZENFELD (2004), baseados em PIDD (1998), apresentam uma definição bastante completa acerca do que seria um modelo:

um modelo é uma representação externa e explícita de parte da realidade, vista pela pessoa que desejar usá-lo para apoiar a execução de tarefas relacionadas com aquela parte da realidade, sejam operacionais ou gerenciais, sendo expresso em termos de algum formalismo (linguagem) definido por construtos de modelagem.

Cabe uma análise mais minunciosa da definição acima. Primeiramente, ao invés de ser uma simples representação da realidade, um modelo deve agregar a idéia de propósito, pois uma mesma realidade pode ser vislumbrada de diferentes formas por pessoas com diferentes objetivos quanto a ela. Segundo, a idéia de propósito traz à tona a necessidade de definição do usuário do modelo: são pessoas que gerenciam processos ou atividades; são pessoas que fazem parte da execução de atividades; são pessoas que analisam atividades com o objetivo de propor melhorias a elas etc. Terceiro, o modelo nunca descreve completamente uma realidade. Ele é sempre limitado aos propósitos do usuário. Mesmo em modelagem de empresas há limites quanto à abrangência dos modelos, por um lado, porque ainda que siga um dado referencial de análise, a visão de mundo de quem modela influenciará o resultado. Por outro lado, aspectos subjetivos como emoções, relações de gênero, aspectos culturais e religiosos etc. serão sempre questões que extrapolam o âmbito do modelo e, ainda que consideradas, 
tornariam o resultado tão complexo que uma das principais contribuições de um modelo para a análise de uma dada realidade, qual seja, a simplificação desta, seria perdida.

Quarto, um modelo é uma representação externa e explícita, ou seja, não se deve confundir um modelo com formas de pensar ou arranjo mental das pessoas ou métodos implícitos de realização de atividades. O que não é explícito, não é um modelo uma vez que não pode ser compartilhado com outros usuários da parte da realidade que é modelada. Quinto, o caráter externo e explícito do modelo é capturado através do que VERNADAT (1996) chama de formalismo ou linguagem de modelagem, que seria a forma de representação do modelo. Essa forma de representação varia entre a matemática (mais formal) e a linguagem natural, que embora menos formal é a mais rica em termos semânticos. O formalismo de um modelo é definido pelos construtos utilizados para representar uma dada realidade.

Segundo VERNADAT (1996), modelos de referência são modelos parciais que podem ser usados como base para o desenvolvimento ou a avaliação de modelos particulares. Modelos são chamados de parciais quando eles não são totalmente instanciados, ou seja, não atendem ao processo existente em uma realidade em particular. São genéricos, normalmente direcionados a um determinado setor da economia. Eles são, portanto, templates que podem ser adaptadas a condições específicas de um dado usuário, uma empresa por exemplo. Os modelos "adaptados" (instanciados) seriam os chamados modelos particulares. Nem todo modelo parcial é um modelo de referência. Para sê-lo é preciso que a template possa ser considerada uma lista de best practices as quais justifiquem a intenção de que seja tomada como referência. Assim sendo, é amplamente aceita a idéia de que modelos de referência são sistematizações do conhecimento disponível sobre um determinado universo de discurso em nível de best practices (SCHEER, 1998; SCHEER, 1999; SANTOS, 2002). 
Um modelo de referência seria, portanto, a representação explícita de best practices relacionadas com uma parte de uma realidade específica. Segundo PIDD (1998) modelos de referência podem ser construídos para diferentes finalidades dentro das ciências administrativas e engenharia de produção: (1) para o suporte à decisões gerenciais; (2) para controlar o desempenho de uma atividade, uma função ou um processo; (3) para definir componentes essenciais e sensíveis a melhorias em processos de negócio; ou (4) para explorar desacordos e incertezas entre diferentes atores envolvidos em decisões complexas. Modelos de referência podem ser desenvolvidos também para a descrição de softwares de gestão (5), como forma de facilitar seu entendimento e sua implantação em empresas usuárias (CURRAN e KELLER, 1998).

\subsubsection{Modelos de processos de negócio}

Modelagem de empresas (ME) são processos de negócio que são representados em modelos. Nessa área, o termo empresa é originado do inglês enterprise (empreendimento) e não company (empresa no sentido mais pragmático). VERNADAT (1996) deixa clara a noção de que a teoria de ME pode ser aplicada a uma empresa como um todo ou a processos da empresa em específico, os quais são considerados empreendimentos.

Um processo é, conforme ROZENFELD (2001), algo que existe. Ou seja, processos são fenômenos que ocorrem em empresas, independente da estrutura organizacional definida por seu organograma. O conceito de processo é base de uma série de abordagens de gestão que começaram a ser implementadas com maior veemência no ocidente no final dos anos 80 juntamente com os programas de gestão pela qualidade. Entretanto, a prática explícita e sistemática da gestão por processos foi introduzida no Brasil através do conceito de reengenharia (HAMMER e CHAMPY, 1994). 
De maneira mais pragmática, um processo é “...um conjunto de atividades estruturadas e medidas destinadas a resultar num produto especificado para um determinado cliente ou mercado" (DAVENPORT, 1994). GONÇALVES (2000a) identifica, com base em uma extensa pesquisa bibliográfica, tipos diferentes de processos nas empresas:

- $\quad$ processos de negócio (ou de cliente): são os que caracterizam a atuação da empresa e que são suportados por outros processos internos resultando no produto ou serviço que é recebido pelo cliente externo;

- $\quad$ processos organizacionais (ou de integração): garantem o suporte aos processos de negócio através da viabilização do funcionamento coordenado da organização; e

- processos gerenciais: focalizam os gerentes e suas relações incluindo ações de medição e ajuste de desempenho da empresa.

Dentro dessa classificação, o processo de desenvolvimento de produtos é um processo de negócio. Esse tipo de processo apresenta uma extrema aderência à essência do funcionamento da organização, ou seja, eles são típicos da empresa, do mercado em que ela atua e de sua estratégia, o que implica que eles diferem muito de uma organização para outra. $\mathrm{Na}$ tentativa de considerar as variações existentes entre processos de negócio, as teorias de modelagem de empresas prevêem a confecção de modelos de referência “...especializados em mercados verticais" (SCHEER, 1998; VERNADAT, 1996) a partir dos quais o, já mencionado, conceito de instanciação deve ser utilizado para a confecção dos modelos particulares. Assim, um modelo de referência para a indústria de eletro-eletrônicos de consumo poderia ser adaptado a uma empresa que desenvolve lavadoras de roupas e assim por diante. 
Um processo de negócio tem uma importante característica que é seu nível de maturidade. O conceito de níveis de maturidade foi sugerido por MACINTOSH ${ }^{2}$ apud AGUILAR-SAVÉN (2004) e passou a ser amplamente utilizado. Segundo CHRISSIS et al. (2003, p.11), níveis de maturidade de processos de negócio "... são perfis de melhoria evolucionários através dos quais uma empresa atinge padrões superiores de desempenho". Como será discutido mais adiante, para diferentes níveis de maturidade há diferentes demandas com relação aos modelos de referência de processos.

Recentemente, CHRISSIS et al. (op. cit.) tem apresentado de forma consistente o conceito de capabilidade de processos. Esse conceito é originário da área de manufatura, em especial de gestão da qualidade de produtos e processos (JURAN, 1997), e tem sido adaptado ao uso em processos de negócio. A capabilidade de um processo seria sua capacidade de ser repetitível. Essa repetibilidade teria relação com a maturidade do processo: a maturidade de um processo como um todo seria o resultado da capabilidade de cada uma de suas áreas de processo. Uma área de processo é assim definida:

"... um aglomerado de melhores práticas relacionadas com uma área que quando implementadas coletivamente satisfazem um conjunto de metas consideradas importantes para permitirem melhorias significativas naquela área". (idem ibidem, p. 8)

Portanto, uma área de processo é uma parte do processo de negócio modelado para o qual é possível estabelecer um modelo de referência. A repetibilidade da execução das atividades da área de processo em uma dada empresa determina a sua capabilidade. Caso a capabilidade das áreas de processo estejam em um mesmo nível de melhoria, é possível identificar um nível de maturidade para o processo de negócio modelado.

\footnotetext{
${ }^{2}$ MACINTOSH, A. L. The need for enriched knowledge representation for enterprise. Artificial Intelligence in Enterprise Modeling, IEE Colloquium on, pp. 3/1-3/3, 1993.
} 
Os níveis de capabilidade das áreas de processo podem ser, segundo CHRISSIS et al. ${ }^{3}$ (2003, p. 74-5):

- $\quad$ incompleto (nível 0) - quando o processo não é realizado ou o é apenas parcialmente;

- $\quad$ realizado (nível 1) - o processo é capaz de gerar os resultados dele esperados;

- $\quad$ gerenciado (nível 2) - processo planejado, provido dos recursos previstos, monitorado, controlado e revisado;

- definido (nível 3) - quando o processo planejado é baseado em padrões organizacionais e está sob melhoria contínua;

- $\quad$ quantitativamente gerenciado (nível 4) - o processo é controlado usando estatística; e

- $\quad$ otimizado (nível 5) - processo melhorado com base no entendimento consensual das causas de variabilidade estatística.

Segundo VERNADAT (1996) “...um modelo de empresa é um conjunto consistente de modelos direcionados e complementares que descrevem as várias facetas de uma empresa para satisfazer os propósitos dos usuários do negócio”. Na construção de modelos de referência para processos de negócio, portanto, há que se considerar que facetas seriam necessárias modelar para que o processo possa ser considerado compreendido sem que o modelo seja tão complexo que prejudique seu compartilhamento com os usuários. Ou seja: que facetas deveriam ser modeladas de forma a atender aos requisitos mínimos necessários à modelagem do processo que se visa entender?

No presente trabalho, as facetas de um modelo são descritas como tipos de conteúdo necessários a um determinado modelo de referência. Há uma relação próxima entre o conceito

\footnotetext{
${ }^{3}$ O modelo desenvolvido por CHRISSIS et al. (2003) é denominado de CMMI - capability maturity model
} 
de tipo de conteúdo e o de construto, já mencionado. O tipo de conteúdo seria o que é modelado dentro de uma dada realidade. O construto seria a forma de representar a "coisa" modelada. Essa forma de representação contém uma semântica e uma sintaxe (VERNADAT, 1996). A sintaxe seria a forma gráfica de apresentação do construto e a semântica seria o significado dessa forma gráfica. No item 4.4 são apresentados os contrutos do MRM, ocasião na qual esse conceito será exemplificado.

\subsubsection{Tipos de conteúdo necessários em modelos de referência}

Ao longo deste trabalho foram analisados uma série de métodos de modelagem de processos de negócio. Uma vez que a sua descrição detalhada foge ao escopo do trabalho, será apresentado abaixo um sumário de cada método. No APÊNDICE D são detalhados os métodos utilizados na confecção do MRM.

O s métodos de modelagem aqui analisados foram os seguintes:

- $\quad$ ARIS: a metodologia Architecture of Integrated Information Systems (ARIS) foi proposta por A.W. SCHEER no início da década de 90 e vem passando por sucessivas atualizações à medida que vai sendo utilizada. O ARIS conta com uma ferramenta considerada tecnologicamente madura para a modelagem integrada de processos (GREEN e ROSEMANN, 2000) sendo utilizada para representar modelos de referência de softwares de gestão empresarial (CURRAN e KELLER, 1998).

- $\quad$ CIMOSA: o projeto Computer Integrated Manufacturing Open System Architecture (CIMOSA), conforme KOSANKE (1995), não se propõe a apenas apresentar uma metodologia de modelagem de empresas, mas arquiteturas de integração de processos, aplicativos e negócios. O CIMOSA se constitui em um esforço da comunidade européia para criar padrões para a manufatura integrada por computador. Segundo VERNADAT (1996, 
p.40), o CIMOSA é responsável pela introdução do termo processo de negócio (business process) e da abordagem orientada a processos para a modelagem de empresas. Apesar do desenvolvimento teórico, poucos resultados práticos têm sido alcançados pelo uso da metodologia.

- EKD: o Enterprise Knowledge Development (EKD) é o estado atual do desenvolvimento de uma metodologia chamada PLANTADA, a qual foi refinada pelo Swedish Institute for Systems Development - Instituto Sueco para o Desenvolvimento de Sistemas (SISU) e posteriormente pelos projetos ESPRIT F3 (From Fuzzy to Formal) e ESPRIT ELEKTRA (Electrical Enterprise Knowledge for Transforming Applications) mediante a realização de uma inteligente integração de "componentes organizacionais de uma especificação, como por exemplo, objetivos de um negócio" (PÁDUA, 2000) com os tradicionais modelos de processo e entidade-relacionamento. Como o próprio nome supõe, o EKD é uma metodologia direcionada para a sistematização, reflexão e desenvolvimento do conhecimento acumulado em uma determinada organização.

- $\quad$ IDEF: o Integrated Computer Aided Manufacturing Definition (IDEF) é originado de um esforço da força aérea americana no sentido de aumentar a produtividade da indústria aeronáutica do país. O padrão foi posteriormente adaptado pelo National Institute of Standards and Technology (NIST) e pelo Institute of Electrical and Electronics Engineers (IEEE) para aplicação nos demais setores industriais americanos (INSTITUTE OF ELECTRICAL AND ELECTRONICS ENGINEERS, 1998b - IEEE STD 1320:1998). O IDEF corresponde a um conjunto de métodos (VERNADAT, 1996) dos quais os mais conhecidos são: o IDEF 0, utilizado para modelagem funcional de organizações ou sistemas; o IDEF 1, para modelagem de informações; e o IDEF 3 para modelagem de processos. A abordagem do IDEF 0, o padrão IDEF mais aplicado, inclui tanto uma linguagem de 
modelamento, com sintaxe e semântica bem definida, quanto uma metodologia para o desenvolvimento de modelos.

- $\quad$ UML: a Unified Modeling Language (UML) é uma linguagem de especificação de software que pode ser utilizada para a modelagem de processos de negócio, conforme BARBALHO et al.. (2002) e KIM et al.. (2003). Em UML, um software é especificado a partir de conceitos de orientação a objetos, conforme discutido em BOOCH (2000).

- MER: o modelo entidade-relacionamento (MER) foi introduzido por CHEN (1976) como uma nova maneira de "enxergar" os dados em uma dada aplicação computacional. O autor analisa os três principais modelos de banco de dados em utilização até então: de redes, relacional e de entidades; caracterizando as principais ambigüidades e limitações dos mesmos e identificando a forma pela qual o modelo apresentado - o entidade-relacionamento - poderia ser confeccionado para atender às especificações de seus predecessores, os quais seriam dessa forma, seus casos particulares. O MER considera o universo informacional de uma aplicação independente do tipo de processamento que faz a transformação dos dados.

- $\quad$ DFD: o diagrama de fluxo de dados (DFD) provê indicação de como os dados, dentre os quais as informações modeladas através do MER, são transformados quando se movem através de um sistema, assim como descreve as atividades (e sub-atividades) que os transformam. Portanto, o diagrama de fluxo de dados, embora seja uma ferramenta de fácil entendimento, permite visualizar simultaneamente aspectos de modelagem de informações e de atividades (PRESSMAN, 2001).

- Fluxograma de processo: o fluxograma de processo é, segundo AGUILAR-SAVÉN (2004), talvez o primeiro formalismo utilizado para descrever processos sendo empregado para representar graficamente desde a seqüência lógica de programas de computador até 
processos de manufatura ou de trabalho. JURAN (1997) e GRYNA (2000) discutem formas de utilização desse método.

- $\quad$ Tabela de fluxo de processo: as tabelas de fluxo de processo identificam tipologias de atividades ao longo de um dado fluxograma de processo, além de permitirem a introdução do tempo despendido em cada uma. Sua utilização é bastante difundida para descrever processos de fabricação (SLACK et al.., 2002), principalmente quando o objetivo da modelagem é a melhoria dos tempos despendidos nos processos (KHAN, 2000).

Esses métodos de modelagem foram estudados como forma de estabelecer linhas gerais para a análise do processo de desenvolvimento de produtos mecatrônicos. Os textos estudados ao longo do trabalho e a análise realizada em atividades de campo se guiaram pelos tipos de conteúdo que esses métodos buscavam captar. Essa discussão é retomada no capítulo 4. 


\section{MÉTODO DE PESQUISA}

No presente capítulo, a metodologia de pesquisa será abordada. No tópico 3.1 será apresentada a classificação da pesquisa, no tópico 3.2 apresentar-se-á as atividades realizadas ao longo do trabalho e no tópico 3.3 serão introduzidos os procedimentos utilizados ao longo do trabalho para levantar as evidências necessárias à conclusão do projeto.

\subsection{Classificação da pesquisa}

A Figura 31 apresenta a classificação da pesquisa quanto a diferentes critérios utilizados na área de metodologia da ciência.

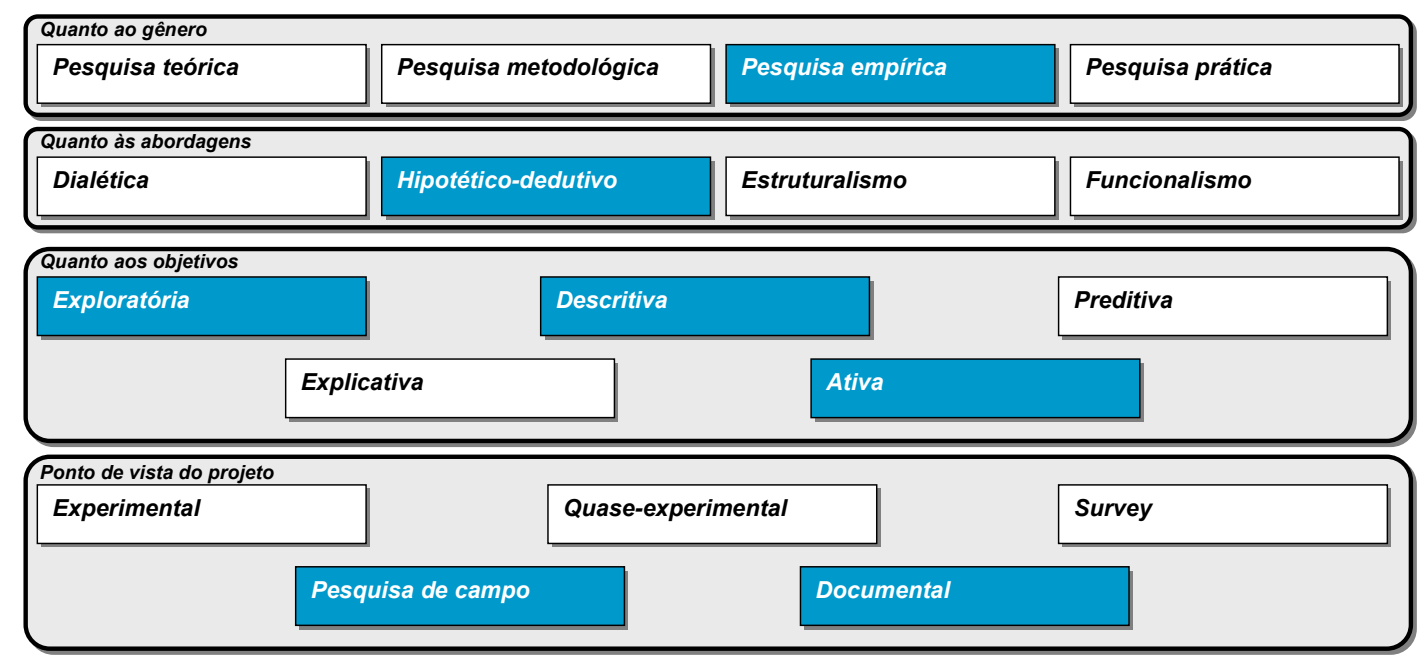

Figura 31 - Classificação da pesquisa

O presente trabalho é pesquisa empírica, segundo a classificação de DEMO (1990). Há aspectos de pesquisa prática previstos uma vez que a teoria desenvolvida precisa ser testada para que o processo de sua confecção e seu resultado (ela mesma) possa ser considerado científico (ALVES, 1994, p. 176). A pesquisa prática, entretanto, não é o principal enfoque do presente trabalho, uma vez que as questões básicas estão no plano teórico: a possibilidade de haver uma referência que descreva completamente o PDP mecatrônico na bibliografia 
especializada, e a possibilidade de construção dessa referência, caso não exista. Pesquisas de caráter prático, por seu turno, têm como objetivo principal a aplicação de teorias a casos (DANE, 1990), a realização de diagnósticos (THIOLLENT, 1994) etc.

Quanto à abordagem metodológica, também conforme a classificação de DEMO (1990), no presente trabalho utiliza-se o positivismo em sua vertente hipotético-dedutiva que pressupõe a realização de uma tentativa de refutação da teoria desenvolvida. Ao invés de comprovar a veracidade de uma afirmação científica, o trabalho do cientista é colocá-la à prova na tentativa de falseá-la. A tentativa de refutar o postulado resultante de uma tese torna o trabalho mais robusto, delimitando os limites de sua validade ou evidenciando sua refutação.

Sob o ponto de vista dos objetivos, uma pesquisa pode segundo DANE (1990), suportar mais de uma tipologia. Pode-se, por exemplo, explorar os conceitos de modelagem de empresas em uma dada bibliografia específica e posteriormente realizar pesquisa descritiva com o objetivo de relatar como empresas que utilizam técnicas relacionadas com o campo específico estudado realizam atividades operacionais utilizando conceitos de modelagem para descrevê-las. Visto que o objetivo geral do presente trabalho é a confecção de um modelo de referência para a gestão do PDP, um processo já bem conhecido, considera-se que a tipologia básica do trabalho é descritiva. Confeccionar o modelo de referência seria, na verdade, realizar uma caracterização mais aprofundada de um PDP específico, qual seja, o de empresas cujos produtos são mecatrônicos.

Entretanto, considerando que o modelo confeccionado é baseado em uma extensa pesquisa bibliográfica na qual é realizada uma investigação sistemática dos conteúdos necessários ao modelo mecatrônico, o caráter exploratório não pode deixar de ser mencionado. Ele se reflete, seja quando se busca identificar os elementos da teoria de modelagem de empresas (ME) que devem estar presentes nos modelos de referência de 
processos de negócio (item 2.4.3), seja quando é realizada uma análise da bibliografia de PDP e de mecatrônica na busca da identificação de modelos de referência aplicáveis ao projeto de produtos mecatrônicos (APÊNDICE C).

Há ainda, um forte caráter ativo da pesquisa quando as versões intermediárias do modelo são utilizadas para realizar efetiva intervenção no PDP de uma empresa que desenvolve produtos mecatrônicos. Essa atividade de aplicação dos conceitos desenvolvidos até um certo ponto do trabalho serve tanto para validar partes do modelo quanto para gerar novos conteúdos não identificados ao longo da pesquisa exploratória realizada na bibliografia especializada.

Do ponto de vista operacional, DANE (1990) sugere que os objetivos da pesquisa científica sejam traduzidos em métodos operacionalizáveis para o levantamento de evidências. Nesse trabalho utilizou-se procedimentos de pesquisa documental para o cumprimento dos objetivos exploratórios e descritivos e de pesquisa de campo para a realização dos objetivos de caráter ativo. No item 3.3 serão apresentados os procedimentos de pesquisa pelos quais as pesquisas documental e de campo foram realizadas.

\subsection{Atividades necessárias à pesquisa}

Segundo LAKATOS e MARCONI (1991) o método hipotético-dedutivo deve seguir a seguinte seqüência de passos:

- identificar um problema, geralmente fruto de conflitos ante expectativas de descrição, explicação ou possibilidade de aplicação de teorias existentes;

- $\quad$ propor uma nova solução para o problema identificado (uma nova teoria);

- deduzir, a partir da teoria proposta, suas conseqüências na forma de proposições passíveis de testes; 
- $\quad$ realizar testes, por meio de observações e experimentações, com o objetivo de refutar as proposições; e

- reformular hipóteses (proposições) falseadas ou ratificar provisoriamente as proposições que superaram os testes de refutação.

Abaixo será discutido como o trabalho contempla os passos do método hipotéticodedutivo.

\subsubsection{Identificação do problema}

A revisão bibliográfica permitiu levantar um conjunto de textos técnicos a respeito das três áreas principais do trabalho. A análise desse material está consolidada no capítulo 2 .

Para determinar o problema de pesquisa, a teoria de modelagem de processos de negócio é utilizada para realizar uma análise sistemática dos textos de desenvolvimento de produtos e mecatrônica selecionados. Isso se deu através da análise da presença dos tipos de conteúdo de processos de negócio nas teorias de PDP. Essa etapa do trabalho é apresentada no APÊNDICE C e está sumarizada no capítulo 4. O problema básico da pesquisa, a lacuna na teoria atacada pela tese por meio de seu objetivo geral, está consolidado no capítulo introdutório do trabalho.

\subsubsection{Proposição de nova solução para o problema}

A nova solução proposta pelo trabalho é o próprio modelo descrito no capítulo 5.

\subsubsection{Dedução de proposições passíveis de teste}

As proposições utilizadas para testar o modelo são de duas diferentes abordagens. Primeiramente, o conjunto dos conceitos utilizados para sistematizar o modelo deve manter alta consistência interna. Isso significa que ao aplicar um determinado elemento do modelo, o resultado deve estar coerente com o referencial teórico utilizado. 
Nesse sentido, foi utilizado o conceito de níveis de capabilidade das áreas de processo (ver item 2.4.2) para direcionar a aplicação do modelo, e portanto, os resultados da aplicação devem manter coerência com a teoria desenvolvida pelo CMMI: as áreas de processo nas quais houve maior grau de aplicação do modelo devem ter maior aumento em seu nível de capabilidade (PROP_1). A análise dessa proposição está consolidada no capítulo 6 e posteriormente avaliada no capítulo final.

A segunda abordagem para teste da solução proposta é baseada no conceito principal relacionado com o trabalho: um modelo de referência de PDP, quando aplicado, deve produzir melhorias significativas no desempenho do processo. Essa idéia, embora tenha motivado a realização do trabalho, não é provada pela teoria de PDP. Portanto, a segunda proposição de uso do modelo é: a aplicação do modelo deve resultar em melhoria significativa em indicadores de desempenho do PDP (PROP_2). A análise dessa proposição também consta nos capítulos 6 e 7.

\subsubsection{Realização de testes}

Os testes realizados com o modelo de referência consistem na sua aplicação a uma situação real de projeto. A aplicação do modelo é uma questão complexa por si só. Primeiramente, ela implica na participação do próprio pesquisador em uma situação de projeto, pois não sendo uma teoria consolidada, mas em construção, o modelo apenas poderia ser aplicado por pessoal com alto grau de envolvimento com sua confecção.

Os testes de aplicação do modelo, ocorreram no período de setembro de 2003 a março de 2005. O pesquisador foi integrado a uma equipe de projeto em uma empresa que desenvolve produtos mecatrônicos. Ao longo do período considerado, as demandas de aplicação do modelo mecatrônico na empresa foram sendo atendidas. 
No período considerado, além das aplicações realizadas pelo próprio pesquisador, outros atores organizacionais realizaram melhorias em seus setores de influência. Essas aplicações foram também monitoradas e incorporadas na análise final da aplicação do modelo de referência.

Os resultados desses testes estão descritos no capítulo 6.

\subsubsection{Reformulação de hipóteses}

A análise final do trabalho consiste nas reflexões sobre a aplicação do modelo realizada, assim como sobre os resultados conseguidos. Essa análise consta no capítulo 7.

\subsection{Procedimentos de pesquisa}

Nesse tópico serão apresentados os procedimentos de pesquisa utilizados ao longo do trabalho. Diferentemente das tipologias classificatórias, os procedimentos de pesquisa assumem um caráter pragmático: eles determinam como a pesquisa deve se desenrolar.

Na realização de pesquisas documentais, segundo GODOY (1995), um dos principais procedimentos é a análise de conteúdo, mediante a qual o pesquisador pode classificar documentos em categorias previamente definidas (BARDIN, 1979).

As pesquisas de campo podem ser realizadas de diversas formas em função de sua aplicação final. Utilizando como referências SERVA e JUNIOR (1995), BRANDÃO (1987), GODOY (1995), YIN (2001) e THIOLLENT (1997) tem-se algumas alternativas à realização de pesquisas de campo, dentre as quais se optou por realizar pesquisa-ação pelo fato de permitir que seja realizada uma intervenção em determinado fenômeno como forma de testar a validade de teorias previamente desenvolvidas. A principal ferramenta de levantamento de evidência utilizada foi a observação partipante.

A seguir serão sumarizados esses procedimentos de pesquisa. 


\subsubsection{Análise de conteúdo}

Para BARDIN (1979), a análise de conteúdo perfaz um conjunto de instrumentos metodológicos que podem ser utilizados a discursos (conteúdos) bastante diversificados. O método nasceu como um instrumento de análise das comunicações tendo sido desenvolvido nos Estados Unidos e na França já na primeira metade do século XX, notadamente para realizar vigilância ideológica sobre os meios de comunicação desses países.

Com a análise de conteúdo, o pesquisador de comunicações se mune de uma ferramenta capaz de reduzir o caráter subjetivo do trabalho de análise desse tipo de material. A questão básica por trás do método é: será que o que você vê é pessoal ou é partilhado por outros? A partir da caracterização dos elementos presentes no método, o pesquisador garante a qualidade de discutibilidade (DEMO, 1990; ALVES, 1994) de seu trabalho de pesquisa. Por outro lado, a análise de conteúdo permite um "aumento da produtividade" do estudo de um determinado texto, já que provê técnicas de análise léxica, de avaliações, de discurso, fraseológicas etc. com as quais o pesquisador pode cercar a comunicação analisada com um arsenal de dados que lhe permitam uma inferência precisa a respeito de seu interesse teórico.

A vertente mais conhecida da análise de conteúdo, segundo BARDIN (1979), é a chamada "categorial", segundo a qual o pesquisador utiliza uma série de "índices" (categorias) para descrever a comunicação analisada. A partir dessa descrição realiza inferências de maneira a interpretar as estruturas sociológicas dos enunciados. Nesse sentido, a leitura efetuada pelo pesquisador, do conteúdo das comunicações não é, ou não é unicamente, uma leitura "à letra", mas antes o realçar de um sentido que se encontra no segundo plano.

A análise categorial é eminentemente qualitativa, porém pode apresentar como subdivisões estruturas do tipo presença/ausência, na qual o pesquisador verifica a existência de uma determinada categoria em uma dada comunicação, ou pode ser realizada a partir de 
escalas de intensidade, como por exemplo: discute demais, discute muito, discute pouco, discute e não discute.

\subsubsection{Pesquisa-ação}

Segundo SPINK (1979) “...pesquisa-ação é um termo aplicado à pesquisa corrente com duplo e explícito propósito de auxiliar a reflexão, formulação ou implementação da ação e de desenvolver, enriquecer ou testar quadros referenciais teóricos ou modelos relevantes ao fenômeno em estudo". A principal diferença entre pesquisa-ação e observação participante estaria na preocupação explícita de trabalhar lado a lado com a organização na solução de seus problemas cotidianos (SPINK, op. cit.). Enquanto a observação participante é um trabalho de campo "sobre" um determinado ator social, a pesquisa-ação, além de ser "sobre", é também "para" auxiliar um determinado tipo de ação ou de ator e é "por", no sentido de buscar melhoria de um determinado quadro referencial quanto a sua aplicação a um determinado ator, ou de contribuir com a adequação de um ator a um quadro teórico-prático considerado importante para ele (DESROCHE apud THIOLLENT, 19974).

A pesquisa-ação constitui-se num procedimento científico bastante importante pois é por meio deste tipo de pesquisa que se consegue testar aplicações de outros resultados de pesquisa. Dentro de uma concepção de conhecimento que seja também ação, pode-se conceber e planejar pesquisas cujos objetivos não se limitam à descrição ou à avaliação. Mais ainda, a pesquisa-ação é recomendada para novas abordagens, onde o pesquisador necessita explorar novas idéias e criar um conhecimento a ser testado na prática.

O teste prático de teorias é discutido por DEMO (1987, p. 111), segundo o qual esse procedimento:

- $\quad$ obriga à revisão teórica, uma vez que na prática a teoria é outra; 
- leva o cientista a "sujar" as mãos, tornando-o concretamente histórico, ou seja, ao mesmo tempo aproveitável e condenável;

- obriga o cientista a realizar controle metodológico de seu trabalho para não cair em justificações políticas para os resultados alcançados;

- $\quad$ torna a teoria muito mais produtiva, porque obriga a adequar-se a uma realidade processual, inquieta, conflituosa, que pouco tem a ver com a visão muito arrumada e estereotipada da realidade social, normalmente presente na academia;

- $\quad$ submete a teoria ao teste saudável da modéstia, porque em contato com a realidade concreta e política descobre-se facilmente que uma coisa é o discurso, outra a prática; e

- $\quad$ leva ao questionamento constante da formação acadêmica.

Embora seja de relevância inquestionável à confecção de teorias, em especial na área de engenharia de produção e afins, a prática impõe uma série de restrições ao pesquisador, as quais são discutidas por DEMO (op. cit.), como por exemplo o fato de ela ser “... sempre uma opção da teoria que a fundamenta”. Normalmente, o cientista não consegue aplicar na prática toda a teoria desenvolvida, mas “...versões concretas dela”. Essas versões normalmente assumem um caráter "limitante" no sentido de que “... toda prática apequena a teoria, porquanto, não ultrapassa a condição histórica de uma versão dela”. Nesse sentido, segundo o autor, a prática sempre trai a teoria. Em função do caráter simplificador e limitante, a prática “é necessariamente ideológica, porque se realiza dentro de uma opção política".

Uma pesquisa-ação bem conduzida deve lidar com todos os aspectos limitantes, ideológicos e políticos impostos pela aplicação prática da teoria sobre um dado fenômeno. Em THIOLLENT (1994), há um conjunto de cuidados metodológicos que o autor sugere que

\footnotetext{
${ }^{4}$ DESROCHE, H. Mouvement coopératif et économie sociale en Europe. La Revue de i Économie Sociale, n. 3 ,
} 
devam ser adotados para controlar as dificuldades de objetivação estabelecidas quando da realização de pesquisas práticas:

- $\quad$ o pesquisador deve buscar imparcialidade para retratar as visões de todos os atores da situação;

- $\quad$ deve-se buscar o consenso entre os pesquisadores para evitar excesso de subjetividade na descrição dos resultados;

- $\quad$ a descrição dos fatos e dados observados deve se dar, sempre que possível, por meio de exemplificação das falas dos participantes da pesquisa e escalas do tipo forte/fraco, grandemédio-pequeno, aumento/diminuição etc.

Por fim, há um ponto fundamental com referência à pesquisa-ação nas áreas ditas aplicadas, como é o caso da engenharia de produção em geral, e da abordagem organizacional em particular: ela é metodológica, prática e eticamente diferente da consultoria, ainda que eventualmente possa ser utilizada pelas empresas como tal (SALERNO, 1999). Metodologicamente porque se trata de uma verdadeira pesquisa, com instrumentos de coleta de dados, controle metodológico frente aos problemas típicos da pesquisa social (construção da amostra, distorções, relevância etc.), com o intuito de avançar no conhecimento. Já a vocação da consultoria é decodificar uma situação para então aplicar um dos seus métodos pré-elaborados, que presumivelmente solucionaria um problema da empresa (MINTZBERG apud. MUNDIN, 2002 $2^{5}$. Assim, coloca THIOLLENT (1997) que na “... vertente crítica da ciência da gerência, a pesquisa-ação tenderia a ser mais complexa e mais exigente que uma simples técnica de consultoria”.

p. $59-87,1987$

${ }^{5}$ MINTZBERG, H. Criando organizações eficazes: estrutura em cinco configurações. São Paulo: Atlas, 1998. 
Os dados levantados em uma pesquisa-ação, podem advir de observação participante e do uso de questionários de diagnóstico e de entrevistas. Na pesquisa ora relatada é usada a observação participante como principal forma de levantar evidências, conforme já mencionado.

Segundo SERVA e JÚNIOR (1995) é necessário que os pesquisadores interessados em utilizar a observação participante na pesquisa de campo em empresas adotem uma "postura antropológica", qual seja, uma sensibilidade para o "fato social total" representado pela atuação das pessoas na organização considerada. O pesquisador deve tentar compreender “... regras, costumes, convenções que orientam a vida do grupo sob observação” (GODOY, 1995). Apesar desse caráter global, SERVA e JÚNIOR (op. cit.) sugerem a utilização do mecanismo de construção de rubricas que representariam as categorias de dados necessárias à confecção da pesquisa, sob o julgo dos aspectos da teoria que se deseja construir, validar ou questionar. As rubricas guiam a sistematização dos dados da pesquisa. Os dados devem ser registrados com o auxílio de um caderno de campo e posteriormente relacionados às rubricas.

A condição de insider and outsider do pesquisador, que em situações importantes para o grupo está dentro da organização, mas que, como condição metodológica está de fato fora, é das mais conflituosas e críticas situações desse ferramental, uma vez que não é possível deixar de estabelecer relações de empatia, concordância ou discordância com posturas adotadas por um ou outro indivíduo da organização pesquisada. Esses sentimentos entretanto, devem ser captados e metodicamente suprimidos. SERVA e JÚNIOR (op. cit.) sugerem que o pesquisador utilize a rubrica "sentimentos do observador" como forma de dar vazão aos aspectos subjetivos relacionados com o trabalho, os quais devem ser refletidos como forma de precaução quanto a sua influência nas análises finais realizadas com os dados de campo.

Uma outra questão muitas vezes levantada no debate sobre esse ferramental diz respeito à influência que a presença do pesquisador causaria, levando os observados a se 
comportarem de forma fictícia (SERVA, 1996). Essa interinfluência observado-observador é inevitável. Não se deve fantasiar sobre este problema. Uma vez que são pessoas, em relação contínua, num dado período de tempo, e compartilhando tarefas, é muito provável que ocorra influências mútuas. O ponto nevrálgico entretanto, situa-se no grau de influência alcançado, ou seja, se ele é suficiente ou não para alterar substancialmente o comportamento dos observados e/ou comprometer a capacidade analítica do pesquisador. Isso remete ao papel que o observador assume no grupo e à forma como ele, observador, é percebido pelos membros da equipe.

\subsection{Utilização dos procedimentos de pesquisa para produzir os resultados esperados da pesquisa e validar a hipótese do trabalho}

Os resultados esperados da pesquisa estão descritos no item 1.2. O resultado $R 1$, qual seja, o próprio modelo de referência mecatrônico é atingido por meio do uso da análise de conteúdo sobre os modelos pré-existentes no grupo de pesquisa ao qual o autor se inseriu e sobre a bibliografia de PDP e mecatrônica. O modelo é sumarizado no capítulo 5 e consta integralmente no APÊNDICE A deste trabalho.

O resultado $R 2$ é atingido através do uso do conceito de áreas de processo e níveis de capabilidade. As diretrizes para a utilização do MRM são extraídas da teoria desenvolvida por CHRISSIS et al. (2003) e estão sumarizadas no item 5.4.3. A utilização do conceito de áreas de processo visa garantir que a aplicação do modelo tenha coerência com o referencial utilizado para confeccioná-lo. As áreas de processo são tipos de conteúdo buscados por meio da análise de conteúdo realizada no material pesquisado. A utilização deste procedimento para identificar as áreas de processo do MRM consta no APÊNDICE C e sua descrição consta no item 5.2.7.

$O$ resultado $R 3$ é buscado utilizando-se a pesquisa-ação. Ele consta na própria análise da validação do modelo de referência mecatrônico. Nesse sentido, as proposições passíveis de 
teste (item 3.2.3) foram desenvolvidas com base na hipótese de pesquisa (HIPI - item 1.2). No capítulo de aplicação do MRM é introduzido o método de aplicação do modelo (item 6.1). 


\section{TIPOS DE CONTEÚDOS NECESSÁRIOS AO MODELO DE REFERÊNCIA PARA O DESENVOLVIMENTO DE PRODUTOS MECATRÔNICOS}

Neste capítulo é apresentada primeiramente uma tabela com os tipos de conteúdo que os teóricos de modelagem de empresas prevêem serem necessários à confecção de modelos de referência conforme discutido no item 2.4.3. Posteriormente apresentar-se-á uma sistematização dos tipos de conteúdo encontrados nas bibliografias de PDP e mecatrônica, e em seguida o método de modelagem e a forma de representação do MRM.

\subsection{Tipos de conteúdo de modelos de referência para processos de negócio}

A Tabela 1 ilustra o conjunto dos elementos de processos de negócio necessários em um modelo de referência de acordo com os métodos de modelagem discutidos no item 2.4.3, sendo a lista complementada por autores que discutem a modelagem de processos de negócio sem, necessariamente, apresentarem modelos de processo através de métodos formais de modelagem. Esses autores foram identificados depois de uma busca pelas palavras-chave modelagem de empresas, modelagem de processos e reengenharia de processos de negócio sendo ainda, complementada por uma busca por citações em bases de dados, assim como em periódicos e congressos nacionais de administração e engenharia de produção.

Nas linhas da Tabela 1 são apresentados os tipos de conteúdo de modelos de referência, conforme tenham sido indicados em pelo menos 1 (um) dos autores estudados. Nas colunas da linha superior são apresentados os autores analisados.

No contexto da análise de um determinado processo, o tipo de conteúdo indica o quê deve ser buscado para o entendimento desse processo, conforme discutido no item 2.4.2.

Esses tipos de conteúdo podem ser assim definidos:

- $\quad$ objetivos de desempenho: objetivos de desempenho globais buscados pelo processo de negócio. 
- $\quad$ atividades: o que precisa ser feito para cumprir um determinado objetivo de desempenho.

- $\quad$ entradas: materiais, informações de serviço ou outros serviços necessários à execução de atividades.

Tabela 1 - Conteúdos necessários em modelos de referência de processos de negócio segundo autores de modelagem de empresas

\begin{tabular}{|c|c|c|c|c|c|c|c|c|c|c|c|c|c|c|}
\hline TIPO DE CONTEÚDO & 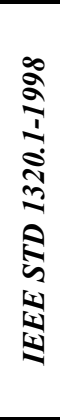 & 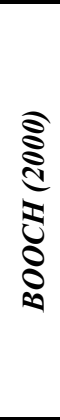 & 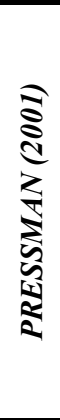 & $\begin{array}{l}\widehat{\mathbb{Z}} \\
\mathbb{Z} \\
\vdots \\
\mathbb{Z} \\
\mathbb{Z}\end{array}$ & 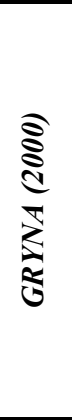 & 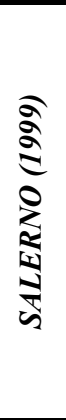 & 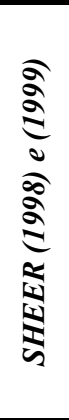 & 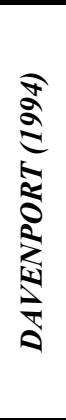 & 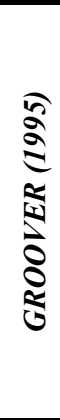 & 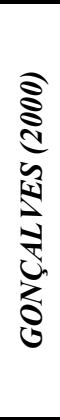 & 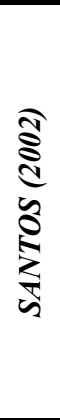 & 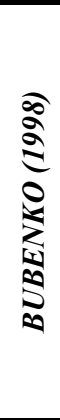 & 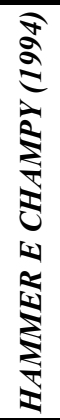 & 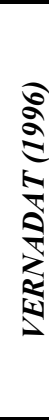 \\
\hline Objetivos de desempenho & & & & & & $\mathrm{X}$ & $\mathrm{X}$ & $\mathrm{X}$ & $\mathrm{X}$ & $\mathrm{X}$ & $\mathrm{X}$ & $\mathrm{X}$ & & \\
\hline Atividades & $\mathrm{X}$ & $\mathrm{X}$ & $\mathrm{X}$ & $\mathrm{X}$ & $\mathrm{X}$ & $X$ & $\mathrm{X}$ & $X$ & $\mathrm{X}$ & $\mathrm{X}$ & $X$ & $\mathrm{X}$ & $\mathrm{X}$ & $\mathrm{X}$ \\
\hline Entradas & $X$ & $\mathrm{X}$ & $X$ & & $\mathrm{X}$ & $X$ & $\mathrm{X}$ & & $\mathrm{X}$ & & $X$ & & $\mathrm{X}$ & \\
\hline Saídas & $\mathrm{X}$ & $\mathrm{X}$ & $\mathrm{X}$ & & $\mathrm{X}$ & $X$ & $X$ & & $\mathrm{X}$ & $\mathrm{X}$ & $X$ & & $\mathrm{X}$ & $\mathrm{X}$ \\
\hline Eventos/mensagens & & $\mathrm{X}$ & $\mathrm{X}$ & & & & $\mathrm{X}$ & & & & & & & \\
\hline Decisões & & & & & $\mathrm{X}$ & & $\mathrm{X}$ & $\mathrm{X}$ & $\mathrm{X}$ & $\mathrm{X}$ & $\mathrm{X}$ & $\mathrm{X}$ & & $\mathrm{X}$ \\
\hline Processo & $\mathrm{X}$ & $\mathrm{X}$ & $\mathrm{X}$ & & $\mathrm{X}$ & & $\mathrm{X}$ & & & & & $\mathrm{X}$ & & \\
\hline Fatores de desempenho & & & & & & $\mathrm{X}$ & $\mathrm{X}$ & $X$ & $\mathrm{X}$ & & & $\mathrm{X}$ & & \\
\hline Informação & $\mathrm{X}$ & $\mathrm{X}$ & $\mathrm{X}$ & & $\mathrm{X}$ & & $\mathrm{X}$ & $\mathrm{X}$ & $\mathrm{X}$ & & & $\mathrm{X}$ & & $\mathrm{X}$ \\
\hline Organização & & $\mathrm{X}$ & & & $\mathrm{X}$ & & $\mathrm{X}$ & $\mathrm{X}$ & $\mathrm{X}$ & $\mathrm{X}$ & $\mathrm{X}$ & $\mathrm{X}$ & & $\mathrm{X}$ \\
\hline $\begin{array}{l}\text { Papéis } \\
\text { P̧a }\end{array}$ & & $\mathrm{X}$ & & & & & $\mathrm{X}$ & & $\mathrm{X}$ & & & $\mathrm{X}$ & & \\
\hline Competências & & & & & & & $X$ & & & & & & & \\
\hline Recursos & $\mathrm{X}$ & $\mathrm{X}$ & & & & $X$ & $X$ & $X$ & & & $\mathrm{X}$ & & & $\mathrm{X}$ \\
\hline Tecnologia & & & & & & & $X$ & $X$ & $\mathrm{X}$ & & & $\mathrm{X}$ & & $\mathrm{X}$ \\
\hline Tempo & & & & $\mathrm{X}$ & & $\mathrm{X}$ & & & $\mathrm{X}$ & & & & & \\
\hline Custo & & & & & & $X$ & $\mathrm{X}$ & & $\mathrm{X}$ & & & & & $\mathrm{X}$ \\
\hline
\end{tabular}

- $\quad$ saídas: resultados de uma atividade têm características similares às entradas.

- $\quad$ eventos/mensagens: significa o status de um processo demonstrando a conclusão de uma atividade e o estado de prontidão para o início de uma outra.

- decisões: lógica de resolução de pendências apresentadas pelas atividades ao longo do processo.

- $\quad$ processo: visão integradora das demais que sumariza o contexto das atividades. 
- fatores de desempenho: indicadores construídos com base nos objetivos de desempenho para que sejam tomadas decisões acerca do processo e suas atividades.

- $\quad$ informação: dados utilizados e gerados pelo processo e suas atividades.

- $\quad$ organização: unidade organizacional na qual as atividades são realizadas.

- papéis: responsabilidades de uma unidade organizacional que é diferenciada em termos de sua competência para a realização de uma atividade.

- competências: habilidades necessárias à unidade organizacional para que sejam realizadas atividades de desenvolvimento e perfil do pessoal que participa do processo.

- $\quad$ recursos: equipamento e dispositivos em geral utilizados em uma atividade.

- $\quad$ tecnologia: software e infra-estrutura de comunicação da empresa.

- $\quad$ tempo: padrão temporal que caracteriza o processo e suas atividades.

- $\quad$ custo: padrão de custo que caracteriza o processo e suas atividades.

Os tipos de conteúdo necessários em um determinado modelo são dependentes do objetivo do modelo, assim como, variam em função do método de modelagem a ser utilizado. No tópico seguinte serão apresentados os tipos de conteúdo existentes nos modelos de PDP estudados nesse trabalho.

\subsection{Tipos de conteúdo identificados na bibliografia de PDP e mecatrônica}

A Tabela 2 apresenta o resumo dos tipos de conteúdo que foram encontrados nos modelos de referência analisados no APÊNDICE C.

Para consolidar os dados levantados, através da análise de conteúdo da bibliografia pesquisada, optou-se por realizar uma análise comparativa dos modelos discutidos. Para isso, 
foi utilizado o artifício de adotar um autor de PDP como referência básica e complementar essa referência com um dos títulos de mecatrônica analisados. Cada tipo de conteúdo em cada um dos outros autores foi comparado com a referência e o resultado dessa comparação foi inserido nas respectivas células da Tabela 2 .

As referências adotadas foram a teoria do projeto para seis sigma - DFSS (CREVELING et al., 2003), por ser uma teoria recente e que utiliza a sistematização de melhores práticas como metodologia de proposição das tarefas necessárias ao PDP; e a publicação de BRADLEY et al. (2000) por ser o livro de mecatrônica mais recente analisado neste trabalho.

Escolhidas as referências, o preenchimento da tabela foi realizado mediante a seguinte metodologia:

- $\quad$ os tipos de conteúdo modelados pela referência foram assinalados com o símbolo (r);

- $\quad$ cada autor, seqüencialmente, e da esquerda para a direita, teve a descrição de cada tipo de conteúdo comparada com a referência;

- $\quad$ em cada célula da tabela, o conteúdo vazio (ou seja, sem qualquer indicação na célula respectiva) significa que o tipo de conteúdo não foi modelado pelo autor identificado na coluna respectiva;

- $\quad$ se o autor modela o tipo de conteúdo comparado de maneira mais detalhada que a referência, na respectiva célula foi introduzido o símbolo $(+)$. Se o tipo de conteúdo é modelado, porém de maneira menos detalhada que a referência, foi introduzido o símbolo (-). No caso de a referência não modelar o tipo de conteúdo discutido pelo autor analisado, o símbolo (+) é introduzido e esse autor passa a ser a referência para a análise dos demais no tipo de conteúdo considerado; 
- $\quad$ o símbolo (+-) significa que o tipo de conteúdo no autor considerado é mais detalhado que na referência, porém, menos detalhado que um outro autor/norma analisado;

- o símbolo (-+) significa que o detalhamento é menor, porém há discussões que agregam à análise realizada pela referência sobre o tipo de conteúdo.

A bibliografia de PDP e de mecatrônica utilizada na análise permitiu constatar a necessidade de integrar à lista de tipos de conteúdo identificados na Tabela 1 outros elementos, com os quais esses autores apresentam importantes conceitos e práticas do desenvolvimento de produtos. Esses elementos e sua aplicação para a gestão do PDP estão listados abaixo:

- $\quad$ conhecimento: tipo de conhecimento gerado ao longo dos projetos;

- métodos: descrição de conjuntos estruturados de passos, formulários e metodologias de análise normalmente relacionadas com alguma "saída" ou "decisão" do PDP;

- $\quad$ áreas de processo: aglomerado de melhores práticas relacionadas com uma área que acontecem nas diversas fases do PDP (ver definição completa no item 2.4.2);

- $\quad$ princípios de projeto: regras de projeto aplicáveis a determinados campos da engenharia;

- tecnologias de projeto: princípios físicos e dispositivos utilizados nos projetos; e

- $\quad$ modelos: representações gráficas, virtuais ou físicas do produto em diferentes etapas de seu desenvolvimento. 
Tabela 2 - Tipos de conteúdo modelados por autores de PDP e mecatrônica ${ }^{6}$

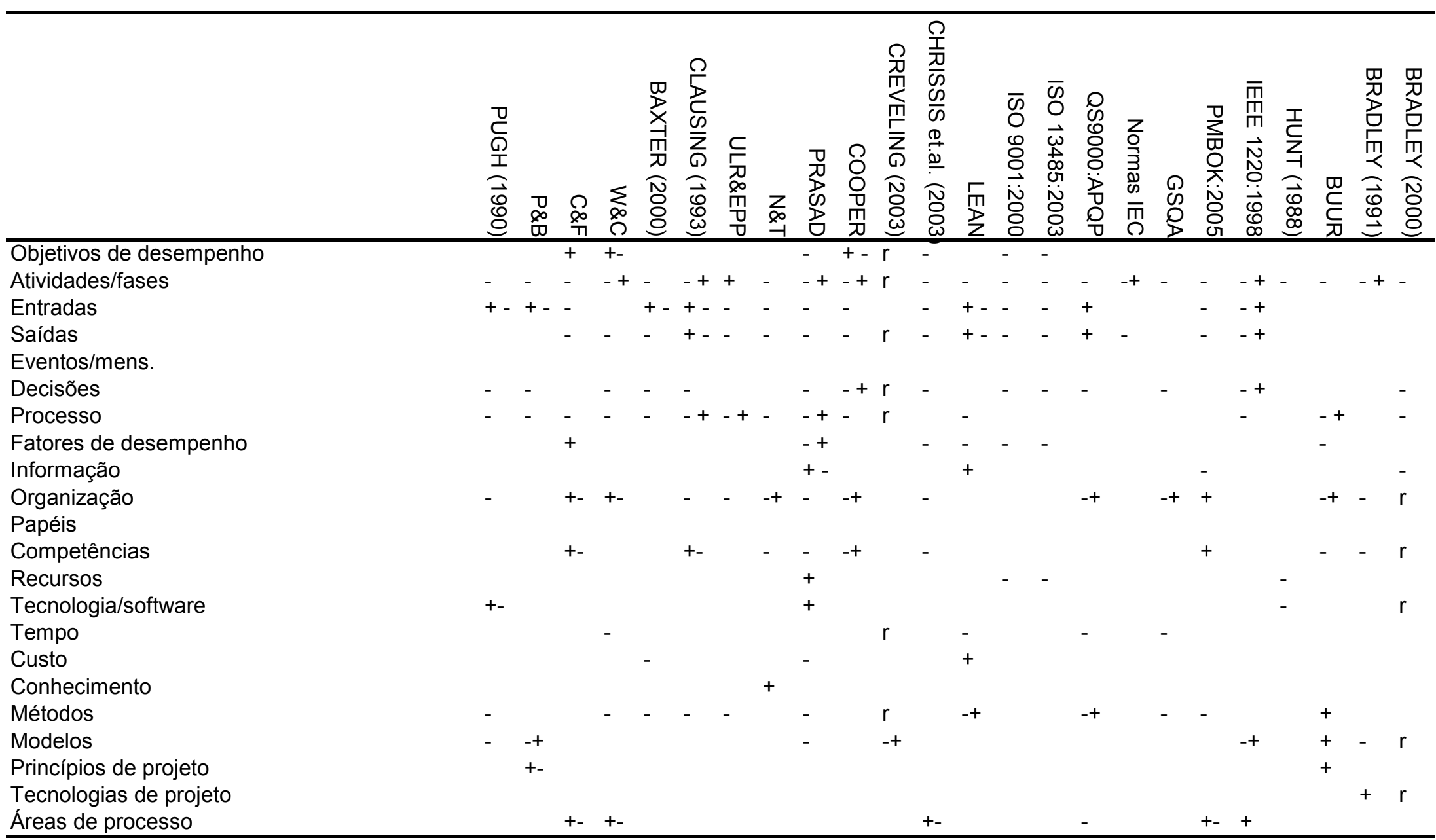

${ }^{6}$ P\&B - Pahl e Beitz (1996); C\&F - Clark e Fujimoto (1991); W\&C - Wheelwright e Clark (1992); ULR\&EPP - Ulrich e Eppinger (1995); N\&T - Nonaka e Takeuschi (1997); LEAN McManun (2003) e Douglas (2002); PRASAD - PRASAD (1996) e PRASAD (1997); Normas IEC - IEC 60601-1, IEC $60601-1-2$ e IEC 60825. 


\subsection{Tipos de conteúdo a serem modelados}

Uma vez que a lista de tipos de conteúdo identificadas na pesquisa documental somou 22 (vinte e dois) tipos de conteúdo (ou facetas) a serem modelados, verificou-se a impossibilidade de elaborar um modelo que contemplasse todas. Foi necessário realizar um recorte nos tipos de conteúdo de maneira a viabilizar o projeto para o período relativo a um doutoramento. Esse trabalho é descrito neste item.

O MRM deve aglutinar contribuições de autores de PDP e mecatrônica de forma consistente e aplicável.

A aplicabilidade do modelo pode ser abstraída de seu vínculo com referências normativas utilizadas há décadas em indústrias cujos produtos utilizam a mecatrônica, tais como a APQP, na indústria automotiva e a GSQA, na indústria de eletro-domésticos de linha branca. Entende-se que realizando esse vínculo, estar-se-á utilizando um formato de modelo cuja aplicação já ocorre, e portanto, sua aplicabilidade estaria garantida. A Figura 32(a) apresenta os tipos de conteúdo presentes nessas duas referências normativas.

Adicionalmente, o MRM deve contemplar facetas descritas pelos autores de mecatrônicas. Essas facetas estão focalizadas na Figura 32(b).

Dentre os tipos de conteúdo identificados na Figura 32(a) apenas "métodos" seria dispensável ao MRM, uma vez que nele é utilizado o conceito definido em BUUR (ver APÊNDICE C), o qual torna redundante a utilização de métodos se a estrutura de atividades estiver bem detalhada, ou seja, o detalhamento das atividades estabelece o método de trabalho para um determinado resultado pretendido. Em (b) apenas os tipos "modelos", "princípios de projeto" e "tecnologias de projeto" podem ser considerados fortemente vinculados à mecatrônica. Os demais são conteúdos genericamente encontrados nos autores de PDP, conforme pode ser visto na Tabela 2. Além disso, o item "tecnologias de projeto" é muito 
dependente do desenvolvimento tecnológico em um dado momento, o que fragiliza a idéia de que a ferramenta aqui desenvolvida possa ser usada como referência. Essa mesma restrição impacta o tipo "princípios de projeto". Adicionalmente, considera-se que o elemento "organização" é muito amplo e caberia em um trabalho de doutoramento específico para propor uma estrutura organizacional de referência para empresas mecatrônicas.

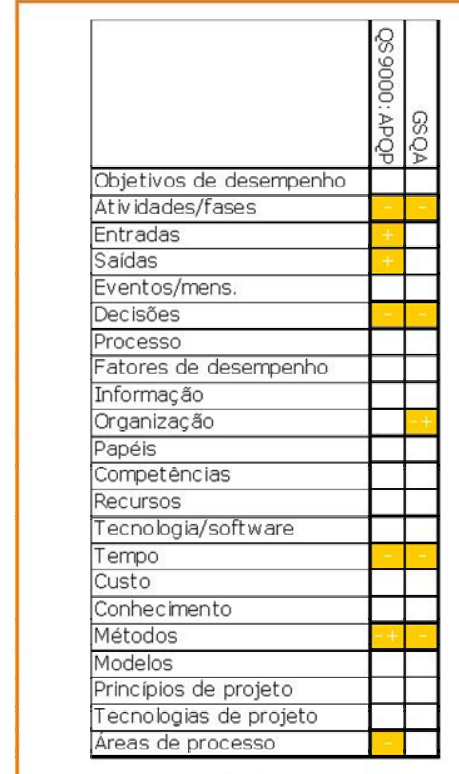

(a)

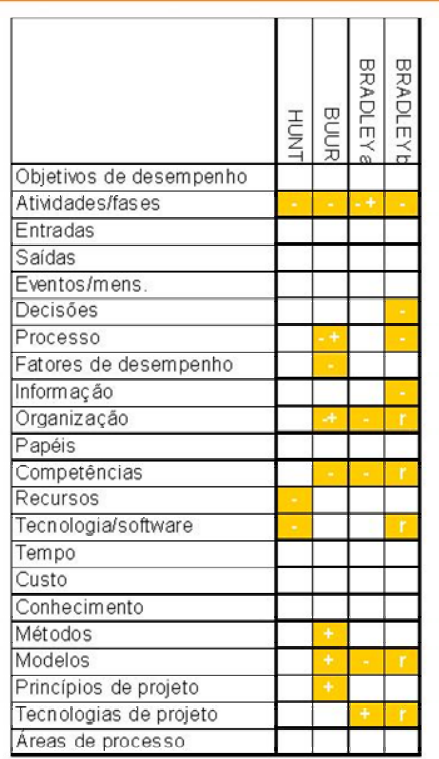

(b)

Figura 32 - Tipos de conteúdo modelados nas normas QS-9000: APQP e GSQA (a) e nos autores de mecatrônica (b)

Sendo assim, os tipos de conteúdo escolhidos para compor a versão definitiva do MRM são: (1) atividades/fases; (2) entradas; (3) saídas; (4) decisões; (5) modelos; e (6) áreas de processo, cujas definições estão elencadas nos itens 4.1 e 4.2.

\subsection{Método de modelagem e forma de representação}

Nesse tópico é discutido primeiramente o método de modelagem utilizado para confeccionar o MRM (item 4.4.1). Em seguida são apresentados os construtos utilizados para representar os tipos de conteúdo modelados (item 4.4.2). 


\subsubsection{Método de modelagem}

A Figura 33 apresenta o método de modelagem utilizado para o desenvolvimento dos conteúdos de cada faceta do MRM. No centro são ilustrados os "passos" de modelagem. O tracejado no interior da coluna "passos" apresenta os diferentes modelos confeccionados para representar o PDP mecatrônico. À esquerda são identificados os "tipos de conteúdo" desenvolvidos em cada passo do processo de modelagem. À direita, estão as técnicas de modelagem - conforme a classificação apresentada no item 2.4.3 - utilizadas para representar cada modelo e os objetivos de cada um deles.

O modelo lógico confeccionado consiste em um modelo entidade-relacionamento (MER - ver item 2.4.3 e APÊNDICE D) no qual os tipos de conteúdo identificados como necessários ao modelo mecatrônico estão inter-relacionados. Esse modelo é apresentado no tópico 5.1 e determina o relacionamento entre os conteúdos a serem representados nos modelos seguintes.

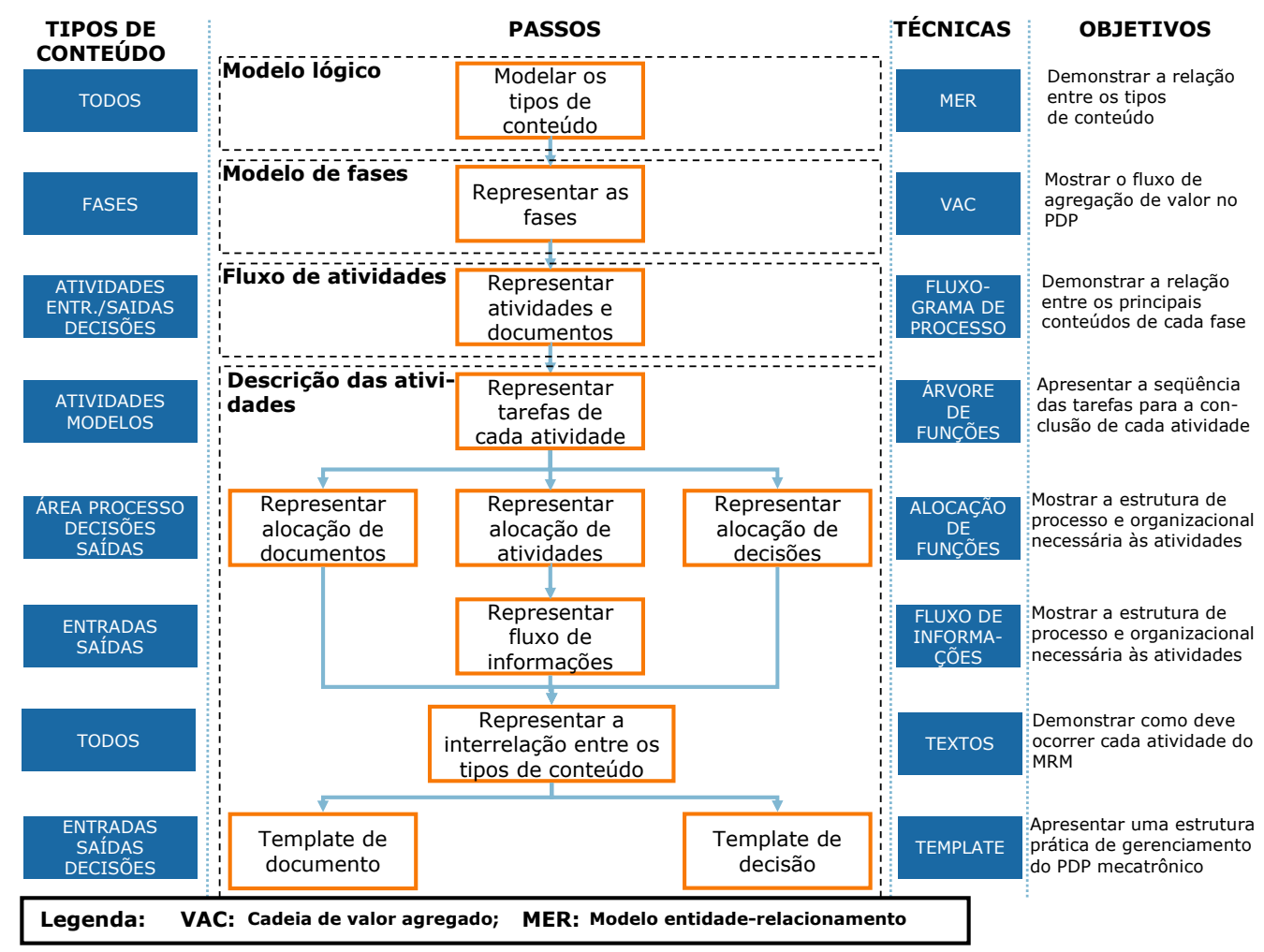

Figura 33 - Passos para a confecção do MRM 
O "modelo de fases" consiste em uma cadeia de agregação de valor (value added chain - VAC) que é um formato de modelagem previsto no ARIS (ver APÊNDICE D) e está descrito no tópico 5.2. Nesse modelo as fases do MRM são apresentadas seqüencialmente e sem uma explicação mais detalhada acerca de seu conteúdo. O detalhamento das fases é descrito através de "fluxos de atividades" que consistem em fluxogramas processo (item 2.4.3 e APÊNDICE D) nos quais são apresentadas as atividades necessárias para que haja agregação de valor em cada fase, assim como suas entradas, saídas e decisões. Esses fluxogramas são apresentados nos itens 5.3.1.1 até 5.3.1.12.

A “descrição das atividades" é um conjunto de modelos cujo objetivo é detalhar a realização de cada atividade. Utiliza-se árvores de função, também um tipo de modelo do ARIS (APÊNDICE D), com o objetivo de descrever as tarefas que compõem cada atividade dos "fluxos de atividades" de cada fase. As tarefas são descritas na forma de texto e a elas são relacionados eventuais modelos de produto. $\mathrm{Na}$ "descrição das fases" constam “representações de alocação"que implementam a técnica de alocação de funções (também do ARIS - APÊNDICE D). As representações de alocação apresentam, de forma sucinta, o conteúdo de todas as "facetas" presentes nas atividades, documentos e decisões apresentadas nos "fluxos de atividades".

A Figura 34 apresenta um exemplo de árvore de função para a atividade "modelar e sistematizar a concepção" que faz parte da fase de concepção do produto, conforme apresentado na Figura 54. É importante observar que no MRM as funções são as tarefas que compõem cada atividade. 


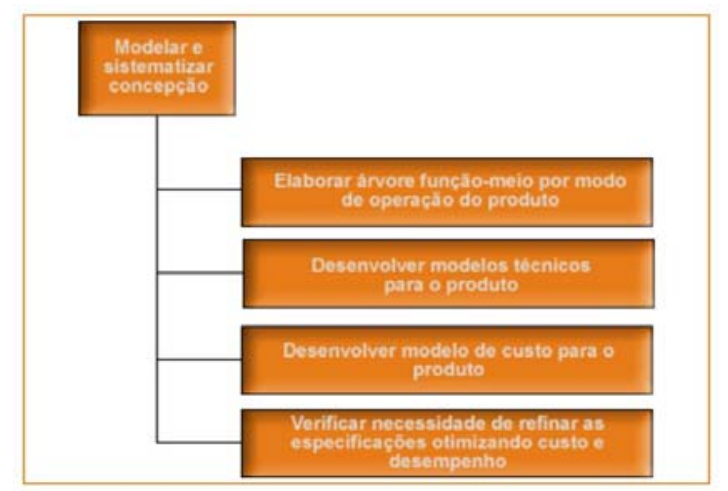

Figura 34 - Árvore de função para a atividade "modelar e sistematizar a concepção"

Os "fluxos de informação" representam as relações estabelecidas entre as entradas e saídas de cada atividade do MRM. Eles são implementados através de uma adaptação da técnica de DFD (item 2.4.3 e APÊNDICE D) na qual não são modelados os repositórios de dados, mas apenas as atividades e informações. A Figura 35 apresenta o fluxo de informações da atividade "modelar e sistematizar a concepção".

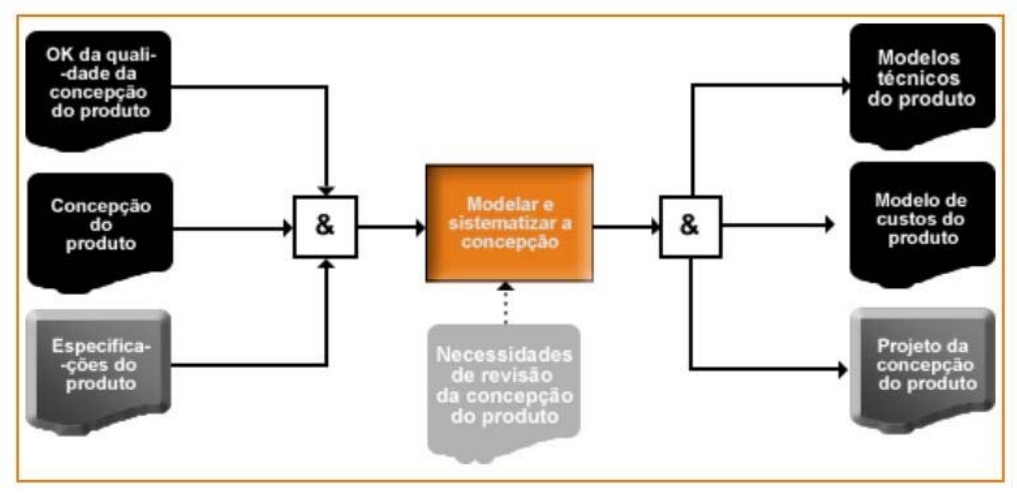

Figura 35 - Fluxo de informações da atividade "modelar e sistematizar a concepção"

As informações que compõem as entradas e saídas do modelo são detalhadas em templates de documentos e, similarmente, as decisões representadas na "alocação de decisões" são detalhadas em templates de decisão que implementam checklists e scorecards para cada fase do MRM. As templates são o nível de maior detalhe na representação do PDP mecatrônico. 
A Figura 36 apresenta uma template de documento para a saída "especificações do produto" e a Figura 37 apresenta um exemplo de uso dessa template para um equipamento de fotografia da retina. As templates e exemplos de decisão têm formato similar. Todas as templates e exemplos constam no APÊNDICE A do trabalho, tendo sido desenvolvidas apenas aquelas que foram efetivamente utilizadas para a validação do modelo no caso descrito no capítulo 6.

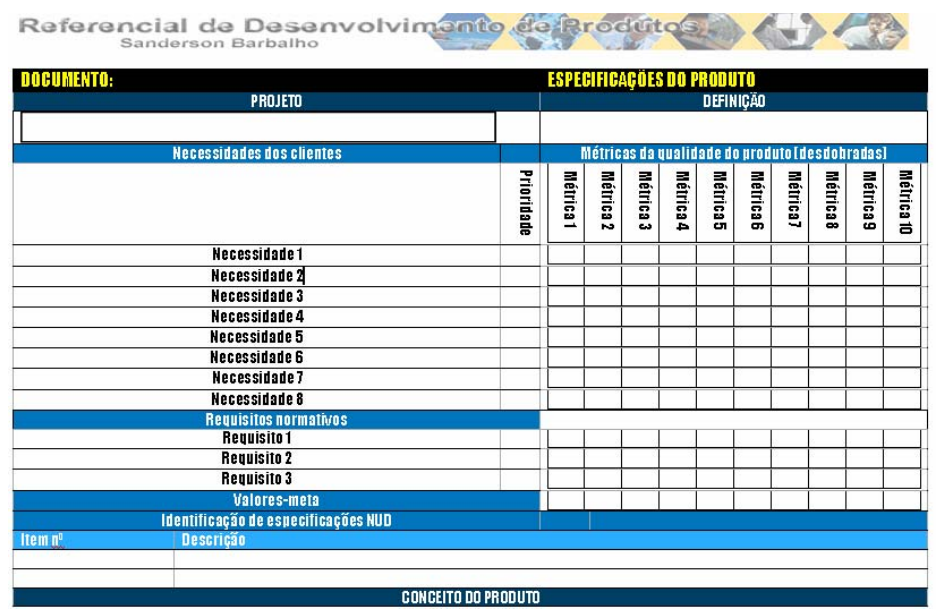

Figura 36 - Template do documento "especificações do produto": modelo sugerido.

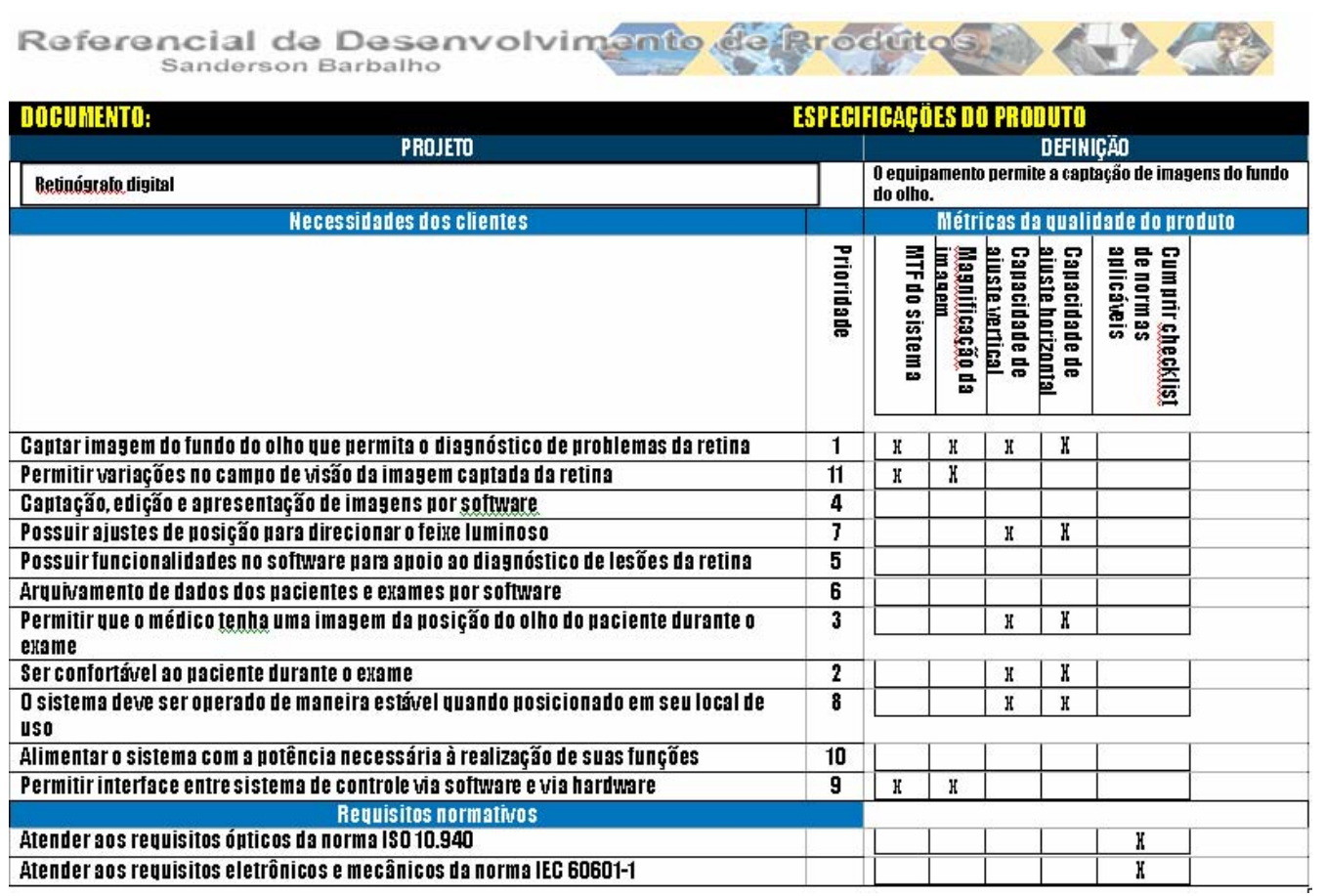

Figura 37 - Exemplo do documento "especificações do produto": aplicação para um retinógrafo digital. 


\subsubsection{Construtos utilizados no modelo}

A Figura 38 apresenta a forma de representação do modelo mecatrônico.

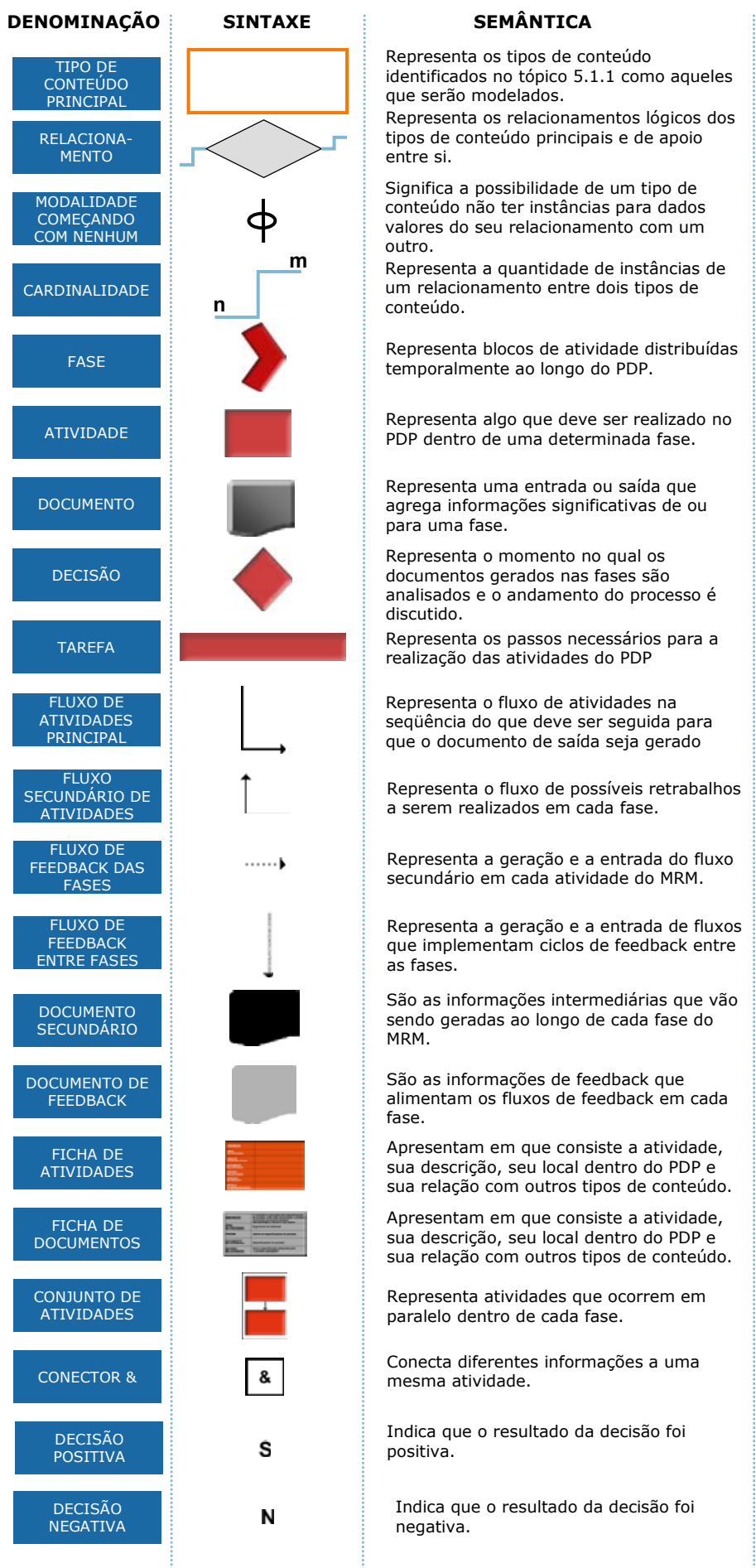

ONDE É USADO

Modelo lógico

Modelo lógico

Modelo lógico

Modelo lógico

Modelo de fases

Fluxo de atividades/ Descrição das atividades

Fluxo de atividades/ Descrição das atividades

Fluxo de atividades/

Descrição das atividades

Fluxo de atividades

Descrição das atividades

Fluxo de atividades

Descrição das atividades

Fluxo de atividades

Descrição de atividades

Fluxo de atividades

Fluxo de atividades/ Descrição das atividades

Descrição de atividades

Descrição de atividades

Descrição de atividades

Fluxo de atividades

Fluxo de atividades/ Descrição das atividades

Fluxo de atividades

Fluxo de atividades

Figura 38 - Forma de representação do MRM 
A forma de representação apresentada na Figura 38 se baseia na identificação dos construtos de modelagem, ou seja, a forma de representar o processo modelado. Essa forma de representação contém uma semântica e uma sintaxe (VERNADAT, 1996). A sintaxe seria a forma gráfica de apresentação do construto e a semântica seria o significado dessa forma gráfica. Na referida figura, à esquerda é apresentada a denominação do construto utilizado, à direita é indicado onde ele é usado e nas duas colunas centrais são apresentados sua sintaxe e semântica.

As entradas e saídas do MRM são modeladas através do construto “documento" e as alocações de entradas e saídas são realizadas através de "fichas de documentos". Similarmente, alocações de atividades e decisões são realizadas através das "fichas de atividade". A Figura 39 apresenta em (a) a ficha da atividade "modelar e sistematizar a concepção", enquanto em (b) ela mostra a ficha do documento "projeto da concepção do produto", o qual é a saída da atividade ilustrada nas figuras Figura 34 e Figura 35.

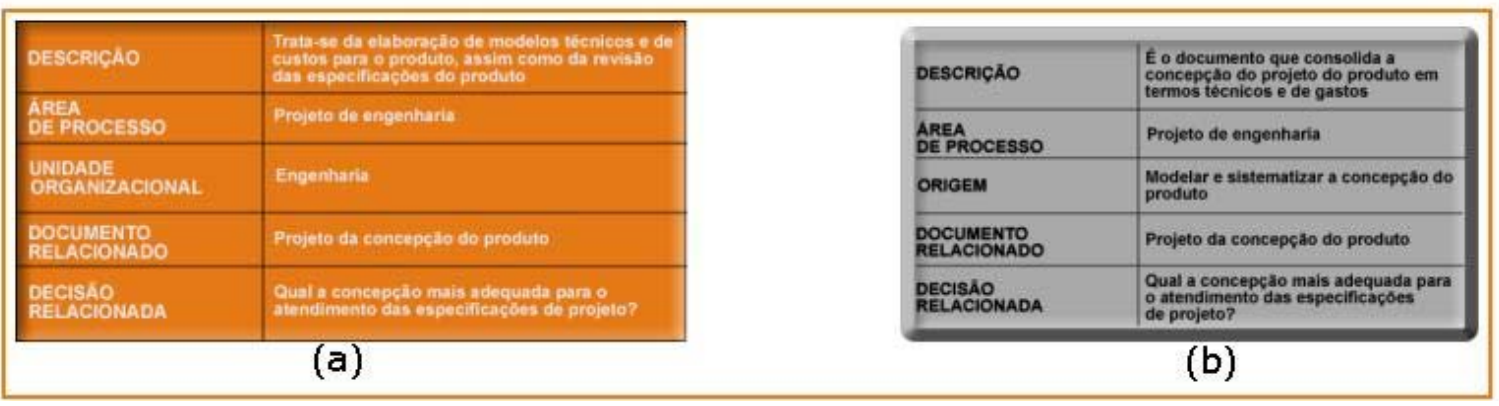

Figura 39 - Fichas de atividade (a) e documento (b) de "modelar e sistematizar a concepção" e de "projeto da concepção do produto", respectivamente.

Os demais construtos identificados na Figura 38 estão exemplificados ao longo do capítulo seguinte, uma vez que o "modelo lógico", o "modelo de fases" e o "fluxo de atividades" são descritos respectivamente nos tópicos 5.1, 5.2 e 5.3. A íntegra da "descrição das atividades" é apresentada no próprio MRM (APÊNDICE A). 


\section{MODELO DE REFERÊNCIA MECATRÔNICO}

Nesse capítulo é apresentado o modelo de referência mecatrônico (MRM).

\subsection{Modelo lógico do MRM}

A Figura 40 apresenta o modelo lógico do MRM. Nele constam os tipos de conteúdo modelados e seu inter-relacionamento.

O processo de desenvolvimento de produtos é composto por "fases" e "áreas de processo", o que é representado na Figura 40 utilizando um relacionamento "parte de" (ver APÊNDICE D). Ambos estão relacionados com "atividade", porém de forma diferente: nas “fases" ocorrem diversas "atividades" que têm relação com apenas uma "fase"; já as "áreas de processo" agregam diversas "atividades" que por sua parte podem ter relação com mais de uma "área de processo".

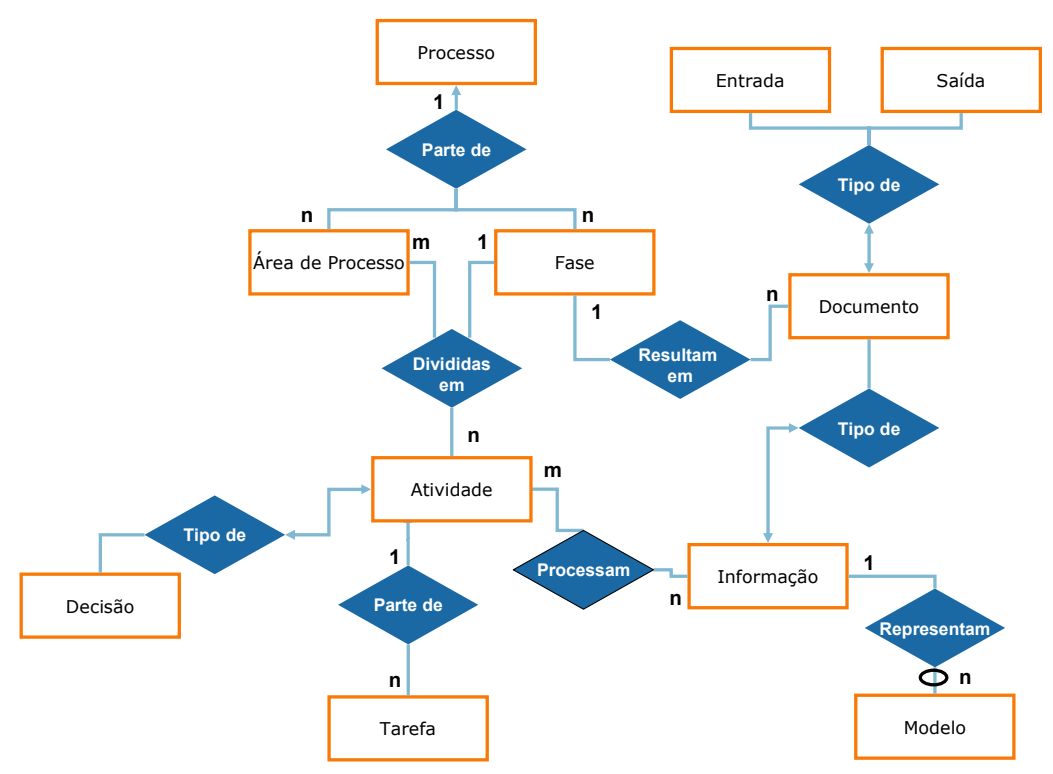

Figura 40 - Modelo lógico da versão final do MRM

Das "fases" resultam "documentos" que podem ser "entradas" ou "saídas". Os "documentos" são um tipo de "informação". As "informações" são processadas nas "atividades" e podem ser representadas através de "modelos" que são as templates do MRM. 
"Atividade" é o principal tipo de conteúdo do MRM, uma vez que ela centraliza os relacionamentos entre as demais facetas do modelo. "Atividades" são compostas por “tarefas". As “decisões" são tipos de "atividade".

No relacionamento entre "informações" e "modelos" consta o construto de "modalidade começando com nenhum", o que significa que apenas algumas "informações" são representadas através de "modelos" (templates).

As "áreas de processo" são, também, agrupamentos de "atividades" necessárias ao PDP. Elas são uma outra forma de visualizar as "atividades" do processo de desenvolvimento. Enquanto as "fases" denotam um caráter temporal de agregação de valor às "entradas", as “áreas de processo" têm relação com os aspectos que, independentemente das "fases", precisam ser gerenciados de maneira que o processo projetado seja capaz, ie. satisfaça a qualidade do produto e do serviço e os objetivos de desempenho do processo (ver também definição de capabilidade de áreas de processo no item 2.4.2).

Caso as "n" "áreas de processo" do PDP sejam abordadas em conjunto, o "processo" como um todo pode ser considerado "mais maduro". O conceito de capabilidade, entretanto, permite que apenas as atividades de uma determinada área sejam objeto de ações de melhoria. Essa discussão será retomada no item 5.4.

\subsection{Modelo de fases do MRM}

A Figura 41 mostra a seqüência das fases do MRM, a qual é baseada na técnica de cadeia de agregação de valor, conforme descrito na Figura 33 e utiliza o construto "fase" (ver Figura 38). 


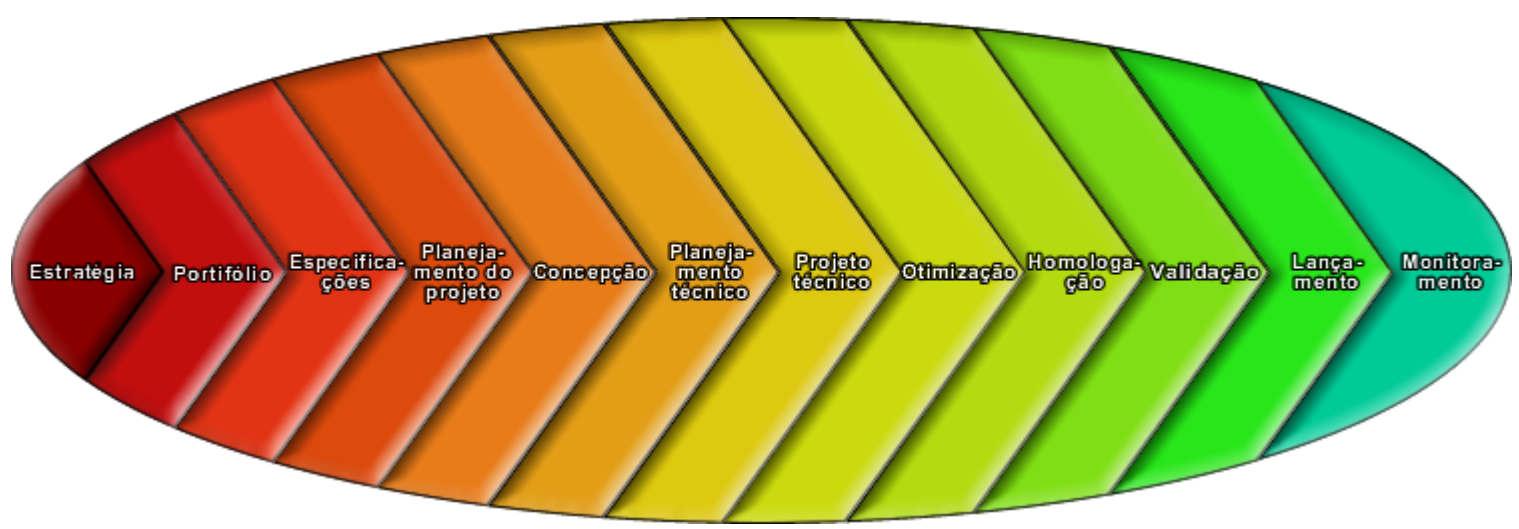

Figura 41 - Fases do MRM

As fases do MRM são definidas em função dos resultados (documentos - ver Figura 40) que geram, conforme a definição de "informações de valor" discutida no item 2.2.2:

- $\quad$ estratégia: definição dos objetivos estratégicos a serem perseguidos em cada linha de produtos (LDP);

- $\quad$ portifólio: definição do portifólio de cada LDP;

- $\quad$ especificações: definição das especificações de cada produto;

- $\quad$ planejamento do projeto: definição do plano de projeto;

- $\quad$ concepção: definição dos principais componentes e princípios de solução para as funções principais do produto mecatrônico;

- $\quad$ planejamento técnico: detalhamento do plano de projeto com base na concepção definida;

- $\quad$ projeto técnico: soluções técnicas para as funções principais do produto;

- $\quad$ otimização: detalhamento e teste de soluções para funções secundárias do produto e realização de análises necessárias ao aumento da robustez e confiabilidade do produto; 
- homologação: homologação do processo de fabricação e montagem do produto;

- Validação: validação e certificação do produto;

- $\quad$ lançamento: lançamento do produto no mercado;

- monitoramento: acompanhamento dos resultados conseguidos com o produto e gerenciamento das modificações realizadas na configuração inicial de produção.

O conteúdo dessas fases será apresentado com mais detalhe no tópico 5.3 e é extensivamente discutido no APÊNDICE A.

A utilização do construto "fase" (ver Figura 33) mediante a técnica de modelagem denominada "cadeia de valor agregado (value added chain - VAC) (ver Figura 38) têm duas funções básicas. A primeira é passar a idéia de que, embora as fases contenham diversas atividades que são desdobradas em um grande número de tarefas a serem realizadas, há um conjunto pequeno de atividades que podem ser consideradas como centrais ao desenvolvimento de produtos mecatrônicos. Essa idéia é baseada no conceito de cerne do projeto de PUGH (1990; ver 2.2.2). Sua introdução no MRM objetiva dar diretrizes para a implementação do modelo em empresas com reduzidos recursos disponíveis. Pode ser utilizado, também, para subsidiar projetos didáticos realizados em cursos de graduação e pós. A Figura 42 mostra o modelo de fases do MRM com ênfase na representação das atividades centrais do PDP mecatrônico. Pode-se observar que entre o intervalo $T_{0}$ e $T_{1}$ um reduzido conjunto de atividades das fases de "planejamento técnico" e de "projeto técnico" são centrais ao PDP mecatrônico, o que é representado pela área que representa a intersecção entre as duas barras horizontais do centro da figura e as barras verticais determinadas pelos tempos $T_{0}$ e $T_{1}$.

O segundo objetivo relacionado com o uso do "VAC", na estrutura de fases do modelo mecatrônico, é a capacidade de demonstrar possíveis paralelismos entre atividades de fases 
distintas. Essa capacidade é ilustrada na Figura 42. Entre os tempos $T_{0}$ e $T_{1}$ de um determinado projeto, a área identificada por " $\mathrm{A}$ " representa as atividades da fase de "planejamento técnico", "B" e "C" as atividades de "projeto técnico" e "D" e "E" as atividades de "otimização" que podem acontecer em paralelo. Essa possibilidade de paralelismo deve ser analisada, caso a caso, de maneira a não implicar em falta de recursos para a conclusão das atividades centrais que estejam dentro dos limites temporais identificados. No exemplo apresentado, a maior parte das atividades centrais está na fase de planejamento técnico.

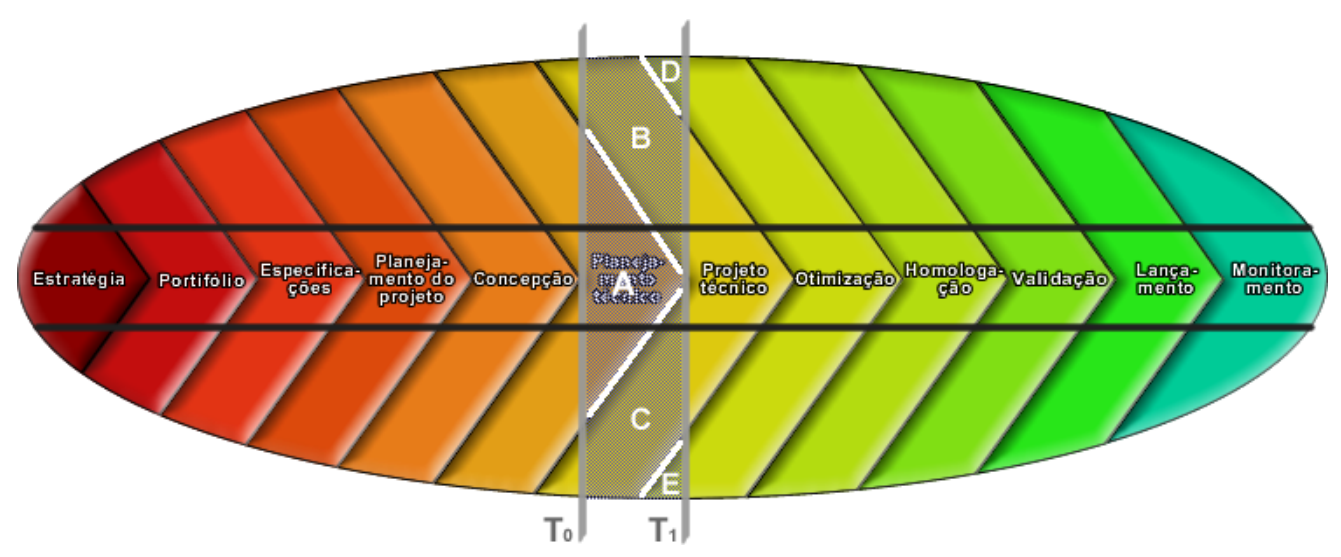

Figura 42 - Atividades centrais e paralelismo entre fases do MRM

O formato elíptico utilizado na figura representativa do "modelo de fases" tem como objetivo introduzir a idéia de que as fases intermediárias do PDP consomem a maior parte do esforço relacionado com o desenvolvimento de um novo produto. Ou seja, nas fases centrais da Figura 41 o trabalho necessário ao projeto se avoluma em tarefas de engenharia, marketing, manufatura, finanças, recursos humanos, provisão de infra-estrutura etc. cujo escopo técnico e o esforço que a empresa deve depreender são bem maiores que nas fases extremas.

No tópico seguinte será apresentada a integração do tipo de conteúdo "decisões" ao modelo de fases do MRM. 


\subsubsection{Decisões do MRM}

A estrutura de decisões do MRM é ilustrada na Figura 43. Elas coincidem com o final de cada fase e na figura estão representados os diferentes tipos de decisão tomados ao longo do PDP. Nas fases de estratégia e de portifólio as decisões não versam sobre um determinado produto, mas sobre o conjunto dos produtos da empresa (estratégia) ou de uma linha de produtos (portifólio) e tem por propósito gerar critérios a serem seguidos nos gates subseqüentes.

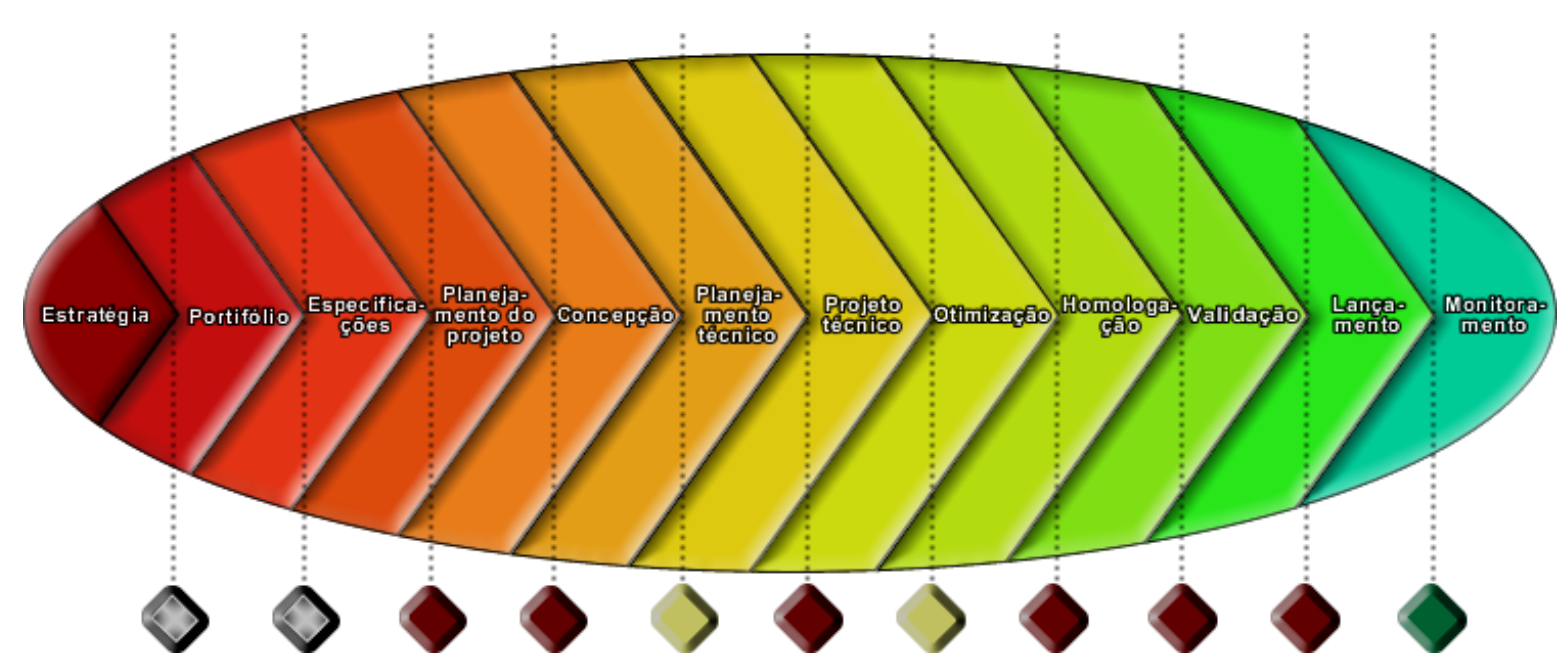

Figura 43 - Estrutura de decisões do PDP

$\mathrm{Na}$ fase de especificações é realizada uma decisão do tipo go/kill cujo teor é vinculado com a viabilidade econômica do desenvolvimento de soluções para as especificações de projeto considerando as restrições tecnológicas e o grau de conhecimento da empresa com relação às tecnologias de produto e processo necessárias ao esforço de desenvolvimento. $\mathrm{Na}$ fase de planejamento do projeto, a decisão go/kill tem relação com a viabilidade dos prazos estimados para ele e os custos dele decorrentes, assim como, as subcontratações necessárias, informações essas que são consolidadas em uma análise dos riscos do projeto. Os gates go/kill são realizados através da submissão dos resultados destas fases à alta direção.

Na fase de concepção, o gate é técnico. Trata-se de uma análise da possibilidade técnica de que as soluções propostas pelos engenheiros envolvidos no projeto utilizem 
tecnologias maduras na empresa, sejam manufaturáveis e atendam de fato às especificações do produto. O gate técnico, diferentemente do go/kill, consiste na realização de revisão de pares (peer reviews). A fase de planejamento técnico comporta um gate go/kill uma vez que nela a concepção selecionada é utilizada para elaborar modelos funcionais e de arquitetura do produto. Esses modelos servem então para detalhar as atividades e os recursos necessários ao projeto. Assim é possível rever a análise de viabilidade de prazos, custos e subcontratações necessárias.

As fases de projeto técnico e de otimização têm uma única finalidade: detalhar as soluções técnicas do produto. Elas estão divididas em função da grande quantidade de atividades necessárias ao seu tratamento conjunto. Além disso, separá-las permite que o projeto de engenharia seja tratado de forma mais sistemática. Primeiramente, permite que as funções primárias sejam atacadas primeiro (fase de projeto) e as secundárias em seguida (fase de otimização), conforme sugere PAHL e BEITZ (1996) (ver APÊNDICE C). Adicionalmente, permite que as atividades de otimização sugeridas por CREVELING et al. (2003) sejam utilizadas para aumentar a robustez e a confiabilidade do produto. Essa complementaridade motivou a introdução de um gate técnico entre as duas fases. Nele, o projeto é avaliado quanto ao cumprimento das especificações do produto. Ao final da fase de otimização é realizado um gate go/kill cujo objetivo é verificar se o produto é atrativo para a empresa ou o projeto deve ser congelado.

Os gates das fases de homologação e validação consistem em atualização do plano de projeto do produto com revisão das metas de custo do projeto, de custo do produto e de previsões de venda. São gates do tipo go/kill realizados pela alta direção da empresa. O gate da fase de lançamento é, na verdade, uma consolidação do projeto em um relatório e uma lista de lições aprendidas que são apreciados pela gerência intermediária da empresa e patrocinadores do projeto. 


\subsection{2 Âmbito de aplicabilidade do MRM}

No item 2.2.1 foi mostrado que há diversas abordagens para entender o processo de desenvolvimento de produtos. Há abordagens que tratam apenas de parte de um deteminado produto (eletrônica, mecânica ou software), abordagens que tratam de uma determinada etapa do processo de desenvolvimento, como por exemplo o marketing, e há abordagens que tratam do conjunto das ações necessárias ao projeto e introdução de produtos no mercado. O conceito de âmbito tenta dar conta de entender essa diversidade de abordagens.

A Figura 44 representa a relação entre as fases do PDP mecatrônico e o âmbito de aplicabilidade do modelo. O MRM se insere no viés das teorias que integram os âmbitos do conjunto de produtos, do produto e dos subsistemas do produto. Na figura, ao invés de nomear as fases do MRM, utiliza-se sua ordem seqüencial numérica (F1 - fase 1, estratégia, até F12- fase 12, monitoramento) de maneira a dar ênfase à representação visual dos âmbitos ao longo das fases.

Nas fases F1 (estratégia) e F12 (monitoramento), os produtos de todas as linhas de produto da empresa são o foco das análises realizadas. Na F1 por objetivar o estabelecimento de diretrizes estratégicas para a empresa e isso implica em analisar todos os negócios da firma. Na F12 em função das normas de garantia da qualidade que preconizam que a empresa implemente ações de monitoramento e controle do produto e de suas alterações para que sejam garantidas as informações acerca do que está sendo consumido pelo cliente. Além disso, em F12 são levantadas grande parte das informações de mercado utilizadas nas fases F1 e F2 (portifólio) do MRM. 


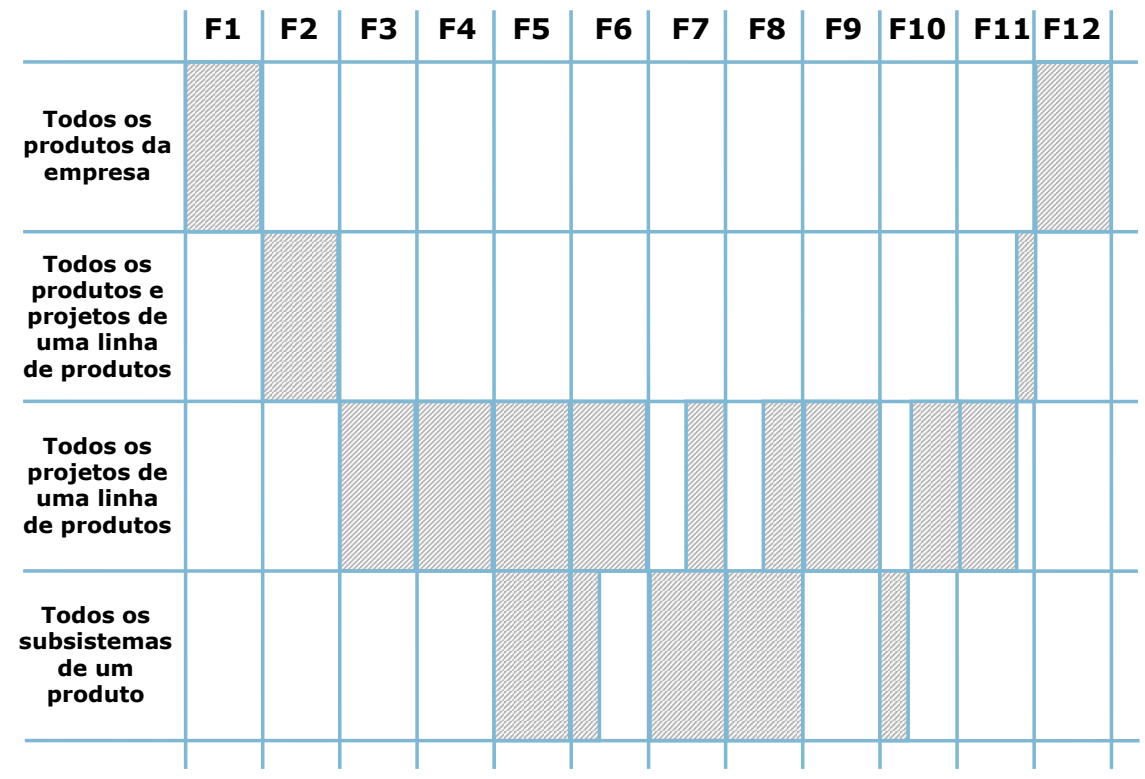

Figura 44 - Âmbito de aplicação do MRM

A fase F2 ocorre totalmente no âmbito da LDP uma vez que seu objetivo é planejar os projetos que movimentam o portifólio da empresa de maneira a adequá-lo aos objetivos estratégicos definidos na fase F1. Esse âmbito é retomado no final da fase F11 onde são tomadas decisões táticas sobre o lançamento do produto: data, aspectos de promoção, pontos de lançamento etc. (BENEDETTO, 1999).

Entre as fases F3 (especificações) e F11 (lançamento), as atividades acontecem no âmbito do projeto como um todo ou de partes do produto. Na fase F3, o produto deve ser considerado como um todo para que possam ser desenvolvidas as suas especificações. O mesmo ocorre na fase F4 (planejamento do projeto). Na fase F5 (concepção) podem ocorrer duas situações distintas: em projetos mais complexos tecnicamente as atividades acontecem em partes do produto (subsistemas), enquanto em projetos mais simples, ocorrem no âmbito do produto como um todo. Na fase F6 (planejamento técnico), as atividades devem ocorrem no âmbito de todos os projetos da linha de produtos, uma vez que nela são estabelecidas a estrutura de documentação necessária ao produto, assim como o detalhamento do cronograma de atividades e da WBS do projeto. Em projetos mais complexos, parte das atividades ocorrem no âmbito dos subsistemas. 
As fases F7 (projeto técnico) e F8 (otimização) podem ocorrer nos âmbitos do produto ou dos subsistemas em função da complexidade do projeto para a empresa. Na fase F9 (homologação) as atividades ocorrem no âmbito do produto como um todo, uma vez que o processo de manufatura e montagem deve ser consolidado e homologado para todas as etapas do fluxograma de produção do novo produto. Na fase F10 (validação), primeiramente acontecem atividades de âmbito de subsistema uma vez que há uma verificação do produto que deve ocorrer em níveis consecutivos de integração de suas partes e componentes. As atividades de validação e certificação, por sua parte, acontecem com o produto totalmente integrado.

A fase F11 acontece, primeiramente, no âmbito do produto já que há uma série de documentos que devem ser confeccionados e consolidados para que o produto possa ser colocado em linha de produção e venda. Após essas atividades, o pessoal de marketing têm o produto disponível para que seja definida sua forma de integração à LDP respectiva.

\subsubsection{Ciclo de gestão da estratégia e do portifólio de produtos}

A Figura 45 ilustra a execução do MRM quando se considera apenas uma das linhas de produto de uma determinada empresa.

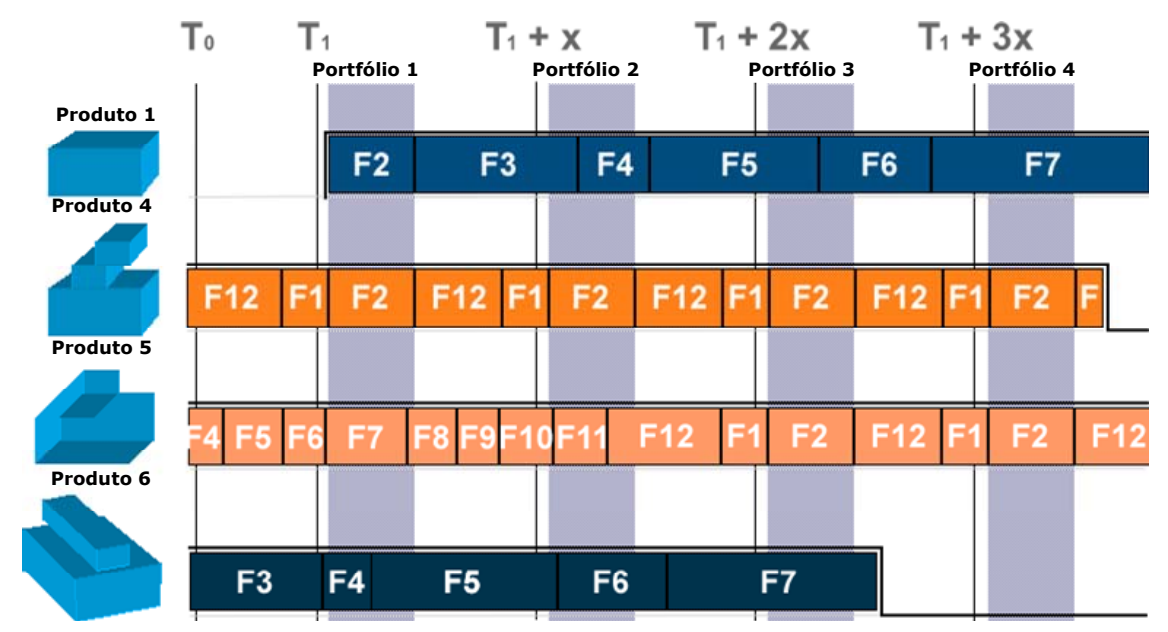

Figura 45 - Ciclo de gestão da estratégia e do portifólio em uma LDP 
No momento $\mathrm{T}_{0} \mathrm{o}$ único produto em processo de fabricação e vendas é o "produto 4". Nesse produto estão acontecendo apenas as fases F12, F1 e F2 nessa seqüência. Ou seja, o produto é monitorado e isso gera as informações necessárias à implementação das decisões relacionadas às fases de estratégia e de portifólio. Ainda no momento $\mathrm{T}_{0}$, observa-se que há dois produtos em desenvolvimento: "produto 5" e "produto 6".

$\mathrm{O}$ momento $\mathrm{T}_{1}$ delimita a primeira revisão da estratégia de produtos, na qual apenas o "produto 4" da LDP considerada é analisado. Mediante as decisões tomadas na fase de estratégia (F1), quando implementada a fase de portifólio (F2) para a LDP, o "produto 1" é introduzido no PDP da empresa. No momento em que o "produto 1" é introduzido na LDP os projetos em andamento nessa linha de produtos são o "produto 5" na fase 7 (F7) e o "produto 6" na fase $4(\mathrm{~F} 4)$.

A partir de $T_{1}$, a cada intervalo $\boldsymbol{x}$, há uma nova revisão da estratégia de produtos e do portifólio de produtos da empresa. A seqüência de fases $\underline{F 12, F 1 \text { e F2 }}$ é denominada nesse trabalho de "ciclo de gestão da estratégia e do portifólio", uma vez que decorre da lógica do próprio processo de desenvolvimento, no qual para planejar os movimentos competitivos de suas linhas de produto, a empresa deve monitorar o portifólio existente e tomar decisões com base nesse monitoramento. O ciclo é, por outro lado, determinado por: (1) o início da fase de monitoramento do primeiro produto de cada LDP; (2) o tempo $\mathrm{T}_{1}$ no qual a primeira revisão da estratégia de produtos ocorre; e (3) o período $\boldsymbol{x}$ estabelecido entre revisões de estratégia consecutivas.

Em cada LDP da empresa, o ciclo do PDP implica que os projetos de novos produtos em desenvolvimento devem gerar informações sincronizadas com a execução das fases de estratégia e de portifólio. Portanto, embora o "produto 5" esteja na fase F7 e o "produto 6" esteja na fase F4, ambos são considerados para que seja projetado o "Portifólio 1". As informações necessárias às tomadas de decisão de portifólio são gerada no gates (item 5.2.1). 
Dessa forma os produtos são integrados à gestão do PDP da companhia. Isso é demonstrado nas LDPs através das faixas verticais que delimitam as fases de portifólio. Esse conceito implementa as "revisões de portifólio" propostas por COOPER (1998) (ver APÊNDICE B).

Quando o produto desenvolvido é lançado no mercado, o processo de monitoramento e confecção de dados para a gestão do portifólio relacionados a esse produto deve ser adaptado aos ciclos $\underline{\boldsymbol{F 1 2 - \boldsymbol { F } 1 - \boldsymbol { F } 2}}$ pré-definidos para a LDP. Isso é exemplificado na Figura 45 pela diferença entre a primeira e a segunda fase F12 do "produto 5". O ajuste é realizado para que a revisão de portifólio (fase F2) dos produtos “4” e "5"coincidam. A implicação prática é que as fases de monitoramento dos produtos em linha acontecem em paralelo, ou seja, o projeto dos procedimentos de aquisição de informações de clientes e de compilação de dados de manufatura e montagem deve ter como um de seus requisitos os limites de tempo de monitoramento de produtos estabelecidos pelo ciclo $\underline{\boldsymbol{F 1 2 - F 1 - F 2}}$ da LDP.

O Quadro 3 apresenta o portifólio da LDP considerada na Figura 45. O quadro é confeccionado através da verificação dos produtos existentes nas faixas verticais apresentadas na Figura 45. Dois aspectos são importantes na análise possibilitada pelo quadro. Primeiramente o "produto 1" é apenas introduzido no portifólio da LDP após o momento T1 (Portifólio 1). Ao sê-lo, a fase inicial relacionada a esse produto é a F2, uma vez que a F1 não abrange o âmbito de aplicabilidade de todos os produtos e projetos de uma LDP (ver item 5.2.2)

Quadro 3 - Evolução do portifólio de uma LDP hipotética

\begin{tabular}{|c|c|c|c|c|c|}
\hline & Momento $T_{0}$ & Portifólio 1 & Portifólio 2 & Portifólio 3 & Portifólio 4 \\
\hline PRODUTOS & $\begin{array}{l}\text { "Produto 4"+ } 2 \\
\text { projetos }\end{array}$ & $\begin{array}{l}\text { "Produto } 4 "+2 \\
\text { projetos }+1 \text { idéia } \\
\text { considerada } \\
\text { viável }\end{array}$ & $\begin{array}{l}\text { "Produto 4"+ } 3 \\
\text { projetos }\end{array}$ & $\begin{array}{l}\text { "Produto 4" e } \\
\text { "Produto 5" + } 2 \\
\text { projetos }\end{array}$ & $\begin{array}{l}\text { "Produto 4" } \\
\text { "Produto } 5 "+1 \\
\text { projeto+ } 1 \text { projeto } \\
\text { congelado }\end{array}$ \\
\hline
\end{tabular}

Outro conceito importante pode ser abstraído da identificação do "Portifólio 4" no qual consta "1 projeto congelado", com referência ao "produto 6". Esse projeto não deixa de constar no portifólio da LDP, e portanto, seus status e potencial tecnológico e comercial 
devem ser mantidos sob monitoramento. Similarmente, no próximo congelamento de portifólio, o "produto 5" constaria como "1 produto descontinuado" para o qual a configuração técnica deveria ser mantida de maneira para dar suporte ao processo de assistência técnica e serviços.

\subsubsection{Ciclos e refinamentos técnicos no MRM}

A Figura 46 apresenta a aplicação do conceito de ciclos, conforme PRASAD (1996, item 2.2.2) no MRM. O conceito é complementado pelo de "refinamento" desenvolvido com base em ULRICH e EPPINGER (1995) - ver APÊNDICE C. Os ciclos são representados no MRM como fluxos secundários de fase e fluxo de feedback entre fases nos fluxogramas de atividades e fluxo de feedback de fases nas descrições de atividades (ver figuras Figura 33 e Figura 38).

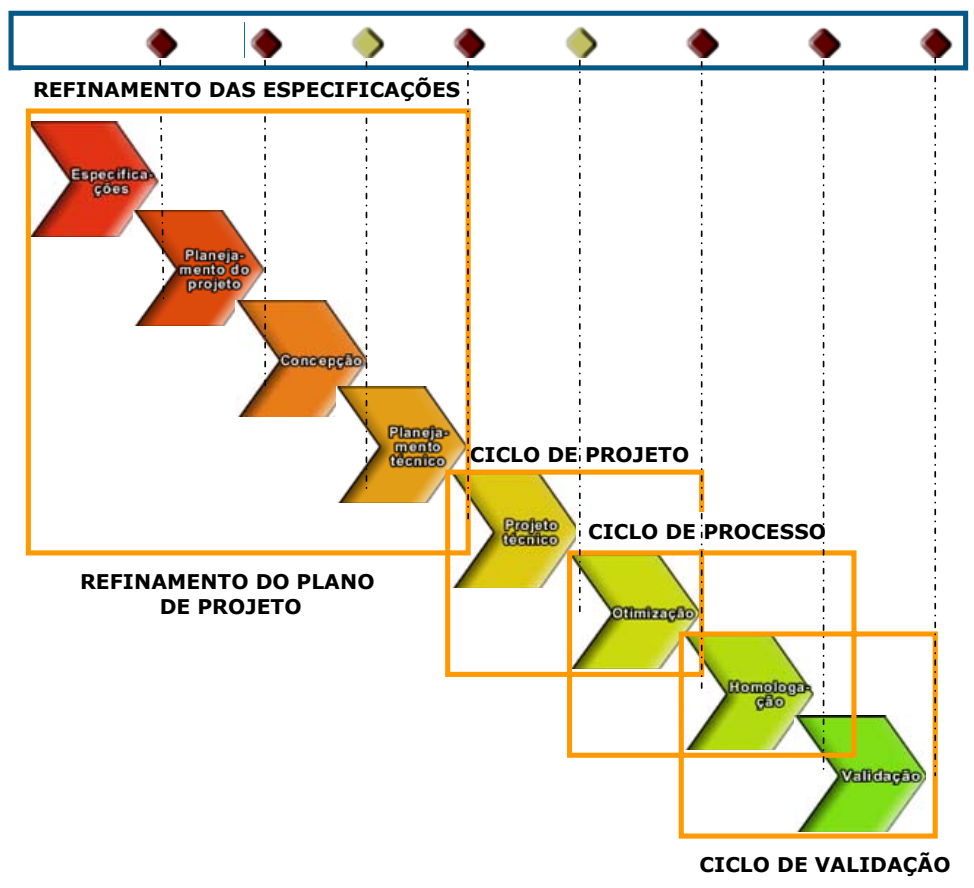

Figura 46 - Ciclos e refinamentos entre as fases do MRM

Os ciclos são definidos como formas de implementação do conceito de engenharia simultânea. Eles representam conjuntos de atividades dentro de uma só fase ou de fases diferentes que devem ser realizadas com um grau considerável de paralelismo. Esse 
paralelismo permite o desenvolvimento antecipado de soluções para problemas de projeto que, se tratados seqüencialmente, poderiam gerar alto grau de retrabalho e de adiamentos nos prazos do projeto. Além disso, os ciclos representam situações nas quais determinados resultados parciais de uma fase demandam o retorno a uma fase anterior para que sejam revistas especificações já desenvolvidas.

Por outro lado, os ciclos tornam mais complexos os fluxos de informação no projeto e isso implica em maior dificuldade de planejamento.

No modelo mecatrônico, o PDP foi projetado para que haja poucos ciclos. Isso implicou em uma rigorosa previsão das atividades a serem realizadas nas fases que antecedem a de projeto técnico. Além disso, adotou-se o conceito de "refinamento" que consiste em uma revisão de algumas atividades realizadas em fases anteriores do PDP. Nesse sentido, as especificações desenvolvidas na fase de "especificações" (F3) são refinadas na fase de “concepção” (F5) quando já há um conhecimento mais maduro sobre as tecnologias a serem desenvolvidas no projeto. Esse processo é denominado de refinamento de especificações.

Similarmente, a fase de "planejamento técnico" (F6) prevê o refinamento do plano de projeto que fora preliminarmente confeccionado na fase de "planejamento do projeto" (F4). Esse refinamento objetiva aprofundar o plano de atividades do projeto, pois na fase F6 já há uma concepção definida e modelos abstratos, tais como arquitetura do produto e análise de requisitos de software que subsidiam o detalhamento do trabalho a ser realizado. Adicionalmente, nos gates que acontecem ao longo de um projeto são revisadas tanto as especificações do produto quanto o plano de projeto, o que pode ser considerado um tipo de refinamento realizado no projeto.

O ciclo de projeto consiste na realimentação da fase de "projeto técnico" com informações levantadas na fase de "otimização". Esse tipo de realimentação acontece por dois 
motivos. Primeiramente devido ao fato de a fase de "projeto técnico" ter sido projetada para comportar soluções desenvolvidas para as funções primárias do produto, enquanto que na fase de "otimização" as soluções são desenvolvidas para as funções secundárias, o que pode implicar em alterações no desempenho das soluções das primárias. Segundo, na "otimização" são realizadas análises técnicas de riscos, confiabilidade e sinal/ruído que também podem demandar modificações nas soluções das funções primárias.

O ciclo de processo consiste no refinamento da documentação de processo e na eventual modificação da baseline resultante da fase de otimização para acomodar restrições dos setores de manufatura da empresa. Eventualmente, o ciclo de processo pode gerar a necessidade de revisão do ciclo de projeto uma vez que determinadas alterações nas especificações das tolerâncias de alguns parâmetros do projeto podem gerar necessidade de revisão das soluções desenvolvidas para as funções primárias.

O ciclo de validação acontece entre as fases de "validação" e "homologação". Esse ciclo tem como objetivos principais a análise de influências de modificações incrementais realizadas no produto com relação aos custos e riscos do processo de manufatura e montagem. As modificações incrementais realizadas na fase de "validação" podem decorrer de mudanças sugeridas por clientes no processo de validação do produto ou de mudanças realizadas em função de problemas encontrados nos testes de certificação do produto.

\subsubsection{Protótipos no MRM}

O MRM contém cinco tipos de protótipo:

- $\quad$ protótipos de concepção: utilizados para provar a concepção do produto em termos de componentes principais e formas de relacionamentos entre eles; 
- $\quad$ protótipos alfa - utilizados na fase de projeto técnico para provar a efetividade das soluções desenvolvidas para as funções primárias do produto;

- $\quad$ protótipos beta - protótipos completos do produto que são utilizados para a otimização do produto;

- $\quad$ protótipos de homologação - utilizados para validar o processo de fabricação em condições normais de operação do produto;

- $\quad$ protótipos piloto - utilizado para validar o projeto junto a clientes e certificar o produto.

\subsubsection{Configurações de produto no MRM}

As configurações congeladas do MRM são denominadas baselines. Elas são seis. Cinco delas são relativas à configurações de projeto em desenvolvimento:

- $\quad$ baseline da configuração de projeto_1 - na fase de projeto técnico. Ela agrega as informações de projeto do protótipo alfa, e portanto, soluções apenas para as funções primárias do produto.

- $\quad$ baseline da configuração de projeto_2 - na fase de otimização. Ela agrega as informações de projeto do protótipo beta, portanto soluções para todas as funções envolvidas no projeto do produto, assim como as análises técnicas realizadas ao longo do projeto.

- $\quad$ baseline da configuração de projeto_3 - na fase de homologação. Ela consiste na documentação do produto ao final da homologação do processo, ou seja, nas soluções de projeto que passaram por todos os testes de capabilidade de processo.

- $\quad$ baseline da configuração de projeto_4 - na fase de validação. É a configuração do produto que resulta da atividade de ajuste da documentação do projeto com base nas normas 
aplicáveis ao produto. Essa documentação engloba manuais de operação do produto a serem utilizados nas atividades de validação e certificação do produto.

- $\quad$ baseline da configuração de projeto_5 - na fase de validação. É a configuração final do projeto do produto, resultante das modificações realizadas para validar e certificar o produto. Essa configuração vai ser utilizada para gerar a baseline do produto_configuração 1 .

A configuração final do projeto é utilizada para gerar a configuração inicial do produto em operação comercial:

- $\quad$ baseline do produto_configuração_1 - é a configuração do produto que inicialmente vai ser introduzida no processo produtivo da empresa. Ela é baseada na configuração 5 do projeto adicionada de informações comerciais como catálogos, manuais de serviço, plano de marketing, plano de logística, plano de produção etc.

\subsection{7 Áreas de processo do MRM}

A Figura 47 apresenta as áreas de processo do MRM distribuídas ao longo das fases anteriormente apresentadas (item 5.2). As barras horizontais demonstram a distribuição das áreas de processo ao longo das fases. Embora todas terminem apenas na fase de monitoramento do produto, o início de cada uma é bastante expressivo de sua função dentro do PDP.

Elas podem ser assim definidas:

- $\quad$ desdobramento da estratégia: atividades pelas quais se garante que as diretrizes da estratégia da empresa serão aplicadas ao longo do processo de desenvolvimento de novos produtos; 
- desenvolvimento de mercados: ações implementadas com o objetivo de identificar os clientes, conhecer suas necessidades, monitorar sua satisfação e introduzir o produto no mercado;

- $\quad$ arquitetura de sistemas: levantamento e gestão de especificações ao longo do PDP, assim como documentação técnica do produto rastreável às especificações;

- $\quad$ gestão de projetos: gerenciamento integrado de escopo, prazos, custos e suprimentos dos recursos necessários à execução de projetos de novos produtos;

- $\quad$ projeto de engenharia: atividades de desenvolvimento e teste de soluções desenvolvidas ao longo do processo de desenvolvimento;

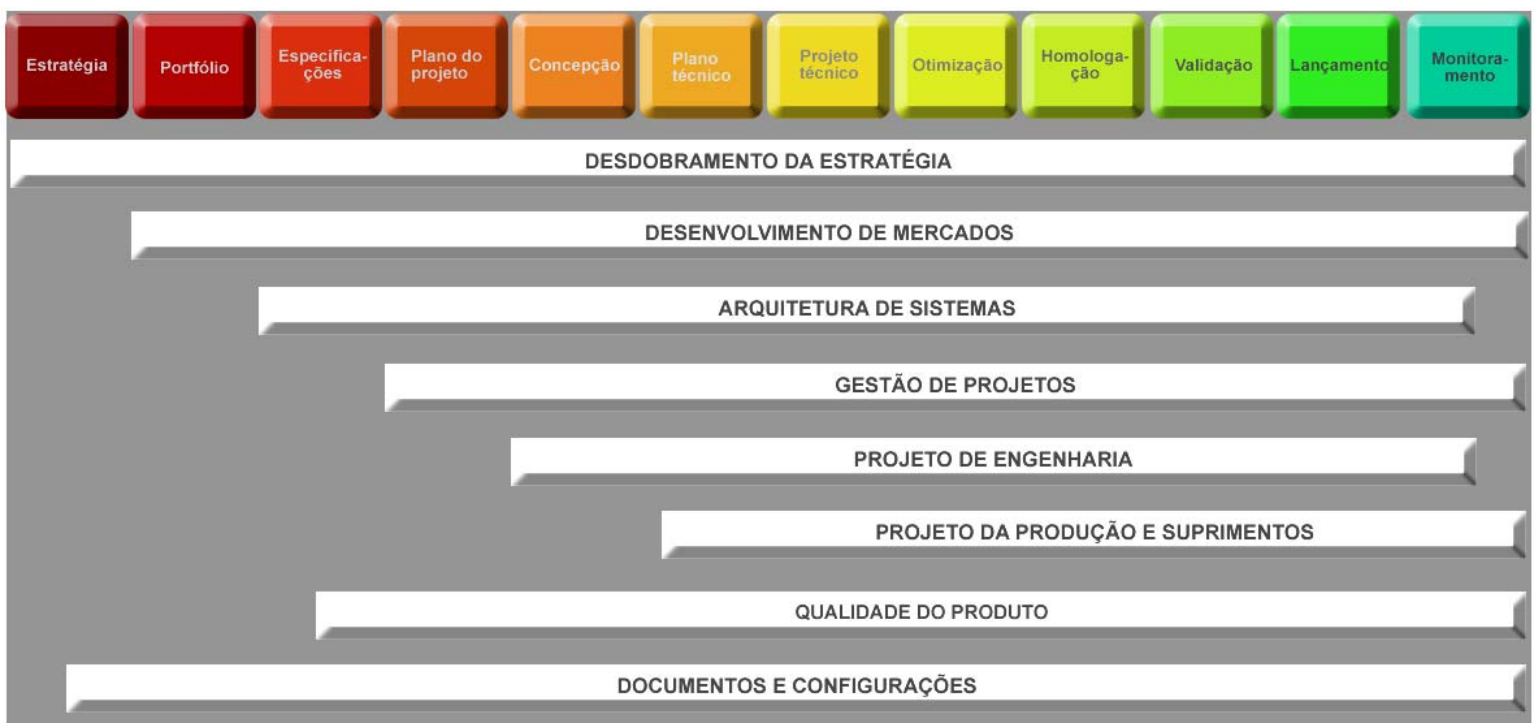

Figura 47 - Áreas de processo do MRM

- $\quad$ projeto da produção e suprimentos: atividades de engenharia de processos e de desenvolvimento da estrutura de fabricação, montagem e das logísticas de suprimentos e de distribuição; 
- $\quad$ qualidade do produto: atividades relacionadas com a predição da qualidade do produto ao longo do projeto e o monitoramento da qualidade da fabricação após o lançamento do produto; e

- documentos e configurações: atividades cujo objetivo é manter o processo registrado e as configurações de projeto e de produto sob controle.

A área de processo de desdobramento da estratégia é baseada na proposição de COOPER (1998) acerca da integração entre decisões de portifólio e decisões de gate (ver APÊNDICE B), e complementada com as diferenciações explicitadas em ROZENFELD et al. (2006) acerca dos conceitos de estratégia e de portifólio (ver APÊNDICE B). O desenvolvimento de mercados é uma proposta do autor e consiste nas atividades desenvolvidas por um considerável número de unidades organizacionais cujo objetivo é fazer com que o produto satisfaça ao cliente.

A arquitetura de sistemas é baseada no conceito de engenharia de sistemas com ênfase nas atividades de desenvolvimento de especificações para o produto e de documentação técnica, conforme discutido no padrão IEEE 1220 (ver APÊNDICE C), sendo, porém complementado pela atividade de análise de requisitos de software, conforme proposta em PRESSMAN (2001) e BRADLEY (2000). Enquanto a área de desenvolvimento de mercados é responsável por identificar os clientes potenciais do produto e levantar suas necessidades, a arquitetura de sistemas, transforma essas necessidades em especificações técnicas a serem entregues às equipes de engenharia.

A gestão de projetos segue o conceito definido no PROJECT MANAGEMENT INSTITUTE (2005; PMBOK:2005) com relação à gestão do escopo, prazos, custos, aquisições de recursos e subcontratações realizadas ao longo do projeto. Entretanto, entendese que à medida que as soluções de projeto vão se tornando robustas, os processos de 
aquisição passam a estar mais relacionados com o projeto da estrutura de produção e suprimentos que com o de desenvolvimento das soluções de engenharia. $O$ ciclo planejamento-execução-controle-fechamento, definido pelo PMBOK:2005, é implementado através dessa área de processo.

O projeto de engenharia consiste nas atividades definidas na bibliografia como “projeto de engenharia", conforme proposições de PUGH (1990) e PAHL e BEITZ (1996) ver APENNDICE C. Tomando por base a proposta desses autores, foram suprimidas apenas as atividades relacionadas com as fases de especificações (PUGH, 1990) e clarificação da tarefa (PAHL e BEITZ, 1996). Nessa área de processo foram agregadas as contribuições dos autores de mecatrônica e das engenharias eletrônica, mecânica e de software.

O projeto da produção e suprimentos consiste nas atividades discutidas por CLARK e FUJIMOTO (1991) e WHEELWRIGHT e CLARK (1993) como "engenharia de processo" e naquelas que consistem no projeto da estrutura fabril necessária à introdução do produto na linha de produção da empresa, conforme propõe SLACK et al. (2002). O DFMA, conforme descrito em BOOTHROYD (1994) e sumarizado em ULRICH e EPPINGER (1995) e CREVELING et al. (2003) e o projeto de tolerâncias são conceitos importantes dessa área de processo.

A qualidade do produto consiste nas atividades relacionadas com as análises realizadas para prever falhas nos produtos, garantir sua confiabilidade e garantir que eles não apresentem riscos de segurança para usuários e operadores (JURAN, 1997). As atividades de identificação e análise de requisitos de clientes, que alguns autores discutem como pertencentes à gestão da qualidade, foram subdivididas de maneira a refletir a origem das necessidades que elas expressam. Dessa forma, as necessidades relacionadas com os clientes têm relação com a área de processo de desenvolvimento de mercados, enquanto que os requisitos normativos, embora relacionados a determinados mercados, foram associados à 
predição da qualidade do produto, já que decorrem do conhecimento acumulado e consolidado em padrões de qualidade em torno de determinadas tipologias de produto.

A área de documentos e configurações é advogada por padrões de engenharia de sistemas a exemplo do IEEE 1220 e está explicitamente colocada em normas de qualidade, a exemplo da ISO 9001:2000, entretanto, optou-se por deixar a temática independente das demais áreas de processo a exemplo do que é proposto no padrão EUROPEAN COOPERATION FOR SPACE STANDARDIZATION (1996b; ECSS-M-40A).

O APÊNDICE E apresenta uma tabela com a classificação das atividades por área de processo do MRM.

\subsection{Fluxos de atividades das fases do MRM}

Nesse tópico serão apresentadas sumariamente as fases do modelo mecatrônico, cuja íntegra consta no APÊNDICE A.

\subsubsection{Fase de estratégia}

A fase de estratégia adota como principais referências os textos de COOPER (1993) e de WHEELWRIGHT e CLARK (1993). Agrega a estas contribuições, análises propostas por PORTER (1990) e KOTLER (2000). No APÊNDICE B consta um tópico de revisão teórica sobre essa temática.

A Figura 48 apresenta o fluxo de atividades da fase de estratégia. A atividade inicial é a análise das LDPs da empresa em confronto com o plano estratégico originalmente desenvolvido. A análise das linhas de produto é complementada pelo estudo das forças e fraquezas da companhia e de seus parceiros estratégicos. Essas análises alimentam a definição dos objetivos das LDPs que são consolidados em diretrizes para o portifólio de cada LDP. 
Passa-se a uma etapa de elaboração de diretrizes para estratégias funcionais. Essas diretrizes não podem ser confundidas com o planejamento de cada uma das principais funções envolvidas no PDP, mas é, na verdade, uma análise da sintonia entre o planejamento funcional e as diretrizes de portifólio, assim como a confecção de propostas de alinhamento entre ambas.

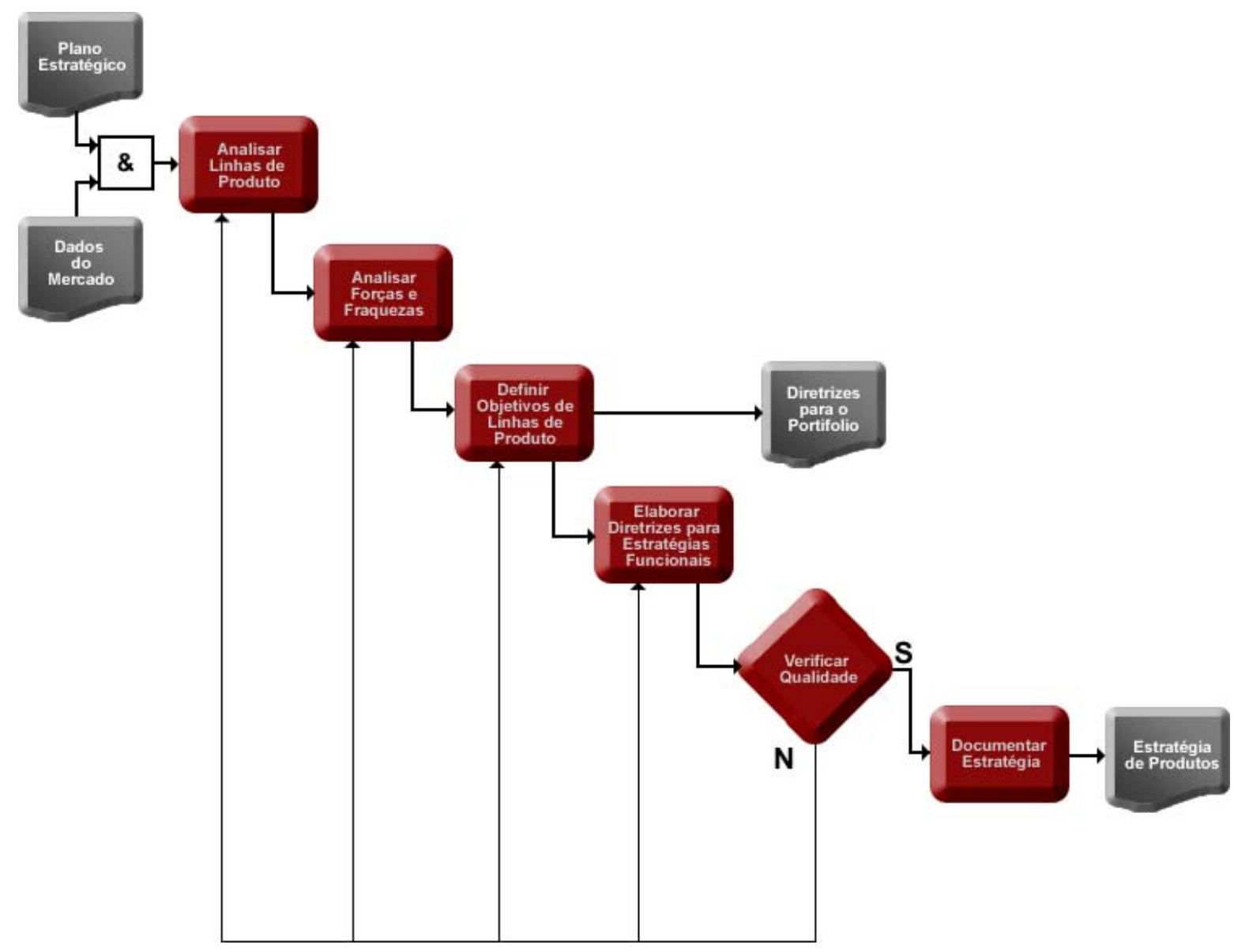

Figura 48 - Fase de estratégia

Deve-se, então, levar os resultados das análises realizadas para o gate da fase que consiste na verificação do alinhamento entre objetivos das LDPs, as estratégias funcionais e os dados de monitoramento de mercado. Ao final, os resultados são consolidados em um documento de estratégia de produtos. 


\subsubsection{Fase de portifólio}

A Figura 49 apresenta o fluxo de atividades da fase de portifólio de produtos. As referências básicas para essa fase foram COOPER (1998, 2000a e 2000b), mais fortemente, e NONAKA e TAKEUSCHI (1997) e WHEELWRIGHT e CLARK (1993).

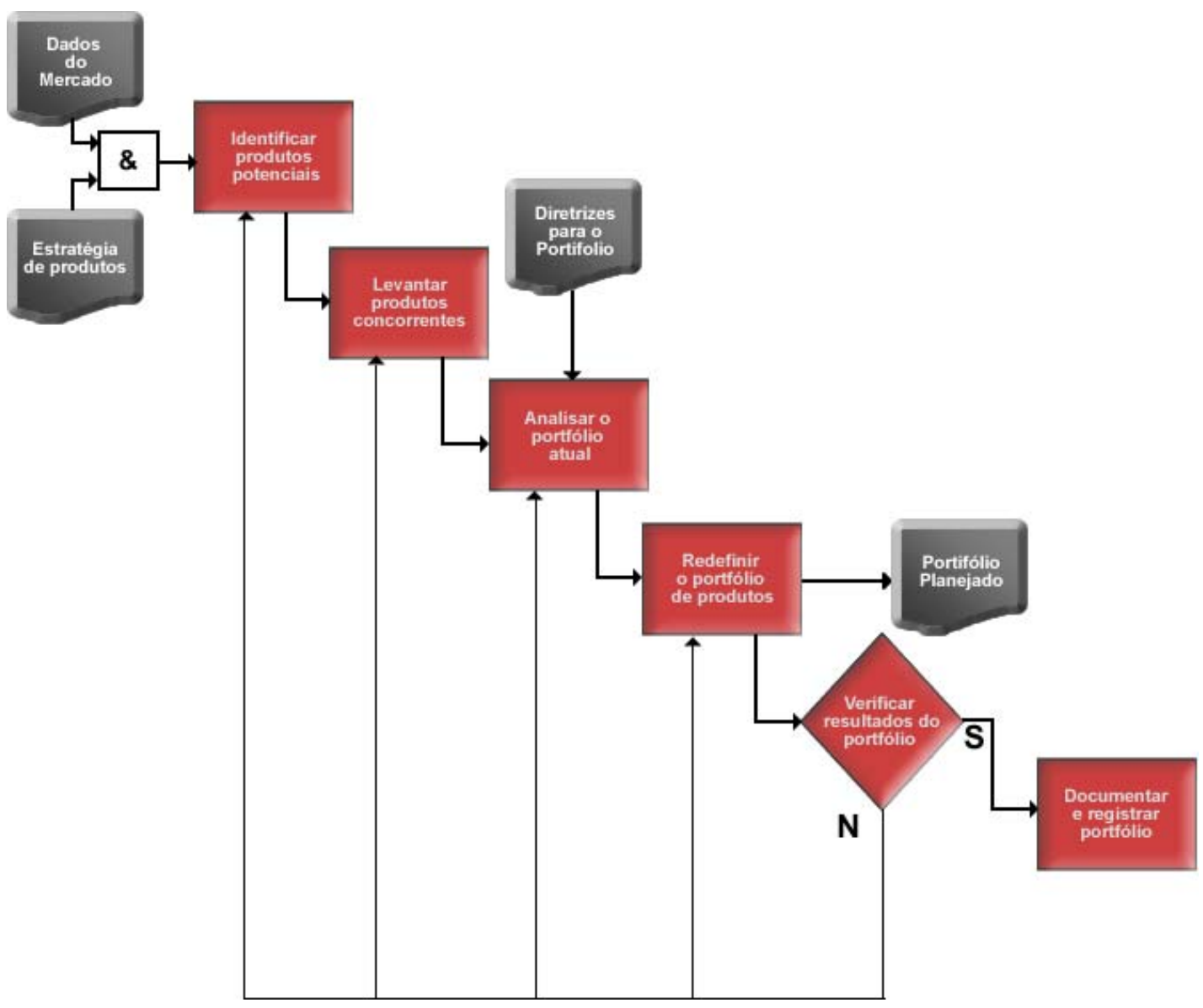

Figura 49 - Fase de portifólio

$\mathrm{Na}$ fase de portifólio há a identificação dos produtos potenciais que podem ser desenvolvidos para que cada LDP esteja alinhada com a estratégia de produtos. Isso significa que as entradas básicas da fase são a estratégia elaborada e as idéias de novos produtos que são geradas dentro da firma.

Dentre as idéias sugeridas, as consideradas mais alinhadas com a estratégia de produtos devem ser filtradas e passadas à etapa seguinte que seria o levantamento de produtos 
concorrentes para cada idéia. Deve-se tentar levantar dados suficientes para elaborar modelos de fluxo de caixa e de probabilidade de sucesso comercial e técnico da empresa.

A análise do portifólio atual da empresa investiga os produtos e projetos atuais quanto aos critérios definidos na fase anterior. A integração entre a estratégia e o portifólio de produtos pode ser garantida por meio do uso de modelos gráficos que permitam, primeiramente, a proposição dos movimentos competitivos necessários às linhas de produto, o que é realizado pela alta direção. Posteriormente, os modelos devem permitir a análise do portifólio dos produtos e projetos existentes, em conjunto, de maneira a verificar se eles permitem o cumprimento dos movimentos competitivos planejados enquanto estratégia.

A Figura 50 ilustra um exemplo desse tipo de integração. Nela utiliza-se a matriz $\mathrm{BCG}^{7}$ (Boston Consulting Group) para comunicar a estratégia e planejar o portifólio das LDPs.
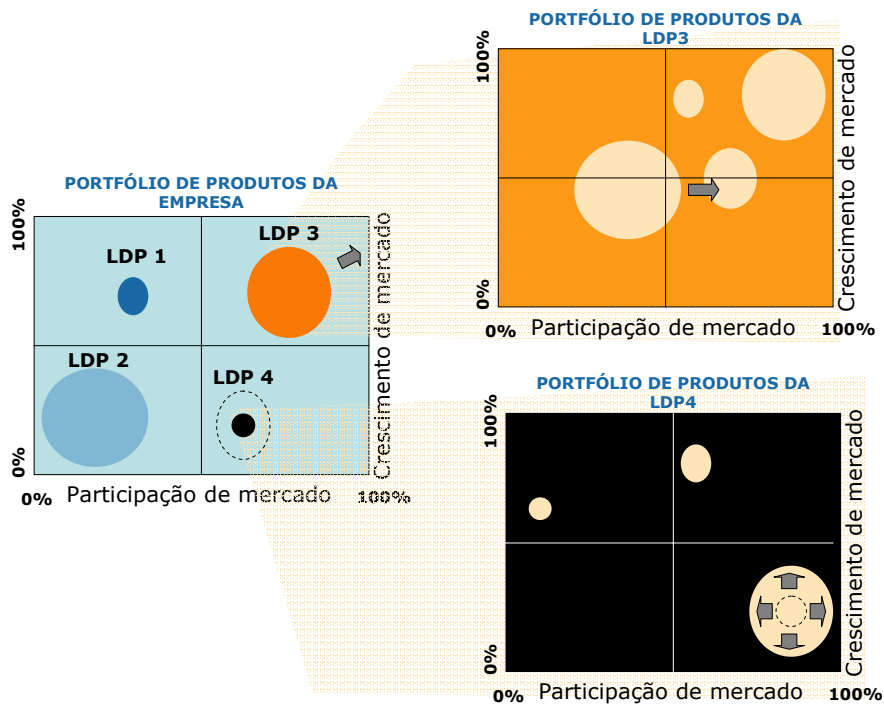

Figura 50 - Exemplo de integração do planejamento de portifólio com a estratégia de produtos

Analisado o portifólio atual contra as diretrizes da estratégia de produtos, a empresa passa à redefinição do portifólio da LDP considerada. Nessa atividade é gerado o portifólio

\footnotetext{
${ }^{7}$ Outros métodos podem ser utilizados para esse fim dentre os quais destaca-se a Matriz GE, descrita em KOTLER, 2000; COOPER, 1998; e ROZENFELD et. All. (2006).
} 
planejado da LDP, documento no qual consta basicamente as definições dos projetos selecionados para o desenvolvimento e seu grau relativo de prioridade na alocação de recursos.

Redefinido o portifólio de produtos, ele deve ser submetido à direção da empresa de maneira que os gestores verifiquem sua adequação às diretrizes estabelecidas na estratégia de produtos e uma possível demanda por revisão das atividades até então realizadas, conforme ilustra a Figura 49.

A mecatrônica têm forte impacto na fase de planejamento de portifólio de produtos em função da flexibilidade permitida pela tecnologia eletrônica utilizada e por uma estratégia deliberada de modularização do produto. Um sensor de monitoramento térmico em usinas siderúrgicas, por exemplo, pode, a partir de um mesmo projeto básico permitir: o monitoramento de barras e linguotes, o monitoramento de chapas, o monitoramento da homogeneidade de barras e chapas, e a regulação automática das condições de cozimento do aço em função de variações na homogeneidade das barras e chapas. Cada uma dessas opções agregaria módulos específicos ao produto.

Ao final deve haver a documentação e registro do processo implementado na fase.

\subsubsection{Fase de especificações}

A Figura 51 apresenta o fluxo de atividades da fase de especificações. As referências básicas utilizadas foram ULRICH e EPPINGER (1995) para a confecção das atividades básicas do fluxo da fase, requisitos de normas técnicas como IEC 60601-1 e IEC 60601-1-2 e as estruturas de listas de requisitos propostas por PUGH (1990) e por PAHL e BEITZ (1996). Utiliza-se a denominação proposta por PUGH (op. cit.), especificações do produto (product development specifications - PDS), para designar a saída principal dessa fase. 
A entrada básica para a fase de especificações é o portifólio planejado que é utilizado para identificar os clientes potenciais do produto ao longo de seu ciclo de vida, conforme descrito em BAXTER $^{8}$ e, mediante isso, levantar as necessidades desses clientes, analisá-las, classificá-las e priorizá-las. Em paralelo, a empresa deve identificar os requisitos normativos relacionados com o produto e os prováveis mercados nos quais ele será introduzido.

Os requisitos de clientes e normativos devem ser utilizados para identificar métricas de qualidade do produto. Essa terminologia é utilizada por ULRICH e EPPINGER (1995 - ver APÊNDICE C) para descrever as características técnicas que o produto deve ter para atender às necessidades dos clientes ${ }^{9}$. Essas métricas devem ser analisadas com o intuito de verificar ocorrências de características NUD (novas, únicas e difíceis), conforme definido em CREVELING et al. (2003). De posse de ambos, requisitos e métricas, é necessário realizar “análises em produtos concorrentes" e simultaneamente, na estrutura de manufatura da empresa.

Parte-se, então, para a definição das especificações do produto, uma atividade que tem como parâmetro o portifólio planejado na fase anterior. O objetivo é identificar as características necessárias à diferenciação do produto contra seus similares e, ao mesmo tempo, manter a integridade entre o produto e as diretrizes da LDP e sua manufaturabilidade.

As especificações do produto consistem em uma lista de itens a serem atendidos pelo projeto, um conceito do produto e uma matriz de verificação. A lista de itens serve de orientação geral ao projeto. Os itens considerados NUD devem ser identificados de maneira a subsidiar o planejamento da gestão de parâmetros críticos do projeto. O conceito serve como

\footnotetext{
${ }^{8}$ BAXTER, 2000, apresenta o método de análise do ciclo de vida do produto para identificar como o produto é utilizado na sua fabricação, manuseio, armazenamento, trasporte, no varejo, pelo cliente final, pelo operador, nas atividades de assistência técnica e disposição final do produto quando ele for ser retirado do mercado.

${ }_{9}^{9}$ A utilização do método de desenvolvimento de especificações proposto por ULRICH e EPPINGER (1995) não é a única forma de planejar o produto. O método aplicável à fase de especificações que é mais discutido na bibliografia de PDP é o QFD (Quality Function Deployment), uma forma sistemática de partir das necessidades dos clientes e desdobra-las em requisitos de produto, processo e operações de manufatura. O método QFD utiliza
} 
forma de comunicar os desafios impostos pelo projeto nos momentos de interface entre as diferentes áreas técnicas envolvidas, assim como entre estas e os setores de manufatura e marketing. Esse conceito é referente ao definido por NONAKA e TAKEUSCHI (1997) como conceito derivado $^{10}$. A matriz de verificação é utilizada para verificar a adequação do produto aos valores estabelecidos para as métricas da qualidade quando da realização de testes com protótipos. Esse documento é proposto na norma EUROPEAN COOPERATION FOR SPACE STANDARDIZATION (2003; ECSS-M-10B). A Figura 37 apresenta um exemplo de matriz de verificação para o caso de um equipamento de fotografia da retina.

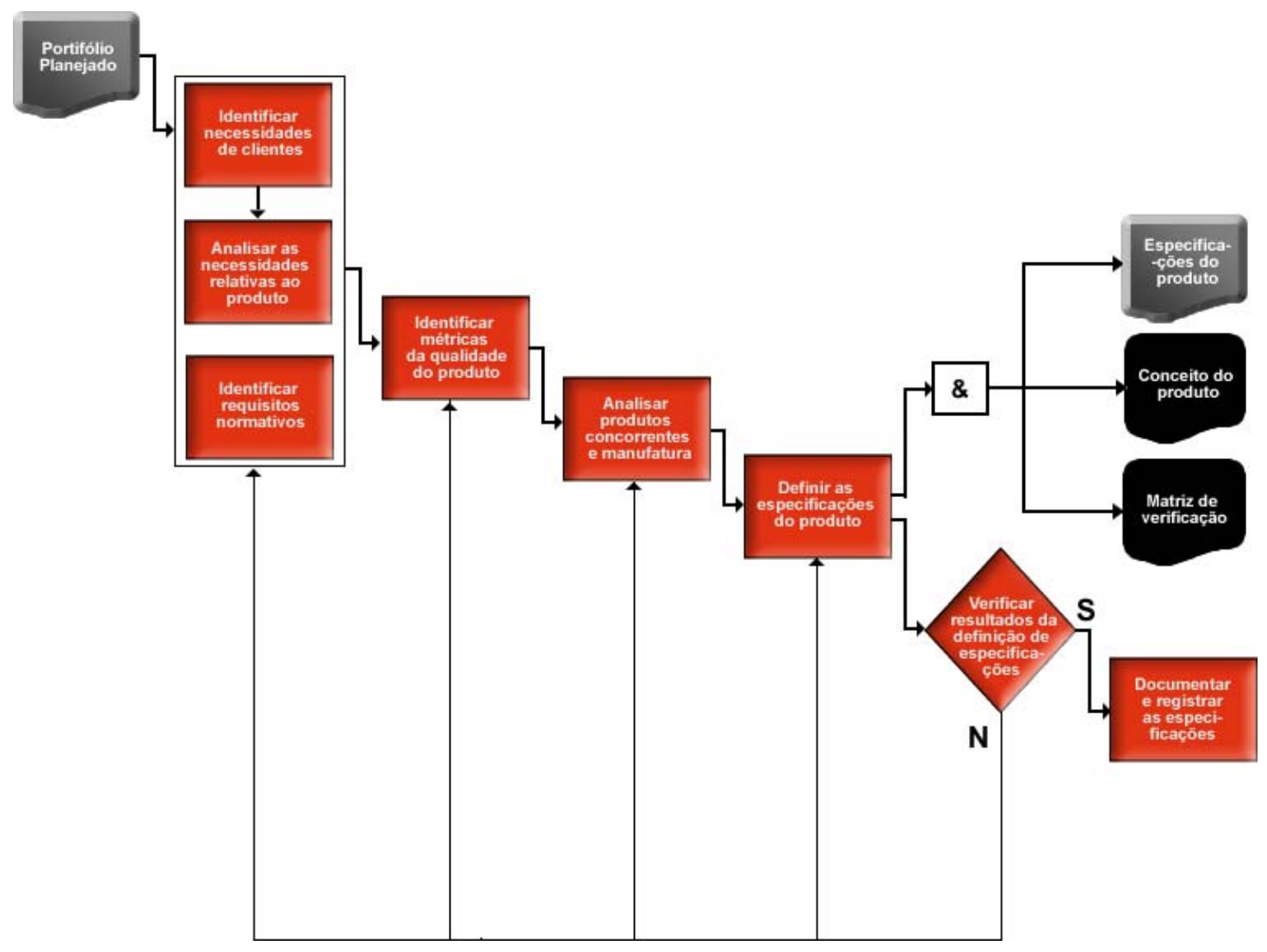

Figura 51 - Fase de especificações

a representação da casa da qualidade (house of quality) para sua implementação. A proposta de ULRICH e EPPINGER (op. cit.) abrange o mesmo tipo de análise sem, entretanto, utilizar a casa da qualidade para tal. ${ }^{10} \mathrm{O}$ conceito derivado é estabelecido para cada projeto, enquanto o conceito genérico tem relação com uma dada linha de produtos. NONAKA e TAKEUSCHI (1997) ilustram como o conceito de "fácil e rico" precisou ser traduzido em um conceito derivado denominado "amassar e esticar" de maneira a demonstrar aos engenheiros envolvidos com o projeto da home backery quais seriam os desafios tecnológicos impostos ao projeto. 
Esse conjunto de documentos é, então, utilizado como subsídio do processo de tomada de decisão no gate da fase de especificações. Nele, a alta gerência verifica a sua adequação ao portifólio planejado. Caso as especificações geradas não sejam consideradas pertinentes ao escopo do projeto, pode ser necessário realizar alguma (s) atividade (s) novamente. Pode-se congelar o projeto, caso o produto seja considerado inviável tecnicamente com base no orçamento previsto. Caso as especificações atendam aos critérios definidos no portifólio da LDP, as especificações do produto são documentadas e são feitos registros sobre a realização da fase de especificações.

\subsubsection{Fase de planejamento do projeto}

A Figura 52 apresenta o fluxo de atividades da fase de planejamento do projeto. As atividades que nela constam são baseadas no PMBOK (2005) e em VERZUH (2000). Essas referências foram complementadas com propostas de planejamento de projetos expostas em ULRICH e EPPINGER (1995).

A entrada dessa fase é a especificação do produto e sua atividade inicial é a declaração do escopo do projeto, atividade na qual é gerada a "declaração do trabalho".

De posse do escopo do projeto e das especificações do produto é realizada uma atividade cujo objetivo é desenvolver uma estrutura da divisão do trabalho (Work Breakdown Structure - WBS) do projeto. A WBS consiste na listagem das atividades necessárias ao desenvolvimento do produto. Para confeccioná-la, primeiramente deve ser desdobrado o produto em uma estrutura analítica de nível $1^{11}$, conforme ilustrado na Figura 53.

\footnotetext{
${ }^{11}$ Há uma certa proliferação de terminologias relacionadas com a WBS do projeto, tais como estrutura analítica do projeto e estrutura da divisão do trabalho. No MRM essas terminologias são utilizadas com significados diferentes: a estrutura analítica do projeto (EAP) representa a quebra do produto em suas partes constituintes adicionadas de outros aspectos a serem entregues no projeto, tais como gerenciamento, treinamento, infraestrutura etc. Os itens identificados na EAP representariam o que deve ser entregável (deliverables) ao longo do projeto. A estrutura da divisão do trabalho (WBS), é, por sua parte, a composição da EAP com as atividades necessárias à entrega de cada um de seus itens.
} 
Essa estrutura consiste nas partes físicas do produto e em determinados aspectos gerenciais que devem ser monitorados ao longo do projeto. O exemplo da figura citada apresenta além dos equipamentos que compõem o satélite, o gerenciamento do projeto e a garantia do produto. Apresenta também um detalhamento da EAP de um equipamento de testes. Essa estrutura deve ser desenvolvida com base em produtos concorrentes ou versões anteriores dos produtos da própria empresa.

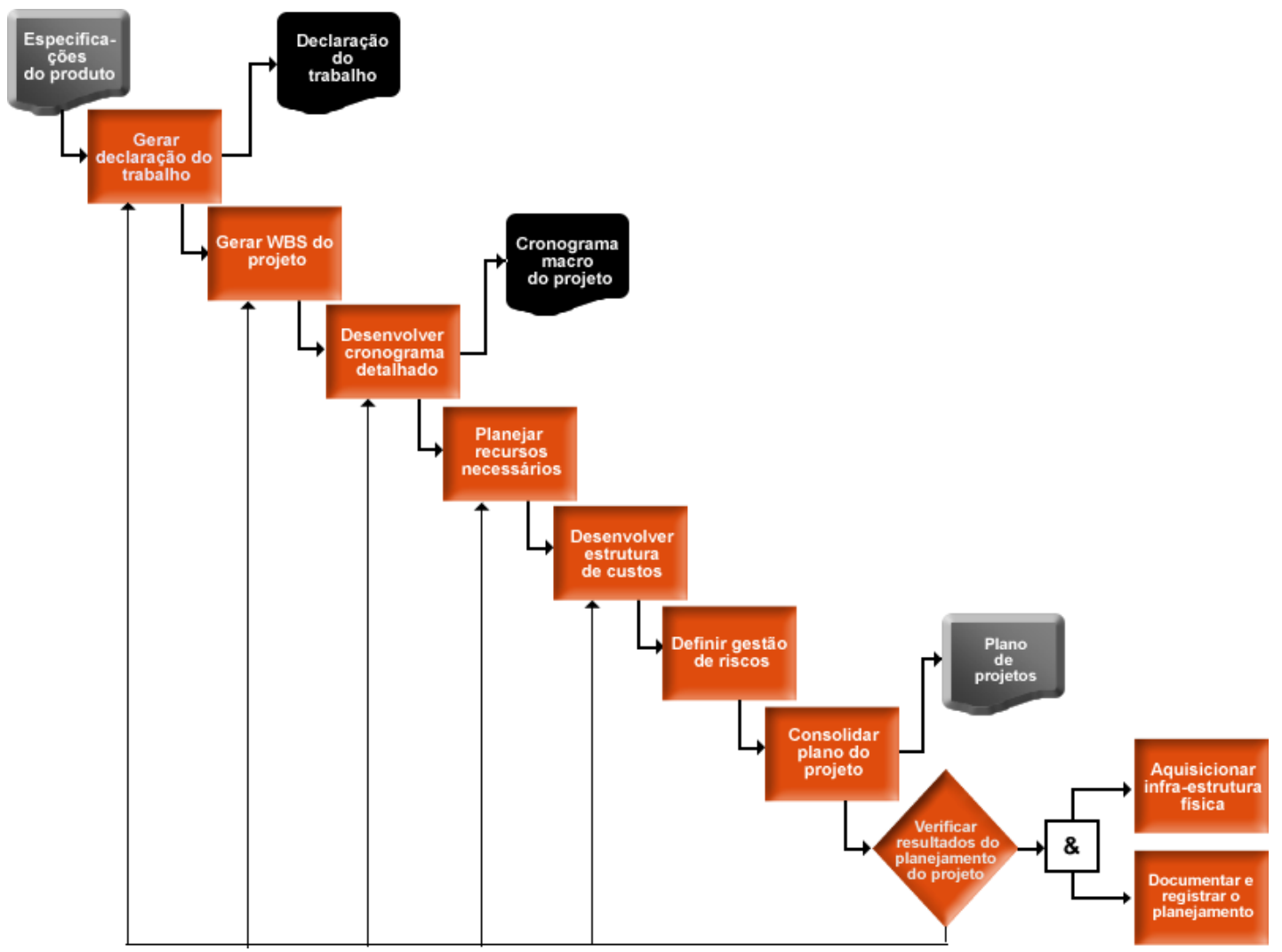

Figura 52 - Fase de planejamento do projeto

A partir da EAP devem ser listadas as atividades a serem desenvolvidas ao longo do projeto com base no modelo de referência mecatrônico. Ou seja, são identificadas as atividades do modelo necessárias ao desenvolvimento do produto em questão. As atividades identificadas devem ser agrupadas em pacotes de trabalho (work package - WP) e deve ser analisada a necessidade de subcontratação de algum (ns) desses pacotes. 


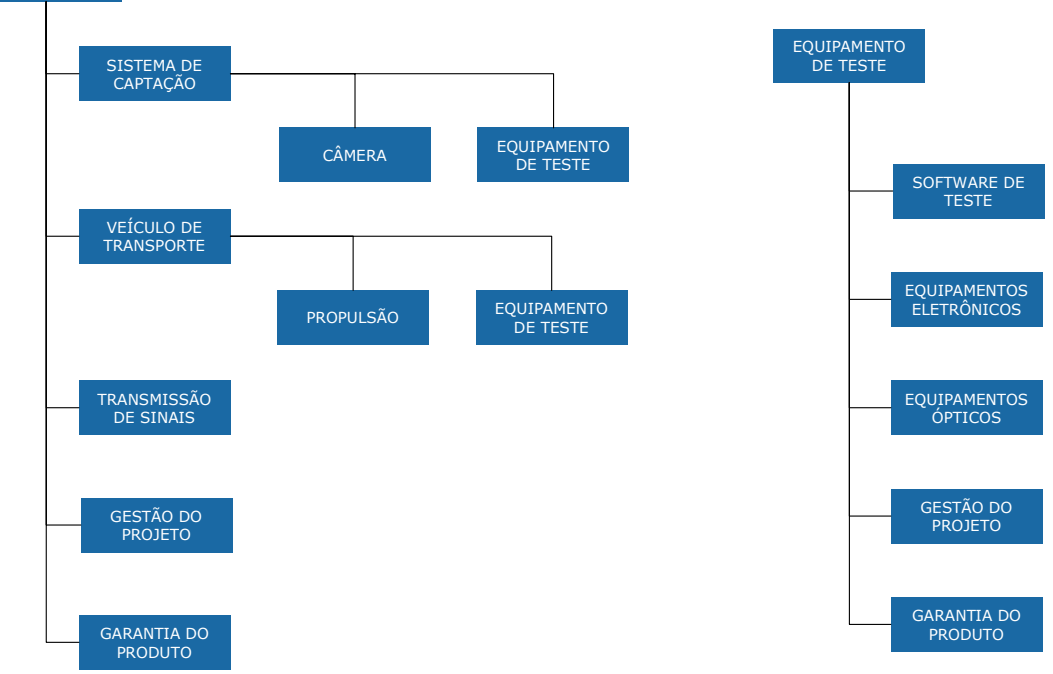

Figura 53 - Estrutura analítica (EAP) de um projeto mecatrônico: satélite de monitoramento ambiental. (Adaptado de MIL-HDBK-881, 2000)

Deve-se, então, identificar os recursos necessários para cada atividade e, com base na disponibilidade destes, alocar prazos para as atividades listadas em cada fase do projeto. Dessa forma é possível desenvolver um “cronograma macro do projeto”.

Uma vez que o cronograma é baseado em algum tipo de premissa acerca dos recursos necessários ao projeto, deve-se identificar os existentes e as lacunas e sistematizá-as em um plano de alocação de recursos no qual são apresentados os recursos demandados ao longo do tempo. O plano de alocação de recursos e o cronograma macro permitem elaborar um modelo inicial da estrutura de custos do projeto pelo qual é possível refinar suas diretrizes de orçamento.

Mediante a análise de custos, cronograma, escopo e recursos necessários, devem ser analisados os principais riscos do projeto. Os riscos são avaliados quanto às probabilidades de ocorrência e de impacto e devem ser previstas estratégias de sua mitigação. O planejamento é, então, consolidado em um documento denominado "plano de projetos" que é submetido à avaliação da alta direção. 
A avaliação dos gestores pode implicar na necessidade de revisão de algumas atividades. Ao final, documentada a fase inicia-se a aquisição dos recursos de infra-estrutura necessários ao projeto, tais como prédios, laboratórios, equipamentos de longo lead-time etc.

\subsubsection{Fase de concepção do produto}

A Figura 54 apresenta o fluxo de atividades da fase de concepção do produto, desenvolvido com base na proposta de ULRICH e EPPINGER (1995), complementada com as análises funcional e de estados propostas respectivamente por PAHL e BEITZ (1996) e BUUR (1990). É provável que em aplicações das indústrias automotiva e de eletroeletrônicos, nos quais há grande estabilidade do conceito do produto, ocorram mais situações nas quais a concepção aconteça abordando o produto como um todo, enquanto nas aplicações das indústrias médica, militar e aeroespacial, a concepção ocorra no nível de subsistemas, como por exemplo, relacionado ao "equipamento de teste" ilustrado na Figura 53.

Como entradas para essa fase, tem-se o "plano de projeto" e as "especificações do produto", que resultam, respectivamente, das fases F3 e F4 do MRM. As especificações do produto subsidiam a definição do problema de projeto de cada subsistema. Isso significa que as métricas de qualidade relacionadas com o subsistema devem ser desdobradas das métricas gerais do produto, estabelecidas na fase de especificações (item 5.3.1.3). De posse das especificações do subsistema, o pessoal de projeto deve realizar duas tarefas imprescindíveis para a estruturação do projeto a ser desenvolvido:

- $\quad$ a identificação dos estados (ou modos de funcionamento) do produto; e

- $\quad$ a identificação das funções a serem executadas em cada estado. 


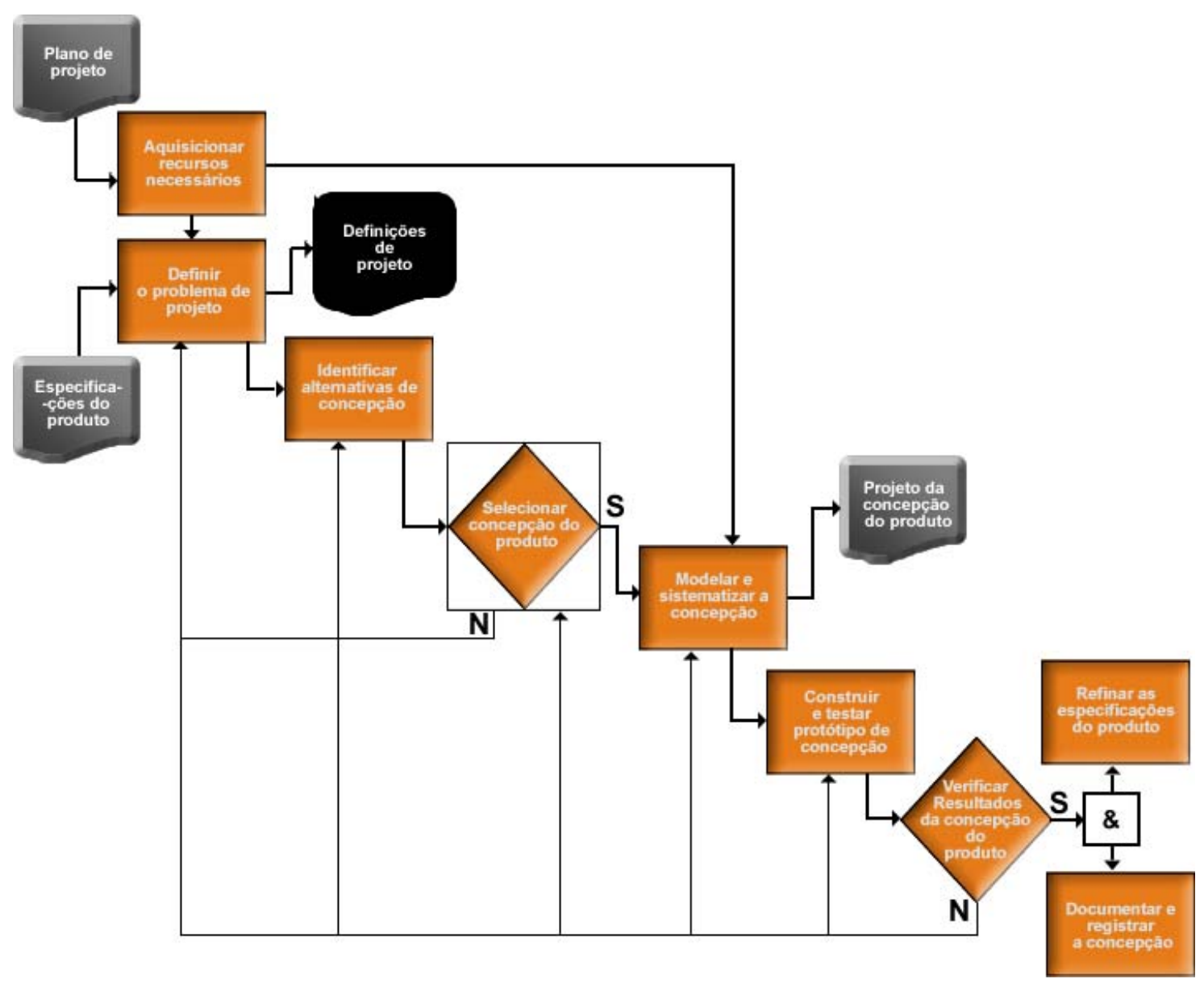

Figura 54 - Fase de concepção do produto

Essas tarefas estão ilustradas na Figura 21 e geram os requisitos técnicos necessários à identificação de alternativas de concepção para o produto. As funções do produto podem ser classificadas de acordo com a estrutura genérica de componentes de um produto mecatrônico apresentada na Figura 12.

Gerar alternativas de concepção significa realizar as atividades de criação necessárias ao projeto do produto. Para cada função primária, em cada estado do produto, devem ser desenvolvidas soluções que posteriormente devem ser analisadas sob a ótica da possibilidade de que sejam combinadas, conforme um padrão similar ao apresentado na Figura 28. Além disso, em projetos mecatrônicos é necessário que sejam definidas:

- a estrutura das interfaces entre as soluções de software, de mecânica e de eletrônica com a definição preliminar de sensores e atuadores a serem utilizados; e 
- uma descrição do comportamento esperado do operador.

Para cada conjunto de soluções que podem ser combinadas há uma concepção. As concepções devem, então, passar por um processo de seleção. Para isso, devem ser estabelecidos critérios, derivados das especificações do produto e do plano de projeto, que permitam a escolha da concepção mais adequada ao projeto do produto.

Selecionada a concepção, a equipe passa a modelá-la e sistematizá-la. Os modelos desenvolvidos são tanto técnicos quanto relacionados aos custos do produto. Para desenvolver os modelos técnicos pode ser necessária a aquisição de recursos adicionais aos existentes na empresa, tais como softwares de simulação por elementos finitos, de simulação de radiação etc. No documento "projeto da concepção do produto" é sumarizado o modelo de custos desenvolvido com base em uma estrutura de lista de materiais (Bill of materials - BOM).

Em algumas situações, especialmente em concepções inovadoras, é necessário realizar testes com protótipos físicos. Eles são submetidos a clientes potenciais, especialmente os “usuários líderes” (lead users). Protótipos de concepção não precisam implementar todas as funções desenvolvidas, mas, tão somente, aquelas identificadas como necessárias ao teste.

Construído e testado o protótipo, deve ser realizado o gate da fase de concepção. Uma vez que houve decisão técnica quanto às soluções propostas na atividade "selecionar a concepção do produto", nesse gate analisa-se o cumprimento de diretrizes do portifólio da LDP e o impacto do projeto da concepção sobre as especificações do produto. A verificação dos resultados da fase de concepção pode demandar uma revisão de alguma das atividades relacionadas.

Se os resultados da concepção do produto forem considerados satisfatórios, deve-se refinar as especificações, pois a concepção pode impor restrições aos valores estabelecidos para as métricas da qualidade elaboradas na fase F3 (item 5.3.1.3). Isso significa a 
possibilidade de haver mudança no conceito do produto, na lista de requisitos e na matriz de verificação.

Paralelo ao refinamento das especificações, a concepção do produto é documentada e o andamento da fase é registrado a contento.

\subsubsection{Fase de planejamento técnico}

Nessa fase é realizado um detalhado planejamento do projeto do produto e do processo. A Figura 55 apresenta o fluxo de atividades dessa fase com base em diversos autores: ULRICH e EPPINGER (1995) discutem o conceito de arquitetura do produto; CREVELING et al. (2003) sugerem o uso da gestão de parâmetros críticos; a norma ECSSM-010B advoga o uso da árvore de produtos para documentar o projeto; CLAUSING (1994) sugere desdobrar especificações de produto em especificações de processo; e BUUR (1990) indica cuidado especial em definir interfaces, sistema de controle e software dos produtos mecatrônicos.

Seria prematuro considerar esses aspectos antes de haver uma concepção selecionada para o produto uma vez que não haveria informação suficiente para tal.

Consolidar a arquitetura do produto consiste em identificar os componentes tecnológicos a serem utilizados para implementar a concepção selecionada, o seu agrupamento em partes que reflitam a estrutura física do produto e a identificação das interações necessárias entre essas partes.

As interações devem ser analisadas de maneira a gerar especificações para as interfaces e o sistema de controle. A arquitetura e as especificações de interface e sistema de controle permitem um mais refinado conhecimento acerca dos riscos associados à segurança de quem vai utilizar o produto. Detalha-se então, a busca pelas normas e padrões aplicáveis. 
O conjunto das informações desenvolvido até então deve ser utilizado para: (1) a identificação de parâmetros críticos do projeto; (2) a identificação e análise de requisitos de software; e (3) o desdobramento das especificações de produto em especificações de processo.

Deve-se então gerar uma árvore de produtos - uma estrutura representativa das partes físicas do produto para as quais é desenvolvida a documentação usada para verificar e validar o projeto. Diferentemente da arquitetura, a árvore de produtos não se relaciona à função das partes. Além disso, a arquitetura demonstra a relação entre as partes de mais alto nível na hierarquia de sistemas, enquanto a árvore está em um nível intermediário para o qual devem ser realizados os testes que verifiquem a funcionalidade do produto.

Há ainda uma diferença conceitual entre árvore de produtos (product tree) e estrutura do produto (bill of materials). A primeira subdivide o produto em partes até o limite para o qual é viável confeccionar uma documentação consistente com o conceito de "sistema" (APÊNDICE B), a estrutura de produto é uma forma de desdobrar o equipamento até o nível de componentes básicos estruturados na forma de montagens que alimentam os sistemas de gestão da produção na empresa. Na prática, a árvore de produtos é uma parte da estrutura do produto agregada de elementos relacionados com a documentação do produto.

A Figura 56 apresenta a arquitetura de produto de um equipamento de fotografia da retina. A Figura 57 apresenta a árvore do produto desse equipamento. 


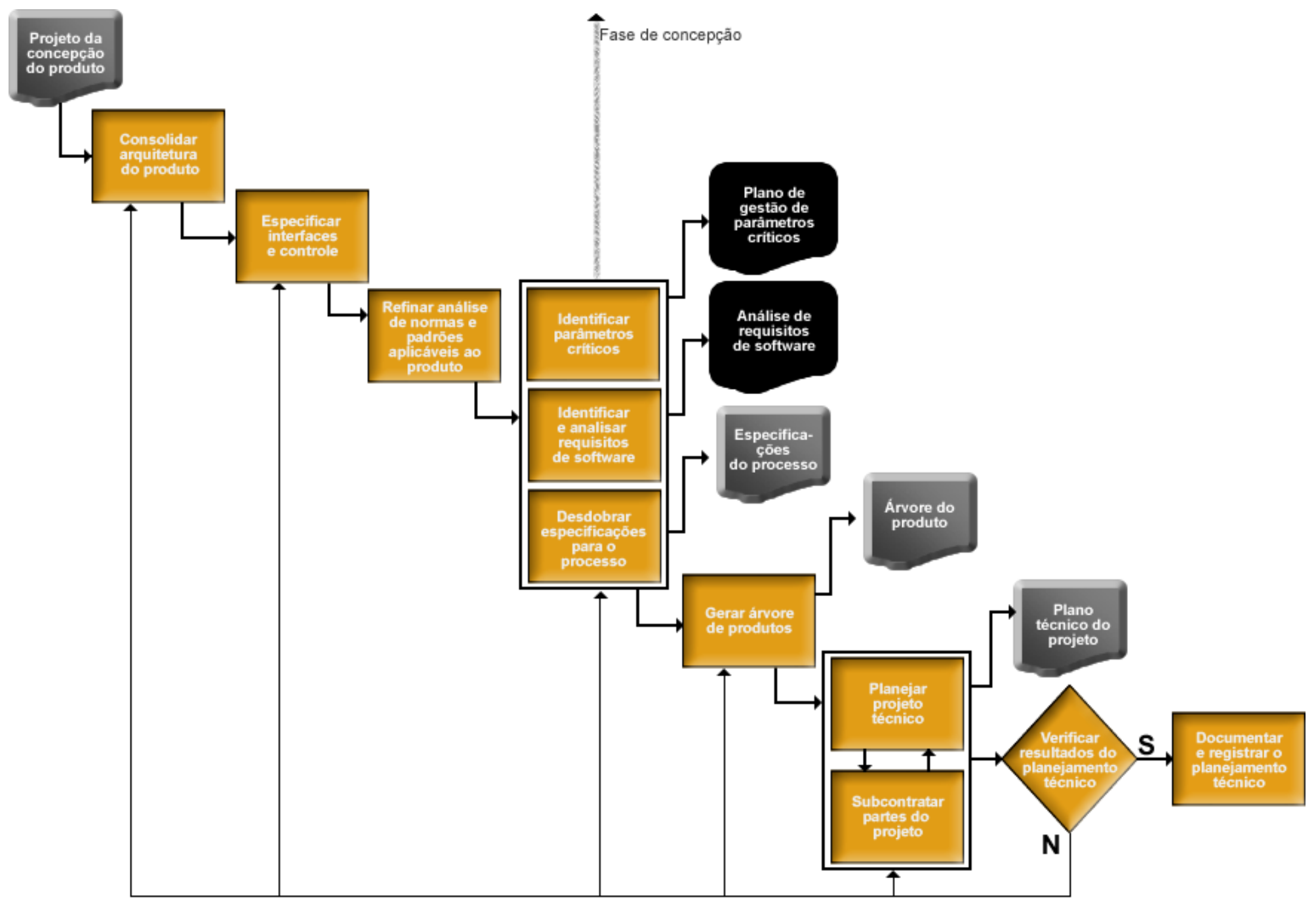

Figura 55 - Fase de planejamento técnico 
Os elementos funcionais indicados na arquitetura do produto são apresentados hachurados na árvore de produtos do equipamento.

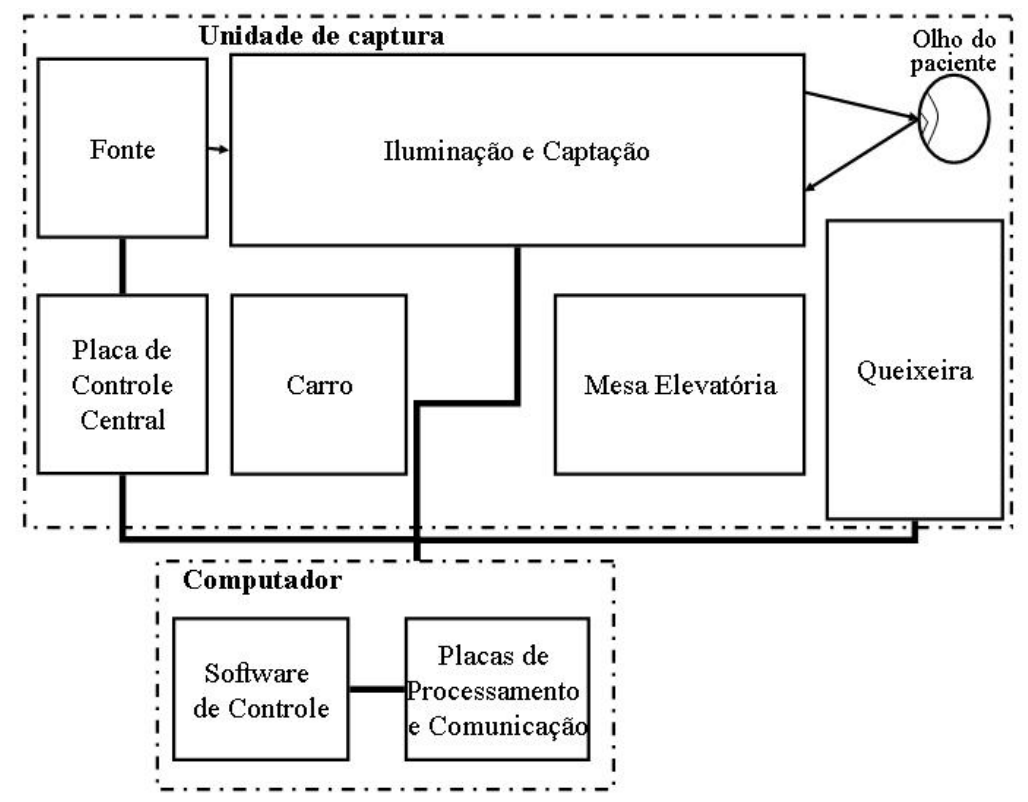

Figura 56 - Arquitetura do produtos: equipamento de fotografia da retina (Fonte: OPTO ELETRÔNICA S.A., 2005a)

De posse das especificações das interfaces e controle, da análise de requisitos de software, dos desafios a serem encontrados no projeto do processo de fabricação e montagem e do volume de documentação necessário ao projeto, é possível detalhar o planejamento de escopo realizado na fase F4 (item 5.3.1.6). Adicionalmente, deve-se redefinir as subcontratações necessárias ao projeto e identificar a necessidade de desenvolver alguma nova tecnologia a integrar o produto.

Os documentos de requisitos e o detalhamento do plano de projeto devem subsidiar a elaboração de um plano técnico que é a saída consolidada dessa fase. O plano técnico é então submetido à alta direção para verificar seu alinhamento ao conceito e às diretrizes de prazo e custo do produto.

Ao final da fase, o processo de confecção desse planejamento é documentado e registrado. 


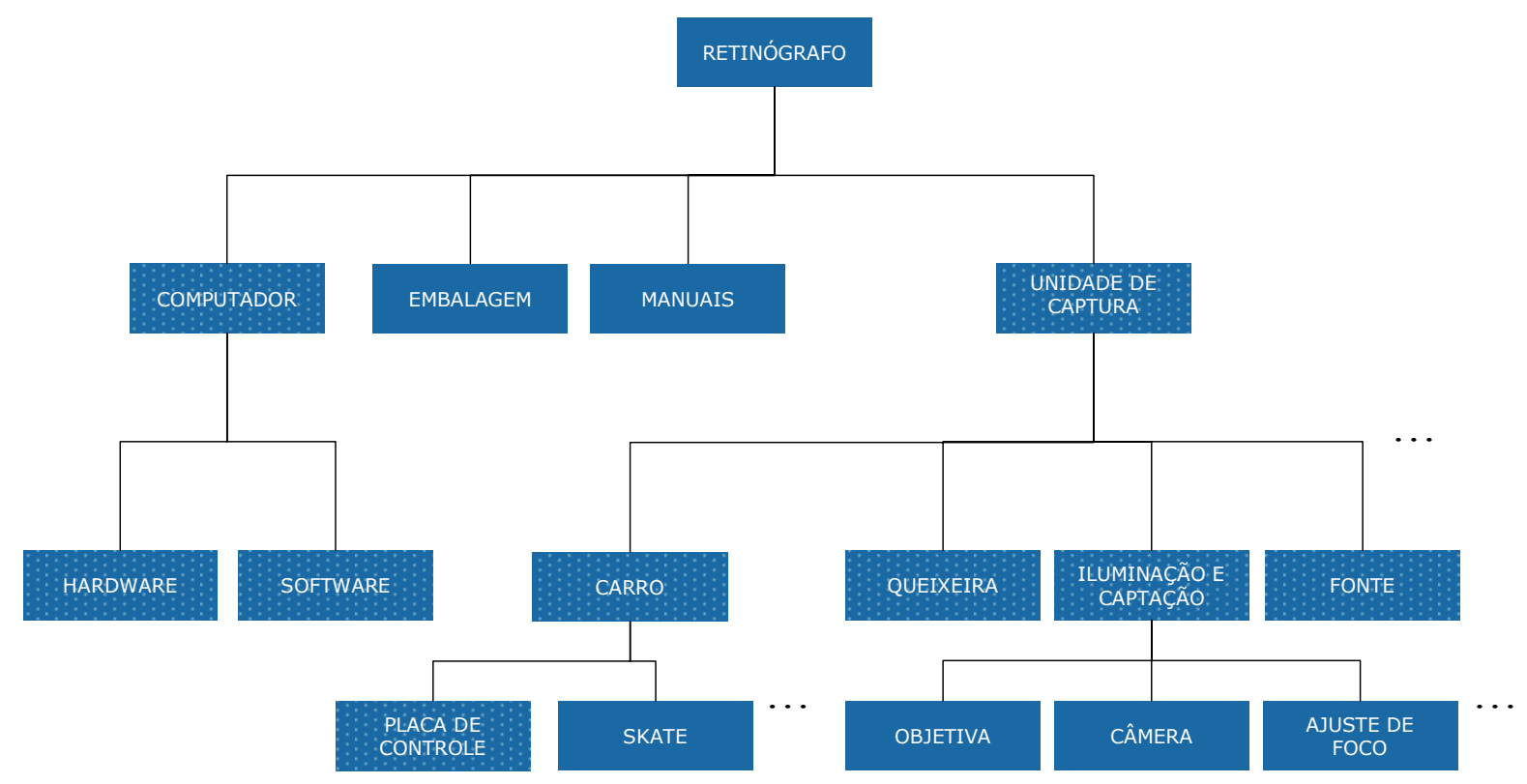

Figura 57 - Árvore de produto: equipamento de fotografia da retina

\subsubsection{Fase de projeto técnico}

A Figura 58 apresenta a fase de projeto do produto. Ela segue a estrutura proposta por CLAUSING (1994) para o qual deve haver a incorporação de novas tecnologias no desenvolvimento de um novo produto quando a tecnologia for considerada madura, o que é comprovado em um documento de análise de robustez da tecnologia.

As atividades ilustradas na parte central esquerda da Figura 58 são detalhadas de acordo com as proposições de BRADLEY (1991, item 2.1.2) e textos técnicos de cada área, tais como DORF e BISHOP (2000), HOROWITZ (1999), PRESSMAN (2001) e catálogos técnicos.

O projeto da engenharia básica consiste no detalhamento da concepção do produto para a sua função principal. O detalhamento das tarefas relacionadas com a engenharia básica do produto depende da área técnica na qual se encontram os desafios da função principal. Em mecânica consistiria no projeto de mecanismos de movimentação, em óptica, no projeto do sistema de iluminação e captação, em ciências térmicas, no projeto de isoladores e radiadores e assim por diante. Essa atividade deve produzir especificações para materiais e componentes 
consistindo no refinamento dos modelos técnicos desenvolvidos na fase de concepção (item 5.3.1.5)

O projeto eletrônico do produto mecatrônico depende da estratégia de controle adotada. Se houver controle em malha aberta, o projeto pode se resumir à definição dos sensores, de seus circuitos de alimentação e dos estágios de pré e pós-processamento necessários. Se o controle for em malha fechada, será necessário especificar o atuador a utilizar e especialmente sua potência máxima de operação. A partir daí, será especificado o circuito driver necessário e projetada a malha de realimentação.

A integração entre o projeto eletrônico e o do sistema de controle é determinada pela familiaridade da equipe de projeto com determinada aplicação. Em projetos comuns à base de conhecimentos estabelecida na equipe, pode-se projetar a malha de realimentação com base na experiência de projetos anteriores. Em projeto novos, é necessário realizar simulações em modelos matemáticos para identificar as melhores combinações para o sistema de controle.

O projeto eletrônico é determinado pelo processo de escolha de componentes. O engenheiro eletrônico, diferentemente do mecânico, estuda o campo de aplicação do projeto e busca em catálogos técnicos os componentes que atendem àquelas especificações. Os componentes, entretanto, não precisam estar disponíveis para que o projeto eletrônico de cada elemento do sistema mecatrônico - sensor, transdutor e controlador - seja detalhado em um esquema elétrico, simulado quanto às saídas de corrente e tensão, e traduzido em lay-out de placas de circuito impresso.

Os sistemas de comunicação utilizados em produtos mecatrônicos são implementados através de projeto eletrônico. Esses sistemas vão desde o processamento de sinais analógicos entre dois pontos de um produto, até a aplicação de técnicas de modulação, transmissão e recepção de sinais tal como ilustrado nas figuras Figura 14 e Figura 16. 
Os módulos de um projeto eletrônico para sistema mecatrônico comumente resultam em diversas placas de circuito impresso (PCBs). É fundamental o desenvolvimento de diagramas de blocos nos quais sejam detalhados os sinais de interface entre as placas. As interfaces são implementadas por concectores e cablagem cujas especificações técnicas devem ser geradas ao longo do projeto. Enfim, o projeto eletrônico pressupõe o suprimento de potência às PCBs e aos componentes discretos utilizados, tais como motores, sensores, geradores de clock etc.

É comum que os sistemas de controle sejam implementados através de componentes microprocessados. Nesse caso, ao invés de um conjunto de circuitos integrados (CIs) discretos, o controle é realizado pela programação assembly do dispositivo microprocessado. Um importante aspecto do projeto é, então, a escolha do CI utilizado. O CI deve ser escolhido com base em: (1) quantidade de portas de entrada e saída (I/O) disponíveis contra as demandas em termos de sinais a serem monitorados e gerados na aplicação; (2) tipo e tamanho da memória interna do dispositivo; e (3) sua capacidade de processamento. Além dos sinais de I/O deve-se identificar as condições da aplicação que determinarão as interrupções a serem respondidas pelo CI.

O projeto de software de alto nível consiste na produção do código que implementa as funções definidas na análise de requisitos de software. Antes de implementado o código, há uma série de questões relacionadas ao software que devem ser contempladas ao longo do projeto. Dentre essas questões estão a escolha da linguagem de programação a ser utilizada, do sistema operacional e da estratégia de implementação do banco de dados do sistema, quando existir. 


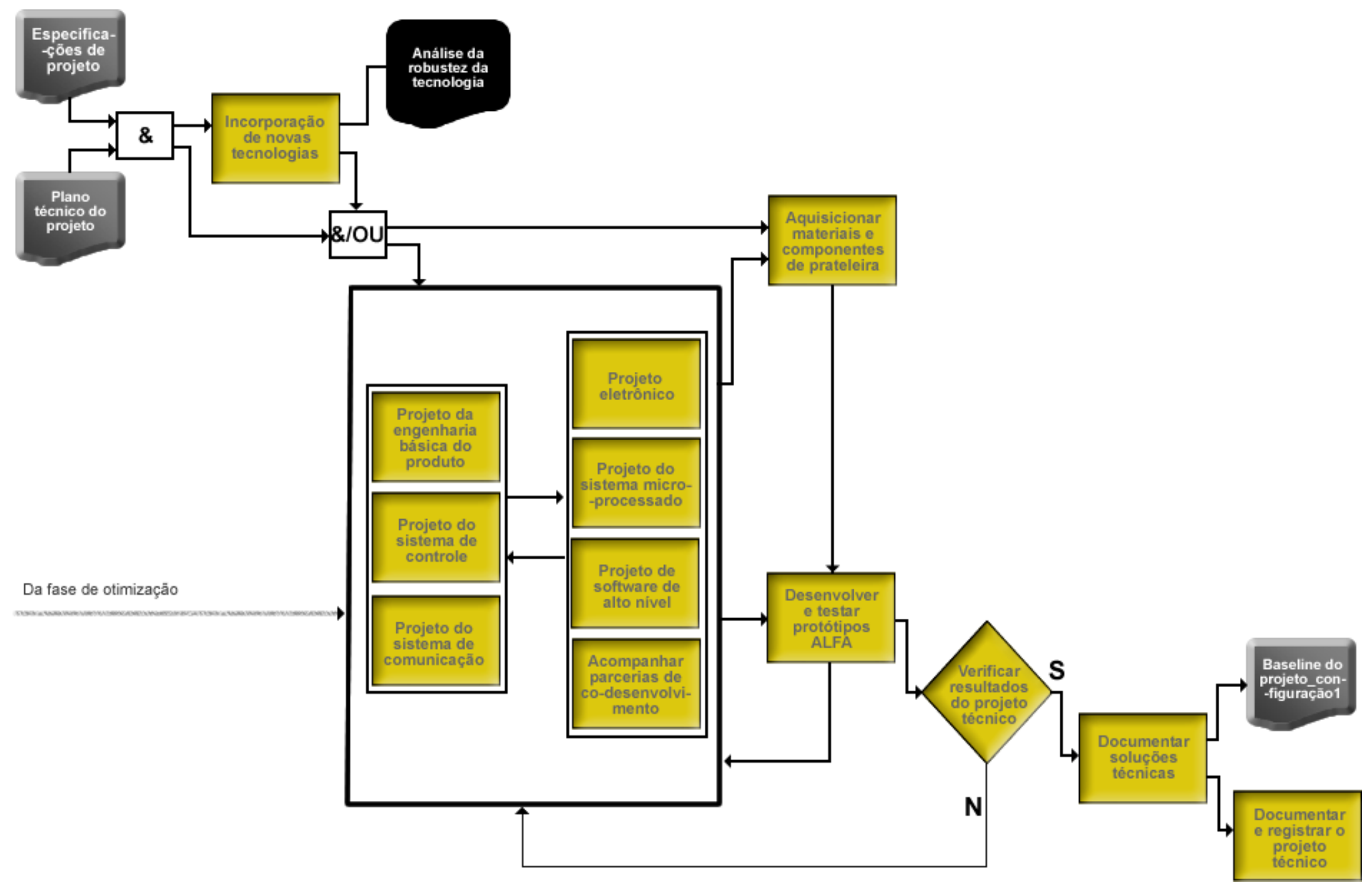

Figura 58 - Fase de projeto do produto 
É importante observar que o projeto de software de alto nível em produtos mecatrônicos pode implicar na utilização de hardware adicional que permita a interface entre o software e o restante do equipamento. Esse hardware consiste em placas de aquisição ou de bancos de funções manipuláveis por software.

As atividades discutidas acima consistem no projeto do produto mecatrônico em termos de suas funções primárias. Esse projeto deve ser testado em um protótipo funcional denominado "protótipo alfa" (ver item 5.2.5). Nele não há funções secundárias implementadas. Para que esse protótipo seja confeccionado, deve-se aquisicionar materiais e componentes de prateleira (on-the-shelf), assim como, acompanhar sistematicamente os parceiros de co-desenvolvimento.

Há um ciclo de realimentação no fluxo principal dessa fase uma vez que o protótipo alfa apenas pode ser considerado aprovado caso os experimentos realizados com ele indiquem o cumprimento das especificações do projeto, através da análise de sua matriz de verificação.

Uma vez considerados satisfatórios os resultados de testes com o protótipo alfa, deve ser realizado o gate da fase. Ele deve ser formatado como gate técnico que consiste em uma revisão de pares. Aprovados os testes, as soluções técnicas são documentadas com base na árvore de produtos e o processo de execução da fase é sistematizado e registrado. Caso negativo, retorna-se ao conjunto de atividades paralelas ilustrado na Figura 58.

As soluções documentadas na fase de projeto subsidiam a confecção da configuração inicial da baseline de projeto (configuração de projeto_1 - ver item 5.2.6).

\subsubsection{Fase de otimização do produto}

A Figura 59 apresenta a fase de otimização do projeto do produto. Além do desenvolvimento das funções secundárias, a otimização comporta atividades de análise que 
visam o aumento da robustez e confiabilidade do produto, conforme CREVELING et al. (2003).

A entrada básica da fase de otimização é a "configuração_1" do projeto. Conforme discutido no item 5.3.1.7 essa configuração consiste no projeto da engenharia básica, mecânico, eletrônico e de software necessário à implementação das funções primárias.

As funções secundárias estão relacionadas com aspectos de suporte físico do produto, interfaces humano-máquina (IHM), sistema de alimentação elétrica e design/mecânica relacionada. Essas atividades devem ocorrer simultaneamente. Em determinadas situações os aspectos de design e IHM podem vir a ser tratados como funções primárias.

A interface humano-máquina pode abranger importantes elementos do projeto de software de alto nível que são normalmente compostos de complexas interfaces gráficas acessadas via computador. Quanto ao projeto de design e carenagem, as tarefas básicas são baseadas nas propostas de ULRICH e EPPINGER (1995).

Os equipamentos de suporte do produto podem ser de diversos tipos, tais como racks, mesas especiais etc., cuja função principal é fixar o produto em seu local de operação, tendo funções auxiliares voltadas à segurança, ao conforto de operação e uso etc. A Figura 60 mostra equipamentos do tipo rack e mesa. A terminologia "equipamentos de suporte" pode ser usada para designar partes do produto com função de teste. Isso é comum em sistemas mecatrônicos usados na áreas espacial. Nesses casos, o desenvolvimento desses equipamentos deve ser tratado como projeto à parte, com planejamento de recursos, WBS e cronograma próprios. 


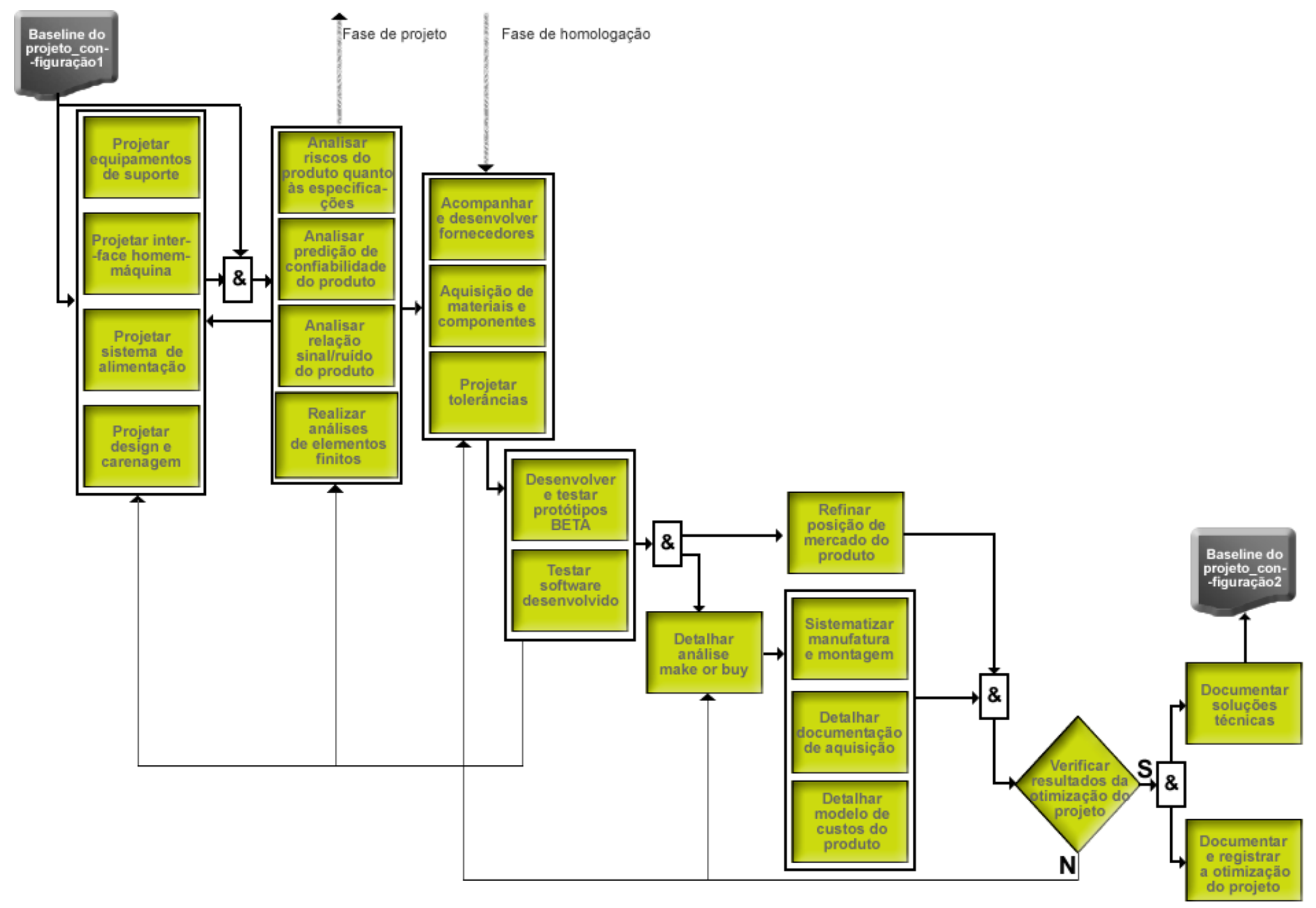

Figura 59 - Fase de otimização do produto 
O sistema de alimentação é a parte do projeto eletrônico de um produto mecatrônico na qual estão consolidadas as decisões de projeto relativas ao aterramento do sistema, nível de ruído em operação, blindagem à radiação eletromagnética e capacidade de suporte a descargas eletrostáticas. A alimentação do equipamento deve ser dimensionada para as condições máximas de carga e considerar o uso de dispositivos de supressão de transientes e de materiais isolantes.
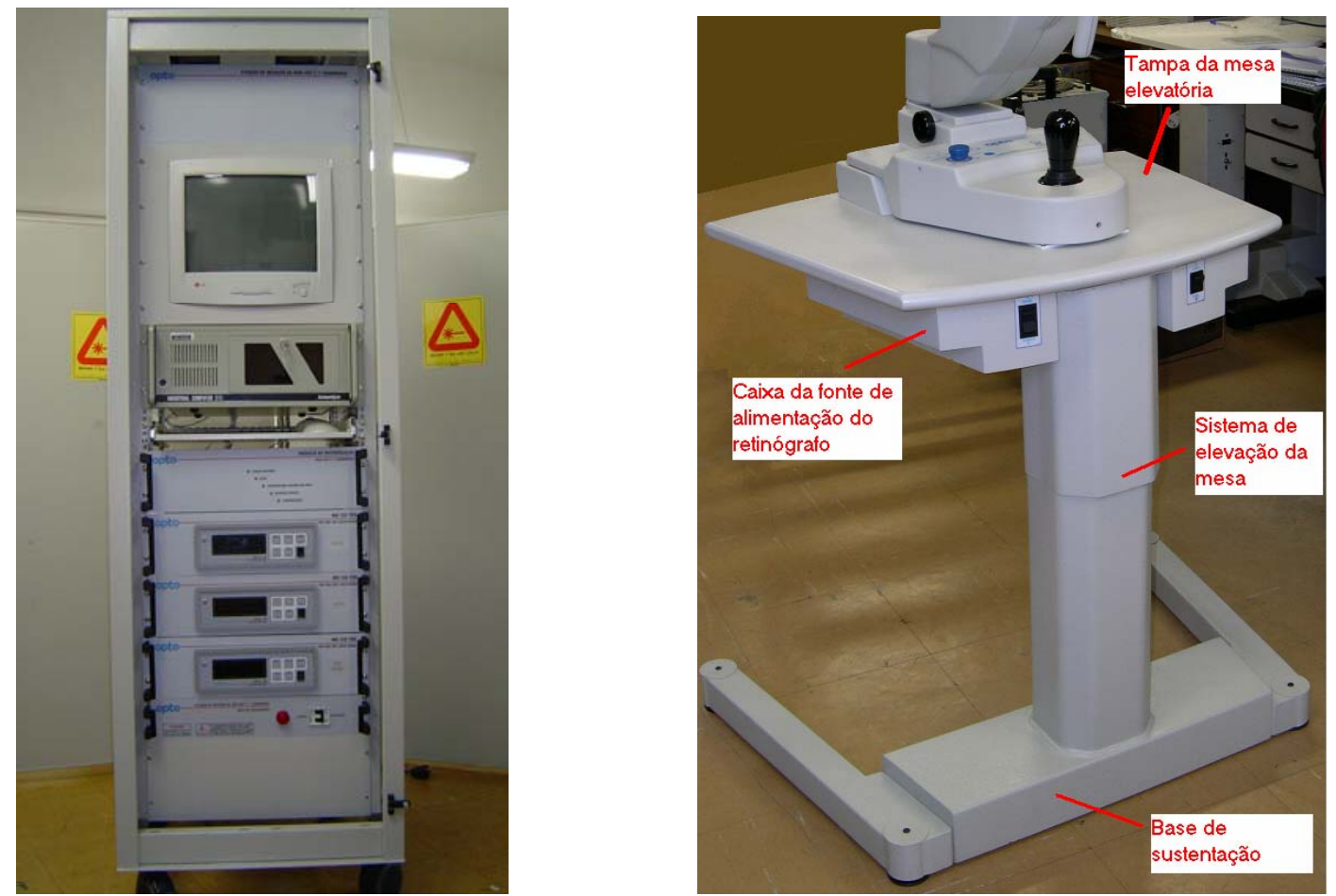

Figura 60 - Ilustrativo de equipamentos de suporte para produtos mecatrônicos: (a) rack de unidade de medição de circunferência; (b) mesa elevatória de retinógrafo digital.

As atividades realizadas na fase anterior e as acima discutidas permitem que sejam desenvolvidas soluções técnicas para todas as partes que compõem o produto mecatrônico. De posse dessas soluções, deve-se realizar análises que permitam refiná-las para evitar a incorrência de riscos de segurança, falhas não previstas e baixa robustez do produto. Essas análises devem ocorrer em paralelo podendo surgir demandas para a revisão das soluções desenvolvidas nas fases de otimização e de projeto técnico, o que implementa o loop de projeto ilustrado na Figura 46. 
A análise de falhas do produto quanto às normas técnicas a ele aplicáveis consiste na realização de uma análise de árvore de falhas (fault tree analysis - FTA) baseada nos riscos identificados nas normas técnicas, podendo também ser realizada através de formulário FMEA. A análise de confiabilidade do produto é realizada sobre os módulos eletrônicos e deve seguir diretrizes de normas militares, tais como MIL-HDBK-217F (1995).

As análises sinal/ruído do produto abrangem a identificação das influências de ruídos impostos por condições ambientais ou gerados internamente por soluções de projeto sobre os parâmetros críticos do produto. Essa análise implica em definir as propriedades físicas, químicas ou biológicas afetadas e tratá-las, o que depende da experiência técnica dos projetistas.

A análise por elementos finitos consiste, primeiramente, na definição das condições de carga, da flexibilidade necessária à estrutura do produto e de condições de vibração às quais ele está exposto. É elaborado um modelo em elementos finitos e são realizadas simulações que permitem refinar as especificações de materiais, geometria e processos construtivos.

Refinado o projeto através do ciclo projeto-análise-projeto, passa-se às atividades necessárias à elaboração do protótipo beta do produto. Deve-se projetar as tolerâncias do produto. As especificações das partes subcontratadas são refinadas com os resultados das análises e são repassadas aos parceiros de desenvolvimento. As partes e componentes são adquiridas, as peças são fabricadas e o protótipo beta é montado, integrado e testado. Os resultados de testes podem indicar a necessidade de mudanças de projeto. Realiza-se novo ciclo projeto-análise-projeto, nova aquisição, fabricação e montagem até que os resultados do protótipo beta sejam satisfatórios.

Os testes de protótipos de produtos mecatrônicos abrangem funcionalidades implementadas por software, mas é normativo que os softwares sejam testados separadamente 
do restante do produto e que esses testes sejam registrados e transformados em relatório técnico.

Um protótipo beta que satisfaça à matriz de verificação indica a conclusão do loop de projeto. Deve-se, então, detalhar a análise make-or-buy realizada anteriormente, assim como a manufatura, a montagem e a documentação necessária à aquisição. Isso permite que o modelo de custos desenvolvido para o produto seja refinado através do detalhamento da lista de materiais (BOM). Em paralelo, deve-se realizar esforço de refinar a posição mercadológica do produto.

Os resultados conseguidos na fase de otimização são analisados quanto ao seu impacto nos prazos e orçamento do projeto e nas metas de vendas, volume e posicionamento do produto. Eles são usados para verificar quanto o produto projetado difere das diretrizes de portifólio e do conceito elaborado e quanto ele é atrativo em função de seu volume, custo e posicionamento.

As soluções técnicas são consolidadas em uma segunda configuração e o processo de otimização é documentado e registrado.

\subsubsection{Fase de homologação do produto}

A Figura 61 apresenta a fase de homologação do produto. Ela é baseada na idéia de que é necessário detalhar o processo de fabricação e montagem antes que sejam incorridos custos com o registro e a certificação do produto. A homologação de processo é um tema bastante discutido nas normas QS-9000 e GSQA.

A entrada da fase de homologação é a configuração do produto consolidada depois de aprovada a fase de otimização. De posse da baseline da configuração de projeto_2 devem ser realizadas atividades cujo objetivo é desenvolver a embalagem do produto que é um elemento 
com funções relativas à proteção do produto e cujo design deve ter sintonia com o conceito dele.

As soluções desenvolvidas para o produto passam por atividades cujo objetivo é detalhar a documentação técnica de fabricação e montagem: (1) a instalação e configuração de software e a eletrônica a ele vinculado; (2) uma revisão nas folhas de processo de fabricação utilizadas para produzir os protótipos alta e beta; (3) a confecção de desenhos de conjunto vinculados a listas de peças e procedimentos que detalhem a montagem e ajustes.

$\mathrm{Na}$ eletrônica, devem ser consolidados os arquivos de projeto de placas, com máscaras e listas de montagem. Detalhes de limpeza, isolação, crimpagem, soldas especiais e introdução de blindagem e dissipadores dos PCBs são demonstrados. O cabeamento utilizado nas interfaces entre os PCBs, assim como os conectores utilizados devem ser especificados. As formas de ancoramento, isolação, derivações etc. devem ser ilustradas. Especial atenção deve ser dada à integração entre as placas eletrônicas que implementam funções de controle e os dispositivos e placas de alimentação do sistema. Métodos de dissipação térmica, de redução da indutância de acoplamento e aumento das distâncias de separação e escoamento devem ser documentados.

A documentação de fabricação e montagem é analisada sob a ótica das possibilidades de redução de custos. Conceitos de projeto para a manufatura e montagem (Design for manufacture and assembly - DFMA) devem ser utilizados para reduzir custos de manufatura e montagem, com materiais e componentes construtivos etc. O DFMA comumente implica em alterações do projeto, o que pode resultar na revisão de atividades da fase de otimização.

Em paralelo à aplicação do DFMA, a empresa deve implementar análises de modos de falha de processo (failure mode and effect analysis - FMEA). Assim, as alterações de projeto necessárias à redução dos custos de manufatura e montagem são analisadas quanto ao seu 
impacto no risco de falhas do processo antes que se determinem ações de revisão do projeto. As alterações de projeto consideradas pertinentes são encaminhadas aos projetistas havendo um retorno do fluxo de projeto para a fase de otimização. Dessa forma, ocorre o loop de processo indicado na Figura 46.

Conclue-se o loop de processo quando todas as possibilidades de redução de custos de manufatura e montagem forem consideradas e os modos de falha do processo estiverem delimitados a valores de risco pré-definidos. Deve-se passar às atividades de refinamento da cadeia de fornecimento e documentação da produção. Seleciona-se os fornecedores que irão suprir partes na produção comercial, os quais são assessorados com vistas a sua homologação.

Essas atividades correm em paralelo com a aquisição ou fabricação de moldes e dispositivos necessários à homologação do produto. Quando dispositivos, moldes e demais recursos de fabricação estiverem disponíveis, deve-se fabricar, montar e integrar o produto de acordo com processos documentados. Os protótipos são testados com base na matriz de verificação do produto.

Deve-se realizar o cálculo da capabilidade do processo descrito no item 2.3.1.3. Os valores-meta para os cálculos de Ppk e/ou Cpk dependem do volume de produção comercial projetado. Em setores como os automotivo e eletro-eletrônico, em função do alto volume e rígidos requisitos de qualidade, esses valores são mais apertados, enquanto para baixo volume, como em produtos médicos, da área espacial, militar etc., ao invés de utilizar esses parâmetros, o processo deve ser orientado pelos métodos de "zero defeito", conforme CROSBY, 1999. 


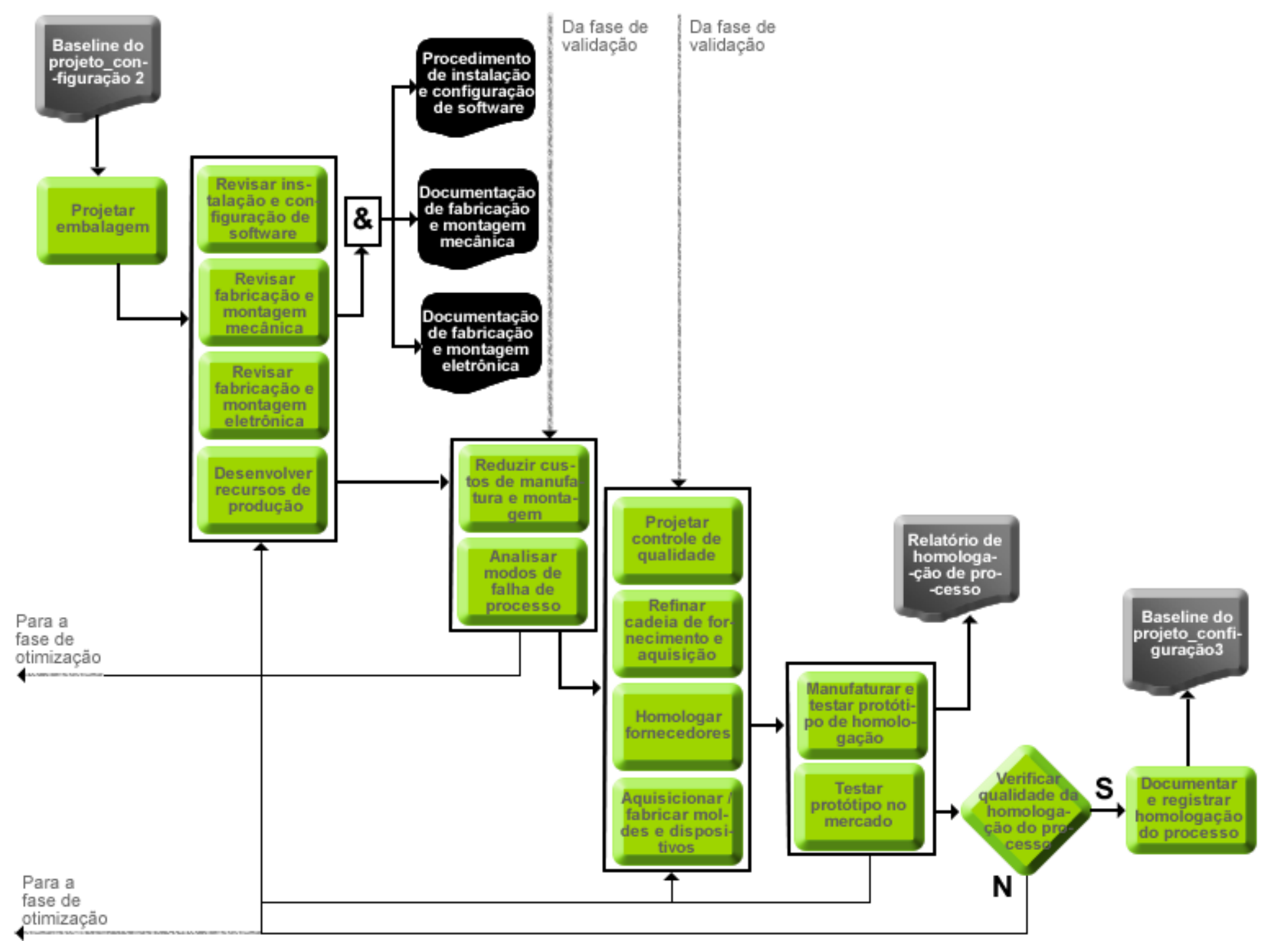

Figura 61 - Fase de homologação 
Ao final desse processo deve ser gerado um "relatório de homologação do processo" no qual constem as modificações que se fizeram necessárias nos documentos de projeto.

O gate da fase de homologação tem o custo de fabricação e montagem do produto como elemento central. Os decisores podem apontar a necessidade de revisar as possíveis reduções de custos. Podem aumentar os valores de número prioritário de risco (RPN) para o processo de manufatura e montagem e podem, ainda, sugerir alterações na cadeia de fornecimento.

Se os resultados da fase de homologação forem considerados satisfatórios, passa-se ao planejamento da fase de validação do produto, à documentação da fase de otimização com o congelamento da configuração de projeto_3 e ao registro das lições aprendidas na fase.

\subsubsection{Fase de validação do produto}

A Figura 62 apresenta a fase de validação do produto. Ela é baseada na idéia de que uma vez que o produto e o processo estão desenvolvidos e consolidados na configuração do projeto_3, é possível submeter o produto à etapas formais de conclusão do projeto estabelecidas nas normas ISO 9001:2000 e derivadas e em procedimentos formais de registro de produtos mecatrônicos em órgãos oficiais similares ao apresentado na Figura 29.

Deve-se inicialmente planejar a validação e certificação do produto. O produto é, então, documentado segundo as normas a ele aplicáveis. Essa documentação consiste de relatórios técnicos que descrevem a concepção e a arquitetura do produto e os detalhes das soluções de projeto. Ela deve ser confeccionada com base nos requisitos de segurança das normas técnicas.

Devem ser fabricados, montados e integrados os protótipos piloto a serem utilizados para a validação do produto que consiste em um processo de experimentação do produto por parte de clientes potenciais. $\mathrm{Na}$ área médica, quando o produto desenvolvido é "novo para o 
mundo", conforme a classificação de ROUSSEL et al. (1992), é necessário realizar testes clínicos que são fiscalizados pelas agências reguladoras do setor.

As sugestões dos clientes que participaram da validação do produto são analisadas quanto ao seu impacto no projeto. Modificações incrementais podem ser implementadas pelos engenheiros e encaminhadas ao pessoal de processo para a realização das mudanças pertinentes. Dessa forma, parte do loop de validação é implementado. Modificações mais impactantes são registradas e submetidas à alta gerência ao final da fase já que podem configurar novos projetos.

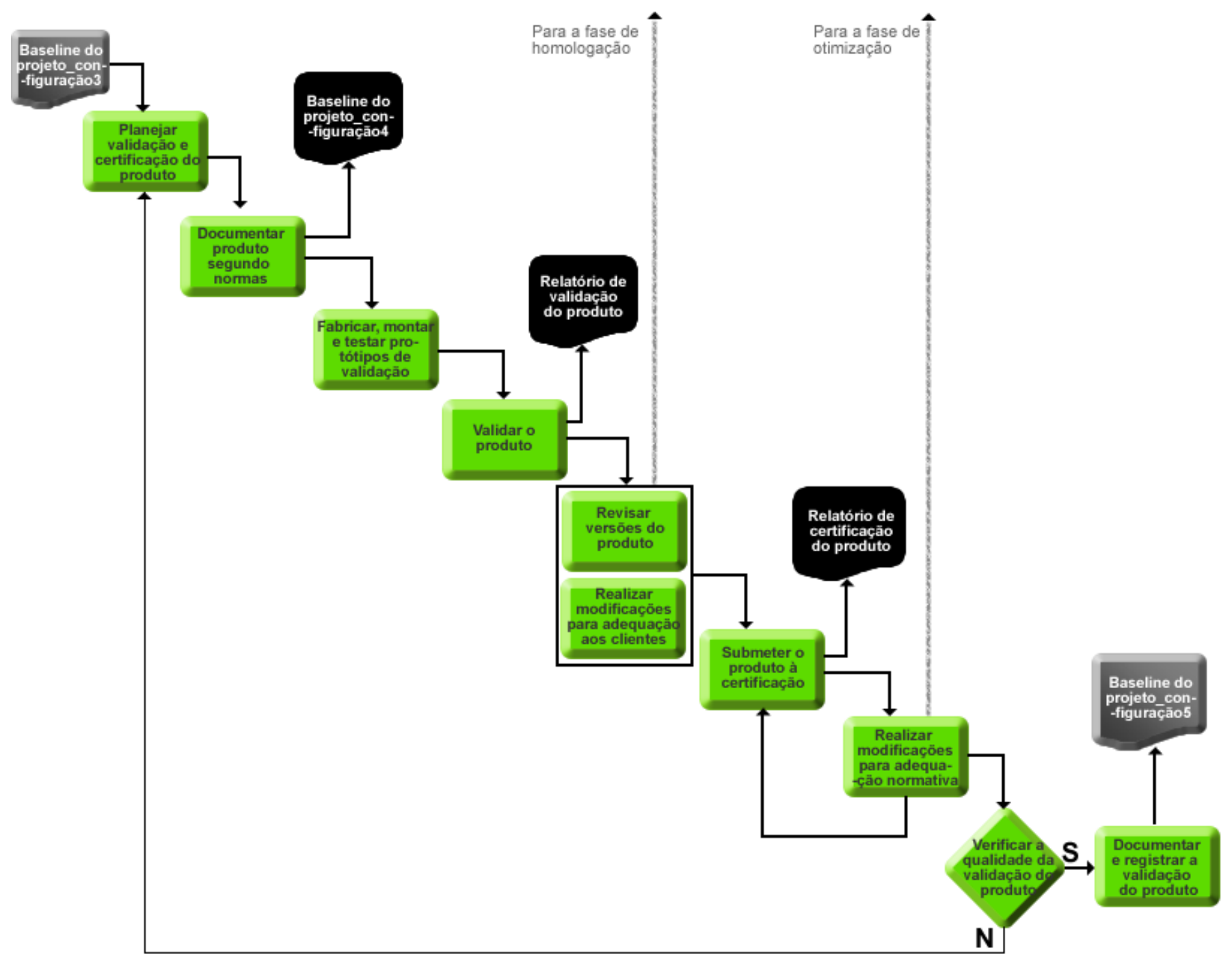

Figura 62 - Fase de validação do produto 
Após validado, o produto é submetido a testes de certificação em laboratórios credenciados para tal. $\mathrm{O}$ escopo dos testes aos quais o produto será submetido depende do mercado ao qual é destinado, entretanto, produtos mecatrônicos devem ser dimensionados pelo menos para resistir a descargas eletrostáticas e ambientes com alto campo eletromagnético.

Ao longo dos testes pode ser necessário realizar alterações incrementais no produto, tais como aumento de proteção elétrica em partes com sinais de $\mathrm{I} / \mathrm{O}$, introdução de filtros de linha, utilização de resinas e materiais isolantes em determinadas partes do circuito etc. Essas modificações incrementais são registradas ao longo dos testes e incorporadas ao projeto do produto. Caso haja implicações na documentação de processo elas devem ser enviadas aos engenheiros de processo.

Caso sejam necessárias alterações mais impactantes no projeto pode ser necessário o retorno do projeto para a fase de otimização. Nesse caso, acontece o loop de validação.

Exitosa a certificação do produto, é consolidada uma baseline do projeto denominada de "configuração de projeto_5". Os resultados da fase são, então, submetidos à alta direção. O processo de certificação pode ser replanejado, caso considerado falho, ou subsidiar o planejamento do início da fase de lançamento do produto. Ao final, os resultados da fase são consolidados e são registradas as lições aprendidas no seu decorrer.

\subsubsection{Fase de lançamento do produto}

A Figura 64 apresenta a fase de lançamento do MRM. A idéia básica dessa fase é que nela são realizadas atividades que permitam introduzir o produto no mercado de forma consistente. Essas atividades são denominadas em BENEDETTO (1999) como "decisões táticas de lançamento". 
$\mathrm{Na}$ fase de lançamento estão integradas atividades que são comumente discutidas em textos de diferentes áreas: marketing, logística, administração da produção e gestão de projetos, além de pesquisadores de PDP. As entradas para o lançamento são a configuração do projeto resultante da validação e o relatório de homologação do processo, informações essas que subsidiam um conjunto de atividades que correm em paralelo.

O desenvolvimento do plano de marketing do produto consiste no desdobramento do conceito do produto elaborado na fase de especificações (ver item 5.3.1.3). O plano de marketing (KOTLER, 2000) consolida decisões de preço, propaganda, promoção e pontos de venda.

Por outro lado, deve-se desenvolver um plano de produção para o produto. Essa atividade pressupõe a realização de tarefas de projeto de fábrica, conforme descrito em SLACK et al. (2002), assim como especificação de lead-times de fornecimento, fabricação e montagem do produto. Deve-se detalhar o projeto do lay-out da estrutura fabril necessária e as especificações acerca do perfil dos operadores a serem utilizados nas linhas de produção.

A política de estoques deve ser traçada, o que implica no dimensionamento da estrutura de almoxarifado necessária ao produto. O processo de fabricação e montagem deve ser estudado de maneira a determinar o tempo de ciclo do produto, seu takt time e os supermercados necessários ao cumprimento das metas de tempo. O controle de qualidade deve ser detalhado e adquiridos equipamentos e dispositivos necessários à medição dos parâmetros de qualidade do produto.

Integrando os planos de marketing e de produção, deve ser projetada a logística de distribuição conforme discute BALLOU (1993). O pessoal de assistência técnica deve ser qualificado para instalar e realizar reparos no produto com base em um manual de serviços. 
O produto, na configuração certificada, deve ser submetido ao registro em órgãos reguladores. Os documentos comerciais e de assistência técnica elaborados, juntamente com a configuração de projeto_5, permitem consolidar uma configuração inicial para o produto a ser lançado.

O sistema de gestão da empresa deve ser alimentado. Isso significa a consolidação do cadastro da estrutura do produto em sistemas de informação gerencial (enterprise resource planning - ERP) e a distribuição dos procedimentos de aquisição, manufatura e controle de qualidade do produto com cópias controladas pelo sistema de gestão da firma.

O produto pode então ser lançado. Cabe ao marketing definir o formato do lançamento que varia em função do tipo de produto e da posição competitiva da empresa

O ramp-up é definido como o período necessário para que o volume de produção atinja o nível pré-estabelecido nas metas de planejamento do projeto. Até esse ponto, o produto deve ser monitorado por marketing e assistência técnica, e eventuais alterações em sua configuração comercial devem ser realizadas por uma equipe de engenheiros de produto e de processo. Atingido o ramp-up, considera-se lançado o produto.

Ao final da fase deve-se consolidar um relatório do projeto. Esse relatório é analisado de maneira a extrair melhorias a incorporar nos procedimentos de gestão do PDP da empresa. 


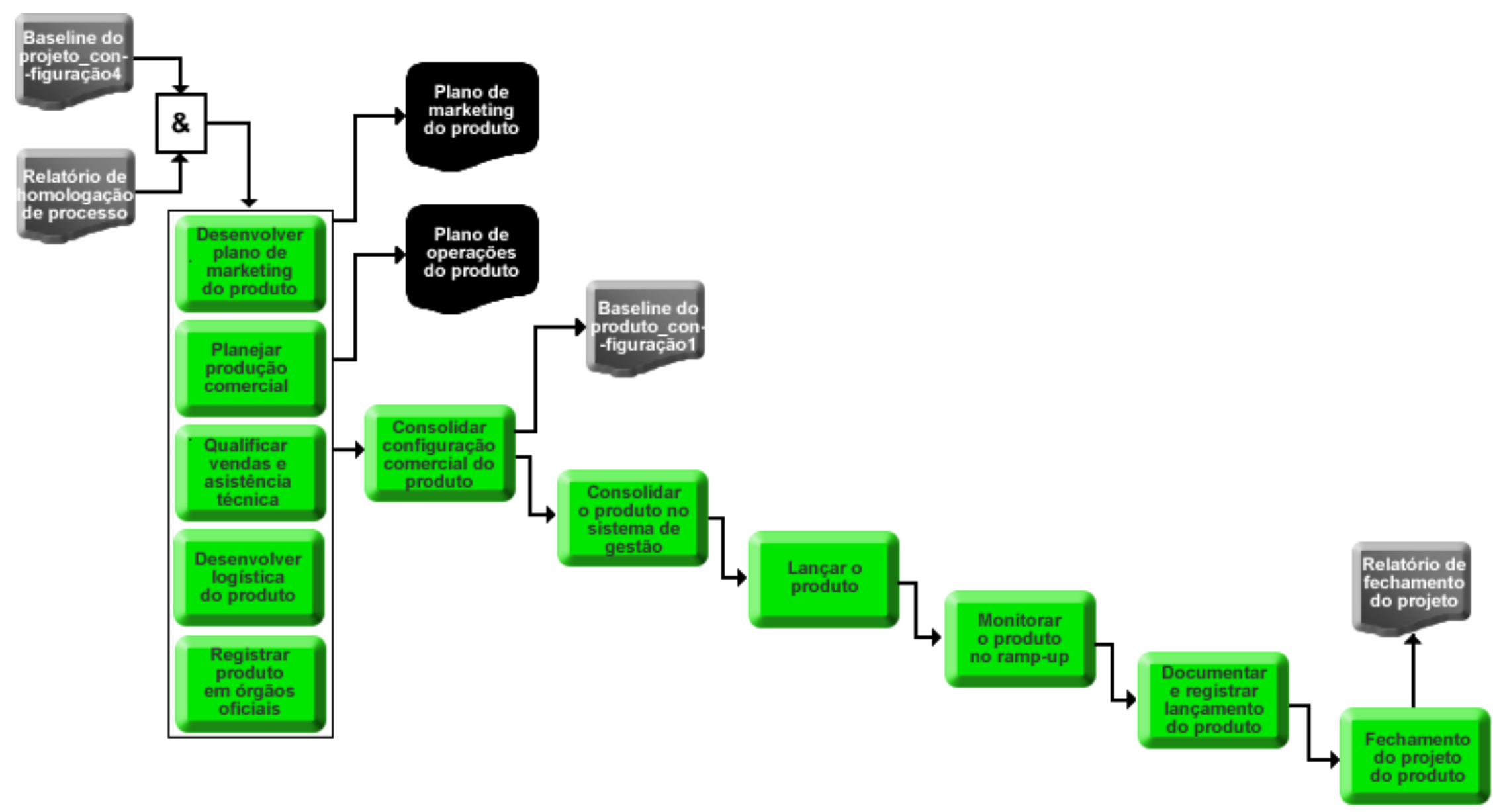

Figura 63 - Fase de lançamento 


\subsubsection{Fase de monitoramento do produto}

A Figura 64 apresenta o fluxo de atividades da fase de monitoramento do produto. Ela se inicia com a configuração do produto_1 e o relatório de homologação do processo. As atividades iniciais do monitoramento são a avaliação do desempenho do produto no mercado, na qual são levantados e sistematizados dados de volume de vendas e satisfação dos clientes; e o monitoramento dos custos, qualidade e demais fatores de desempenho relacionados com os processos de fabricação e montagem do produto.

Essas atividades permitem relacionar o que implica na satisfação dos clientes e ao mesmo tempo levantar gráficos que ilustrem o fluxo de caixa do produto e o desempenho da fábrica.

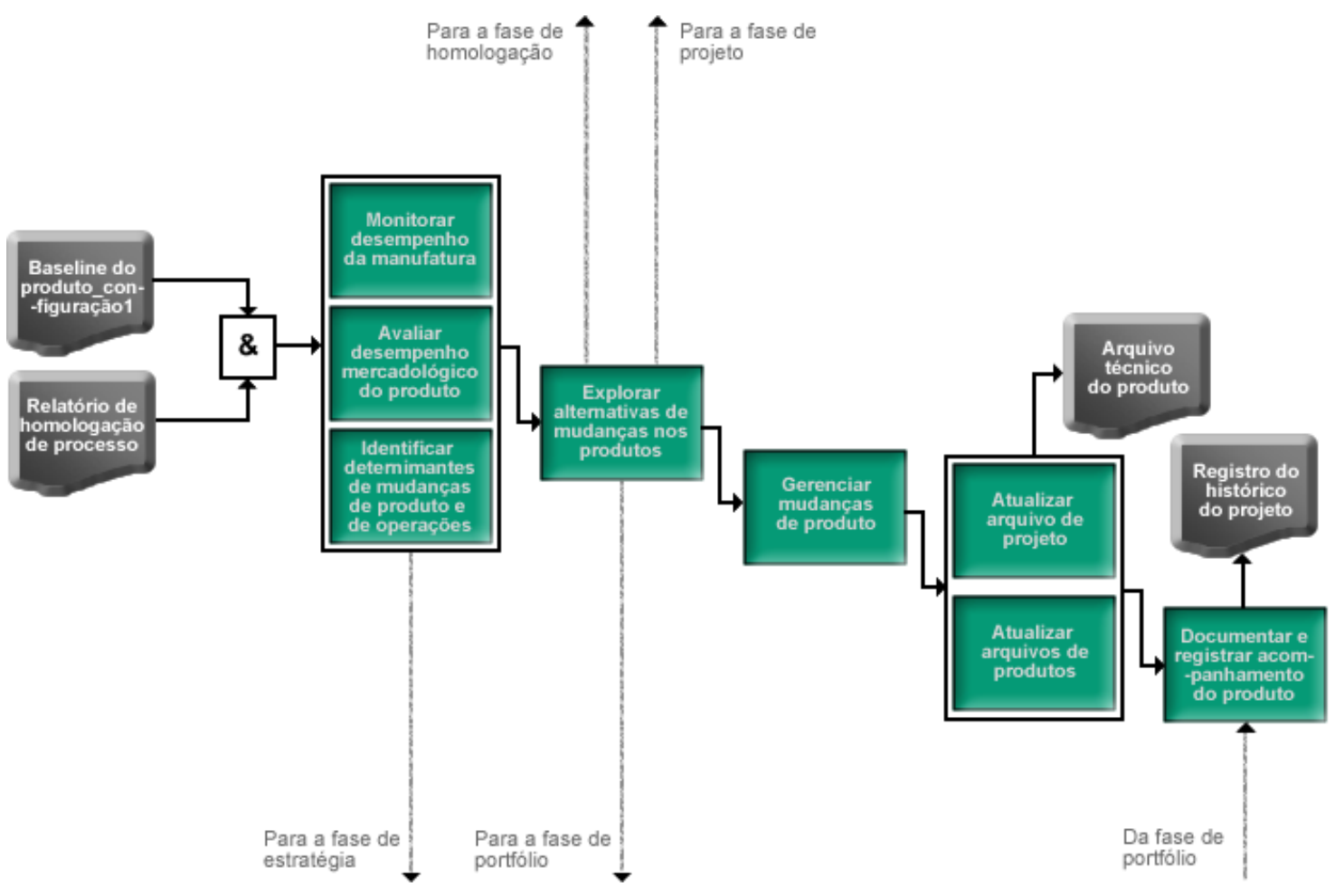

Figura 64 - Fase de monitoramento

As informações de monitoramento alimentam diretamente as fases de estratégia e portifólio, conforme ilustrado no item 5.2.3. Elas também servem para explorar possibilidades 
de melhoria no produto e no processo de fabricação. As melhorias propostas são avaliadas quanto ao seu impacto no custo e na qualidade do produto, no conceito do produto e no orçamento.

As mudanças consideradas de maior impacto e orçamento acima de determinado nível pré-estabelecido devem alimentar a fase de planejamento do portifólio de produtos. Elas podem implicar em novos produtos ou versões significativamente diferentes dos existentes. Mudanças de menor impacto e orçamento são especificadas e alimentam a execução das fases de projeto do produto ou do processo (F7, F8 e F9).

Passa-se, então, a gerenciar as mudanças de menor impacto a serem realizadas nos produtos em linha. Esse processo é comumente chamado de gestão de mudanças de engenharia (engineering change management - ECM) e consiste em uma das principais atividades de controle de configurações descritas na bilbiografia técnica em PDP, como por exemplo em ROZENFELD et al. (2006).

Após concluídas as mudanças em produtos e/ou processos, realiza-se um conjunto de tarefas que objetivam atualizar os arquivos técnico do projeto e do produto. Essas atividades permitem a manutenção do histórico técnico do produto, o que é importante para efeito da realização de auditorias de certificação realizadas por terceiros.

\subsection{Formas de aplicação do modelo}

Os conceitos desenvolvidos neste capítulo permitem que sejam realizadas algumas considerações acerca da aplicação do MRM baseada em:

- fases: adequação do PDP de uma empresa à estrutura de fases do MRM, conforme descritas no tópico 5.3.; 
- $\quad$ atividades centrais: aplicação apenas das atividades centrais de desenvolvimento de produtos ao longo do PDP;

- $\quad$ âmbito: exploração das atividades relacionadas com um determinado âmbito de aplicação do modelo, conforme conceituado em 5.2.2.;

- $\quad$ ciclo de gestão da estratégia e portifólio: definição das atividades relacionadas com a revisão da estratégia de produtos e do portifólio da empresa, conforme item 5.2.3.;

- $\quad$ ciclos técnicos do PDP: enfoque na melhoria dos ciclos identificados em 5.2.4.;

- $\quad$ resultados: aplicação do modelo com base nos resultados a serem atingidos ao longo do PDP mecatrônico, tais como os documentos descritos ao longo das fases (tópico 5.3), protótipos (item 5.2.5) e configurações (5.2.6);

- $\quad$ áreas de processo: utilização de conceitos vinculados com áreas de processo (tópico 5.2.7) para implementar melhorias no PDP da empresa;

- $\quad$ atividades: uso dos conceitos relacionados com o aumento da capabilidade das áreas de processo para implementar melhorias nas atividades previstas no MRM sem uma preocupação sistemática na melhoria da área de processo na qual ela está inserida.

Essas formas de aplicação são possibilidades teóricas abertas pelo modelo, entretanto, sua implementação detalhada não foi abordada no trabalho. As exceções são as aplicações por áreas de processo e por atividades, as quais foram implementadas no estudo de caso longitudinal mencionado no item 3.2.4, sendo descritas nos tópicos 5.4 .3 e 6.2 .

\subsubsection{Aplicação por áreas de processo}

A Figura 65 apresenta a aplicação do modelo de referência através do conceito de áreas de processo. 


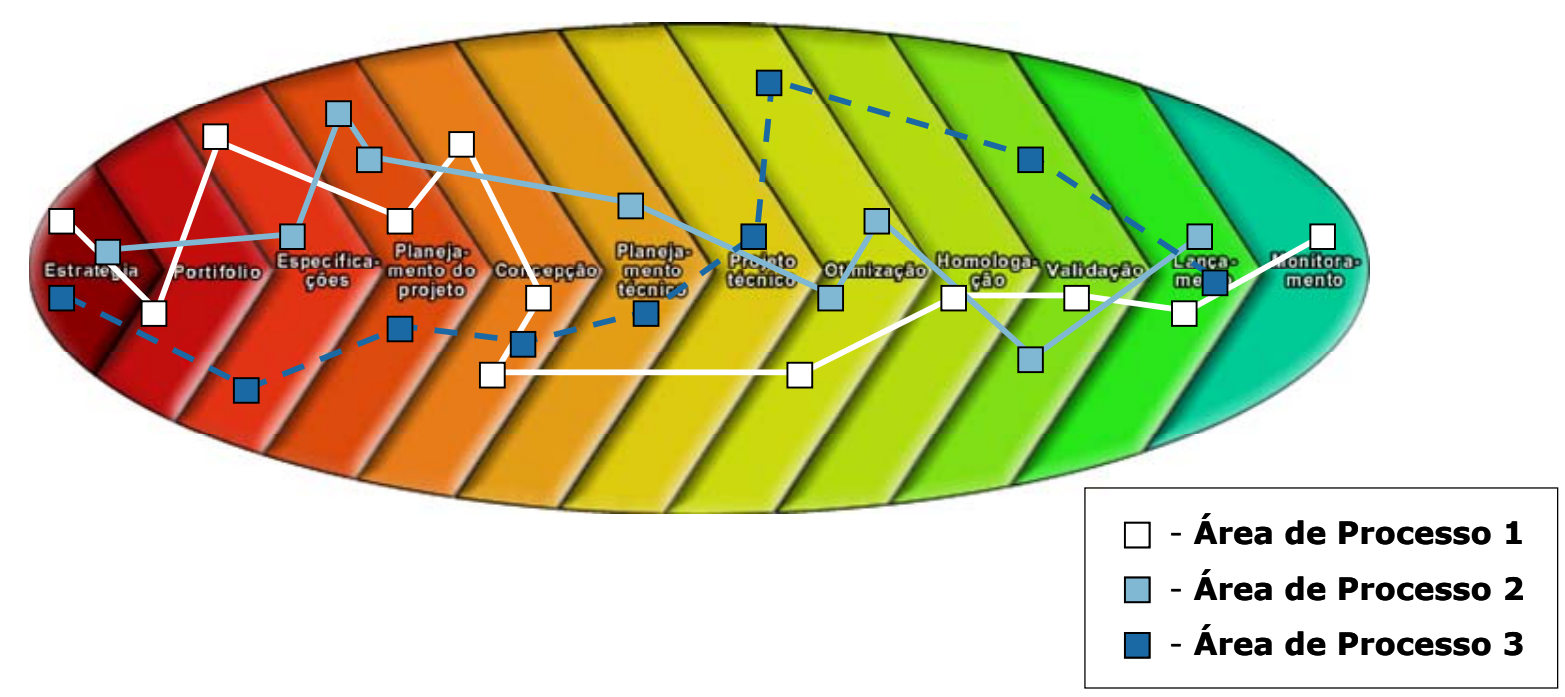

Figura 65 - Aplicação do MRM por áreas de processo

A aplicação por áreas de processo consiste em selecionar as atividades de uma determinada área, verificar seu estágio atual de capabilidade e identificar formas de melhoria a serem aplicadas em cada área de processo ou no conjunto delas. A aplicação é focada no conceito de atividade, porém não se preocupa na melhoria sistemática das fases do PDP, mas das atividades de uma mesma área de processo ao longo de todas as fases.

O MRM oferece ferramentas para transições de níveis de capabilidade de 0 (zero) para 1 (um), 1 (um) para 2 (dois) e 2 (dois) para 3 (três), conforme discutido no item 2.4.2. A aplicação por nível de capabilidade segue basicamente as regras a seguir:

- $\quad$ se o nível de capabilidade de uma determinada área de processo é 0 , utiliza-se as atividades do MRM como checklist do que deve ser realizado para aumentar a capabilidade da área para 1;

- $\quad$ se o nível de capabilidade é "1", as atividades devem ser planejadas para que as informações intermediárias/documentos sejam geradas de forma sistemática, o que pode ser realizado tendo como referências as templates de documentos alocadas em cada atividade do modelo e isso aumentará a capabilidade para " 2 "; 
- $\quad$ se o nível de capabilidade é "2", há alguns métodos previstos no modelo que podem ser transformados em padrões de processo a serem aplicados para que haja aumento de capabilidade para " 3 ".

A aplicação por área de processo traz a vantagem de permitir que a empresa determine suas prioridades de melhoria do PDP sem afetar significativamente sua forma de organização e enfatizando questões consideradas prioritárias pela alta gerência. Por outro lado, pode haver uma discrepância muito grande entre diferentes áreas de processo e isso implicar em subaproveitamento da alta capabilidade conseguida na área de processo enfatizada pela aplicação do MRM.

\subsubsection{Aplicação por atividade}

A Figura 66 demonstra a aplicação do modelo de referência enfatizando o tipo de conteúdo "atividade".

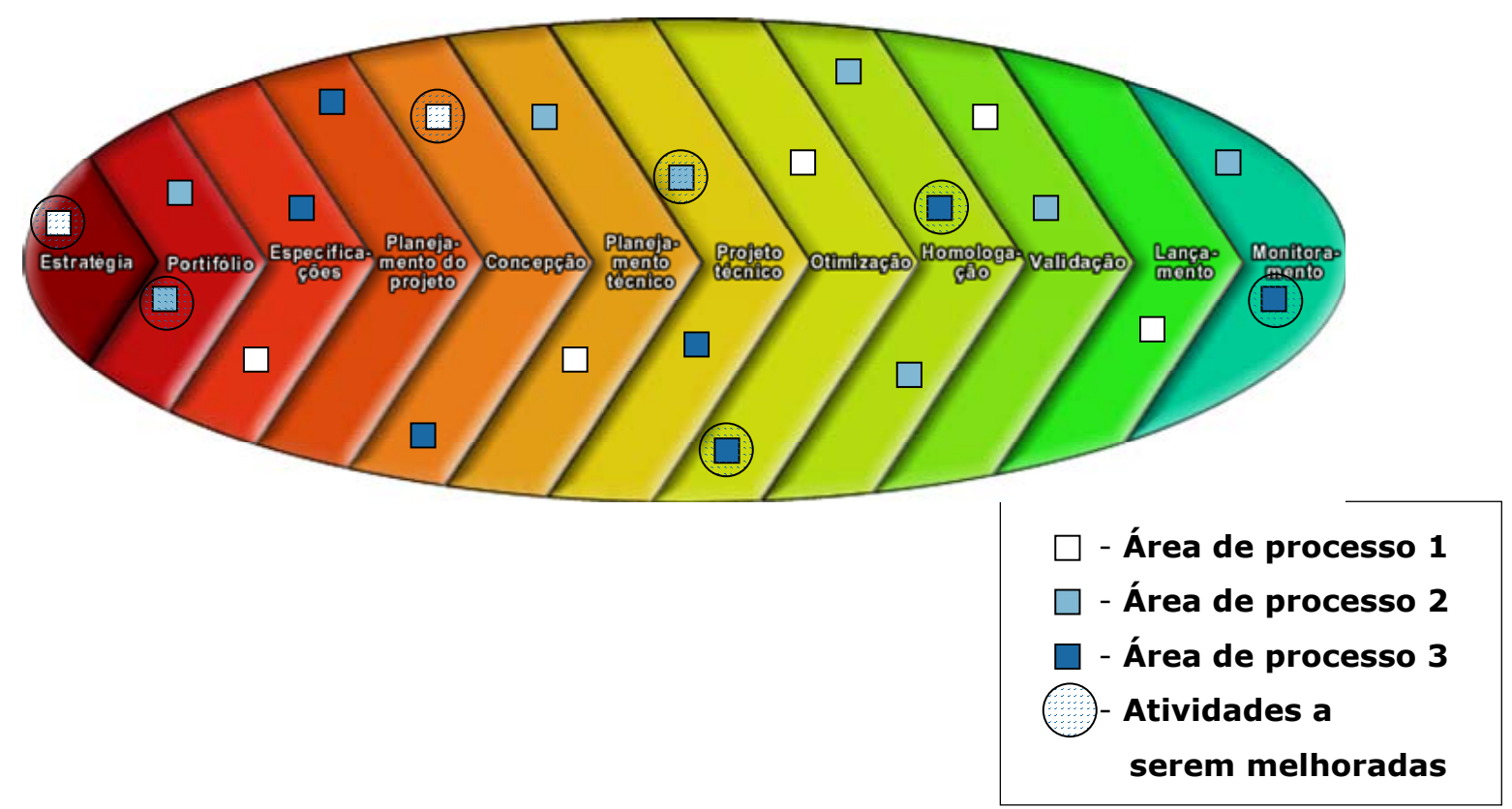

Figura 66 - Aplicação do MRM por atividade

A aplicação do modelo de referência por atividade é o formato mais simples de seu uso. Essa aplicação contempla situações nas quais a empresa deseje realizar melhorias 
pontuais no PDP em função de demandas não relacionadas com os conceitos de fases e de áreas de processo.

Esse tipo do aplicação do MRM utiliza os conceitos desenvolvidos para a aplicação por área de processo, conforme apresentado no item anterior. Nesse caso, ao invés de ser enfocada a melhoria de todas as atividades de uma determinada área de processo, a atividade na qual o modelo será aplicado é tratada individualmente. Embora se possa aplicar o modelo a todas as atividades de uma determinada área tratando uma a uma, isoladamente, isso não significa que houve aplicação por área de processo, uma vez que essa última demanda um planejamento integrado para a sua implementação.

Embora seja simples e consista na forma mais fácil de uma empresa tomar contato com o MRM, a aplicação por atividade implica em desequilíbrio entre atividades da mesma área de processo, o que pode resultar em perda do esforço de melhoria implementado, uma vez que não há sinergia entre atividades da área de processo ao longo de todas as fases do PDP, além de incorrer no mesmo problema de sub-aproveitamento da melhoria da capabilidade na área de processo considerada com relação às demais (ver 5.4.1).

\subsubsection{Método sugerido de uso do MRM por áreas de processo e por atividades}

A Figura 67 ilustra o método desenvolvido para a aplicação do MRM por áreas de processo e por atividades, conforme discutido nos itens 5.4.1 e 5.4.2.

A aplicação se baseia no desenvolvimento de um questionário de diagnóstico de capabilidade. Uma vez que o conceito de capabilidade de processo (ver item 2.4.2) se aplica à "[...] melhoria de processos organizacionais em áreas de processo individuais" (CHRISSIS et al., 2003, p.75), é elaborado um questionário que reflita as áreas de processo do MRM descritas no item 5.2.7, ou seja, se baseie diretamente nas atividades do modelo. 


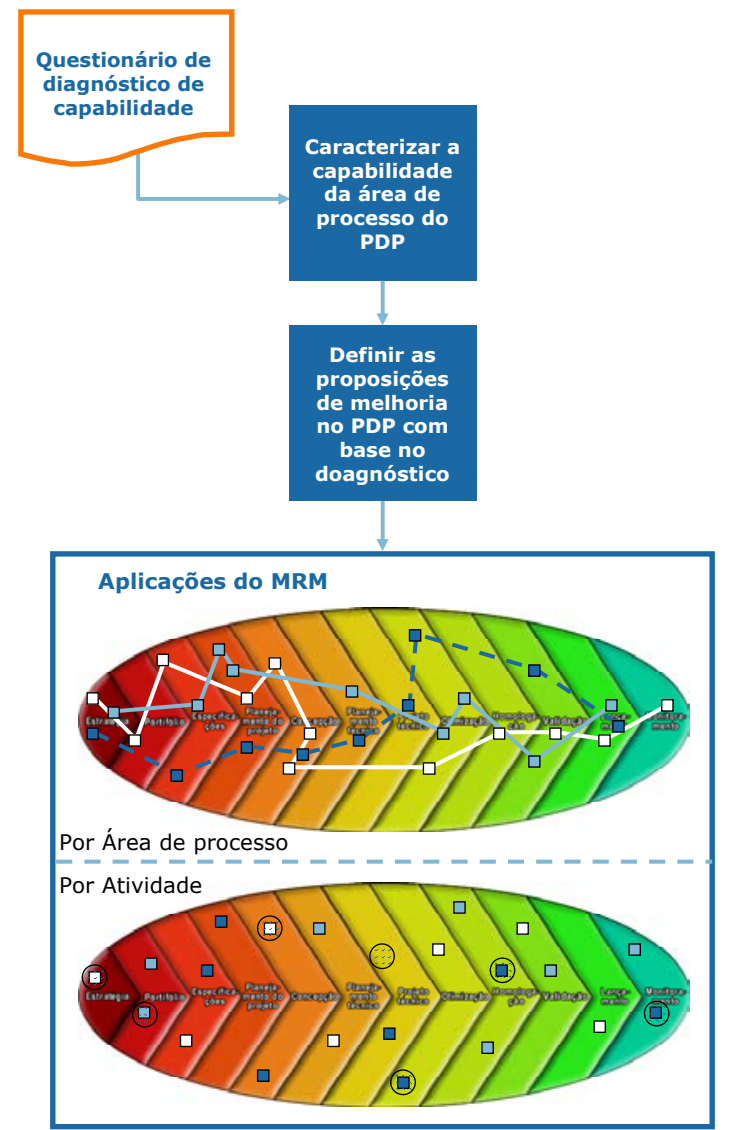

Figura 67 - Aplicação do modelo mecatrônico

Para avaliar a capabilidade de cada atividade das áreas de processo deve-se então utilizar a escala apresentada na Figura 68, cuja definição de cada nível de capabilidade baseado no CMMI seria:

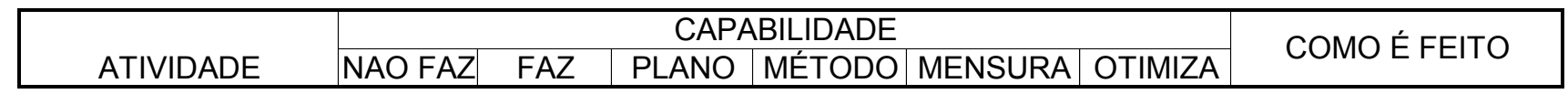

Figura 68 - Escala de aferição da capabilidade das áreas de processo do PDP

- “NÃO FAZ" - nível de capabilidade "incompleto" ou 0 (zero);

- "FAZ" - nível de capabilidade "realizado" ou 1 (um);

- "PLANO" - nível de capabilidade "gerenciado", ou 2 (dois);

- "MÉTODO" - nível de capabilidade "definido", ou 3 (três); 
- "MENSURA" - nível de capabilidade "quantitativamente gerenciado", ou 4 (quatro);

- "OTIMIZA" - nível de capabilidade "otimizado", ou 5 (cinco).

Com base no questionário, deve-se "caracterizar a capabilidade das áreas de processo do PDP”. Para isso, as atividades a serem listadas na coluna “ATIVIDADE” da Figura 68 que são baseadas nos fluxos de atividades das fases (itens 5.3.1.1 até 5.3.1.12) do MRM, podem ser desdobradas em suas tarefas (como por exemplo na Figura 34) se considerado necessário explicitá-las às pessoas a serem entrevistadas para a caracterização do PDP da empresa.

Uma vez que as denominações descritas na coluna "CAPABILIDADE” da Figura 68 podem implicar em confusões de entendimento por parte dos respondentes, o questionário é projetado para aplicação direta pelo aplicador do MRM.

Aplicado o questionário, sua análise consiste em calcular em uma escala de seis valores, o nível de capabilidade de cada área de processo. Define-se, então, as proposições de melhoria do PDP com base no diagnóstico de capabilidade, as quais são sumarizadas no item 5.4.1. Deve-se observar que se o aumento do nível de capabilidade projetado para a área de processo (conforme o conceito de perfil projetado - targeted profile, CHRISSIS et al.., 2003, p. 95) for maior que "1", pode haver problemas de implementação decorrentes da falta de maturidade do PDP da empresa, e portanto, deve ser sempre preferível aumentos de capabilidade de "1" nível.

O conceito de perfil projetado pode ser utilizado para prever resultados da aplicação do MRM, o que pode ser discutido com os decisores para esclarecer os potenciais e limitações da aplicação. 


\section{APLICAÇÃO DO MODELO DE REFERÊNCIA MECATRÔNICO}

Nesse capítulo será discutida a aplicação do Modelo de Referência Mecatrônico. Inicialmente será discutido o método de aplicação do MRM com vistas à validação das proposições de uso do modelo (item 6.1), posteriormente será apresentada a aplicação propriamente dita (item 6.2) e, então, seus resultados (item 6.3).

\subsection{Método de aplicação do MRM}

As formas de aplicação do MRM propostas no item 5.4 são baseadas no conceito de áreas de processo. $\mathrm{O}$ método de aplicação do MRM apresentado nesse item tem uma forte sinergia com a validação da hipótese de pesquisa construída no item 1.2 e deve permitir o teste das proposições formuladas no item 3.2.3, a saber:

- as áreas de processo nas quais houve maior grau de aplicação do modelo devem ter maior aumento em seu nível de capabilidade (PROP_1) - caso o modelo seja aplicado e o resultado final aponte para o aumento da capabilidade das áreas de processo nas quais houve maior número de atividades abordadas na aplicação, pode-se considerar que houve consistência teórica das áreas de processo desenvolvidas, ou seja, que elas representam de fato o conceito desenvolvido por CHRISSIS et al. (2003).

- $\quad$ a aplicação do modelo deve resultar em melhoria significativa em indicadores de desempenho do PDP (PROP_2) - independente das áreas de processo nas quais o modelo foi aplicado, o resultado final deve indicar melhoria em fatores de desempenho consagrados na literatura de PDP, conforme descritos no APÊNDICE B.

A validação dessas proposições é testada através das etapas ilustradas na Figura 69 que são em número de três: uma etapa inicial de teste da PROP_1 mediante a aplicação de um questionário de diagnóstico e do próprio MRM; uma etapa intermediária de teste de refutação 
da PROP_1 e análise do relacionamento entre capabilidade de processos e melhoria de indicadores de desempenho; e uma etapa final de compilação de lições aprendidas na aplicação do modelo. Abaixo essas etapas são descritas:

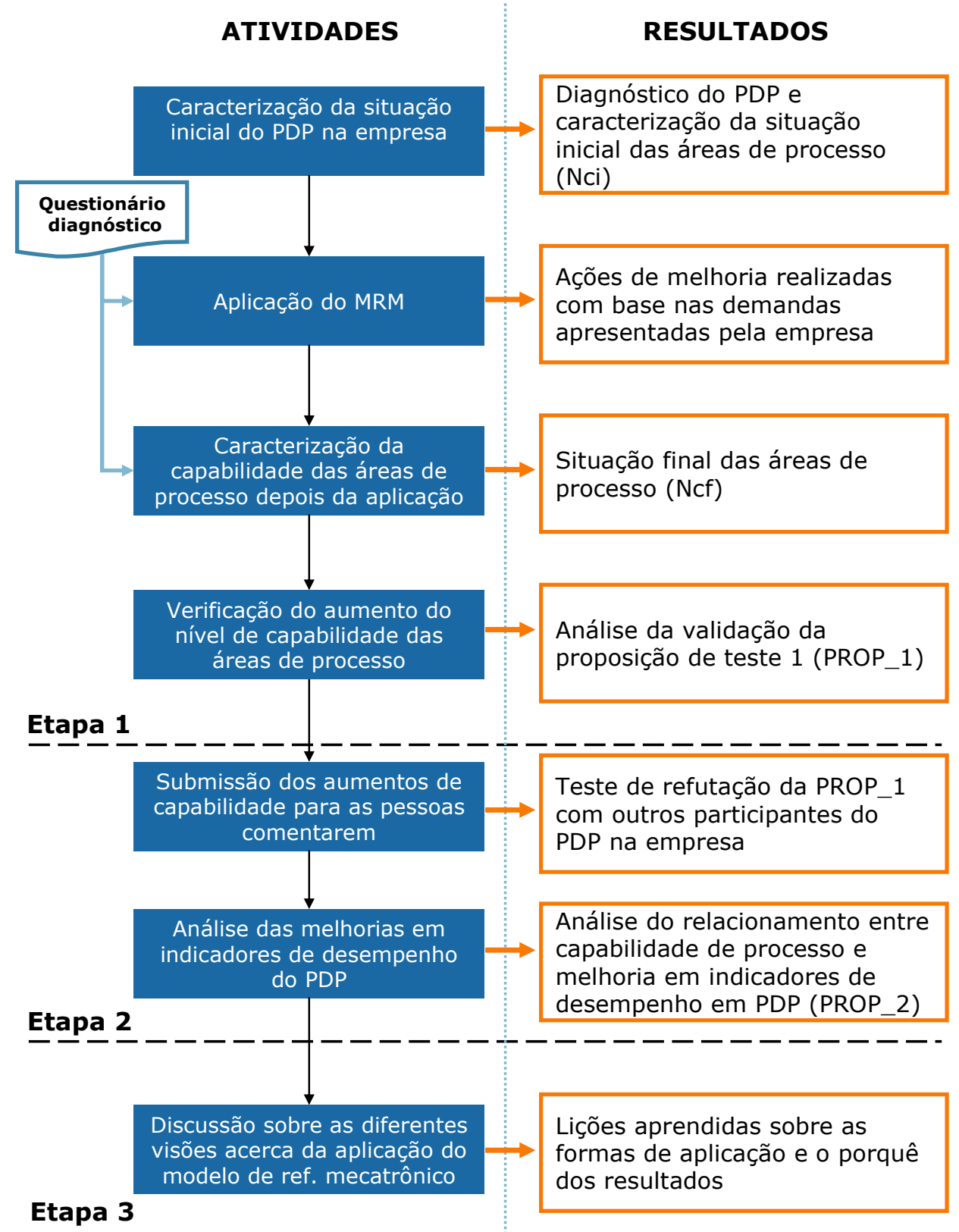

Figura 69 - Utilização do método sugerido para a aplicação do MRM para o teste das proposições de validação do modelo

Na ETAPA 1, inicialmente o questionário diagnóstico de capabilidade (ver Figura 68) é aplicado à empresa sendo registrada a situação inicial das áreas de processo (nível de 
capabilidade inicial $-\mathrm{N}_{\mathrm{ci}}$ ). Para cada atividade é estabelecida uma estratégia de aplicação do modelo conforme o procedimento sugerido no item 5.4.3. Aplica-se o modelo e ao final, uma outra aplicação do questionário de capabilidade registra a situação final das áreas de processo (nivel de capabilidade final $-\mathrm{N}_{\mathrm{cf}}$ ).

O grupo ao qual é submetido o questionário de diagnóstico de capabilidade deve ser designado pela alta direção da empresa ou pelo responsável pela gestão de processos na empresa. É importante que as pessoas às quais seja submetido o questionário tenham respaldo para responder oficialmente pela empresa com relação a suas áreas específicas de atuação.

Levantados o $\mathrm{N}_{\mathrm{ci}}$ e o $\mathrm{N}_{\mathrm{cf}}$, calcula-se o grau de melhoria do nível de capabilidade do processo através da fórmula:

$$
\Delta_{\mathrm{c}}=\mathrm{N}_{\mathrm{cf}} / \mathrm{N}_{\mathrm{ci}}
$$

Compara-se em seguida, as aplicações realizadas com base no modelo de referência, com as estratégias de melhoria. Tem-se então as seguintes possibilidades:

- Situação_1: se $\Delta_{c}>1$ a hipótese de pesquisa está validada e o modelo pode ser considerado potencialmente validado; e

- $\quad$ Situação_2: se $\Delta_{c}<1$ o modelo não está validado pela aplicação, e portanto, seus conceitos devem ser revistos.

Caso tenha sido detectado aumento da capabilidade do PDP na empresa com base nas aplicações do MRM, há, ainda, duas fontes potenciais de erro que podem mascarar os dados necessários à validação do modelo. São elas: (1) a pessoa entrevistada pode tender a responder que houve melhoria nas atividades em que é questionada; e (2) as pessoas avaliam a capabilidade com base no próprio modelo, o que pode reforçar a tendência de considerá-lo validado. 
Esses erros implicam em se considerar que na situação_1, há a possibilidade de não ter sido validado o modelo. Ou, em outras palavras, a aplicação do questionário de capabilidade apenas demonstra que o modelo está potencialmente validado. Em função desses erros potenciais, realiza-se a ETAPA 2 da validação das hipóteses de pesquisa, conforme ilustrada na Figura 69 que consiste em elaborar uma segunda ferramenta de levantamento de dados que permita:

- $\quad$ submeter os resultados de aumento de capabilidade das áreas de processo para que pessoas que não responderam ao questionário original exponham sua opinião de concordância ou discordância em relação a eles; e

- $\quad$ analisar a melhoria de indicadores de desempenho do PDP na empresa.

Submetendo os resultados detectados para o aumento de capabilidade de cada área de processo a pessoas que não participaram do diagnóstico de situação inicial e final de capabilidade é possível verificar se os resultados do primeiro grupo analisado se repetem. Além disso, como esse último grupo analisado não é o designado pela alta direção da empresa, há um relaxamento na tendência de responder que houve melhoria nas áreas de processo. Outro aspecto que tende a relaxar distorções da ETAPA 1 da validação é o fato de escolher para o grupo ao qual é submetido o modelo na ETAPA 2 pessoas que são usuárias operacionais das melhorias implementadas.

A segunda fonte de erro é minimizada pela não-utilização direta dos conceitos do modelo de referência para avaliá-lo. Ou seja, ao invés de utilizar o próprio modelo para verificar sua validade, utiliza-se indicadores de desempenho reconhecidos como capazes de demonstrar a melhoria do PDP, conforme ilustrados no APÊNDICE B. Adicionalmente, esse procedimento permite relacionar aumento de capabilidade com melhoria de indicadores de desempenho do PDP, relação não identificada na bibliografia especializada na área. 
Com base na ETAPA 2, pode-se considerar o modelo de referência mecatrônico validado caso haja concordância dos entrevistados com relação aos graus de aumento de capabilidade detectados na ETAPA 1. A concordância é suficiente para validar a hipótese da pesquisa, uma vez que ela demonstra que o projeto do processo com base na teoria de PDP gerou um modelo de referência capaz de ser aplicado em situações reais e que tem resultados capazes de serem explicados pelos próprios referenciais teóricos que o embasaram, no caso, o conceito de capabilidade de processos.

A análise da melhoria de indicadores de desempenho do PDP permite agregar uma contribuição ao referencial teórico de PDP no sentido de entender as relações entre aumento de capabilidade e melhoria de indicadores de desempenho.

As análises realizadas nas ETAPAS 1 e 2 de validação do modelo permitem identificar aumento, ou não, de capabilidade e melhoria de indicadores de desempenho no caso de o modelo ser considerado validado. Porém, não permitem entender o que determinou a validade ou rejeição do modelo, no sentido de identificar características da forma de aplicação, do mercado, do pessoal envolvido, da cultura da empresa e dos desafios a ela impostos etc. que refletiram nos resultados da aplicação do MRM.

Esses aspectos são abordados na ETAPA 3 da validação do MRM. Nela, solicita-se ao grupo pesquisado na ETAPA 2 que comente como vê o processo de desenvolvimento de produtos na empresa em comparação com o momento delimitado pela situação inicial de capabilidade, que comente o porquê dos graus de aumento de capabilidade detectados e teça comentários gerais sobre a aplicação do modelo mecatrônico na empresa. Dessa forma, buscase entender o porquê dos resultados conseguidos no processo de validação e isso implica no registro de lições aprendidas com relação à aplicação, e ao desenvolvimento, de modelos de referência. 
A ETAPA 1 do trabalho de aplicação do modelo é realizada utilizando-se o questionário que consta no APÊNDICE F e as ETAPAS 2 e 3 são realizadas mediante o questionário do APÊNDICE G.

\subsection{Aplicação do MRM}

Nesse tópico é discutida a aplicação do MRM. Inicialmente é caracterizada a empresa (6.2.1), os projetos nos quais o modelo foi aplicado (6.2.2), seu PDP (6.2.3), o nível de capabilidade das áreas de processo do PDP no início do trabalho (6.2.4) e as aplicações do MRM realizadas (6.2.5).

\subsubsection{Caracterização da empresa}

A empresa na qual foi aplicado o MRM foi fundada em 1985 sendo uma das mais respeitadas empresas de alta tecnologia do pólo tecnológico de São Carlos. Sua trajetória teve origem na USP São Carlos, tendo sido constituída por pesquisadores e técnicos do Instituto de Física desta Universidade. Na época de sua inauguração a empresa já trabalhava com áreas importantes no seu portifólio atual como filmes finos especiais e aplicações industriais a laser. Posteriormente destaca-se sua entrada nos mercados de defesa, espacial e médicooftálmico.

Atualmente a empresa conta com cerca de 300 funcionários divididos na sede em São Carlos, em um escritório comercial de São Paulo, um escritório recém aberto em Porto Alegre/RS e um outro em Miami, Estados Unidos. Há representantes na Europa, na Ásia e na Oceania. As unidades de São Carlos e Porto Alegre realizam operações industriais, as demais, apenas vendas e assistência técnica. Apenas em São Carlos há desenvolvimento de produtos.

Devido à origem da empresa e sua vocação para o desenvolvimento de tecnologias e equipamentos ela tem em seu portifólio de produtos: 
- $\quad$ produtos industriais: medidor a laser para controle de pneus e multiposicionador laser;

- produtos da área médica: microscópios cirúrgicos oftálmico e odontológico, retinógrafo digital ADS1.5 e laser fotocoagulador para cirurgia de retina;

- $\quad$ produtos de defesa: componentes ópticos e sistemas de detecção a laser para a aeronáutica brasileira, unidades de apontamento e guiamento laser para o exército brasileiro etc.; e

- $\quad$ produtos da área espacial: subsistemas completos para integração em satélites de monitoramento ambiental realizando a captação e o processamento de imagens da Terra.

A empresa adota estratégias de produção diferentes para suas linhas de produto, segundo a classificação de PIRES (1995). Há uma linha de produtos de catálogo disponibilizada para produção e venda. Esses produtos, entretanto, não estão disponíveis em estoque sendo produzidos de acordo com o fechamento de pedidos. Os equipamentos médicos, científicos e fabris são produzidos nessa filosofia que configura sistemas de montagem por encomenda (ATO).

Há uma outra tipologia de produto que é vendido como projeto mediante contatos com os departamentos de marketing e engenharia. É fechada uma proposta de fornecimento e o aparelho passa a ser projetado e posteriormente, prototipado, testado, homologado e entregue ao cliente. Esse tipo de manufatura é caracterizado como engenharia por encomenda (ETO).

Há projetos governamentais que podem ser caracterizados como produtos MTO (produção por encomenda), uma vez que, embora o projeto seja financiado pelo contratante, sua entrega não se resume a uma unidade, como no caso dos projetos ETO. Ao invés disso, o produto é fabricado a pedido do órgão de defesa. 
As aplicações do MRM se deram em projetos do tipo ATO e MTO, os quais serão apresentados a seguir.

\subsubsection{Caracterização dos projetos nos quais o MRM foi aplicado}

Os projetos nos quais o modelo de referência mecatrônico foi implementado na empresa foram o retinógrafo digital ADS, o microscópio-CAN, o fotocoagulador i-MP e a câmera multiespectral.

O retinógrafo digital é um equipamento cujo objetivo é fotografar a retina de um paciente para detectar possíveis lesões que possam implicar em grave prejuízo ou perda da visão. O sistema ADS, como é designado na empresa, é ilustrado na Figura 70.

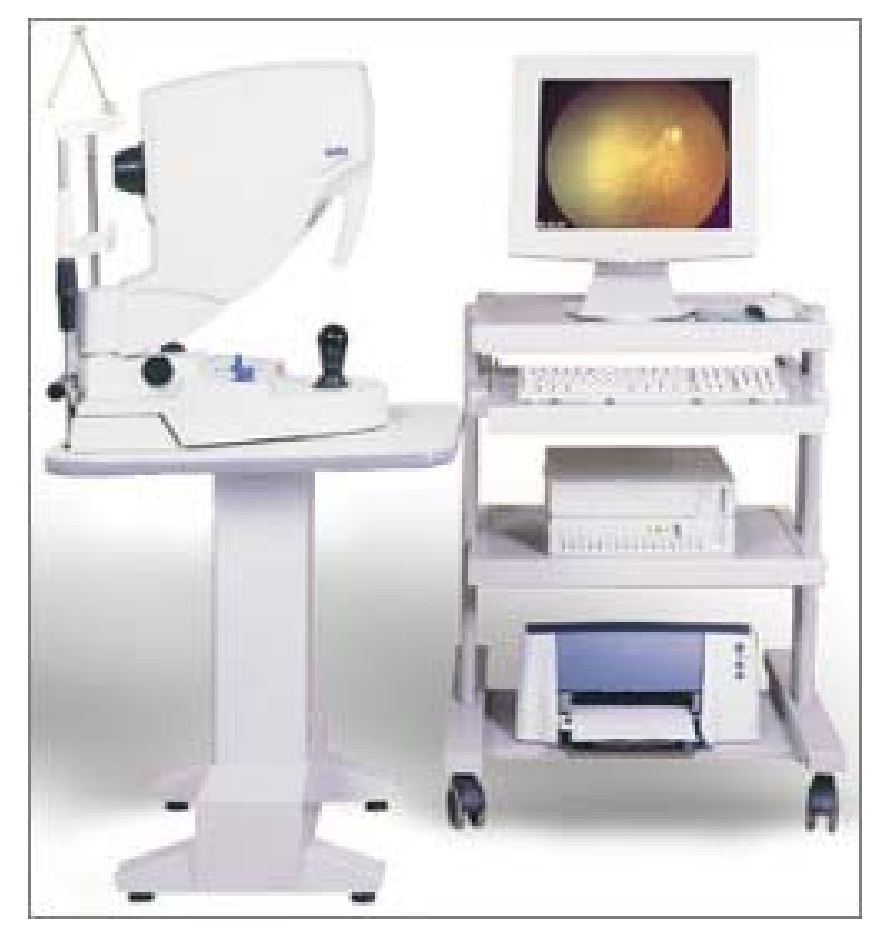

Figura 70 - Retinógrafo ADS1.5 (Fonte: OPTO ELETRÔNICA S.A., 2005b)

O retinógrafo consiste em uma unidade de captura de imagem na qual há uma complexa óptica de iluminação do olho e captação do reflexo do feixe projetado na retina do paciente. O sinal de luz captado é convertido em pulsos elétricos através de um sensor charge-coupled device (CCD) e transformado em imagem digital em uma câmera de 1.5 Megapixels. A imagem é transmitida para um computador equipado com um software de 
processamento de imagens e um banco de dados para o armazenamento de informações geradas nos exames, tais como nome do médico, do paciente, data e diagnóstico. As imagens podem ser apresentadas aos pacientes através do monitor do computador ou de impressões de qualidade fotográfica.

A Figura 71 apresenta o microscópio oftalmológico desenvolvido pela empresa para dar suporte a cirurgias realizadas no olho humano. O equipamento realiza a função tradicional de microscopia e permite aumentos de até 30x o tamanho da estrutura observada. $\mathrm{O}$ microscópio permite controle de foco e zoom ópticos, assim como do movimento x-y e possui uma função de micro-focalização. Todos os ajustes são operados através de um pedal e controlados por eletrônica embarcada no painel central do equipamento.

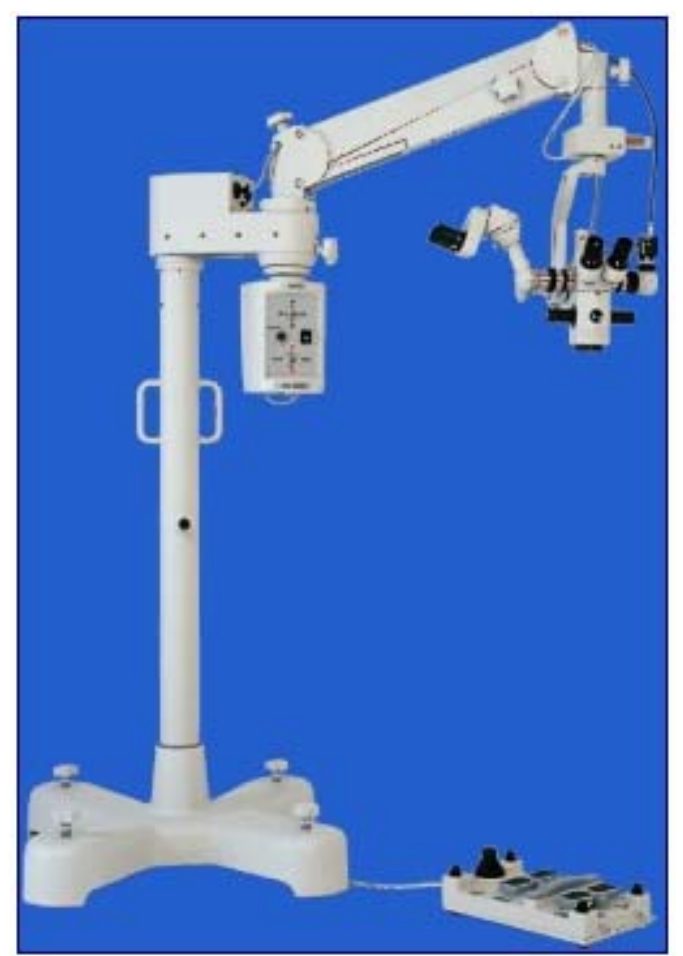

Figura 71 - Microscópio oftálmico (Fonte: http://www.opto.com.br/divmedica/produtos/opto-SM2002.htm, acesso em 27/11/2005)

O projeto Microscópio- $\boldsymbol{C A N}$ consistia em distribuir os módulos de controle do microscópio oftalmológico de maneira a permitir uma arquitetura plug-and-play. A utilização 
de um sistema de controle por RedeCan permitiria, ainda, a redução da quantidade de fios passando ao longo do equipamento, o que implicaria em maior facilidade de montagem.

O fotocoagulador (Figura 72) é um equipamento que gera pulsos laser de uma dada potência em miliwatts $(\mathrm{mW})$ durante um certo intervalo de tempo. Os pulsos objetivam coagular lesões da retina e reduzir a possibilidade de espalhamento que aumente o prejuízo à visão do paciente. A aplicação dos pulsos laser é considerada invasiva ao paciente e com alto grau de risco à visão. Isso faz com que os requisitos normativos aplicáveis a esse produto sejam bastante rigorosos.

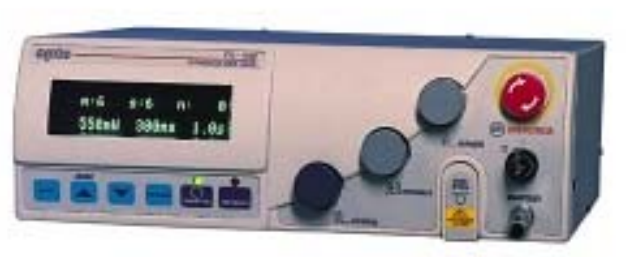

Figura 72 - Fotocoagulador desenvolvido pela OPTO ELETRÔNICA S.A. (Fonte: http://www.opto.com.br/ divmedica/produtos/opto-FTC.htm ,acesso em 27/11/2005)

O projeto Fotocoagulador $\mathbf{i}-\mathbf{M P}$ consiste em uma revisão do protocolo de tratamento a ser adotado pelo médico oftalmologista utilizando variações de potência e tempo de exposição do paciente ao laser. Nos protocolos comuns, esses valores são definidos pelo médico usuário. No i-MP, os valores resultarão de otimização realizada por software e padronizada para o tratamento de Degeneração Macular Relacionada à Idade (DMRI), nome técnico dado à tendência de perda de visão apresentada por pessoas na terceira idade.

A câmera multiespectral é um projeto hoje em pleno desenvolvimento e consiste no desenvolvimento de um subsistema a integrar o satélite sino-brasileiro a ser lançado em meados de 2008. Esse subsistema é composto por três equipamentos cujas funções são a captação da imagem da terra na faixa de freqüências que vai do início do visível ao infra- 
vermelho próximo, o tratamento e formatação desse sinal para envio à Terra e o controle de funções de manutenção automática que garantam que as imagens recebidas em Terra estejam dentro de determinados parâmetros de qualidade. Um esquema ilustrativo da câmera consta na Figura 73.

O projeto básico do equipamento é óptico tendo, porém, um sistema de controle malha fechada para o controle térmico e sistemas malha aberta para ajuste de foco e de radiometria.

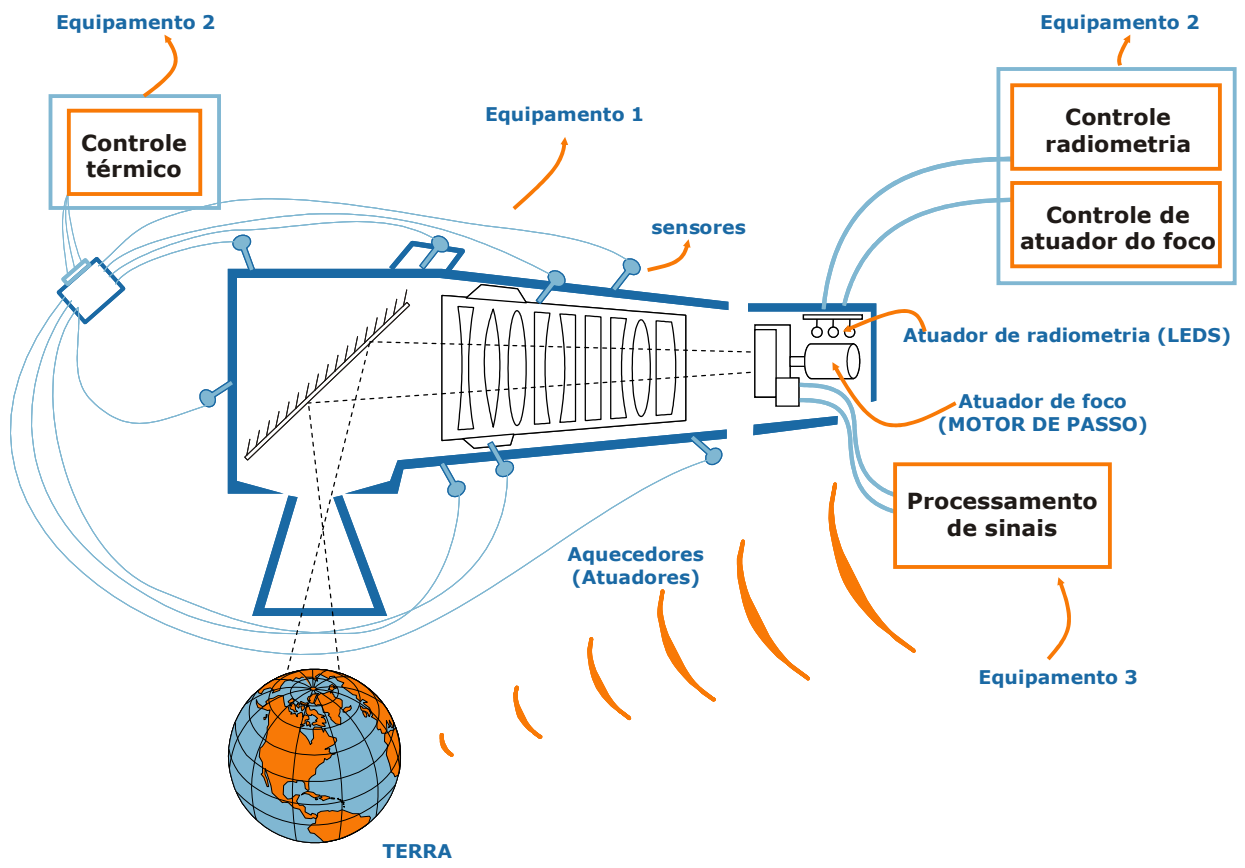

Figura 73 - Sumário da arquitetura funcional da câmera multiespectral

\subsubsection{Caracterização do PDP na empresa no início do trabalho de aplicação do modelo}

A Figura 74 apresenta o organograma da empresa quando do início do trabalho de aplicação do MRM. 


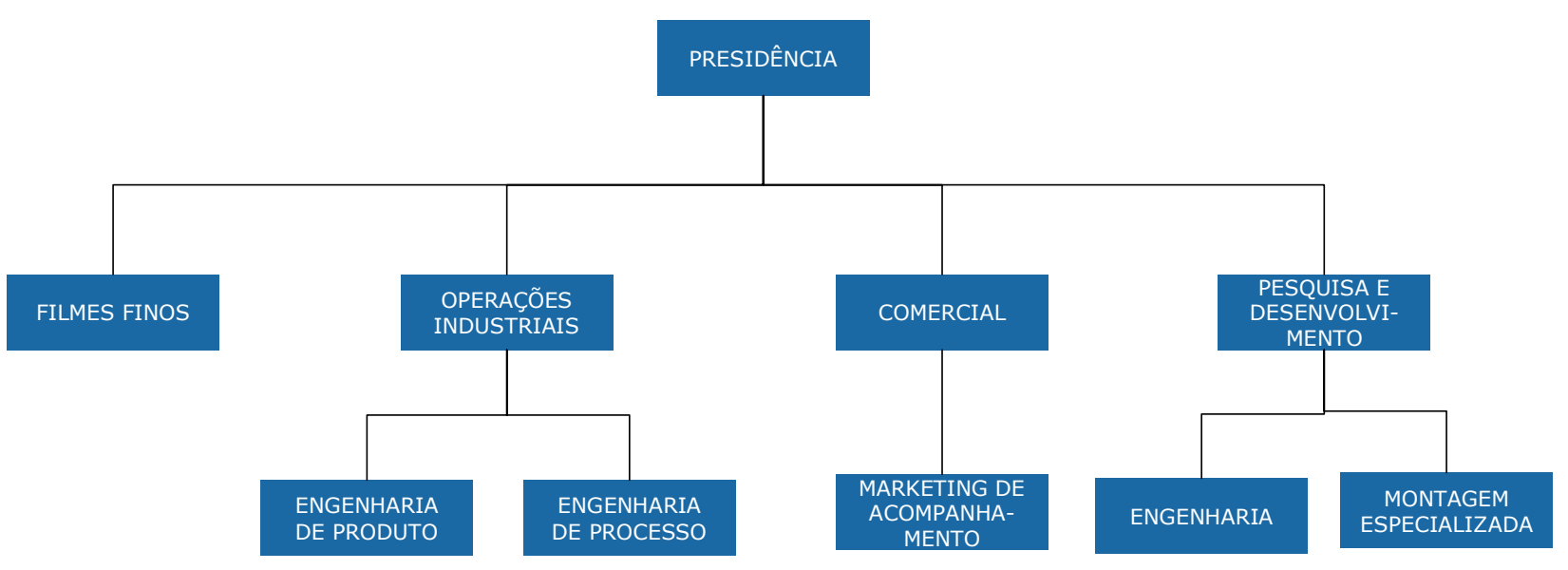

Figura 74 - Organograma da empresa no início da aplicação do MRM

A empresa compõe-se de quatro diretorias, duas delas podendo ser consideradas divisões de engenharia, uma diretoria comercial e uma outra de manufatura. A diretoria denominada "filmes finos" é responsável pelo desenvolvimento e fabricação de filmes ópticos para o tratamento de lentes de óculos comerciais e para o desenvolvimento de refletores utilizados em aparelhos de diagnóstico e cirurgia odontológica. Essa diretoria comporta setores de engenharia de produto e de processo, mas como não se tratam de produtos mecatrônicos sua estrutura organizacional foi omitida.

A diretoria de "pesquisa e desenvolvimento" (P\&D) é responsável pelo projeto dos equipamentos mecatrônicos listados no item anterior. Ela é composta de um grupo de engenharia formado por engenheiros mecânicos, eletrônicos, de software e físicos e por um grupo de montagem especializada, composto por técnicos em eletrônica e mecânica, o qual é responsável pela integração dos equipamentos de defesa desenvolvidos. Quando do início do trabalho de aplicação do MRM, essa área era composta por 4 (quatro) engenheiros, 3 (três) físicos e 5 (cinco) técnicos. O pesquisador foi integrado à equipe de engenharia do setor.

A diretoria comercial mantém um departamento de acompanhamento pós-venda do produto e de organização de feiras e eventos de marketing. Sua responsabilidade consistia em 
propor novos projetos de produtos do tipo ATO e em acompanhar o grau de satisfação dos clientes com relação a esses produtos.

A diretoria de "operações industriais" gerencia todo o processo de aquisição, fabricação, montagem e expedição dos produtos mecatrônicos desenvolvidos por P\&D. Além das operações de manufatura, essa diretoria comporta os setores de engenharia de produto e de engenharia de processo. Enquanto o P\&D é responsável pelo projeto de produtos inovadores para a empresa, as engenharias de produto e de processo tratam da realização de melhorias incrementais cujo objetivo é a redução dos custos de manufatura e montagem, assim como a introdução do produto na estrutura de fabricação da empresa.

A Figura 75 apresenta o fluxo de atividades genérico do PDP da empresa no momento inicial do trabalho de aplicação do MRM.

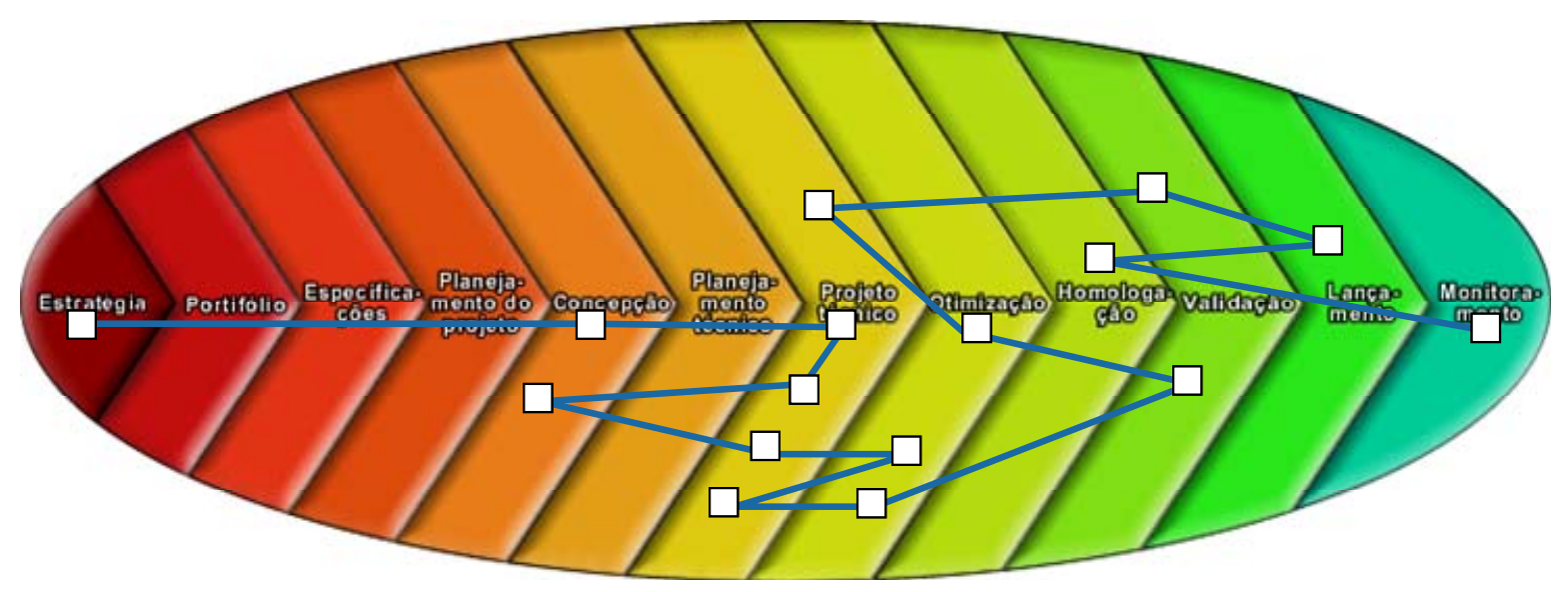

Figura 75 - Processo de desenvolvimento típico de um produto considerado inovador para a empresa

A integração entre os setores envolvidos no PDP da empresa se dava da seguinte forma: a diretoria comercial concentrava as demandas por novos projeto. Essas demandas eram discutidas nas reuniões do conselho diretor da empresa. Caso considerado interessante o projeto era encaminhado ao $\mathrm{P} \& \mathrm{D}$. Projetos de novos processos de pequeno impacto financeiro eram disparados pela diretoria de operações industriais à engenharia de processos. Novos 
processos com alto impacto financeiro eram encaminhados para a discussão conjunta da diretoria da empresa.

Uma vez que o novo produto tinha seu projeto iniciado sem que fosse feita qualquer análise de portifólio das LDPs, fossem geradas especificações mais detalhadas do projeto ou fosse feito um planejamento de prazos e custos, a resposabilidade passava à diretoria de $\mathrm{P} \& \mathrm{D}$ para que fosse realizada a concepção do projeto. Em P\&D o projeto ficaria até que as soluções desenvolvidas fossem consideradas satisfatórias. Em função de comportar um setor de montagem especializada, o P\&D desenvolvia, além do produto, seu processo de fabricação macro e o processo detalhado de montagem. Assim, quando o produto era considerado desenvolvido, o projeto mecânico era repassado à engenharia de produto que o adaptava à estrutura de produto da empresa, ou seja, analisava as peças de maneira a verificar similaridades com produtos existentes e as reprojetava para explorar essas semelhanças, gerava a $B O M$ e a encaminhava para o planejamento e controle da produção (PCP) que a cadastrava no sistema de gestão integrada (ERP) da firma.

Para o projeto eletrônico, a responsabilidade se mantinha com o setor de montagem especializada do P\&D mesmo após a transferência do projeto mecânico para os setores vinculados à diretoria de operações industriais. O mesmo ocorria com o projeto do software. As listas dos materiais a serem adquiridos para a montagem eletrônica eram repassadas diretamente do P\&D para o PCP da empresa sem que fossem integradas com a BOM gerada para o projeto mecânico.

As atividades necessárias para o projeto do controle de qualidade necessário ao produto eram desenvolvidas ao longo do projeto pelos grupos de "engenharia" e de "montagem especializada" do P\&D, entretanto as atividades de certificação do produto eram realizadas pelo setor de qualidade da empresa. A documentação técnica necessária à certificação do projeto, inclusive com as análises de confiabilidade e riscos, eram realizadas 
pelo grupo de "engenharia", normalmente depois de concluído o projeto. Nessa ocasião, o setor de qualidade da empresa tinha acesso à documentação do produto e verificava os documentos e as soluções técnicas que deveriam ser desenvolvidos para que o produto pudesse ser certificado.

Certificado o produto, ele era lançado, ocasião na qual o projeto era repassado à engenharia de processos que desenvolvia as folhas de fabricação das peças e também as reprojetava se necessário para adaptação à estrutura fabril da empresa.

Considera-se, portanto, que a estrutura organizacional do PDP da empresa era funcional e que ocorria um processo caótico com áreas de processo características do nível de capabilidade "incompleto" (ver item 2.4.2).

Os principais projetos desenvolvidos na empresa passaram por esse tipo de processo caótico:

"[...] O microscópio, o foto, esses lasers, tiveram seu processamento normal. Uma parte do foto, por exemplo, foi feita no $P \& D$ e a outra parte foi feita assim: o Presidente da Empresa tinha umas idéias e bolava algumas coisas [...] e ai manda fabricar e deu certo e ai essas coisas começaram a passar para a engenharia de produto que tem que fazer aquela coisa mais burocrática de gerar desenho e todo o sistema que existe para ir para a produção. O microscópio não passou pelo $P \& D$. Ele começou na engenharia de produto e as coisas foram indo dessa maneira [...]"

O MRM é projetado para comportar alguns ciclos entre as fases, conforme ilustrado na Figura 46, entretanto, o que transparece na ilustração de um projeto típico (Figura 75) é a dificuldade de manter um fluxo de atividades consistentes com as demandas de um projeto de produto mecatrônico. Isso pode ser ilustrado em alguns trechos das entrevistas realizadas com o pessoal da empresa.

Sobre a ligação direta entre estratégia e concepção do produto, um engenheiro menciona: 
"[...] que às vezes os diretores têm uma idéia diferente e pedem para fazer um negócio. Ai eu faço um projeto. Aí, depois vai para um engenheiro de produto que é a pessoa que faz a mecânica[...]".

O fato de não haver um momento dedicado a especificar o produto é ilustrado por um dos profissionais de nível técnico entrevistado:

"[...] algumas coisas a gente tinha certeza do que devia ser e outras foram surgindo e a gente tinha que fazer modificações. Então, muitas vezes nós pensávamos que iríamos entregar alguma coisa em certo prazo e houve uma demora porque você tinha que ajustar para a nova situação [...] “

As atividades relacionadas com a certificação de produtos apresentavam uma grande demanda por alterações de projeto e por necessidades de documentá-lo:

"[...] as ações de certificação para o foto geraram uma série de ações corretivas que permitiram a gente recuperar informações do passado e construir uma base para esse produto [...]"

O caráter tecnológico da empresa pode ter implicado em uma série de deficiências no entendimento do que seriam os resultados necessários a um projeto, conforme ilustra a fala de um dos gerentes dos setores de manufatura:

"[...] o produto era visto apenas como objeto fisico[...] Só que um produto ele tem rotulagem, embalagem, controle da qualidade, infra-estrutura. Todos esses aspectos são necessários para você implementar o processo de manufatura e a qualidade do produto é resultado desse processo[...]"

Grande parte dos problemas tem relação com o que o Diretor Comercial da empresa descreve a seguir:

"[...] Tem uma coisa que a gente fez no microscópio e no foto e que a gente está fazendo também no retinógrafo digital. Qual forma eu digo: nós fazemos assim. A gente está desenvolvendo o produto e já começa a comercialização, que significa a gente colocar na mão do nosso cliente um produto que não foi completamente testado e avaliado pelo mercado. É um produto desenvolvido apenas da nossa visão e de poucos clientes sobre o que esse produto tem que $\operatorname{ser}[\ldots]$ "

Portanto, o processo ilustrado na Figura 75, no qual as especificações não são definidas a contento no início do desenvolvimento, há vínculo direto entre estratégia e concepção, o planejamento dos requisitos de certificação não ocorre, o que demanda um conjunto grande de mudanças de projeto etc. é resultado de uma atitude deliberada da 
empresa, através da Diretoria Comercial. As conseqüências deste processo são também reconhecidas pela empresa, conforme discute o referido Diretor:

“[...] Então acontecem duas coisas, a primeira é que algumas características que o produto possui e que não são boas ou algumas características que ele não possui e são fundamentais. E o segundo são problemas de produção mesmo, de fabricação porque sempre os primeiros produtos acabam carregando consigo alguns problemas que não foram totalmente resolvidos durante a produção[...]"

A atitude deliberada é justificada da seguinte forma:

“[...] se você deixar só na mão do pessoal de desenvolvimento de produto ele nunca vai acabar porque na visão do engenheiro e do técnico o produto nunca tá bom. Se você deixar só com eles vai levar dez anos e em dez anos o produto não está pronto ainda. Então qual seria nossa função seria jogar no mercado e ai não teve jeito ele teve que ficar pronto para a gente entregar para o cliente de uma forma ou de outra. No final acaba sendo uma forma ruim porque ele vai com defeito, mas você acaba o produto[...]"

Obviamente, essa atitude tem uma justificativa financeira, pois para o Diretor entrevistado:

"[...] acho que custo do projeto não tinha muito controle e não acredito que tenha muito controle, o pessoal de desenvolvimento é normalmente um gastador [...]"

Outra atitude dos dirigentes da empresa que justifica o processo caótico é ilustrada pela afirmação do Diretor de P\&D:

"[...] Na verdade é preferivel ao invés de você ficar perdendo tempo no papel para você fazer o projeto, pôr ele para funcionar, pôr ele para clientes amigos testarem. Ai é que você depura na realidade e isso ai não é papel. É muito bacana você fazer um big estudo teórico, é confortável, mas nada como a realidade para permitir que a natureza se imponha. Você faz um protótipo. Põe na mão do cliente. Testa. Deixa o cliente usar. Ai o cliente vai começar dar respostas que antes você não tinha e a ntureza, a fisica vai se impor. Tudo bem, tem certas coisas que você consegue pegar na época do projeto e eu acho que você deve perder um pouco de tempo no projeto para não fazer certos absurdos. Mas não precisa escrever uma tese sobre isso. Tem que ser bem objetivo, não estou provando nenhuma tese acadêmica. E monta o protótipo e testa[...]"

Uma vez que, segundo o Diretor Comercial, o cliente "comprava o produto", e que as especificações não eram detalhadas, o processo de depuração acima citado implicava em riscos potenciais para a empresa, sejam eles legais, sejam eles relacionados com o fato de a 
realimentação provida pelo cliente ser bastante específica de sua situação prática de uso. Deixar a "física se impor" tem relação com um entendimento do projeto de um produto como algo bastante similar à atividade de pesquisa realizada na Universidade:

"[...] o cara que entrava no P\&D sabia que ia ter que mexer com um espectro muito grande de atividades, desde coisas prosaicas como limpar o chão do laboratório até ter que debulhar um equipamento que ele nunca viu na vida [...]" (Grifos nossos)

Um processo de desenvolvimento mais sistemático é entendido pelo Diretor de P\&D como algo bom para outras situações que não as vivenciadas pela empresa:

"[...] Esse esquema de gestão muito bitolado, burocrático não vai funcionar. É o que eu falo. Uma fábrica de geladeira sempre projetou uma geladeira, mas vai projetar uma nova, eu acho que ela tem certas ferramentas de gestão que funcionam muito bem. O cara vai começar um novo projeto de geladeira ele já projetou 500 e vai projetar a 501. Então, ele sabe as etapas que ele vai passar. Já sabe as dificuldades que vai ter, sabe que precisa de um engenheiro de refrigeração, de manufatura, de design. Ele sabe exatamente o que tem que dar para o cara fazer. Ele já tem a receita prontinha. Então fica fácil você planejar, medir resultados, contabilizar custo, estimar prazo, fica fácil. É diferente do nosso caso que um dia está fazendo um pedaço de um missel, outro um equipamento médico, no dia seguinte está fazendo um equipamento industrial e outro dia um equipamento para um satélite. Então, não tem receita[...]"

O processo ilustrado na Figura 75 é apenas um representativo do que foi detectado na análise do PDP a empresa no início da aplicação do MRM. Embora reflita um caso em específico ele demonstra a grande demanda que uma empresa como a pesquisada tem por estabelecer um modelo de referência para o seu PDP uma vez que o modelo não é uma "receita prontinha" para a engenharia da empresa, mas o estabelecimento de um fluxo previamente pensado de ações a serem realizadas por diversos setores da companhia de maneira a evitar ciclos desnecessários nos quais o produto retorna a atividades de fases anteriores devido à não-produção de resultados intermediários quando as atividades de projeto estavam sendo realizadas. 


\subsubsection{Nível de capabilidade das áreas de processo do PDP no início do trabalho de aplicação do modelo}

O questionário de diagnóstico (APÊNDICE F) foi utilizado para identificar o nível inicial da capabilidade das áreas de processo do MRM na empresa.

Como pode ser visto na descrição das atividades de cada fase do modelo (itens 5.3.1.1 a 5.3.1.12), elas têm um alto nível de agregação de tarefas, o que dificultaria o processo de diagnóstico, pois haveria a tendência de que algumas tarefas fossem realizadas e não pudessem ser computadas como tal pelo fato de que a atividade da qual elas fazem parte pode não ter sido realizada a contento pela empresa. Em função disso, algumas tarefas foram integradas à lista apresentada no APÊNDICE E de maneira que as ações de PDP analisadas nos questionários têm o número ilustrado na Tabela 3 para cada área de processo do MRM.

Tabela 3 - Quantidade de ações de PDP analisadas em cada área de processo do MRM

\begin{tabular}{cc}
\hline ÁREA DE PROCESSO & NÚMERO DE \\
\hline Desdobramento da estratégia & 32 \\
Desenvolvimento de mercado & 34 \\
Gestão de projetos & 25 \\
Arquitetura de sistemas & 27 \\
Projeto de engenharia & 46 \\
Projeto da produção e suprimentos & 39 \\
Qualidade do produto & 12 \\
Documentos e configurações & 23 \\
\hline
\end{tabular}

A Figura 76 apresenta o nível de capabilidade do PDP da empresa no início da aplicação do modelo de referência mecatrônico.

Os números apresentados em cada área de processo significam a média da capabilidade das atividades de cada área de processo, avaliada conforme ilustrado na Figura 68. Pode-se verificar que o nível de capabilidade das áreas de processo estava em torno de 0.5. As áreas de processo com maior capabilidade eram as de projeto de engenharia e de qualidade do produto, ambas em torno de 1.0. A menor capabilidade estava na área de documentos e configurações. 
As configurações dos produto eram controladas de forma bastante frágil, conforme pode ser visto no trecho abaixo:

"[...] Era comum você gerar várias especificações, estou falando de desenhos, onde o upgrade dessa especificação era rastreado pelo código de documento e não por nivel de revisão. Então você tinha ao longo de seis meses a produção de cinco códigos diferentes para o mesmo item, a mesma peça contemplando as alterações desse periodo fazendo com que vc perdesse completamente a rastreabilidade porquê cada desenho um código. Então se chegava a uma estrutura de produto inadministrável, então isso era transferido para a produção[...]"

Nível de capabilidade das áreas de processo no início do trabalho

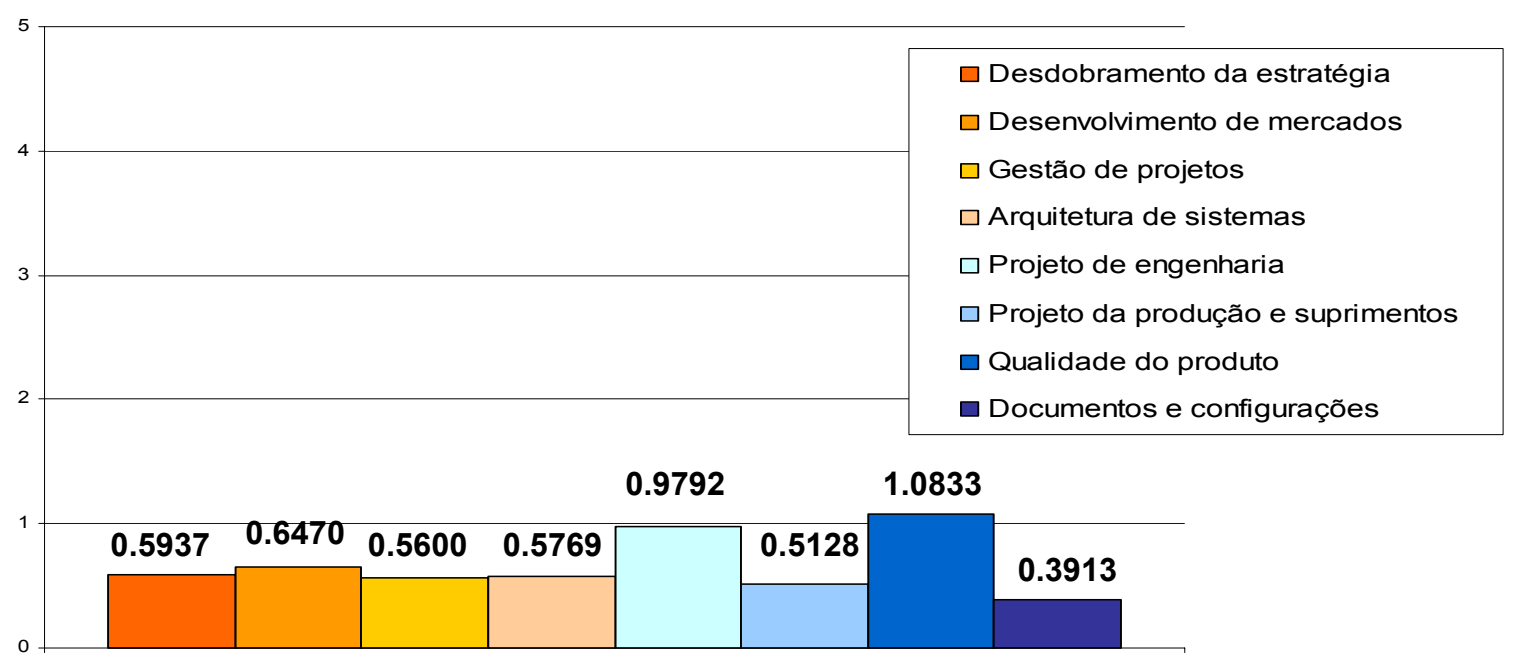

Figura 76 - Nível de capabilidade das áreas de processo do MRM no início de sua aplicação $\left(\mathrm{N}_{\mathrm{c}}\right)$

A forma de modificar essas especificações é ilustrada no trecho:

"[...] você chegava para a pessoa e dizia: muda tal coisa no software, muda uma letra, alguma coisa. Não tinha documentação, não tinha nada [...]"

Os resultados desse nível de capabilidade podem ser entendidos na seguinte afirmação

de um dos engenheiros envolvidos com os projetos:

"[...] eu comecei a ver o que está sendo produzido e aí peguei nos sistemas que eu tinha e modifiquei tudo para os que estão sendo produzidos hoje que foi modificado sem ter uma atualização do projeto, mais por uma questão técnica-mecânica de produção mecânica ou óptica. E aí então eu tive que readaptar o sistema original para as coisas que são hoje[...]" 
A baixa capabilidade da área de "documentos e configurações" é entendida como fortemente relacionada com dificuldades relativas à organização do PDP:

"[...] várias pessoas envolvidas de diferentes departamentos só que sem haver uma gerência, uma coordenação dessas ações. Muitas vezes você incorria em erros extremamente primários[...] havia alterações no produto que você não conseguia validar, então você alterava o painel e o próprio departamento de origem, o P\&D, não ficava sabendo disso, a própria produção tinha autonomia para alterar qualquer item do produto[...]"

Além disso, considera-se que há forte vínculo dessa área com a de "gestão de projetos":

"[...] o pessoal precisa colocar em mente: é dificil você cumprir os prazos no desenvolvimento e mais difícil ainda é quando você passa os prazos e o pessoal corta o prazo pela metade e começa a vender. Aí você não consegue documentar as coisas direito, porque você acabou de fazer o negócio e tem que fazer. Ai, quando você for documentar [...] você não vai estar ainda com aquilo fresco para fazer. Você vai atrasando um pouco e ai você acaba perdendo muito da documentação e do próprio projeto[...]"

De maneira geral, o gráfico de capabilidade apresentado na Figura 76 demonstra que a maioria das áreas de processo contém ações que não eram realizadas no momento inicial do processo de aplicação do MRM. Isso significa que, em geral, as aplicações deveriam seguir uma estratégia de melhoria baseada na realização dessas ações. Teoricamente, isso resultaria em avanço de um nível "NÃO FAZ”para um nível "FAZ”, conforme discutido em 5.4.3.

\subsubsection{Aplicações do modelo de referência mecatrônico na empresa}

A Figura 77 apresenta as aplicações do MRM realizadas na empresa pesquisada. Círculos concêntricos (०) são aplicações realizadas com a participação do pesquisador e círculos fechados (○) são as iniciativas de melhoria aplicadas por outras unidades organizacionais que foram monitoradas pelo pesquisador ao longo do trabalho de campo. 


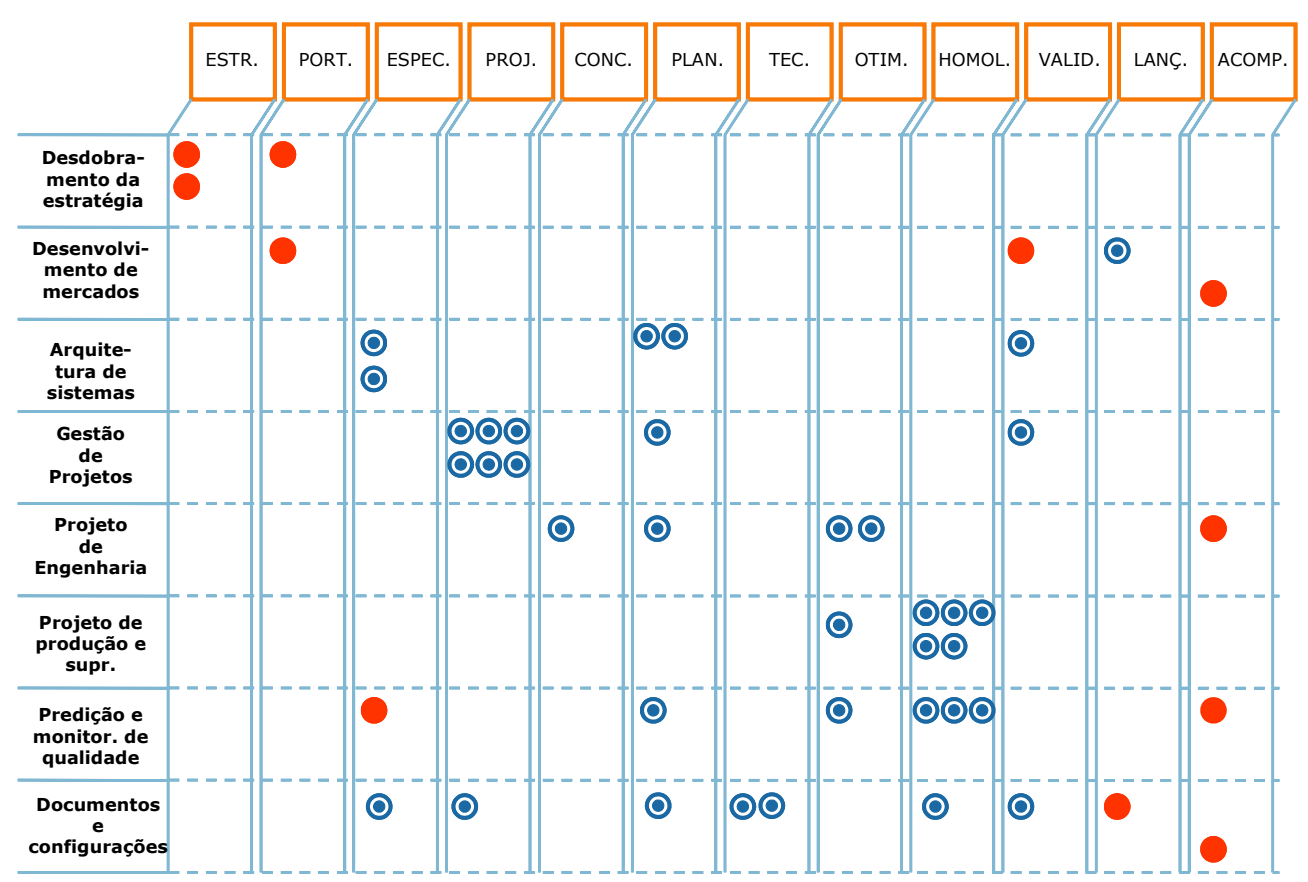

Figura 77 - Aplicações do MRM na empresa pesquisada

As colunas representam as aplicações realizadas em cada fase do MRM. As linhas são as aplicações realizadas em cada área de processo do modelo. Por exemplo, na fase de especificações há “4” (quatro) aplicações do MRM, das quais, “3” (três) foram realizadas com a participação do pesquisador e "1" (uma) foi apenas monitorada pelo pesquisador.

A seguir serão discutidas as aplicações do modelo de referência ao longo das fases do PDP modelado. Todas as iniciativas detectadas no decorrer da pesquisa serão apresentadas, embora apenas aquelas nas quais houve participação efetiva do pesquisador serão analisadas quanto à adequação às estratégias de melhoria previstas teoricamente pelo MRM (item 5.4.3). Para serem aplicadas, as ferramentas disponibilizadas pelo MRM foram adaptadas à forma de gestão do PDP utilizada na empresa: cadernos de projeto com registros manuais datados e assinados. Esses cadernos são apresentados em BARBALHO e ROZENFELD (2005b). O trabalho de aplicação do modelo se estendeu por cerca de 24 meses.

Ao longo dos tópicos de descrição das ações realizadas no PDP da empresa, os quadros Quadro 4 a Quadro 15 apresentarão as unidades organizacionais da empresa que 
foram responsáveis pela aplicação, assim como uma pequena descrição dela. $\mathrm{Na}$ coluna “AÇÕES” são identificadas atividades ou tarefas do MRM.

As ações realizadas são, na medida do possível, ilustradas com figuras de documentos e arquivos de fotografias fornecidos pela empresa pesquisada. Algumas ações não puderam ser assim registradas por serem tratadas com confidencialidade pela empresa.

\subsubsection{Fase de estratégia}

As atividades da fase de estratégia são realizadas através de um estreito canal de comunicação entre a diretoria comercial e a presidência da empresa que discutem a estratégia a ser adotada pelas LDPs e estendem a discussão para os demais diretores.

Embora a discussão colegiada seja enfatizada no processo de decisão de estratégia de produtos, o diretor comercial realiza pessoalmente a caracterização da situação das linhas de produto - apesar de para isso não utilizar fluxo de caixa, mas apenas gráficos de volume de vendas - e a análise do ambiente competitivo no qual a empresa está inserida. Ambas atividades estão apresentadas na Figura 48 e as aplicações citadas constam no Quadro 4.

Quadro 4 - Sumário das aplicações do MRM na fase de estratégia

\begin{tabular}{|c|c|c|c|}
\hline$A C ̧ \tilde{O} E S$ & $\begin{array}{c}\text { AREA DE } \\
\text { PROCESSO }\end{array}$ & APLICADOR & 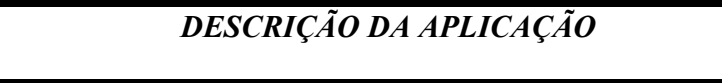 \\
\hline $\begin{array}{l}\text { Caracterizar linhas de } \\
\text { produto }\end{array}$ & $\begin{array}{l}\text { Desdobramento } \\
\text { da estratégia }\end{array}$ & Dir. comercial & $\begin{array}{l}\text { Melhoria conceitual da forma de realização da } \\
\text { caracterização de linhas de produto, usando matriz BCG }\end{array}$ \\
\hline $\begin{array}{l}\text { Analisar o ambiente } \\
\text { competitivo }\end{array}$ & $\begin{array}{l}\text { Desdobramento } \\
\text { da estratégia }\end{array}$ & Dir. comercial & $\begin{array}{l}\text { Melhoria conceitual da forma de análise do ambiente } \\
\text { competitivo utilizando conceitos de Michael Porter }\end{array}$ \\
\hline
\end{tabular}

\subsubsection{Fase de portifólio}

Similarmente à fase de estratégia, a de portifólio é também realizada pelo Presidente e o diretor comercial em estreita parceria. Nessa fase as melhorias são bem parecidas com o que ocorreu na estratégia estando ilustradas no Quadro 5.

Segundo os diretores da empresa - todos foram entrevistados -, tanto a identificação de produtos potenciais como a priorização dos projetos, ambas atividades descritas no 
fluxograma de atividades da fase de portifólio (ver Figura 49), se davam por busca de oportunidades de negócio sem uma preocupação maior com a compatibilidade deles com a estratégia de produtos da empresa. Além de uma melhoria conceitual isso refletiu também a maior estabilidade financeira da companhia. $\mathrm{O}$ aumento de faturamento no último ano foi da ordem de $100 \%$, o que deu maior tranqüilidade quanto à sobrevivência da empresa.

Quadro 5 - Sumário das aplicações do MRM na fase de portifólio

\begin{tabular}{|c|c|c|c|}
\hline$A C ̧ \tilde{O} E S$ & $\begin{array}{c}\text { AREA DE } \\
\text { PROCESSO }\end{array}$ & APLICADOR & 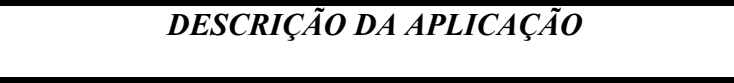 \\
\hline $\begin{array}{l}\text { Identificar produtos } \\
\text { potenciais }\end{array}$ & $\begin{array}{l}\text { Desenvolvimento } \\
\text { de mercados }\end{array}$ & Dir. comercial & $\begin{array}{l}\text { Melhoria da forma de realização através da análise da } \\
\text { relação entre os novos produtos e a estratégia da empresa }\end{array}$ \\
\hline $\begin{array}{l}\text { Priorizar projetos em } \\
\text { desenvolvimento }\end{array}$ & $\begin{array}{l}\text { Desdobramento da } \\
\text { estratégia }\end{array}$ & Dir. comercial & $\begin{array}{l}\text { Análise dos produtos potenciais com relação à estratégia } \\
\text { da empresa }\end{array}$ \\
\hline
\end{tabular}

6.2.5.3 Fase de especificações

O Quadro 6 reflete as aplicações do MRM na fase de especificações do produto. As ações listadas na primeira coluna estão descritas no item 5.3.1.3 e constam na Figura 51.

Quadro 6 - Sumário das aplicações do MRM na fase de especificações

\begin{tabular}{|c|c|c|c|}
\hline$A C ̧ \tilde{O} E S$ & $\begin{array}{l}\text { ÁREA DE } \\
\text { PROCESSO }\end{array}$ & APLICADOR & 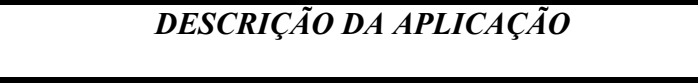 \\
\hline $\begin{array}{l}\text { Definir as especificações } \\
\text { do produto }\end{array}$ & $\begin{array}{l}\text { Arquitetura de } \\
\text { sistemas }\end{array}$ & Engenharia & $\begin{array}{l}\text { No projeto Foto i-MP, houve um grande esforço em } \\
\text { gerar especificações para o protocolo a ser } \\
\text { desenvolvido. Esse esforço se repetiu no projeto MUX. }\end{array}$ \\
\hline $\begin{array}{l}\text { Estabelecer matriz de } \\
\text { verificação do produto }\end{array}$ & $\begin{array}{l}\text { Arquitetura de } \\
\text { sistemas }\end{array}$ & Engenharia & $\begin{array}{l}\text { Para os projetos retinógrafo e MUX foi confeccionada } \\
\text { uma matriz de verificação do produto }\end{array}$ \\
\hline $\begin{array}{l}\text { Documentar e registrar as } \\
\text { especificações do produto }\end{array}$ & $\begin{array}{l}\text { Documentos e } \\
\text { configurações }\end{array}$ & Engenharia & $\begin{array}{l}\text { Ocorreu sistematicamente ao longo dos projetos } \\
\text { pesquisados utilizando registros no livro de projetos }\end{array}$ \\
\hline $\begin{array}{l}\text { Identificar requisitos } \\
\text { normativos }\end{array}$ & $\begin{array}{l}\text { Qualidade do } \\
\text { produto }\end{array}$ & Qualidade & $\begin{array}{l}\text { Nos projetos anteriores ocorreu de forma reativa. Em } \\
\text { todos os projetos pesquisados isso se deu de forma } \\
\text { planejada. }\end{array}$ \\
\hline
\end{tabular}

A definição das especificações do produto no projeto fotocoagulador i-MP foi realizada com bastante sinergia entre o pessoal de engenharia e os clientes potenciais do produto. Foram realizadas entrevistas com o cliente e elas foram transformadas em um fluxograma de software assembly. Esse fluxograma foi apresentado ao cliente e validado. No caso do projeto MUX, as especificações foram geradas pelo próprio cliente, refinadas pela equipe de engenharia e sistematizadas na forma de lista de requisitos. A Figura 78 apresenta 
em (a) parte do fluxograma de especificação do projeto i-MP, e em (b) parte dos requisitos do projeto MUX.

No projeto retinógrafo foi confeccionada uma matriz de verificação utilizada nos testes com os protótipos do equipamento. Essa sistemática foi utilizada no projeto MUX para identificar os valores a serem atingidos nas métricas de qualidade do projeto. Vale salientar que a matriz do projeto MUX não fora ainda utilizada devido a inexistência de protótipos testados. A Figura 79 apresenta a matriz desenvolvida para o projeto retinógrafo.

As especificações geradas para os produtos que foram pesquisados passaram a ser documentadas e registradas em arquivos eletrônicos ou em cadernos de projeto.

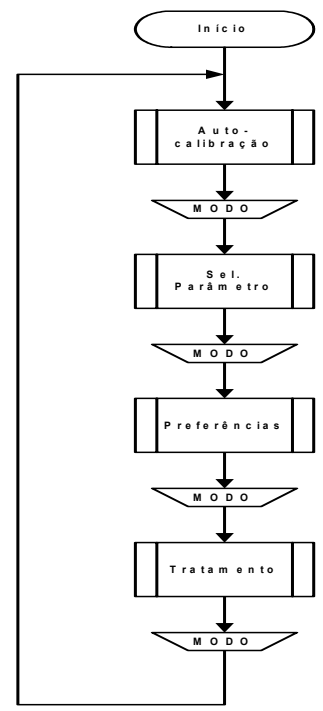

(a)

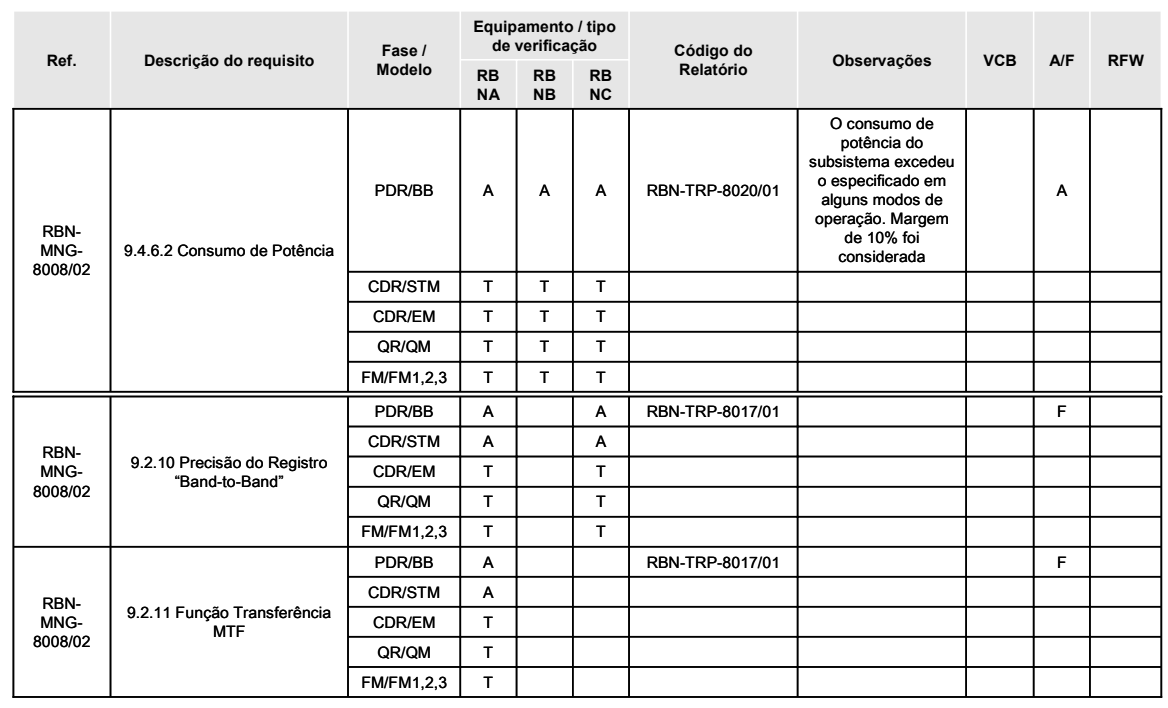

(b)

Figura 78 - Especificações do produto: (a) parte do software i-MP; (b) parte dos requisitos do projeto MUX. 

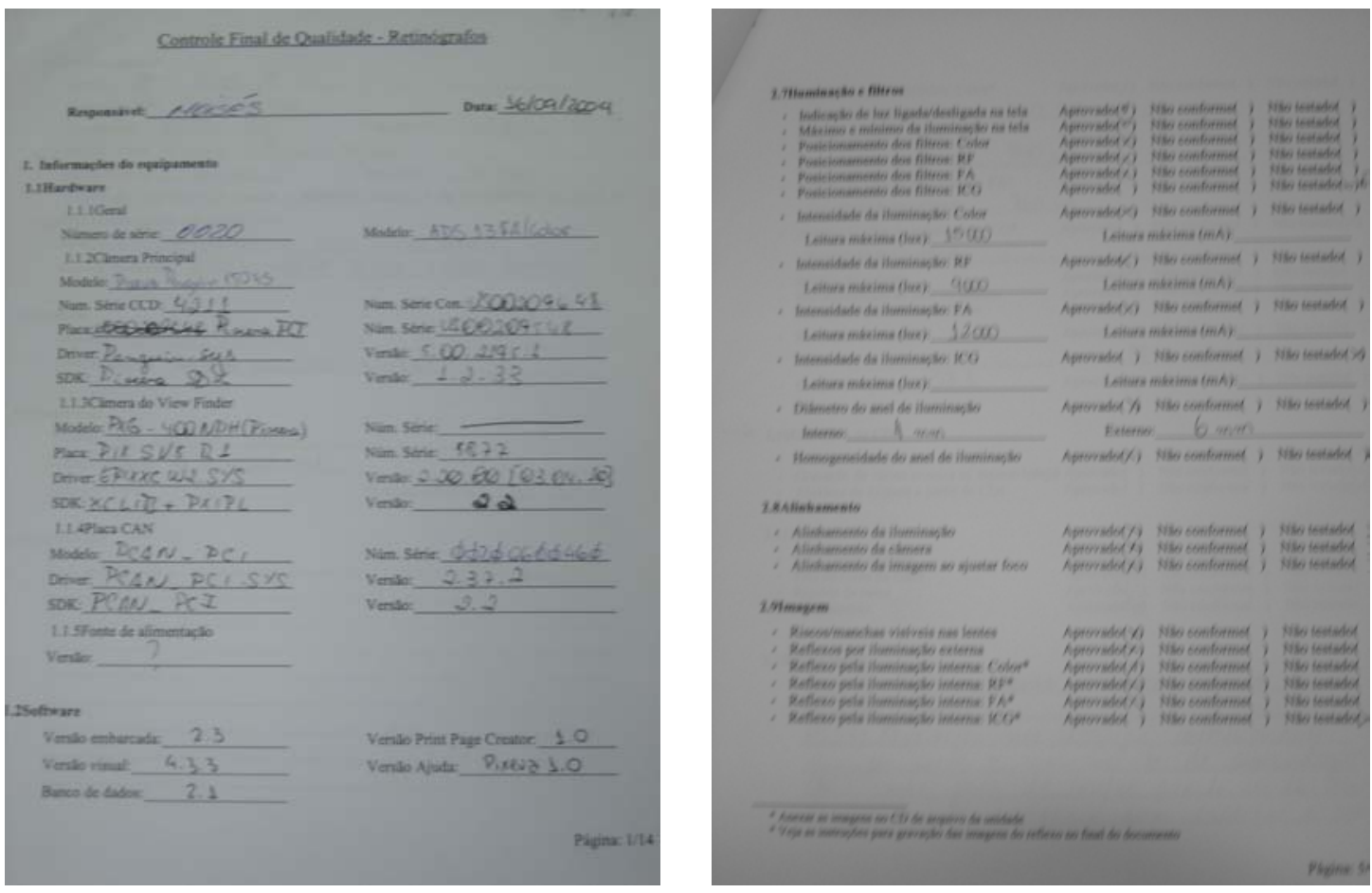

Figura 79 - Matriz de verificação do projeto retinógrafo: (a) capa; (b) folha de medidas de segurança.

$\mathrm{Na}$ Figura 80 são apresentados resgistros de especificações desenvolvidas para o projeto retinógrafo.

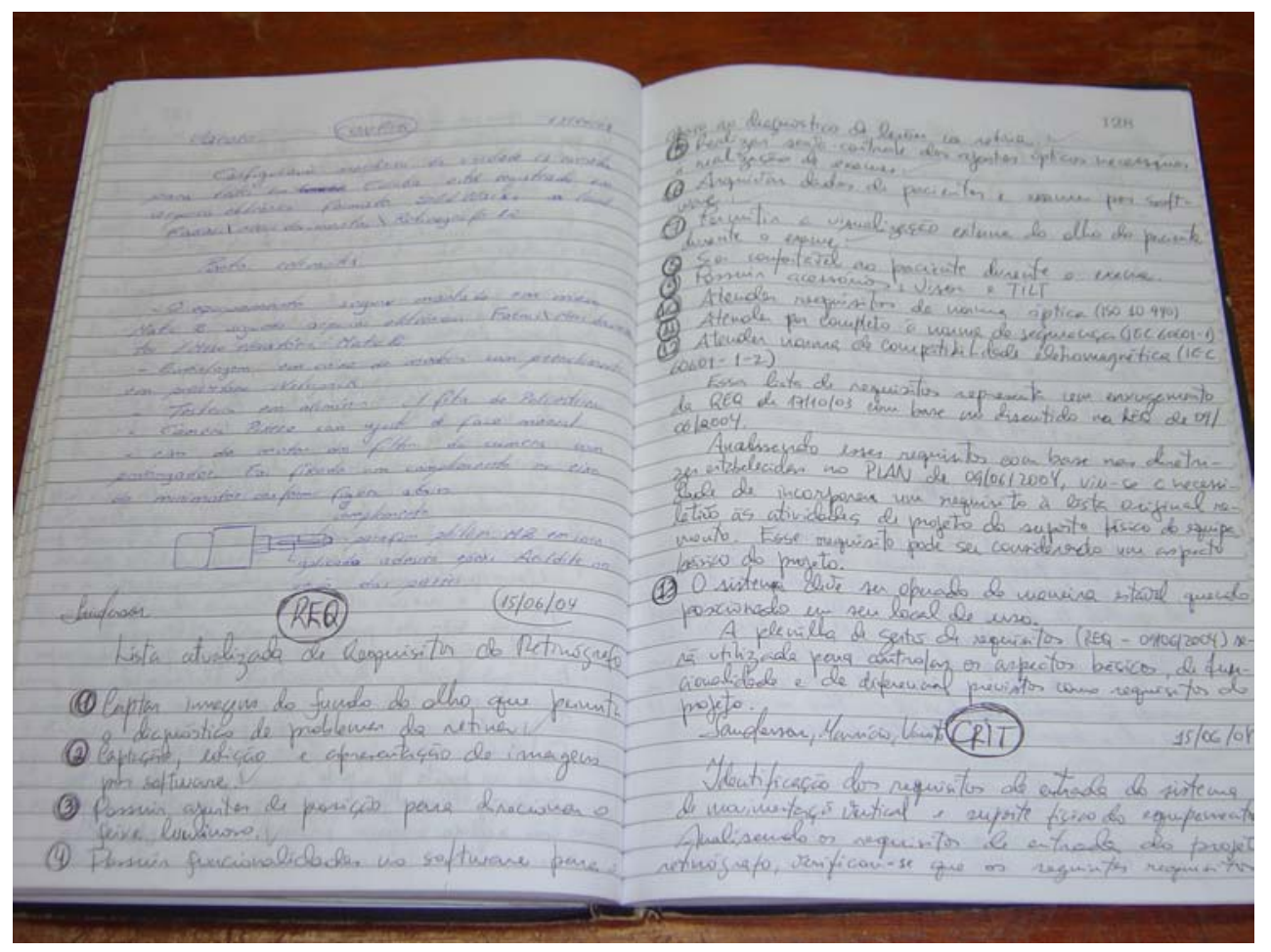

Figura 80 - Registro de especificação do produto do projeto retinógrafo 
A identificação de requisitos normativos é realizada pelo setor de qualidade da empresa. Essa atividade ocorria de forma reativa, após o produto ser reprovado em testes de certificação. Passou a ser realizada no início dos projetos, conforme o MRM (Figura 51).

\subsubsection{Fase de planejamento do projeto}

O Quadro 7 ilustra as aplicações do MRM na fase de planejamento do projeto.

Quadro 7 - Sumário das aplicações do MRM na fase de planejamento do projeto

\begin{tabular}{|c|c|c|c|}
\hline$A C ̧ \tilde{O} E S$ & $\begin{array}{c}\text { AREA DE } \\
\text { PROCESSO }\end{array}$ & APLICADOR & 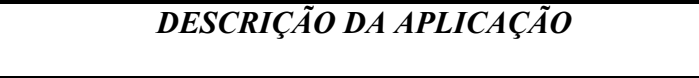 \\
\hline Gerar WBS do projeto & Gestão de projetos & Engenharia & $\begin{array}{l}\text { Estabelecimento de procedimento para o planejamento } \\
\text { dos projetos. }\end{array}$ \\
\hline $\begin{array}{l}\text { Desenvolver cronograma } \\
\text { detalhado }\end{array}$ & Gestão de projetos & Engenharia & $\begin{array}{l}\text { Estabelecimento de procedimento para o planejamento } \\
\text { dos projetos e confecção de cronograma para o MUX. }\end{array}$ \\
\hline $\begin{array}{l}\text { Planejar recursos } \\
\text { necessários }\end{array}$ & Gestão de projetos & Engenharia & $\begin{array}{l}\text { Elaboração de plano de recursos humanos e de infra- } \\
\text { estrutura para o projeto MUX. }\end{array}$ \\
\hline $\begin{array}{l}\text { Desenvolver estrutura de } \\
\text { custos }\end{array}$ & Gestão de projetos & Engenharia & $\begin{array}{l}\text { Desenvolvimento de estrutura de gestão de custos no } \\
\text { projeto MUX }\end{array}$ \\
\hline Definir gestão de riscos & Gestão de projetos & Engenharia & $\begin{array}{l}\text { Desenvolvimento de processo de gestão de riscos no } \\
\text { projeto MUX. }\end{array}$ \\
\hline $\begin{array}{l}\text { Consolidar plano de } \\
\text { projetos }\end{array}$ & Gestão de projetos & Engenharia & Consolidação do plano do projeto MUX \\
\hline $\begin{array}{l}\text { Documentar e registrar } \\
\text { planejamento }\end{array}$ & $\begin{array}{l}\text { Documentos e } \\
\text { configurações }\end{array}$ & Engenharia & $\begin{array}{l}\text { Estabelecimento de procedimento para o planejamento } \\
\text { dos projetos. }\end{array}$ \\
\hline
\end{tabular}

A WBS de projeto foi introduzida no projeto MUX. Nesse projeto, a partir da WBS foi desenvolvido um cronograma detalhado de atividades. A WBS do projeto MUX é inspirada na estrutura apresentada na Figura 53 enquanto o cronograma do projeto MUX é apresentado na Figura 81. As atividades necessárias ao desenvolvimento de um determinado projeto passaram a ser sistematizadas no projeto retinógrafo e se repetiu para os projetos Microscópio-CAN e fotocoagulador i-MP. O grau de detalhamento do cronograma desses projetos não segue o do MUX, pois neste último há imposições estabelecidas em contrato.

Embora não haja formato padronizado, há um padrão consolidado em procedimento de gestão de projetos (OPTO ELETRÔNICA S.A., 2006) que estabelece o conteúdo mínimo dos cronogramas de projeto. Na Figura 82 consta o cronograma do projeto Microscópio-Can. 


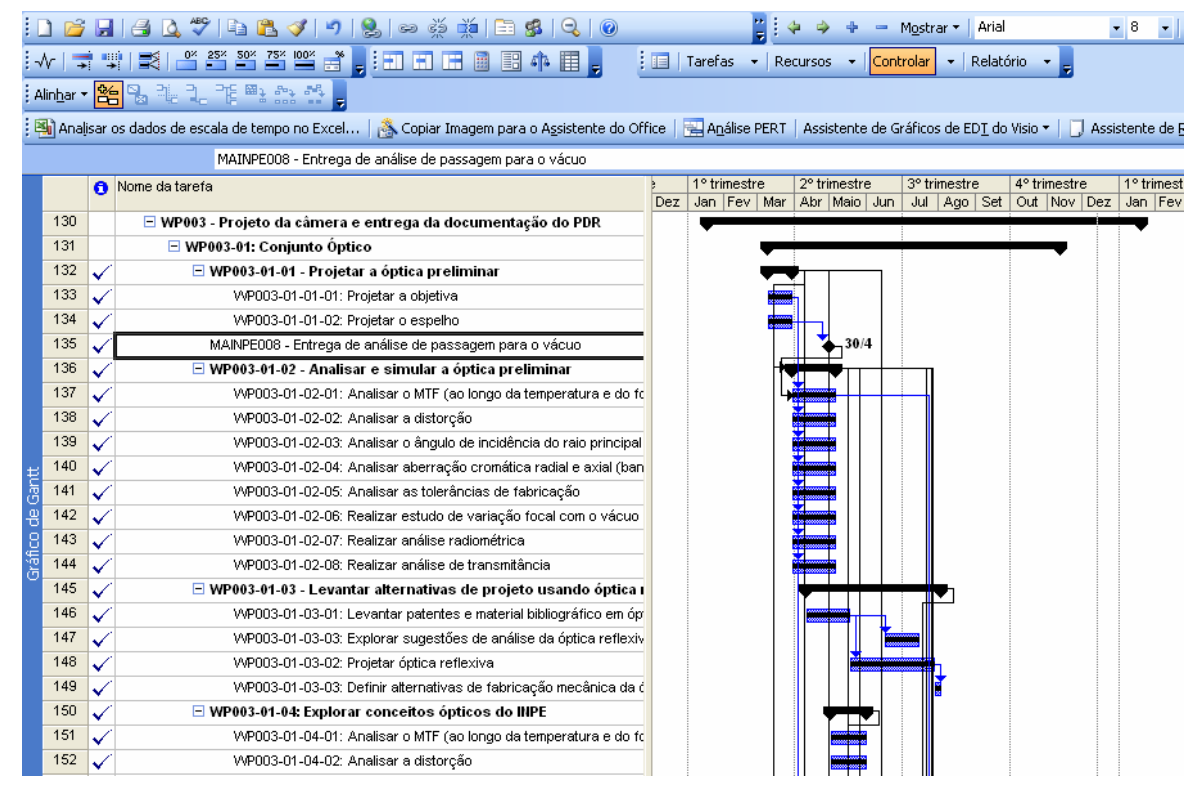

Figura 81 - Cronograma do projeto MUX

As atividades de planejamento de recursos, desenvolvimento de estruturas de custos e de gestão de riscos e consolidação do plano de projetos aconteceram em função da necessidade de atender às exigências contraturais do projeto MUX. A documentação e registro do planejamento dos projetos se deu em todos os projetos pesquisados e refletia um procedimento elaborado para cumprir os requisitos da ISO 9001:2000 na empresa.

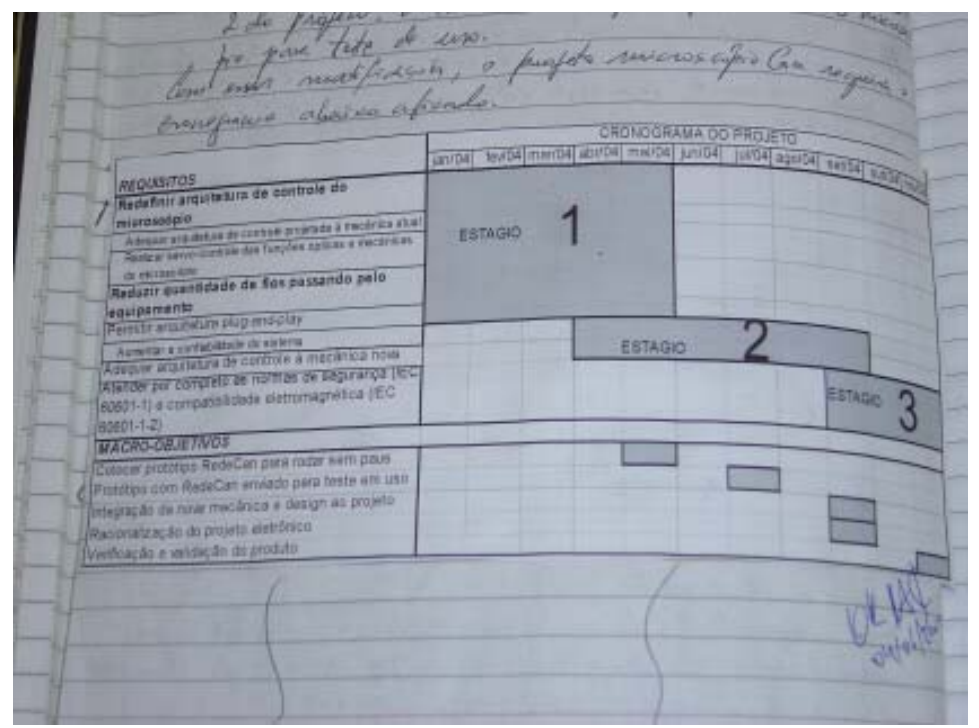

Figura 82 - Cronogramas de atividades no projeto microscópio-Can 
6.2.5.5 Fase de concepção do produto

As aplicações do MRM na fase de concepção são ilustradas no Quadro 8.

Quadro 8 - Sumário das aplicações do MRM na fase de concepção

\begin{tabular}{|c|c|c|c|}
\hline AÇÕES & $\begin{array}{c}\text { ÁREA DE } \\
\text { PROCESSO }\end{array}$ & APLICADOR & 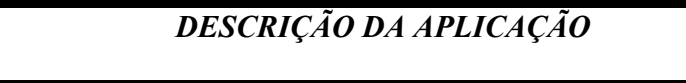 \\
\hline $\begin{array}{l}\text { Modelar e sistematizar a } \\
\text { concepção }\end{array}$ & $\begin{array}{l}\text { Projeto de } \\
\text { engenharia }\end{array}$ & Engenharia & $\begin{array}{l}\text { A concepção do retinógrafo e do microscópio-Can foi } \\
\text { modelada na forma de diagrama de blocos }\end{array}$ \\
\hline
\end{tabular}

O modelamento da concepção do produto na empresa sempre foi tratado apenas como formulação matemática da engenharia básica do produto. No planejamento do projeto microscópio-Can e na documentação de certificação do projeto retinógrafo houve um esforço para representar o produto por meio de esquemas de funcionamento que apresentavam as principais tecnologias utilizadas ou a integrar o produto. A concepção do projeto retinógrafo sem a identificação das principais tecnologias desenvolvidas é ilustrada na Figura 83.

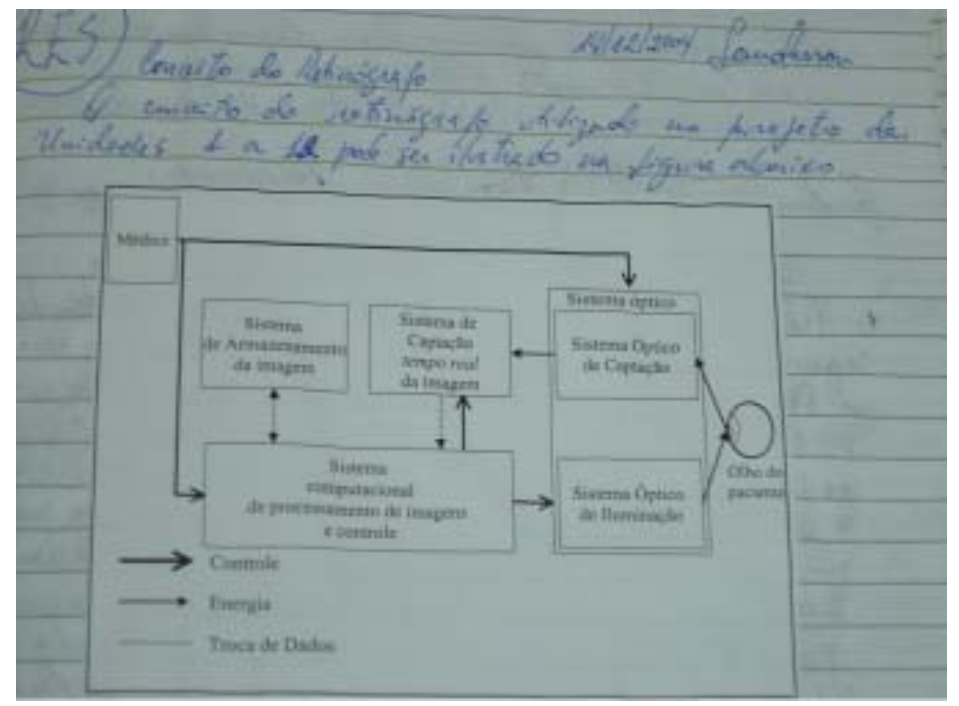

Figura 83 - Concepção do projeto retinógrafo

\subsubsection{Fase de planejamento técnico}

O Quadro 9 apresenta as aplicações do MRM na fase de planejamento técnico do produto. 
Quadro 9 - Sumário das aplicações do MRM na fase de planejamento técnico

\begin{tabular}{|c|c|c|c|}
\hline$A C ̧ \tilde{O} E S$ & $\begin{array}{l}\text { AREA DE } \\
\text { PROCESSO }\end{array}$ & APLICADOR & 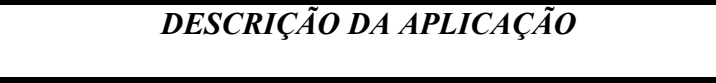 \\
\hline $\begin{array}{l}\text { Definir arquitetura do } \\
\text { produto }\end{array}$ & $\begin{array}{l}\text { Arquitetura de } \\
\text { sistemas }\end{array}$ & Engenharia & $\begin{array}{l}\text { A arquitetura do retinógrafo foi modelada com base nos } \\
\text { fluxos de informação, energia e materiais }\end{array}$ \\
\hline $\begin{array}{l}\text { Refinar análise de normas } \\
\text { e padrões }\end{array}$ & $\begin{array}{l}\text { Qualidade do } \\
\text { produto }\end{array}$ & Engenharia & $\begin{array}{l}\text { Foi confeccionado um checklist de itens normativos a } \\
\text { serem obedecidos nos projetos }\end{array}$ \\
\hline $\begin{array}{l}\text { Identificar e analisar } \\
\text { requisitos de software }\end{array}$ & $\begin{array}{l}\text { Arquitetura de } \\
\text { sistemas }\end{array}$ & Engenharia & $\begin{array}{l}\text { Foi confeccionado um procedimento de validação de } \\
\text { software e detalhado em modelos de DFD e MER que } \\
\text { foram utilizados no retinógrafo. }\end{array}$ \\
\hline Gerar árvore de produtos & $\begin{array}{l}\text { Documentos e } \\
\text { configurações }\end{array}$ & Engenharia & $\begin{array}{l}\text { Foi desenvolvida uma árvore de produtos par o projeto } \\
\text { MUX }\end{array}$ \\
\hline $\begin{array}{l}\text { Planejar tecnicamente o } \\
\text { projeto }\end{array}$ & Gestão de projetos & Engenharia & $\begin{array}{l}\text { O projeto MUX foi detalhadamente planejado com base } \\
\text { na árvore de produto elaborada }\end{array}$ \\
\hline $\begin{array}{l}\text { Especificar interfaces e } \\
\text { controle }\end{array}$ & $\begin{array}{l}\text { Projeto de } \\
\text { engenharia }\end{array}$ & Engenharia & $\begin{array}{l}\text { No projeto MUX, as interfaces entre as partes do } \\
\text { equipamento foram sistematizadas em documentos } \\
\text { específicos }\end{array}$ \\
\hline
\end{tabular}

A definição da arquitetura do produto foi realizada para documentar o projeto retinógrafo e tem sido realizada para a documentação do projeto MUX e outras iniciativas da Engenharia. A arquitetura confeccionada foi o ponto de partida para vincular a concepção do projeto à descrição das soluções de engenharia desenvolvidas. No retinógrafo, cada bloco da arquitetura (ver Figura 56) transformou-se em um tópico do relatório técnico confeccionado para submeter o produto à AGÊNCIA NACIONAL DE VIGILÂNCIA SANITÁRIA (ANVISA), conforme pode ser visto na Figura $84^{12}$.

A análise de normas e padrões aplicáveis foi realizada para adequar o retinógrafo à legislação específica. Foi desenvolvido um checklist para analisar o impacto da norma nos produtos em desenvolvimento. Esse checklist consta no MRM (APÊNDICE A). A estrutura de documentação elaborada para o projeto MUX teve como fundamento o conceito de árvore de produtos, conforme descrito no MRM (ver item 5.3.1.6 e Figura 57). A Figura 85 apresenta os níveis 01 e 02 dessa estrutura.

\footnotetext{
${ }^{12}$ Manteve-se às divergências de terminologia que acompanharam o produto na documentação referenciada ao longo deste tópico. Por exemplo, a "unidade de captura" da arquitetura do produto foi denominada "unidade de aquisição de imagens" no relatório técnico, conforme pode ser visto na Figura 84.
} 


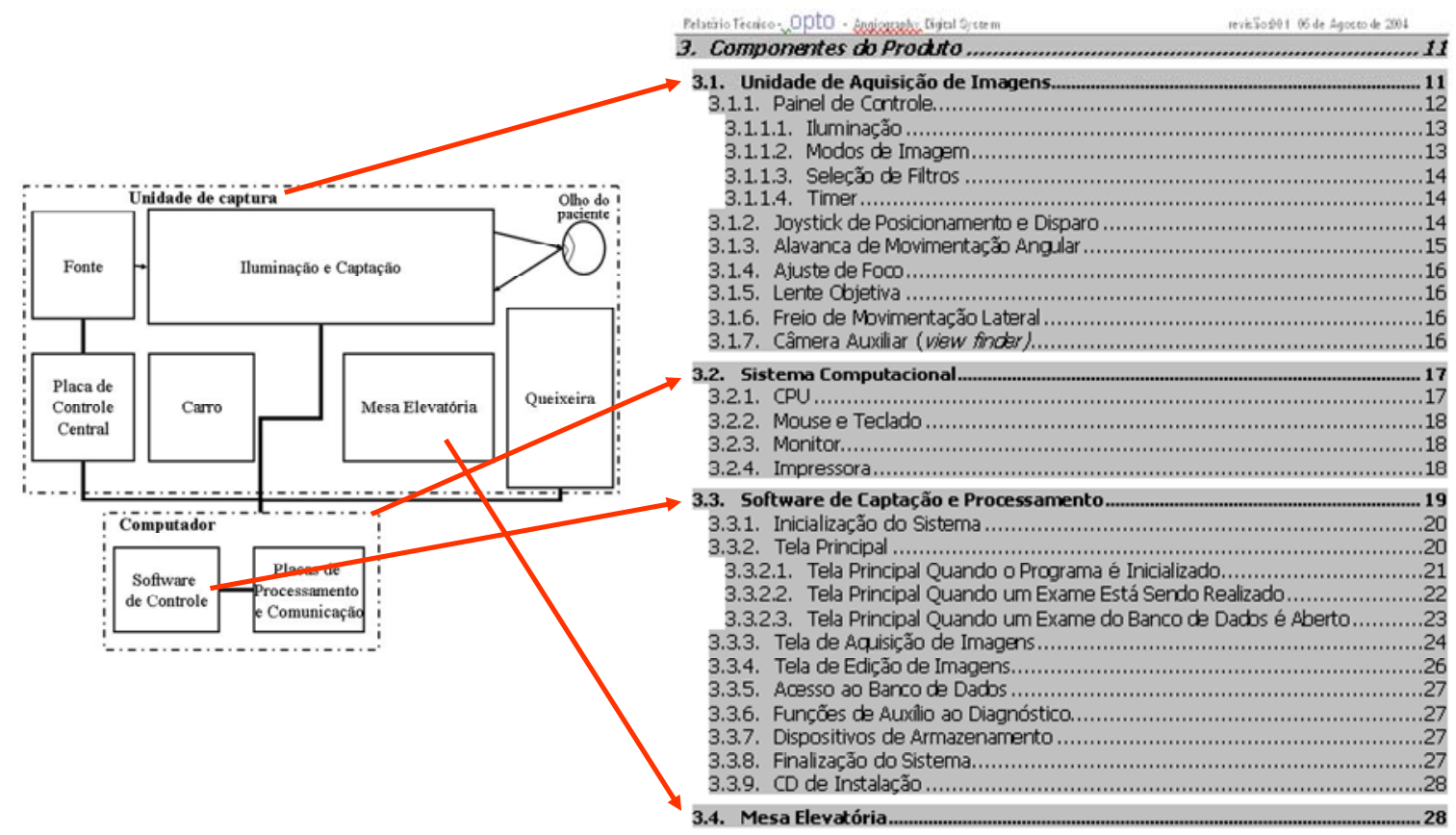

Figura 84 - Arquitetura do retinógrafo e seu vínculo com tópicos do relatório técnico do equipamento (Fonte: OPTO ELETRÔNICA S.A., 2005a)

As siglas que constam abaixo da identificação dos ramos da árvore de produtos da MUX são referentes aos documentos vinculados em cada um. Por exemplo, "EC” significa “especificação do contratante", documento elaborado pelo Instituto Nacional de Pesquisas Espaciais (INPE).

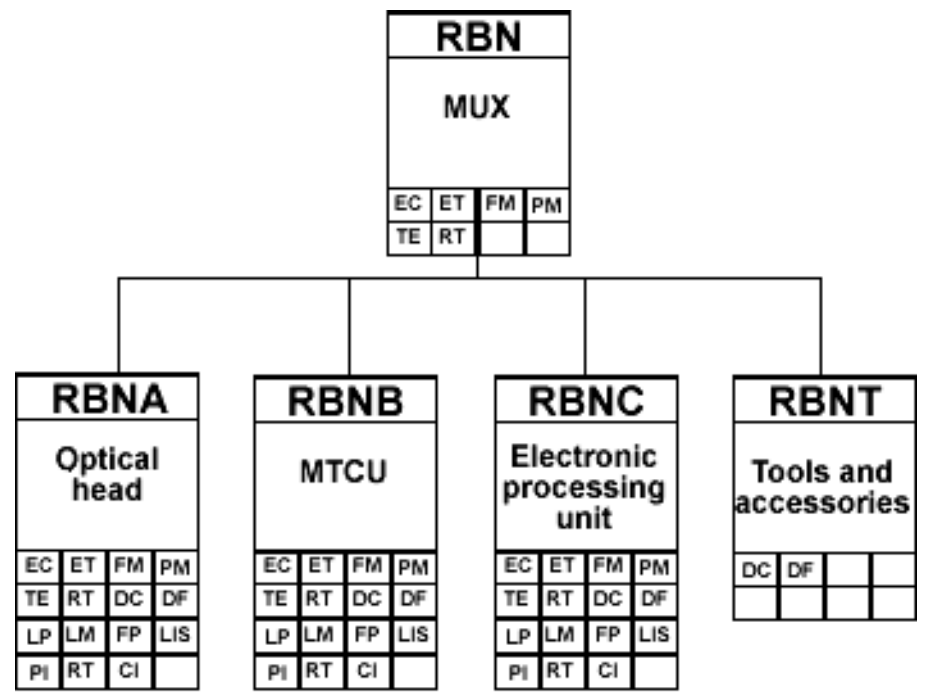

Figura 85 - Níveis 01 e 02 da árvore de produtos da MUX 
No projeto MUX, a WBS foi estruturada com base na árvore de produtos e a fase de projeto preliminar (conforme definição dos padrões da área espacial - ver APÊNDICE C) foi extensamente detalhada, tanto em termos de mecânica, como de eletrônica e óptica. Esse planejamento técnico foi utilizado para subsidiar a gestão dos prazos dessa fase do projeto MUX e consistiu na identificação de pacotes de trabalho com descrição detalhada de entrada e saída das atividades que os compunham e cronogramas detalhados com marcos intermediários rastreáveis aos marcos contratuais do projeto.

As interfaces e sinais de controle necessários à integração dos equipamentos que compõem o MUX foi detalhadamente especificada, tanto em termos mecânicos quanto eletrônicos. Embora isso fosse realizado em projetos anteriores, no MUX as interfaces foram transformadas em diagramas de blocos e sistematizadas em documentos específicos.

\subsubsection{Fase de projeto técnico}

$\mathrm{Na}$ fase de projeto técnico, as atividades relacionadas com a produção de soluções para as funções primárias do produto que atenderiam ao conceito de mecatrônica utilizado no MRM (ver Figura 12) já eram realizadas com nível de capabilidade inicial $\left(\mathrm{N}_{\mathrm{ci}}\right)$ de "1" (um) e não houve possibilidade de aplicar padrões ou métodos de projeto de maneira a aumentar sua capabilidade. As aplicações do MRM na fase de projeto técnico são ilustradas no Quadro 10.

Quadro 10 - Sumário das aplicações do MRM na fase de projeto técnico

\begin{tabular}{|c|c|c|c|}
\hline$A C ̧ \tilde{O} E S$ & $\begin{array}{c}\text { AREA DE } \\
\text { PROCESSO }\end{array}$ & APLICADOR & 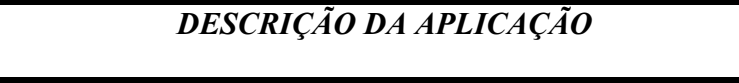 \\
\hline $\begin{array}{l}\text { Documentar as soluções } \\
\text { técnicas }\end{array}$ & $\begin{array}{l}\text { Documentos e } \\
\text { configurações }\end{array}$ & Engenharia & $\begin{array}{l}\text { Todos os projetos foram extensamente documentados do } \\
\text { ponto de vista técnico utilizando o livro de projetos }\end{array}$ \\
\hline $\begin{array}{l}\text { Documentar e registrar o } \\
\text { projeto técnico }\end{array}$ & $\begin{array}{l}\text { Documentos e } \\
\text { configurações }\end{array}$ & Engenharia & $\begin{array}{l}\text { Todos os projetos passaram a ter um registro de seu status } \\
\text { ao final da fase de projeto técnico }\end{array}$ \\
\hline
\end{tabular}

A documentação de soluções técnicas acontecia na empresa antes de aplicado o MRM, porém de forma bastante pessoal. Cada engenheiro documentava quando considerasse necessário e à sua maneira. Foi planejado um procedimento de utilização do livro de projetos para documentar as soluções dos principais problemas de cada projeto. Na Figura 86 constam 
registros de soluções de projeto eletrônico do retinógrafo (a) e do microscópio-Can (b). Foi desenvolvido um checklist para orientar a documentação de projetos eletrônicos (Figura 86(a)).
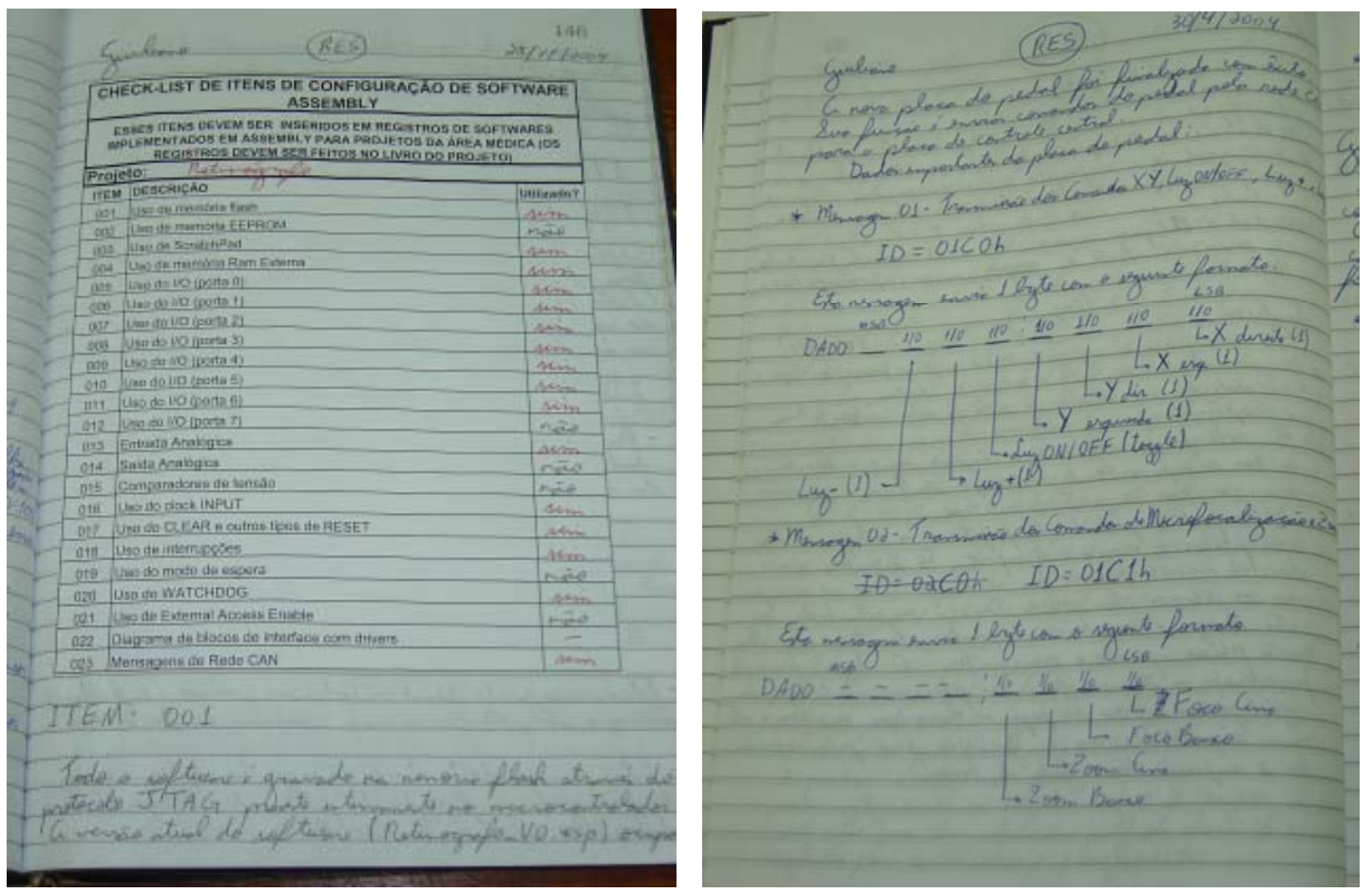

Figura 86 - Documentação técnica: (a) retinógrafo; e (b) microscópio-Can.

A cada conclusão de projeto técnico, com envio de protótipos tipo ALFA para testes, passou-se a realizar um registro detalhado de suas configurações. Além do aspecto técnico da configuração enviada para testes, a descrição das diferenças entre os protótipos e a localização dos arquivos de origem das partes mecânica, óptica, eletrônica e de software passaram a ser registrados no livro de projetos. Esse tipo de registro é apresentado na Figura 87 para os projetos retinógrafo e fotocoagulador i-MP.

A documentação das soluções técnicas culminou com a consolidação do que fora desenvolvido a título de projeto do produto. A engenharia básica do projeto retinógrafo é ilustrada na Figura 88. Na Figura 89 consta o sistema de controle do equipamento enquanto na Figura 90 consta a arquitetura do software projetado. Esse tipo de documentação não era 
realizada em projetos antigos, tendo sido, ao longo da aplicação do MRM, incorporada na etapa de validação de projetos, conforme OPTO ELETRÔNICA (2006).
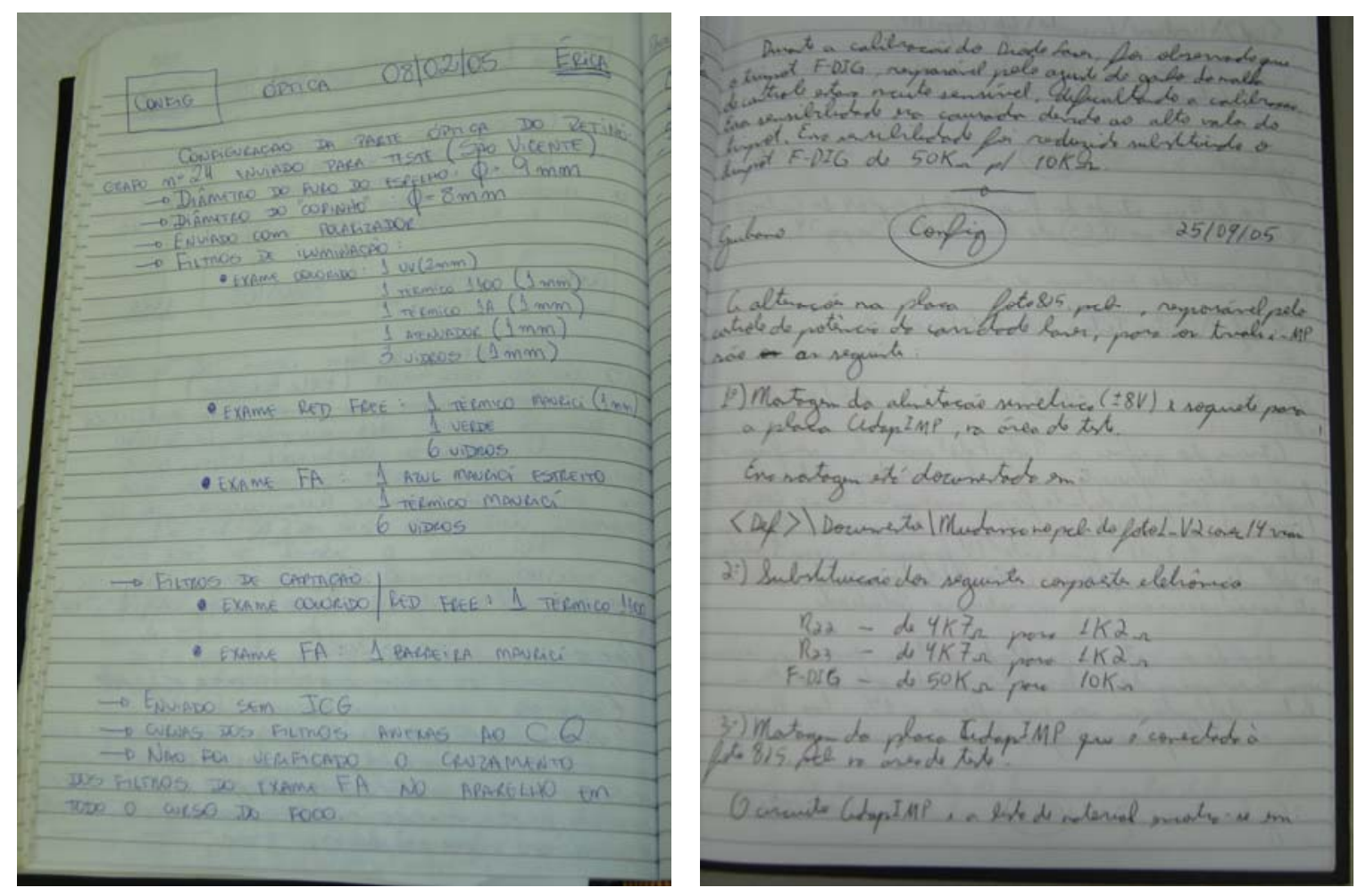

Figura 87 - Registros de configuração do projeto técnico

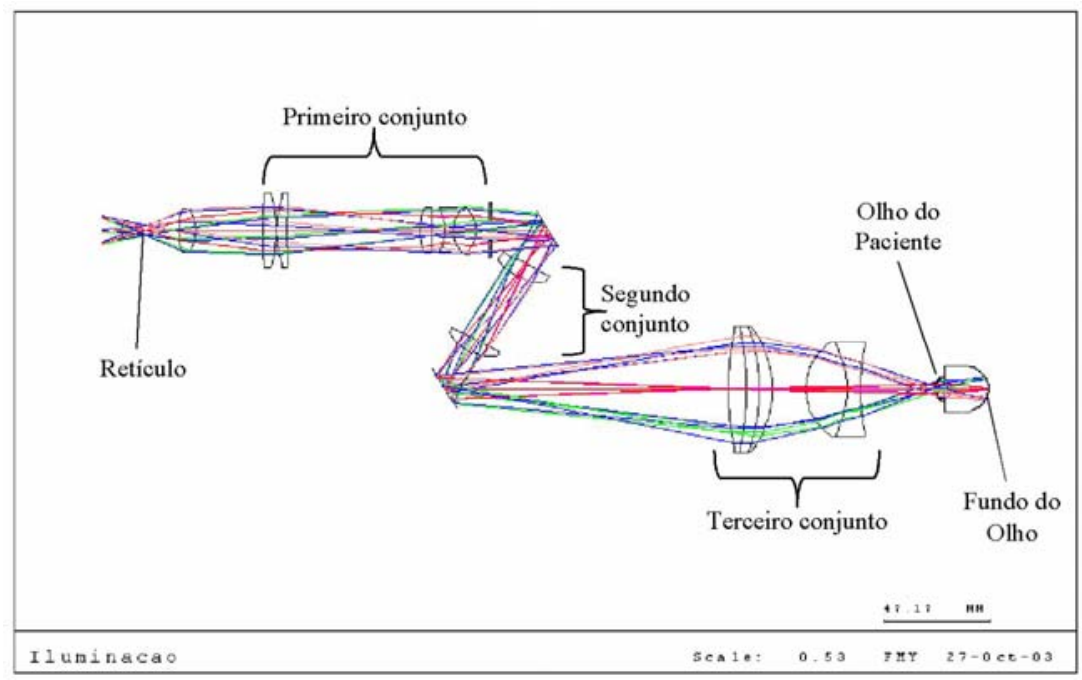

Figura 88 - Ilustrativo de engenharia básica do equipamento de fotografia da retina - sistema óptico de iluminação. (Fonte: OPTO ELETRÔNICA S.A., 2005a) 


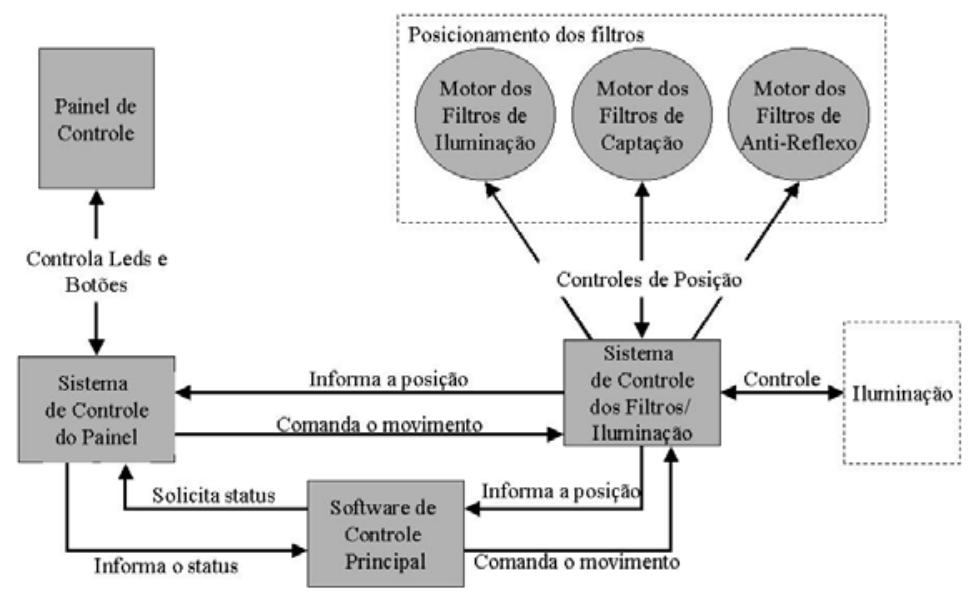

Figura 89 - Ilustrativo do sistema de controle do equipamento (Fonte: OPTO ELETRÔNICA S.A., 2005a)

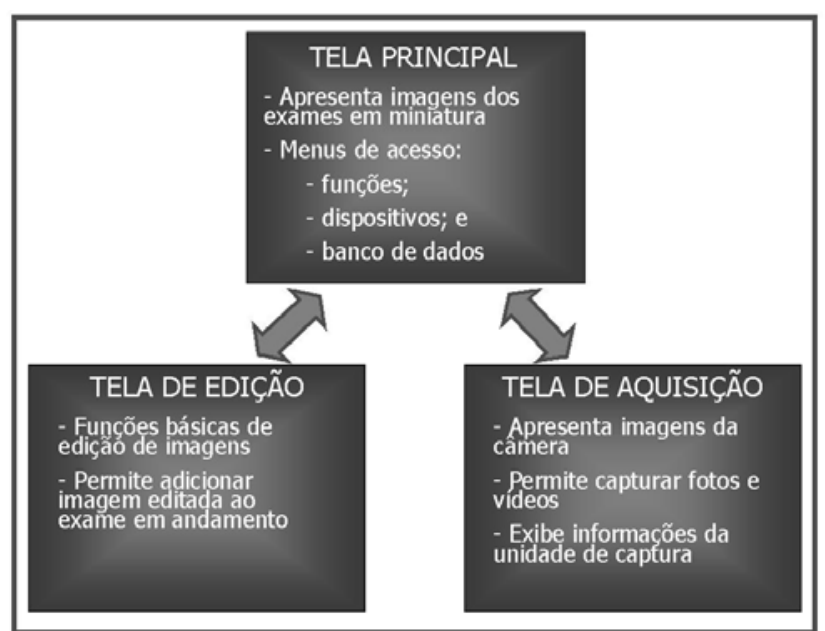

Figura 90 - Arquitetura do software de alto nível projetado (Fonte: OPTO ELETRÔNICA S.A., 2005b)

A documentação e registro do projeto técnico se deu em todos os projetos pesquisados e refletia o procedimento OPTO ELETRÔNICA (2006).

\subsubsection{Fase de otimização do projeto}

O Quadro 11 apresenta as aplicações do MRM na fase otimização do projeto com base no fluxograma de atividades ilustrado na Figura 59. As atividades relacionadas com a produção de soluções para as funções secundárias dos produtos mecatrônicos (item 5.3.1.8) já eram realizadas em projetos anteriores da empresa. O nível de capabilidade dessas atividades $\left(\mathrm{N}_{\mathrm{ci}}\right)$ era de "1" (um) e não realizou-se aplicações que aumentassem sua capabilidade. 
Quadro 11 - Sumário das aplicações do MRM na fase de otimização

\begin{tabular}{|c|c|c|c|}
\hline$A C ̧ \tilde{O} E S$ & $\begin{array}{l}\text { ÁREA DE } \\
\text { PROCESSO }\end{array}$ & APLICADOR & 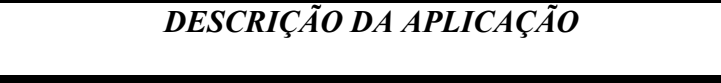 \\
\hline $\begin{array}{l}\text { Analisar riscos do produto } \\
\text { quanto às normas }\end{array}$ & $\begin{array}{l}\text { Qualidade do } \\
\text { produto }\end{array}$ & Engenharia & $\begin{array}{l}\text { Foi desenvolvido um procedimento para análise de } \\
\text { riscos dos produtos }\end{array}$ \\
\hline Projetar tolerâncias & $\begin{array}{l}\text { Projeto de } \\
\text { engenharia }\end{array}$ & Engenharia & $\begin{array}{l}\text { As tolerâncias das peças ópticas do retinógrafo foram } \\
\text { detalhadamente analisadas }\end{array}$ \\
\hline $\begin{array}{l}\text { Testar software } \\
\text { desenvolvido }\end{array}$ & $\begin{array}{l}\text { Projeto de } \\
\text { engenharia }\end{array}$ & Engenharia & $\begin{array}{l}\text { Foi elaborado um procedimento para a realização de } \\
\text { testes de software nos equipamentos }\end{array}$ \\
\hline $\begin{array}{l}\text { Detalhar manufatura e } \\
\text { montagem }\end{array}$ & $\begin{array}{l}\text { Produção e } \\
\text { suprimentos }\end{array}$ & Engenharia & $\begin{array}{l}\text { Foram elaborados documentos de montagem mecânica, } \\
\text { eletrônica e óptica detalhados para o projeto retinógrafo, } \\
\text { os quais passaram a ser usados como templates para } \\
\text { outros projetos. }\end{array}$ \\
\hline
\end{tabular}

As análises de riscos dos produtos foram padronizadas através de um procedimento que definia uma seqüência de passos a serem executados e o uso de formulários do tipo FMEA para sistematizar os riscos identificados e as ações corretivas ou preventivas realizadas e sugeridas, respectivamente. Esse procedimento passou a ser seguido sendo identificados os riscos dos produtos decorrentes de requisitos normativos, os quais eram registrados no caderno de projetos, conforme ilustrado na Figura 91.

Os registros de análise de riscos foram compilados posteriormente em um documento de análise de riscos do equipamento retinógrafo, conforme ilustra a Figura 102. Nesse documento, os riscos identificados foram sistematizados em um formulário FMEA.

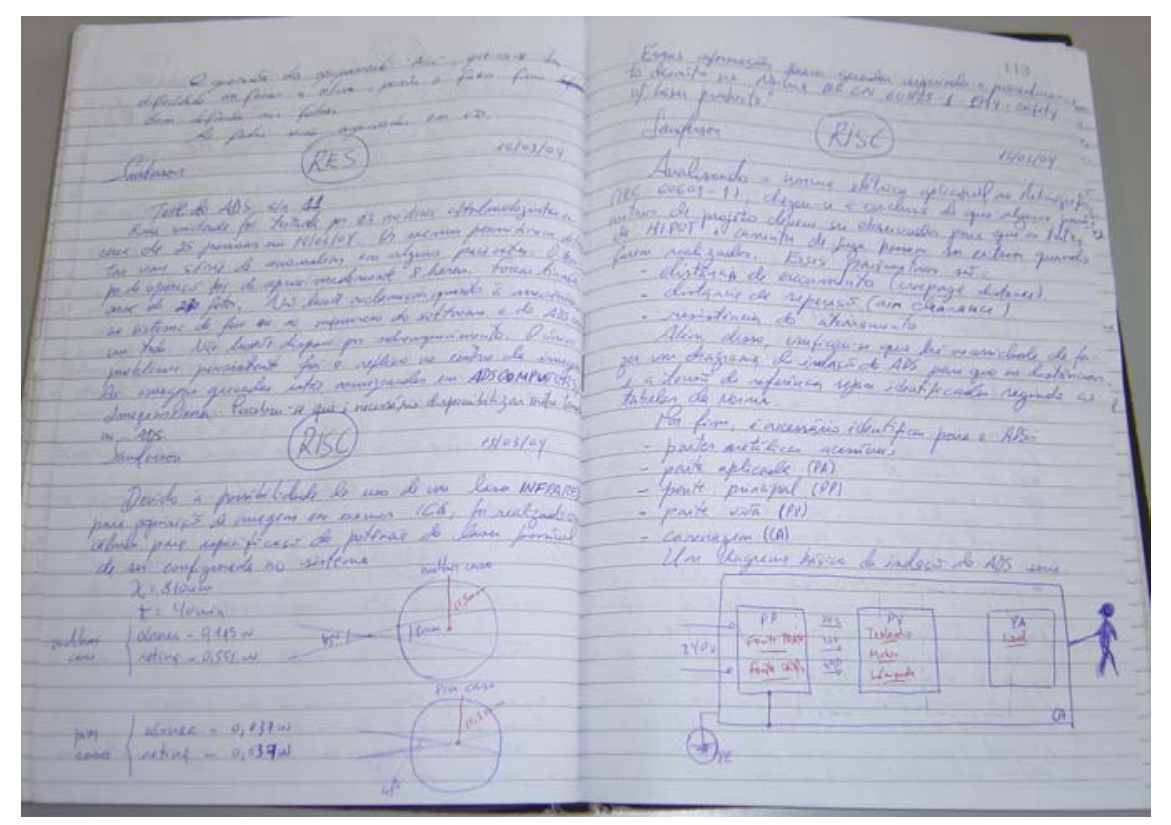

Figura 91 - Registros de análise de riscos do projeto Retinógrafo 
Foi realizada uma tentativa de aplicar formulários FMEA como método de identificação de riscos de projeto através de uma abordagem bottom up baseada nos modos de falha de componentes e partes do produto. Essa tentativa foi realizada no projeto Microscópio-Can, conforme ilustrado na Figura 92.

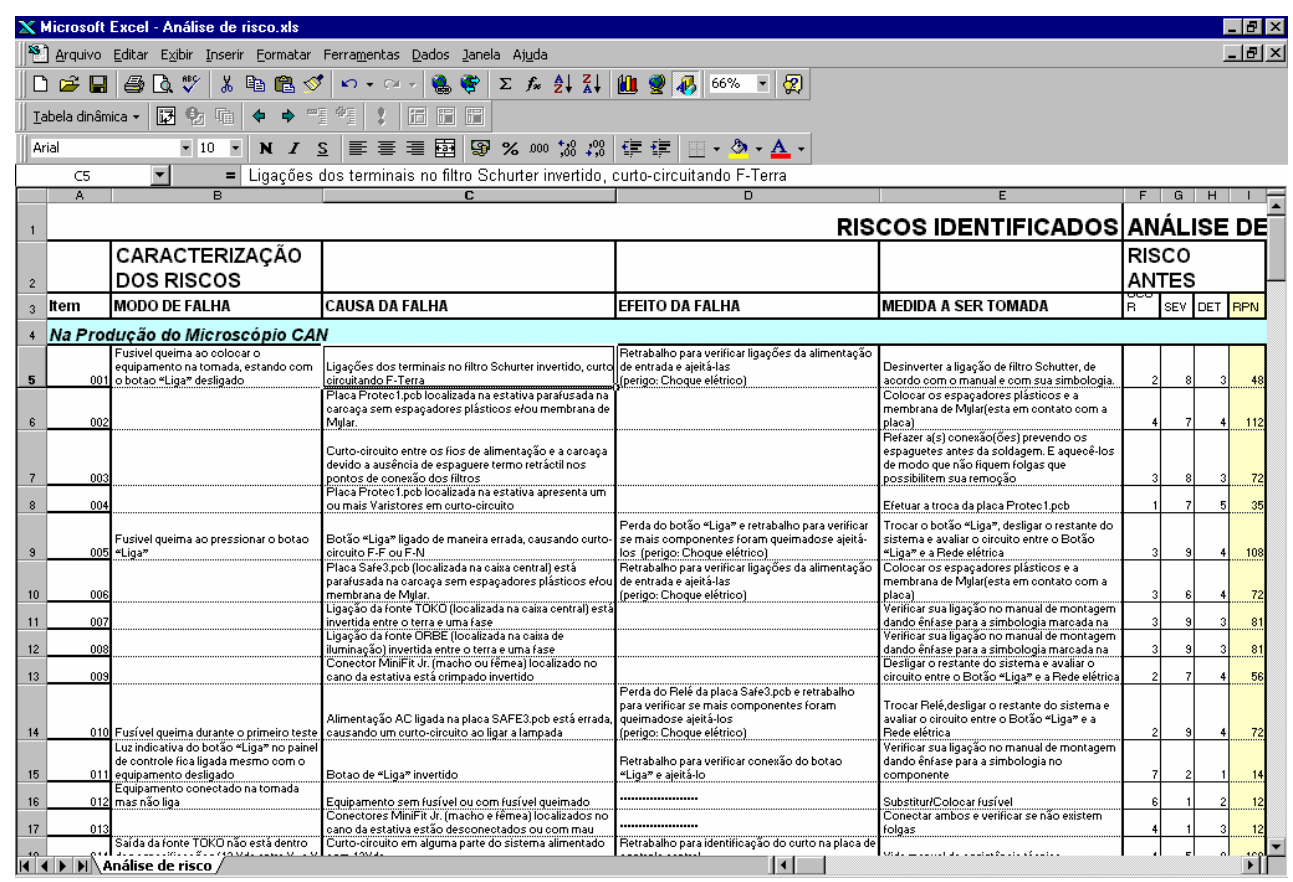

Figura 92 - Formulário FMEA preenchido para análise de riscos através da identificação de modos e efeitos de falha em soluções de projeto

A utilização da FMEA como método de identificação e priorização dos riscos do projeto não foi incorporada pela equipe, entretanto, o uso da FMEA como formulário de sistematização foi.

O projeto de tolerâncias foi realizado devido à alta dependência da qualidade da imagem captada pelo retinógrafo digital quanto às tolerâncias dimensionais da fabricação óptica. Uma análise de tolerâncias foi realizada para projetar a cadeia dimensional das lentes e espaçadores utilizados no equipamento.

O teste dos softwares desenvolvidos para os projetos retinógrafo e fotocoagulador iMP seguiram um procedimento que previa a identificação de parâmetros críticos com base em análises de risco e a realização de experimentos com testes caixa preta e caixa branca. 


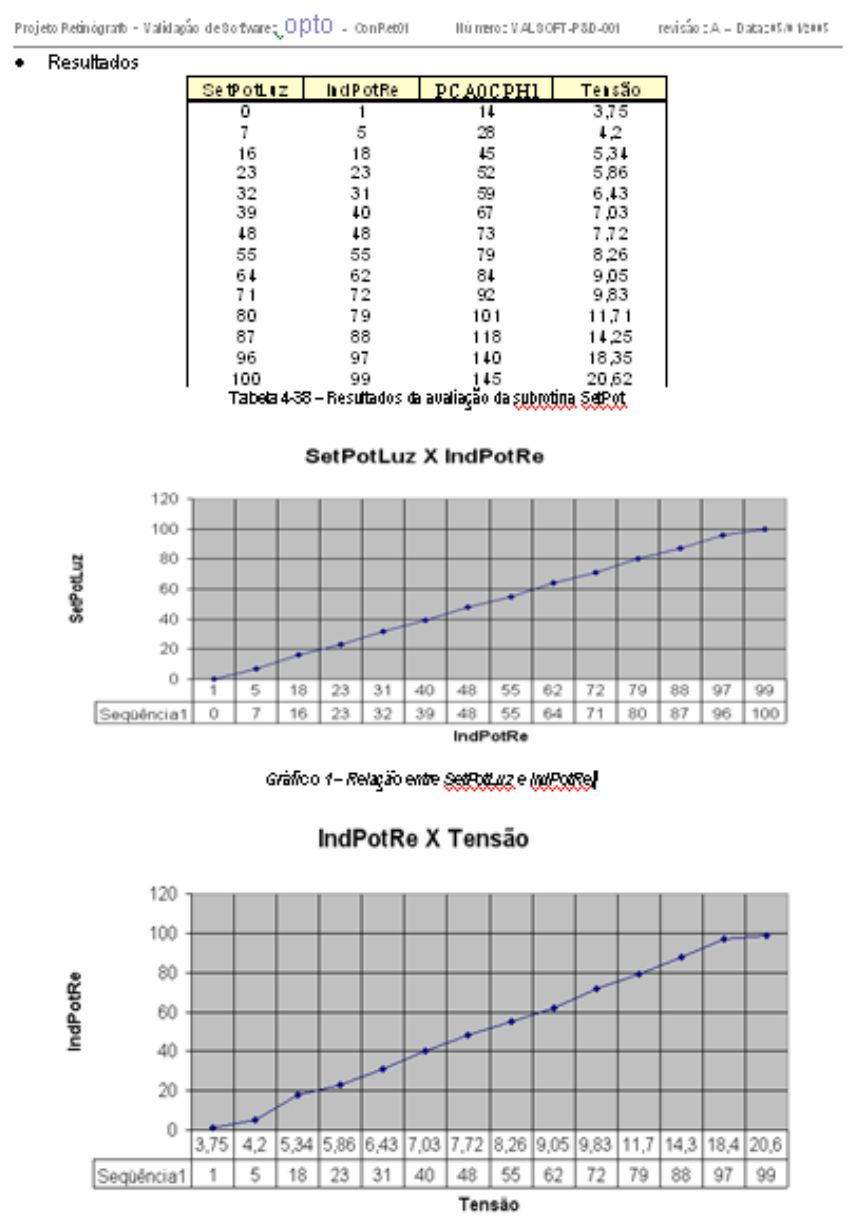

Figura 93 - Experimentos de software do projeto retinógrafo (Fonte: OPTO ELETRÔNICA S.A., 2004b)

Na Figura 93 consta a análise realizada com a função que controla a intensidade luminosa na saída do retinógrafo em função do nível imposto ao sistema de controle por meio de um encoder. A luminância é convertida em sinal de tensão na saída da lâmpada halógena utilizada. Essa função implementa soluções de controle que integram os blocos "painel de controle", "sistema de controle do painel", "sistema de controle dos filtros/iluminação" e “iluminação” da Figura 89.

A documentação de montagem mecânica, óptica e eletrônica do projeto retinógrafo foi implementada com base na descrição da seqüência de passos necessária à montagem das partes da arquitetura do equipamento. Os procedimentos inicialmente desenvolvidos foram usados como templates para os demais projetos transferidos para os setores de manufatura da empresa. 
Na Figura 94 constam partes de documentos de montagem mecânica e eletrônica do retinógrafo.

\section{2 - Pré-Montagem do Mecanismo de Elevação} A seguir é apresentada uma figura do mecanismo de elevaç̃o com uma vista $3 \mathrm{D}$ explodida, oqual se encontra em anexo em uma visão $2 \mathrm{D}$ com lista de materiais. As peras numeradas na figura são:

\begin{tabular}{|c|c|c|c|}
\hline 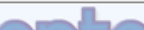 & SISTEMA DE GESTAO DA QUALIDADE & Edisto: & Data En Es \\
\hline $0: 10$ & PROCEDIMENTO & 1 & 13/40R2004 \\
\hline L & 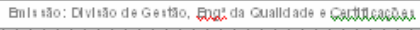 & Renis & Dit Reus \\
\hline Nơndera: & T & 2 & $06,05 / 05$ \\
\hline $\begin{array}{l}\text { RETINÓGRRFO } \\
7.5 .1-\mathrm{PR} 0-05\end{array}$ & MONTAGEM DQ FONTE DE RLIMENTAÇ,̌̃O & \multicolumn{2}{|c|}{ 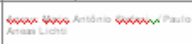 } \\
\hline
\end{tabular}

A figura abaixo mostra as ligações de saída do filtro Schaffiner e de entrada e saida das fontes ORBE e TOKO.

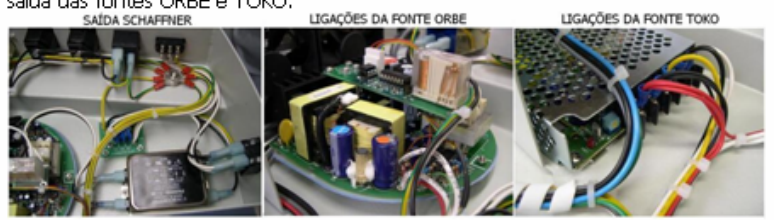

Figura 2-21 - Lizară das Fontes

2.1.5. Ligaçäo elétrica do circuito de iluminaçäo

Para as ligações elétricas da fonte deve se seguir o esquema elétrico RETINÓGRAFO-7.5.1-ELE-03.

Passo 20: Ligaçöes dos Conectores de Saída Crimpe todos os cabos utilizando terminal Molex 5558 e a ferramenta adequada para crimpagem

Faça a montagem do conector BNC do View Finder. Insira o copinho de resinagem no cabo coaxial $7^{\prime} 5^{\prime} \Omega, 0.3 / 1.8 \mathrm{~mm}$ e, enfim, solde-o mo BNC e a malha direto mo corpo do conector do BNC. Bosqueje o copinho de resinagem na porca de travamento do PVC e adicione a essa montagem o Adesivo Epóx Claro DP 105.

OBS. É importante que ao final desse procedimento seja feita uma medida de continuidade entre a entrada do conector BNC do dhassi externo da fonte e a superfície metálica montada nessa etapa.

Figura 2-1- Mecanismo de elevaç̆o explodido

Figura 94 - Documentação de montagem: (a) mecânica; (b) eletrônica. (Fonte: OPTO ELETRÔNICA S.A. (2004a; OPTO ELETRÔNICA S.A. (2005d)

\subsubsection{Fase de homologação do produto}

Nessa fase estão atividades nas quais deve ocorrer estreito relacionamento entre engenharia e manufatura, conforme pode ser visto no item 5.3.1.9. O Quadro 12 apresenta as aplicações do MRM na fase de homologação do produto.

Quadro 12 - Sumário das aplicações do MRM na fase de homologação

\begin{tabular}{|c|c|c|c|}
\hline$A C ̧ \tilde{O} E S$ & $\begin{array}{c}\text { AREA DE } \\
\text { PROCESSO }\end{array}$ & APLICADOR & 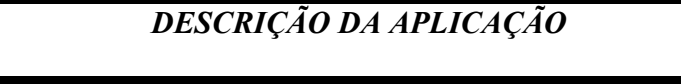 \\
\hline $\begin{array}{l}\text { Revisar documentos de } \\
\text { instalação e configuração } \\
\text { de software }\end{array}$ & $\begin{array}{l}\text { Produção e } \\
\text { suprimentos }\end{array}$ & Engenharia & $\begin{array}{l}\text { O procedimento de instalação e configuração do } \\
\text { software do retinógrafo foi sistematizado e utilizado } \\
\text { como referência para outros projetos }\end{array}$ \\
\hline $\begin{array}{l}\text { Revisar documentação de } \\
\text { fabricação e montagem } \\
\text { mecânicas }\end{array}$ & $\begin{array}{l}\text { Produção e } \\
\text { suprimentos }\end{array}$ & Engenharia & $\begin{array}{l}\text { A documentação produzida na fase de otimização foi } \\
\text { revisada e ampliada com um fluxograma macro de } \\
\text { processo }\end{array}$ \\
\hline $\begin{array}{l}\text { Revisar documentação de } \\
\text { montagem eletrônica }\end{array}$ & $\begin{array}{l}\text { Produção e } \\
\text { suprimentos }\end{array}$ & Engenharia & $\begin{array}{l}\text { A documentação produzida na fase de otimização foi } \\
\text { revisada e ampliada com um fluxograma macro de } \\
\text { processo }\end{array}$ \\
\hline $\begin{array}{l}\text { Analisar modos de falha } \\
\text { de processo }\end{array}$ & $\begin{array}{l}\text { Qualidade do } \\
\text { produto }\end{array}$ & Engenharia & $\begin{array}{l}\text { Os modos de falha relacionados com os processos de } \\
\text { montagem mecânica e eletrônica foram detectados e } \\
\text { foram estabelecidas ações corretivas / preventivas }\end{array}$ \\
\hline
\end{tabular}




\begin{tabular}{|c|c|c|c|}
\hline$A C ̧ \tilde{O} E S$ & $\begin{array}{l}\text { AREA DE } \\
\text { PROCESSO }\end{array}$ & APLICADOR & 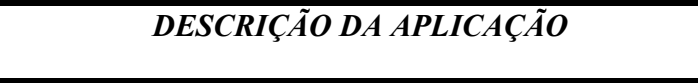 \\
\hline $\begin{array}{l}\text { Refinar cadeia de } \\
\text { fornecimento e } \\
\text { documentação de } \\
\text { aquisição }\end{array}$ & $\begin{array}{l}\text { Produção e } \\
\text { suprimentos }\end{array}$ & Engenharia & $\begin{array}{l}\text { Foram identificados os principais fornecedores do } \\
\text { projeto retinógrafo e foi confeccionada uma detalhada } \\
\text { documentação contratual e de PCP }\end{array}$ \\
\hline $\begin{array}{l}\text { Planejar controle de } \\
\text { qualidade do produto }\end{array}$ & $\begin{array}{l}\text { Qualidade do } \\
\text { produto }\end{array}$ & Engenharia & $\begin{array}{l}\text { Ao final do projeto retinógrafo, os riscos relacionados } \\
\text { com o produto e com sua montagem são } \\
\text { transformados em checklists de recebimento, } \\
\text { montagem e expedição }\end{array}$ \\
\hline Homologar fornecedores & $\begin{array}{l}\text { Qualidade do } \\
\text { produto }\end{array}$ & Engenharia & $\begin{array}{l}\text { Os fornecedores de partes consideradas limitantes para } \\
\text { os custos e montagem do retinógrafo foram } \\
\text { homologados }\end{array}$ \\
\hline $\begin{array}{l}\text { Treinamento de } \\
\text { operadores }\end{array}$ & $\begin{array}{l}\text { Produção e } \\
\text { suprimentos }\end{array}$ & Engenharia & $\begin{array}{l}\text { O lote piloto do retinógrafo foi utilizado para o } \\
\text { treinamento dos setores de manufatura da empresa }\end{array}$ \\
\hline $\begin{array}{l}\text { Documentar e registrar } \\
\text { homologação do processo }\end{array}$ & $\begin{array}{l}\text { Documentos e } \\
\text { configurações }\end{array}$ & Engenharia & $\begin{array}{l}\text { O processo de homologação passou a ser registrado no } \\
\text { livro de projetos com a indicação da documentação } \\
\text { relacionada }\end{array}$ \\
\hline
\end{tabular}

O detalhamento dos procedimentos de montagem do equipamento retinógrafo, ilustrado na Figura 94, permitiu desenvolver um fluxograma de montagem (Figura 95) que foi posteriormente analisado para verificar sua adequação à estrutura fabril da empresa. Adaptar o fluxograma de montagem aos setores de fabricação possibilitou revisar a documentação produzida inicialmente.

A revisão dos documentos de montagem mecânica e eletrônica seguiu o padrão de documentação que consta na Figura 94. O processo permitiu o amadurecimento dessa documentação e a produção de templates para esses tipos de procedimentos que estão sendo utilizadas no projeto MUX. Foi desenvolvido um procedimento de instalação e configuração de software para o equipamento retinógrafo.

A análise de modos de falha do processo foi realizada no projeto retinógrafo tomando por base a montagem do equipamento e os aspectos dela que implicariam em riscos de segurança para os pacientes e operadores. Para isso, além de desenhos de conjunto e procedimentos de montagem, foram também analisados os esquemas elétricos das placas e da cablagem, e as próprias placas de circuito impresso montadas e inseridas no equipamento.

As peças de montagem mais críticas passaram a ter seu processo de fabricação detalhado. A Figura 96 apresenta a análise de modos de falha da montagem do retinógrafo. 
Nesse caso, além de riscos de segurança são analisados riscos relativos à quantidade de retrabalho necessária para sanar determinadas falhas de processo. Essa análise gerou um documento que orienta o pessoal de montagem sobre possíveis não-conformidades detectadas na montagem da parte considerada, conforme exemplificado na Figura 97.

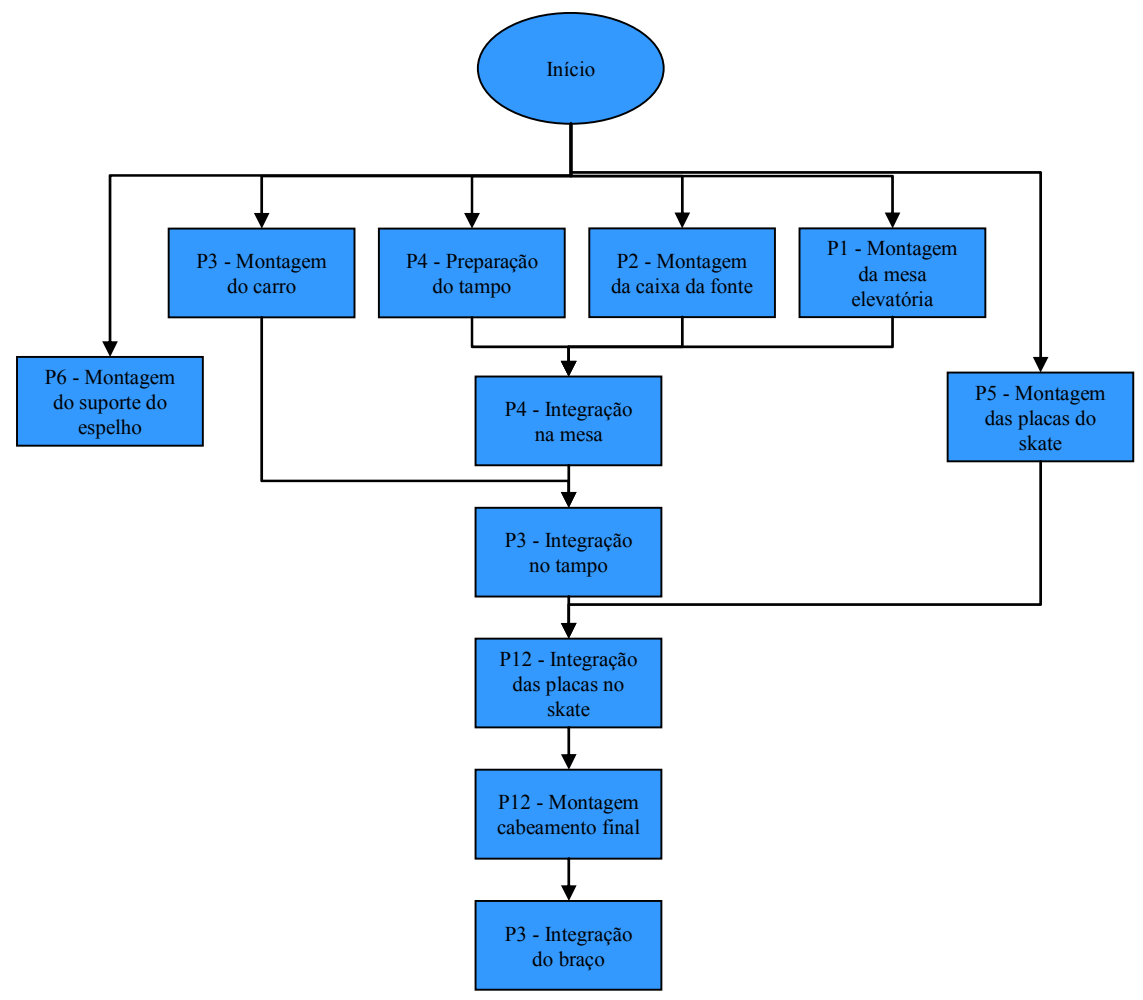

Figura 95 - Parte do fluxograma de montagem do retinógrafo digital

\begin{tabular}{|c|c|c|c|c|c|c|c|c|c|c|c|c|c|}
\hline \multicolumn{4}{|c|}{ RISCOS IDENTIFICADOS } & \multicolumn{9}{|c|}{ ANÁLISE DE RISCOS } & \multirow{3}{*}{$\begin{array}{c}\text { AÇÃO CORRETIVA } \\
\text { (PREVENTIVA) IMPLEMENTADA } \\
\text { (SUGERIDA) }\end{array}$} \\
\hline & \multicolumn{3}{|c|}{ CARACTERIZAÇÃO DOS RISCOS } & \multicolumn{4}{|c|}{ RISCO ANTES } & \multicolumn{4}{|c|}{ RISCO DEPOIS } & \multirow{2}{*}{$\begin{array}{c}\text { REDU- } \\
\text { ÇAOO }\end{array}$} & \\
\hline ITEM & MODO DE FALHA & CAUSA DA FALHA & EFEITO DA FALHA & OCOR & SEV & DET & RPN & OCOR & SEV & DET & RPN & & \\
\hline NAPR & KODUÇÃO DA MESA ELEVATÓRIA & & & & & & & & & & & & \\
\hline 001 & $\begin{array}{l}\text { Eixo de elevaçäo nä́o desliza } \\
\text { normalmente dentro do tubo externo }\end{array}$ & $\begin{array}{l}\text { Grande variação do diâmetro do eixo de elevação } \\
\text { ao longo de seu cumprimento }\end{array}$ & $\begin{array}{l}\text { Retrabalho para identificar o oerro e corrigir o } \\
\text { diâmetro do eixo de elevaçăa }\end{array}$ & 6 & 4 & 4 & 96 & 6 & 4 & & 24 & $75 \%$ & $\begin{array}{l}\text { Tolerância nos desenhos e checklist de montagem } \\
\text { mecañica }\end{array}$ \\
\hline 002 & & $\begin{array}{l}\text { Dimensõos dos apoios e buchas de TEFLON } \\
\text { acima da tolerância especificada }\end{array}$ & $\begin{array}{l}\text { Retrabalho para identificar o erro e fazer } \\
\text { chanfros manualmente nas peças }\end{array}$ & 6 & 2 & 4 & 48 & 6 & 2 & & 12 & $75 \%$ & $\begin{array}{l}\text { Tolerância nos desenhos e checklist de montagem } \\
\text { mecânica }\end{array}$ \\
\hline 003 & $\begin{array}{l}\text { Fuso não rosqueia normalmente no eixo } \\
\text { de elevação }\end{array}$ & Rosca do fuso fora da especificação ou tolerâncias & Setrabalho na confecção do fuso & 6 & 4 & 4 & 96 & 6 & 4 & & 24 & $75 \%$ & $\begin{array}{l}\text { Tolerância nos desenhos e checklist de montagem } \\
\text { mecânica }\end{array}$ \\
\hline 004 & & $\begin{array}{l}\begin{array}{l}\text { Rebarbas do fuso não realizadas em sua } \\
\text { totalidade }\end{array} \\
\end{array}$ & $\begin{array}{l}\text { Retrabalho para a realização de rebarbas no } \\
\text { fuso }\end{array}$ & 5 & 3 & 4 & 60 & 5 & 3 & & 15 & $75 \%$ & Checklist de montagem mecânica \\
\hline 005 & $\begin{array}{l}\text { Mecanismo não corre centrado na torre } \\
\text { bipartida }\end{array}$ & Bipartido soldado sem centralizar mecanismo & Perda da peça & 3 & 9 & 4 & 108 & 2 & 9 & & 18 & $83 \%$ & $\begin{array}{l}\text { Termo de contrato de fornecimento e checklist de } \\
\text { montagem mecânica }\end{array}$ \\
\hline 00 & $\begin{array}{l}\text { Há interfência do ajuste da saia com } \\
\text { relaçẫo à caixa da fonte ou pé-de-pato }\end{array}$ & Furação da saia fora do especificado & $\begin{array}{l}\text { Retrabalho para ajsutar dimensōes da saia } \\
\text { e/ou furação do tampo }\end{array}$ & 3 & 2 & & 24 & & & 4 & 16 & $33 \%$ & $\begin{array}{l}\text { Desenhos mecânicos com tolerâncias e checklist de } \\
\text { montagem mecânica }\end{array}$ \\
\hline 007 & $\begin{array}{l}\text { Mesa não funciona quando ligada na } \\
\text { rede }\end{array}$ & Defeito em cabo (s) utilizado (s) & $\begin{array}{l}\text { Retrabalho para identificação do defeito e } \\
\text { remontagem dos cabos }\end{array}$ & & 8 & & 24 & & 1 & & & $71 \%$ & Checklist de montagem eletrônica \\
\hline 008 & & $\begin{array}{l}\text { Terminal de alimentação no conector MiniModul } \\
\text { estar com mau contato }\end{array}$ & $\begin{array}{l}\text { Retrabalho para identificação do defeito e } \\
\text { remontagem dos MiniModul }\end{array}$ & & 7 & & 63 & & 7 & & 21 & $67 \%$ & Checklist de montagem eletrônica \\
\hline 009 & & Motor com defeito & $\begin{array}{l}\text { Retrabalho para identificação do defeito e } \\
\text { troca do motor }\end{array}$ & 1 & 8 & 3 & 24 & 1 & 7 & 1 & & $71 \%$ & Checklist de montagem eletrônica \\
\hline 010 & & TRAFO com defeito & $\begin{array}{l}\text { Retrabalho para identificação do defeito e } \\
\text { troca do TRAFO }\end{array}$ & & 7 & 3 & 21 & & 7 & & & $67 \%$ & Checklist de montagem eletrônica \\
\hline 012 & & $\begin{array}{l}\text { CFDC posicionada no rasgo quando há inversão } \\
\text { na polaridade de ligacăo da chave ou motor }\end{array}$ & $\begin{array}{l}\text { Retrabalho para identificação do defeito e } \\
\text { inversão da ligacăano do motor }\end{array}$ & & 7 & & 56 & 2 & 7 & & 14 & & Checklist de montagem eletrônica \\
\hline
\end{tabular}

Figura 96 - Parte da análise de falhas de processo de montagem e fabricação da mesa elevatória do retinógrafo 
A cadeia de fornecimento e documentação de aquisição foi detalhada para o projeto retinógrafo. Com base na análise de falhas do processo de montagem, identificou-se os fornecedores mais críticos e foram elaborados checklists de controle de qualidade e termos contratuais de aquisição. Ademais, alguns fornecedores foram visitados e selecionados mediante um processo de homologação que previa a entrega de protótipos para serem analisados pela equipe de engenheiros da empresa. Na Figura 98 apresenta-se parte de um termo de contrato desenvolvido no projeto retinógrafo.

Os procedimentos de montagem, integração e testes do retinógrafo foram complementados com checklists a serem utilizados para controlar a qualidade da fabricação e montagem do produto. $\mathrm{O}$ controle de qualidade desse equipamento foi projetado para que os setores de montagem e testes finais não precisem retrabalhar as peças, partes e componentes do produto. O envio de peças e subconjuntos de uma etapa a outra do processo de montagem foi projetado para ser acompanhado pelo checklist da etapa anterior devidamente preenchido, datado e assinado. Isso é ilustrado na Figura 99.

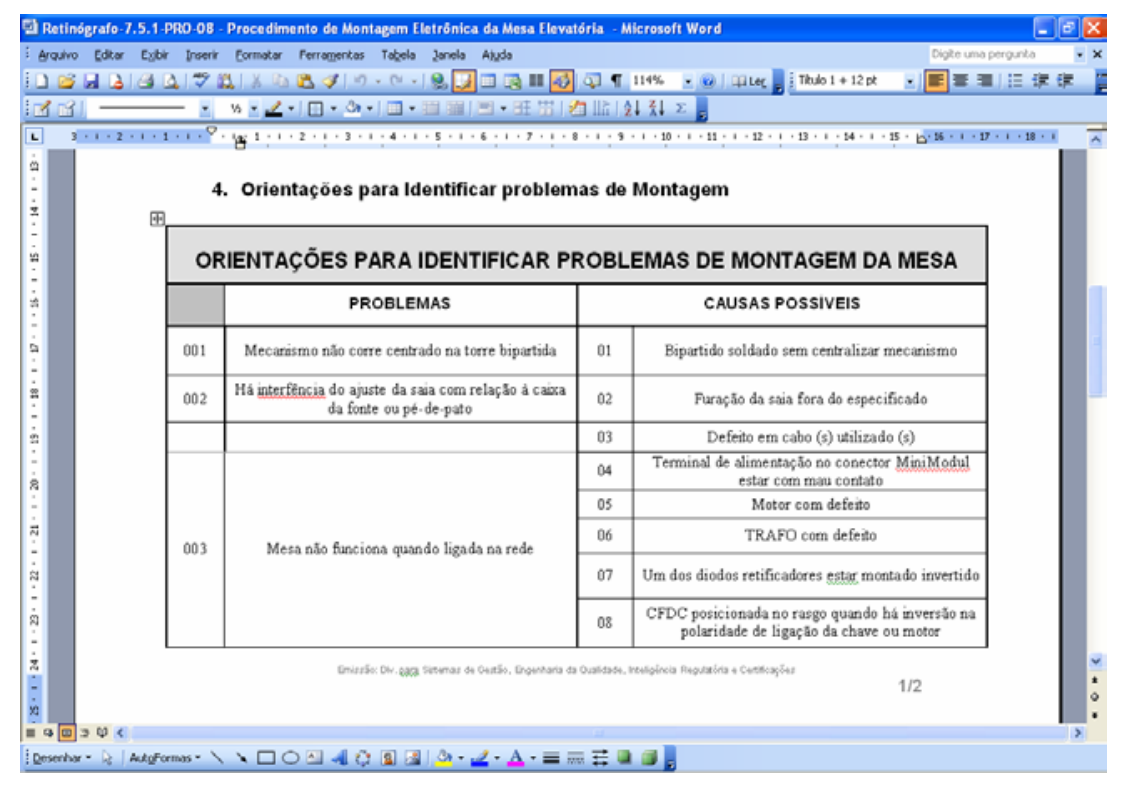

Figura 97 - Orientações para o pessoal de montagem 


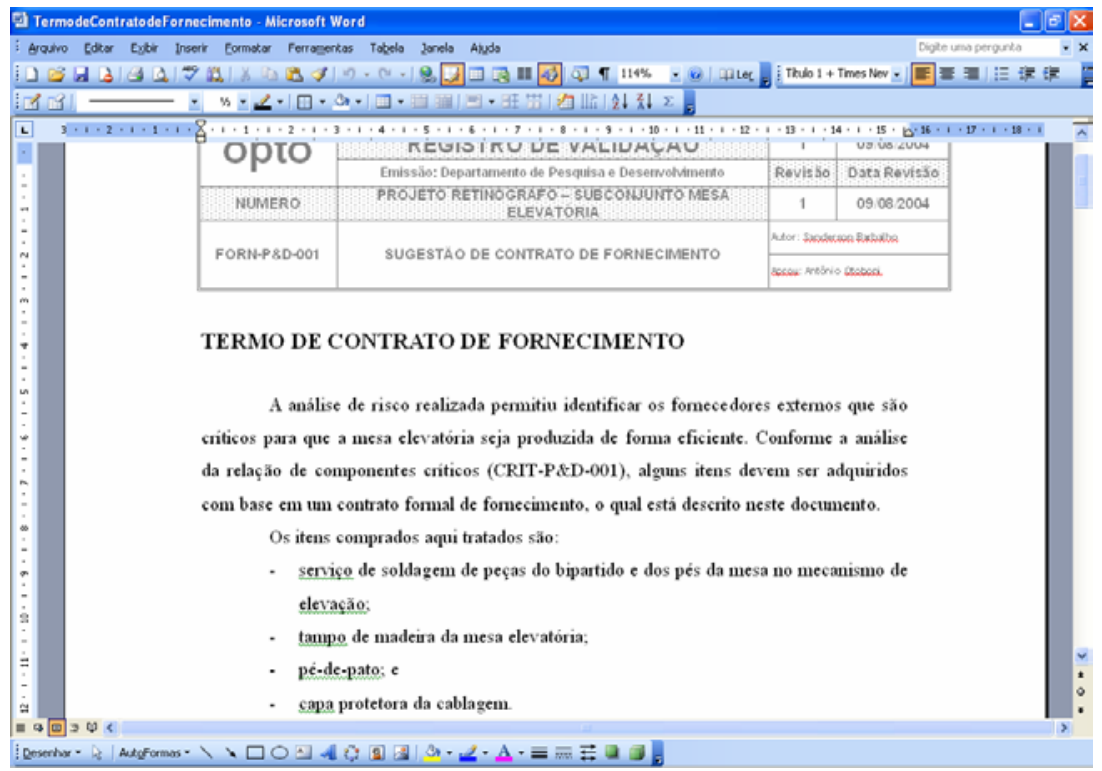

Figura 98 - Parte de termo de contrato de fornecimento desenvolvido para o projeto retinógrafo

A documentação de montagem desenvolvida, após testada pela equipe especializada do setor de P\&D da empresa, é submetida aos setores de fabricação e montagem. São, então, desenvolvidos protótipos a serem utilizados para o treinamento do pessoal de manufatura da empresa. Esses treinamentos, adicionalmente, permitem a validação dos documentos de montagem desenvolvidos ao longo do projeto, e portanto, a homologação dos processos de montagem descritos nos procedimentos exemplificados na Figura 94. A Figura 100 ilustra o treinamento realizado com parte do retinógrafo.

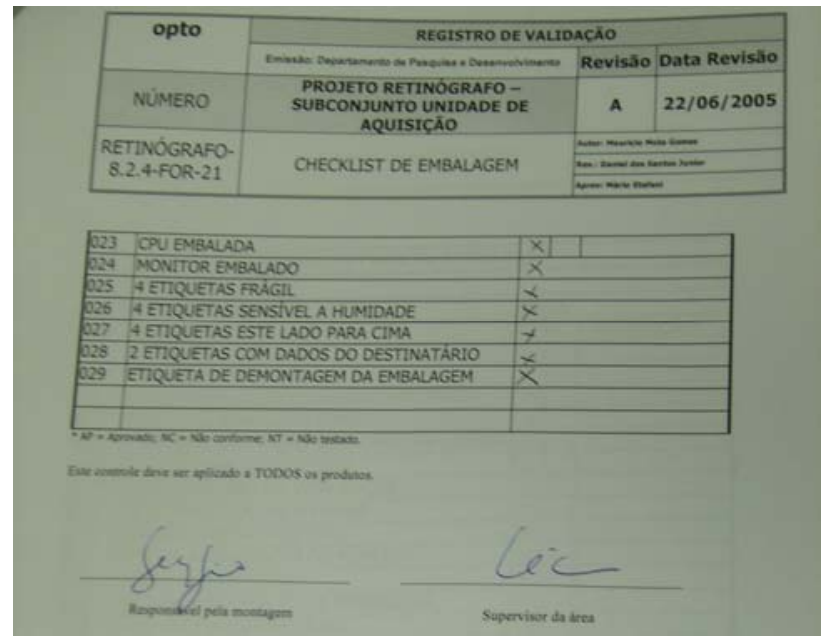

Figura 99 - Checklist de montagem de parte do retinógrafo devidamente preenchido. 
Após realizados os treinamentos e verificado que os protótipos cumprem às especificações da matriz de verificação do projeto, é realizado um registro do livro de projetos que valida a documentação de processo desenvolvida e sua aplicação, conforme exemplo da Figura 101.

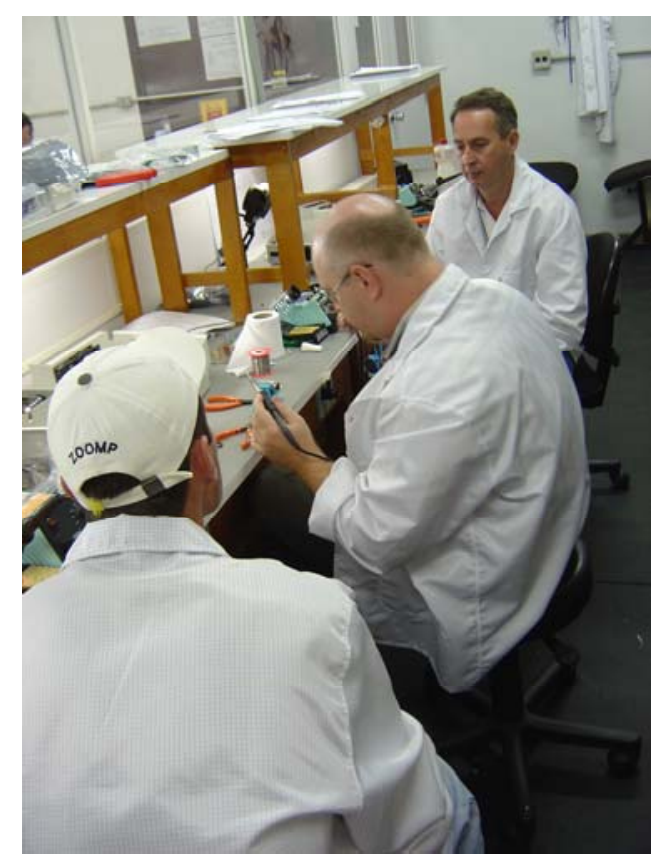

Figura 100 - Treinamento da fonte de alimentação do retinógrafo: (a) foto ilustrativa; (b) registro no livro de projetos.

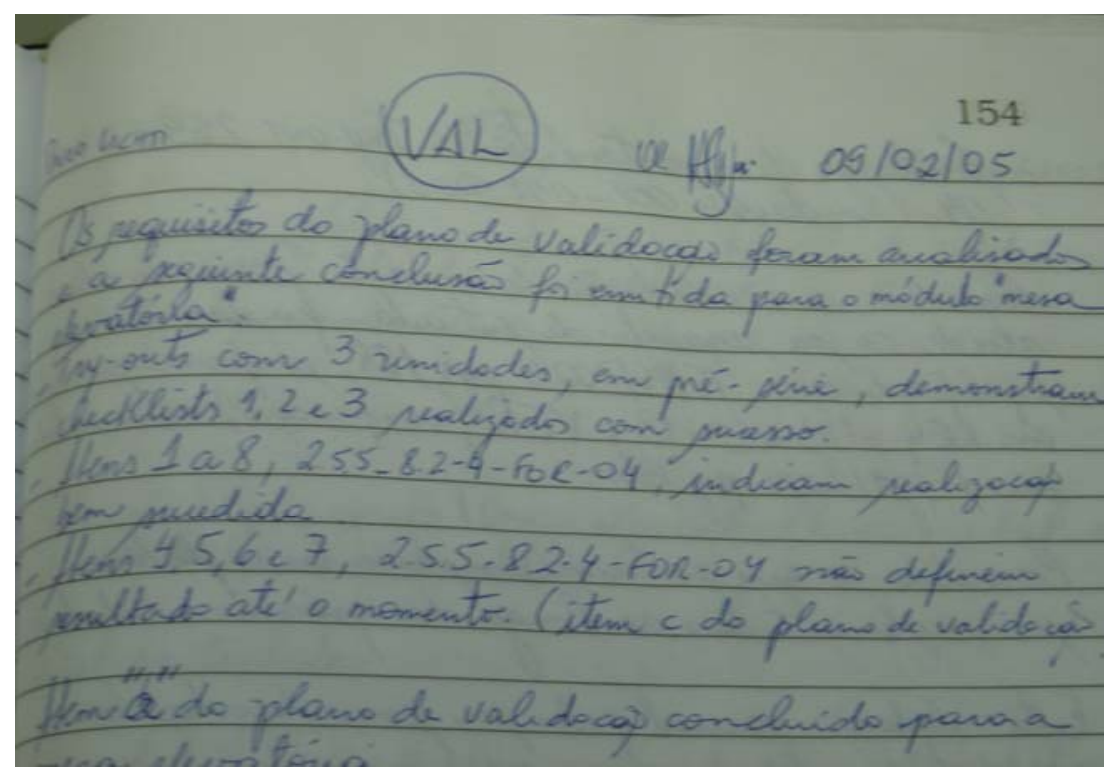

Figura 101 - Registro de homologação de processo de montagem 


\subsubsection{Fase de validação do produto}

O Quadro 13 apresenta as aplicações do MRM na fase validação do produto, conforme as atividades que constam no fluxograma da Figura 62.

Quadro 13 - Sumário das aplicações do MRM na fase de validação

\begin{tabular}{|c|c|c|c|}
\hline$A C ̧ \tilde{O} E S$ & $\begin{array}{c}\text { AREA DE } \\
\text { PROCESSO }\end{array}$ & APLICADOR & 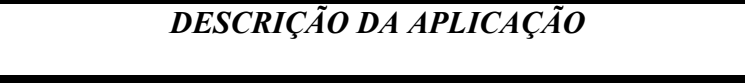 \\
\hline $\begin{array}{l}\text { Planejar validação e } \\
\text { certificação do produto }\end{array}$ & $\begin{array}{l}\text { Gestão de } \\
\text { projetos }\end{array}$ & Engenharia & $\begin{array}{l}\text { A validação dos projetos fotocoagulador i-MP e MUX } \\
\text { foram previamente planejadas }\end{array}$ \\
\hline $\begin{array}{l}\text { Documentar o produto } \\
\text { segundo as normas } \\
\text { aplicáveis }\end{array}$ & $\begin{array}{l}\text { Arquitetura de } \\
\text { sistemas }\end{array}$ & Engenharia & $\begin{array}{l}\text { O retinógrafo foi documentado com base nas normas } \\
\text { ANVISA }\end{array}$ \\
\hline Validar o produto & $\begin{array}{l}\text { Desenvolvime } \\
\text { nto de } \\
\text { mercados }\end{array}$ & Comercial & $\begin{array}{l}\text { O projeto fotocoagulador i-MP está sendo validado em } \\
\text { parceria com médicos oftalmologistas }\end{array}$ \\
\hline $\begin{array}{l}\text { Documentar e registrar a } \\
\text { validação do produto }\end{array}$ & $\begin{array}{l}\text { Documentos e } \\
\text { configurações }\end{array}$ & Engenharia & $\begin{array}{l}\text { Todo o processo de validação foi documentado no livro de } \\
\text { projetos }\end{array}$ \\
\hline
\end{tabular}

O projeto fotocoagulador i-MP foi planejado com base no processo de validação e certificação necessário a esse tipo de produto, uma vez que se trata de um equipamento com protocolo de software inovador no mundo. Para o projeto MUX, validar e certificar consistem em uma etapa denominada de qualificação, com base nas normas da área espacial (ver APÊNDICE C). Diferentemente dos projetos anteriormente desenvolvidos pela empresa, nesses foram previamente identificados os laboratórios de certificação, os procedimentos utilizados para certificar os produtos, assim como os usuários aos quais o fotocoagulador seria submetido e os tipos de teste que seriam realizados.

A documentação do projeto retinógrafo foi realizada com base nas normas a ele aplicáveis. Foram elaborados um relatório técnico detalhado do produto que teve como ponto de partida a sua arquitetura (Figura 56), um relatório de análise de riscos de projeto, no qual foram abordados os requisitos técnicos das normas aplicáveis ao equipamento, conforme os registros de riscos descritos na fase de otimização (ver Figura 91) e um relatório detalhado de experimentos realizados com os softwares desenvolvidos, os quais são ilustrados na Figura 93. Esses relatórios são apresentados na Figura 102. 
A documentação ilustrada na Figura 102 é baseada nos requisitos da resolução RDC 185 (AGÊNCIA NACIONAL DE VIGILÂNCIA SANITÁRIA, 2001). Nessa resolução, a agência define as classes de risco de produtos eletro-médicos e o que deve constar nos relatórios a ela enviados para efeito de registro de produto.
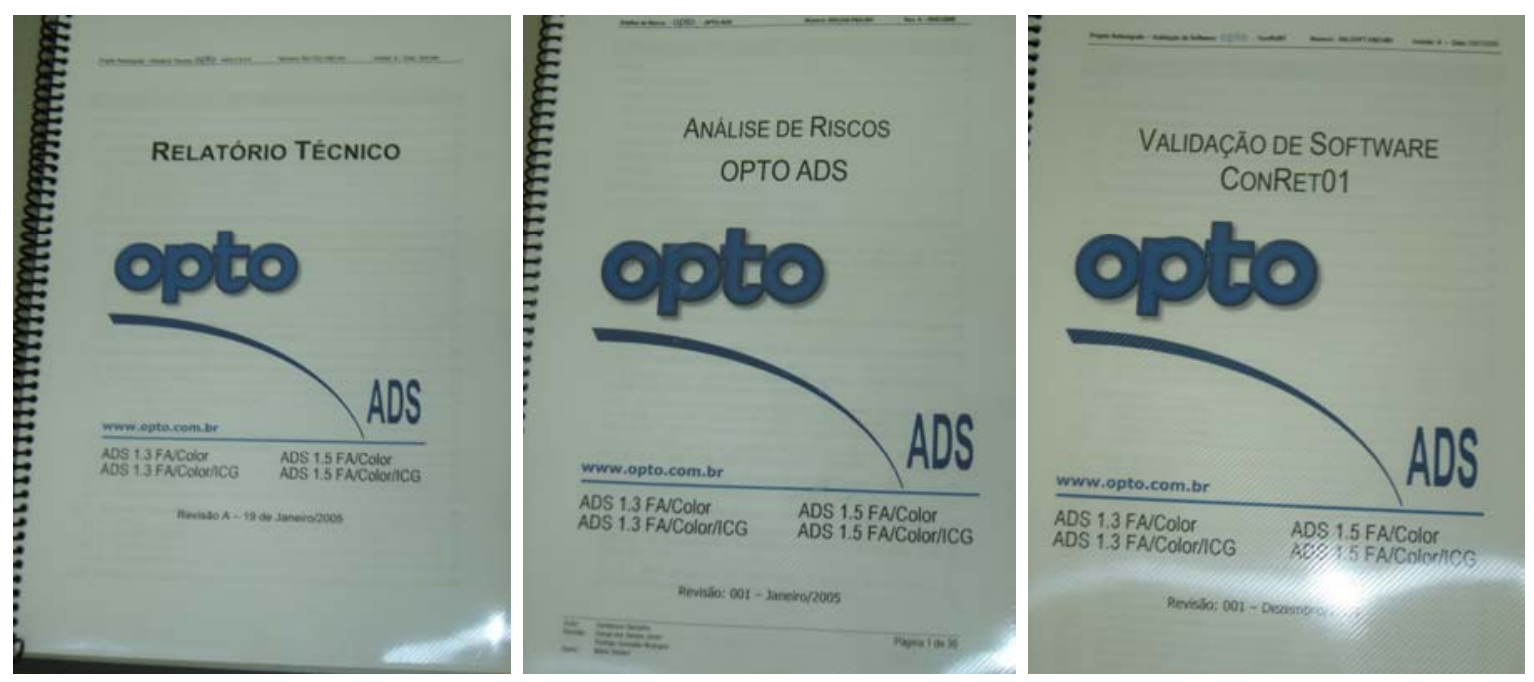

Figura 102 - Documentação técnica do projeto retinógrafo: (a) relatório técnico; (b) análise de riscos; e (c) validação de software .

Todos os projetos antigos e atualmente em curso na empresa foram validados através da submissão de protótipos piloto a clientes potenciais. A Figura 103 ilustra registros de resultados de testes com clientes, os quais são realizados no caderno de projetos.
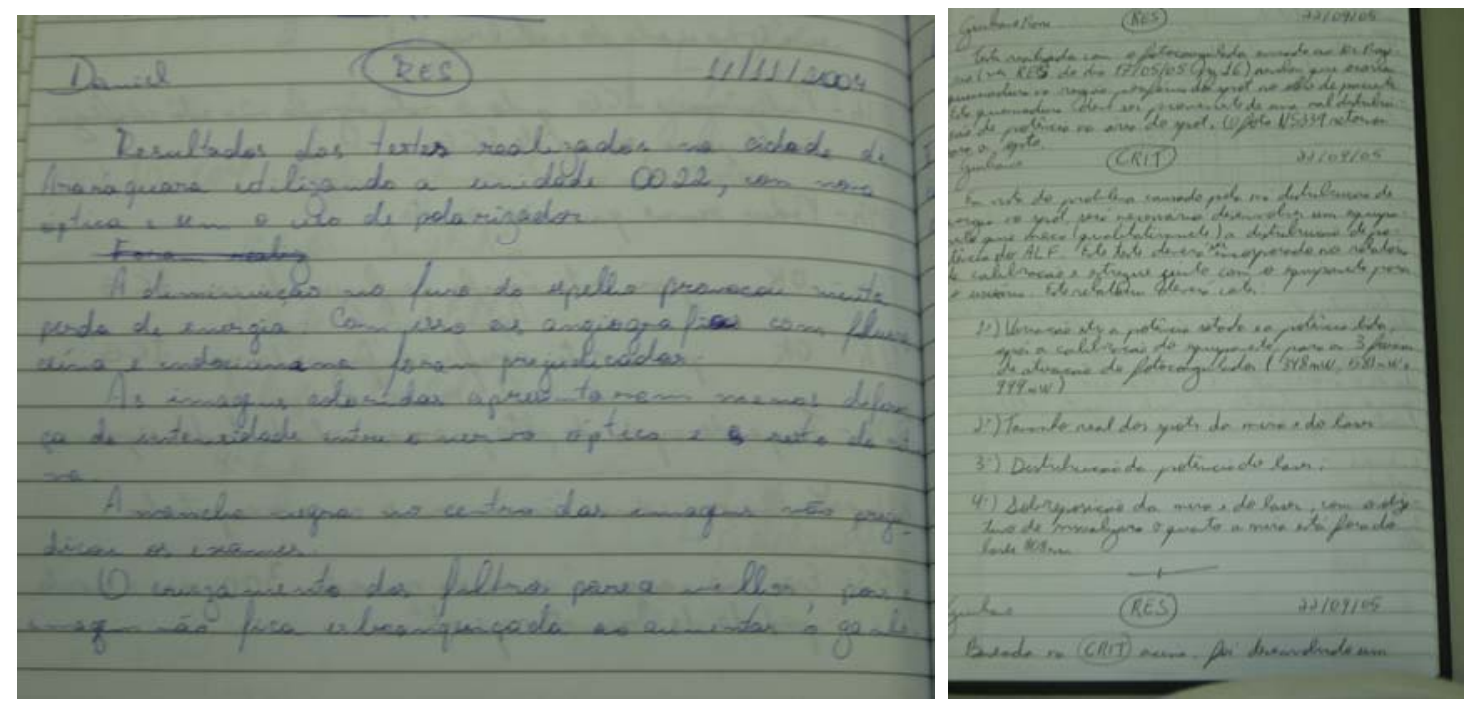

Figura 103 - Registros de testes de validação com protótipos piloto: (a) retinógrafo e (b) fotocoagulador i-MP. 
A Figura 103 (a) mostra resultados de testes com protótipos do retinógrafo. No projeto i-MP, esse processo entretanto, foi planejado previamente e está em curso com avaliação contínua de uma equipe de médicos oftalmologistas cujos resultados são registrados no livro de projetos como resultados de testes, conforme pode ser visto na Figura 103 (b). Registros como os ilustrados na Figura 103 documentam a validação dos produtos.

\subsubsection{Fase de lançamento do produto}

O Quadro 14 apresenta as aplicações do MRM na fase lançamento do produto, conforme as atividades descritas no item 5.3.1.11.

Quadro 14 - Sumário das aplicações do MRM na fase de lançamento

\begin{tabular}{|c|c|c|c|}
\hline$A C ̧ \tilde{O} E S$ & $\begin{array}{l}\text { ÁREA DE } \\
\text { PROCESSO }\end{array}$ & APLICADOR & DESCRIÇÃO DA APLICAÇÃ O \\
\hline $\begin{array}{l}\text { Qualificar assistência } \\
\text { técnica }\end{array}$ & $\begin{array}{l}\text { Desenvolvimento } \\
\text { de mercados }\end{array}$ & Engenharia & $\begin{array}{l}\text { Foi realizado treinamento da assistência técnica quanto } \\
\text { ao projeto retinógrafo }\end{array}$ \\
\hline $\begin{array}{l}\text { Consolidar configuração } \\
\text { comercial do produto }\end{array}$ & $\begin{array}{l}\text { Documentos e } \\
\text { configurações }\end{array}$ & Qualidade & $\begin{array}{l}\text { A documentação gerada ao final do projeto retinógrafo } \\
\text { é consolidada em documentos que são arquivados e } \\
\text { distribuídos como cópias controladas }\end{array}$ \\
\hline
\end{tabular}

Foi realizado um treinamento com os engenheiros e técnicos da assistência técnica da empresa para qualificar a manutenção que esse pessoal presta aos clientes do retinógrafo. Sendo esse produto bem mais complexo que os anteriormente desenvolvidos na empresa, essa atividade permitiu que houvesse maior integração entre assistência técnica e projeto.

Uma vez que o projeto retinógrafo foi concluído, validado e o produto foi registrado nos órgãos competentes, sua documentação foi consolidada em arquivos escritos e eletrônicos. Embora isso tenha ocorrido em projetos anteriores, neste esse processo se deu de maneira planejada.

\subsubsection{Fase de monitoramento do produto}

O Quadro 15 apresenta as aplicações do MRM na fase monitoramento do produto, as quais são baseadas no fluxograma de atividades da 5.3.1.12. 
Quadro 15 - Sumário das aplicações do MRM na fase de monitoramento do produto

\begin{tabular}{|c|c|c|c|}
\hline$A C ̧ \tilde{O} E S$ & $\begin{array}{l}\text { AREA DE } \\
\text { PROCESSO }\end{array}$ & APLICADOR & 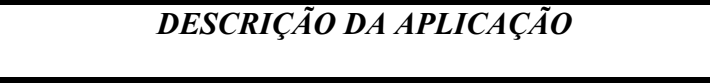 \\
\hline $\begin{array}{l}\text { Avaliar o desempenho do } \\
\text { produto no mercado }\end{array}$ & $\begin{array}{l}\text { Desenvolvimento } \\
\text { de mercados }\end{array}$ & Comercial & $\begin{array}{l}\text { Os novos produtos passaram a ser monitorados quanto à } \\
\text { satisfação dos clientes depois de lançados }\end{array}$ \\
\hline $\begin{array}{l}\text { Monitorar o desempenho } \\
\text { da manufatura }\end{array}$ & $\begin{array}{l}\text { Qualidade do } \\
\text { produto }\end{array}$ & Engenharia & $\begin{array}{l}\text { Os checklists desenvolvidos passaram a serem } \\
\text { utilizados para monitorar a qualiade da manufatura no } \\
\text { projeto retinógrafo }\end{array}$ \\
\hline $\begin{array}{l}\text { Explorar alternativas de } \\
\text { mudanças no produto }\end{array}$ & $\begin{array}{l}\text { Projeto de } \\
\text { engenharia }\end{array}$ & $\begin{array}{l}\text { Engenharia de } \\
\text { produto }\end{array}$ & $\begin{array}{l}\text { Há um procedimento estabelecido para a detecção e } \\
\text { exploração de possíveis melhorias de produto }\end{array}$ \\
\hline $\begin{array}{l}\text { Gerenciar mudanças no } \\
\text { produto }\end{array}$ & $\begin{array}{l}\text { Documentos e } \\
\text { configurações }\end{array}$ & Qualidade & $\begin{array}{l}\text { Há um procedimento estabelecido para o gerenciamento } \\
\text { de mudanças nos produtos }\end{array}$ \\
\hline
\end{tabular}

A diretoria comercial da empresa criou um serviço de monitoramento da satisfação dos clientes que tem sido utilizado para identificar oportunidades de melhoria nos produtos ou de desenvolvimento de novos acessórios e mesmo de novos produtos para o portifólio da empresa. O desempenho da manufatura de equipamentos mecatrônicos tem sido realizado pelo uso dos checklists de controle de qualidade desenvolvidos. Como a montagem final dos retinógrafos ainda é realizada no $\mathrm{P} \& \mathrm{D}$ da empresa, esta atividade é realizada pela engenharia.

A exploração de alternativas de mudanças no produto e o seu gerenciamento é realizada pelos setores de engenharia de produto e de qualidade da empresa. A Figura 104 apresenta o uso de uma solicitação de alteração de produto ou processo (SAPP) para controlar a mudança de especificação de um transformador utilizado no projeto retinógrafo.

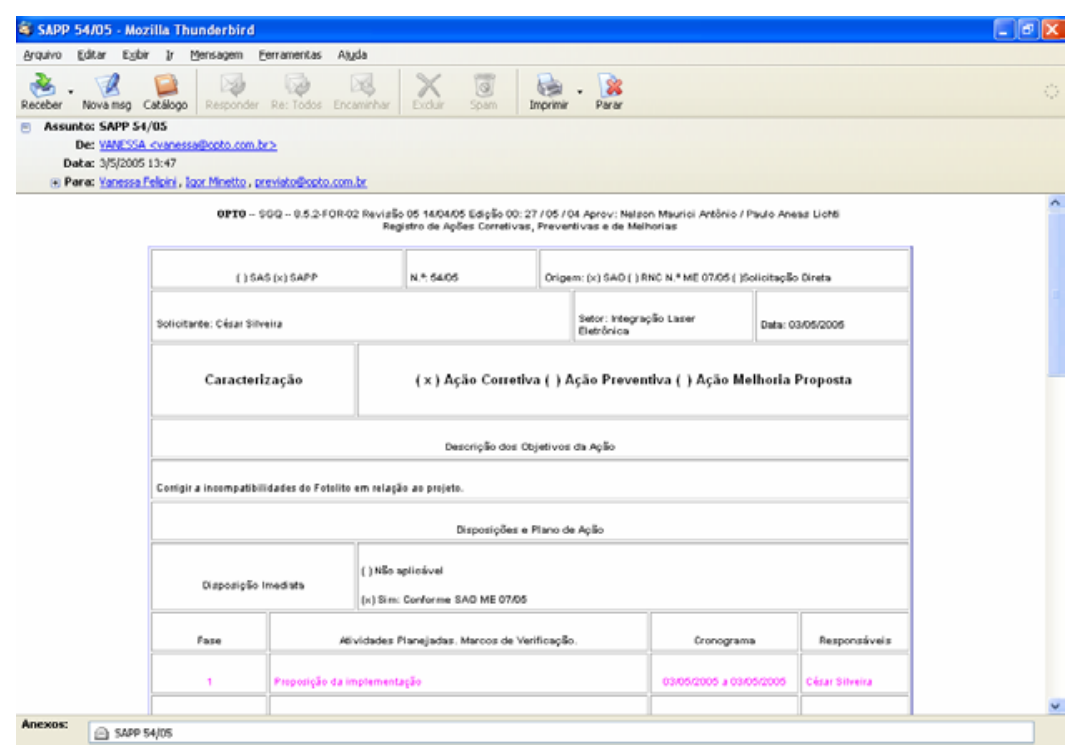

Figura 104 - Exemplo da forma de gerenciamento de mudanças de produto utilizado na empresa 


\subsection{Resultados da aplicação do MRM}

No item 6.3.1 são apresentados resultados práticos conseguidos através do uso do MRM na empresa pesquisada.

\subsubsection{Resultados da aplicação do modelo}

As iniciativas de melhoria do processo de desenvolvimento de produtos na empresa pesquisada possibilitaram a consecução de alguns resultados práticos. Esses resultados são aqui apresentados como forma de ilustrar o potencial do MRM para a solução de problemas práticos de empresas mecatrônicas.

\subsubsection{Implantação da ISO 9001:2000}

As aplicações do MRM relacionadas com a documentação e registro das atividades do PDP (ver quadros Quadro 6 a Quadro 13), assim como do planejamento das atividades de projeto (ver Quadro 7), foram consolidadas no já mencionado procedimento que visava adequar as práticas de projeto do setor à ISO 9001:2000 (OPTO ELETRÔNICA, 2006). Usando o procedimento foi possível conseguir a certificação ISO 9001 para o setor de pesquisa e desenvolvimento, o que entretanto, se deu apenas na segunda tentativa (follow-up), uma vez que a falta de um gerenciamento adequado do setor de projetos da empresa foi apontada como uma não-conformidade impeditiva para que a empresa fosse considerada conforme à ISO 9001:2000. A Figura 105 apresenta em (a) a notificação de não-conformidade resultante da primeira tentativa de adequação da empresa à ISO, e em (b), o certificado de adequação conseguido com base nas aplicações do MRM. 

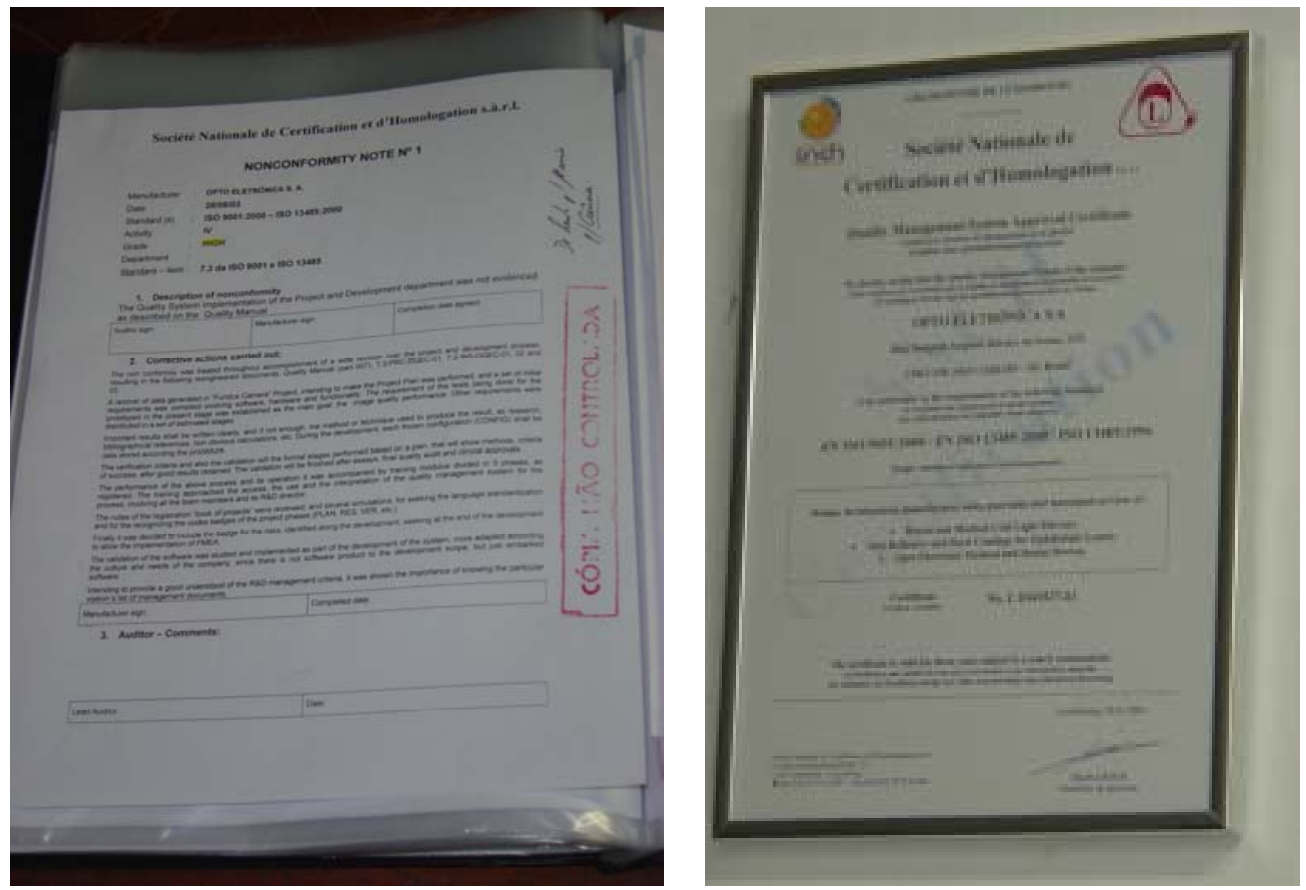

Figura 105 - Certificado ISO 9001:2000

O conjunto de iniciativas que permitiu a certificação ISO 9001:2000 no setor de P\&D da empresa sofreu uma série de resistências de caráter organizacional relacionados com as atitudes descritas no item 6.2.3, dentre as quais destaca-se uma compreensão de que gerenciamento e burocracia são sinônimos, conforme pode ser abstraído do trecho de entrevista realizada com o Diretor de P\&D, transcrita abaixo:

- "[...] Antigamente a equipe de desenvolvimento eram 4 ou 5 pessoas. Hoje estamos com 25, são projetos maiores de alta reponsabilidade, custos elevados, a equipe nossa hoje tem 8 doutores então começa a te obrigar a usar ferramentas mais adequadas. Mas, de qualquer forma, a gente não tem o perfil de ser muito burocrático não e a gente não vê resultado com muita burocracia, a gente precisa de agilidade".

- "Burocracia seria o gerenciamento?"

- "É o gerenciamento tem que vir para ajudar e não para atrapalhar".

- "É porque existe uma diferença entre o gerenciamento e a burocracia".

- "É o pessoal confunde um pouco. Tinha que ter um gerenciamento para acompanhar para poder registrar os resultados, ver os investimentos que precisam ser feitos, mas também não pode ser um troço que amarre o trabalho da turma, porque o cara que tem muita imaginação, gosta de trabalhar pesado não gosta de burocracia. Ele não vai perder tempo com burocracia. Ele vai passar por cima, então o ponto de equilíbrio é que é 
importante chegar. Então, a gente fala que o paperwork tem que ser mantido

no mínimo e o hardwork no máximo". (Grifos nossos)

Assim, todo o trabalho relacionado com a certificação de produtos é definido como paperwork, que teria como um contraponto o hardwork. Esse último seria o trabalho do engenheiro de projeto, aquele, do gerenciador. A pouca ênfase no gerenciamento teria relação com um perfil profissional de alguém com "muita imaginação", e que "gosta de trabalhar pesado". Se por um lado, esse tipo de percepção enfatiza o profissional de engenharia, e o fato de utilizar mecatrônica, conforme visto no item 2.3.1.1, implica em necessidade de valorizar esse profissional, ela secundariza o trabalho de quem faz gerenciamento.

Anteriormente à implementação da ISO 9001:2000, houve duas experiências de gestão de projetos de novos produtos:

"[...] Teve um consultor que apesar de tudo foi muito bom, de muito bom senso. Ele disse que a gente é que ia ter que achar o caminho porque 'as receitas que eu tenho não se aplicam a vocês'. Isso faz 15 anos[...]"

Mais recentemente, por imposição de um cliente:

"[...] O projeto do MAR mesmo, por exemplo, veio com a espec de uma estrutura de controle de projeto que tinha 5 vezes o número de páginas que o projeto. $O$ aspecto técnico não foi utilizado. Ai a gente chegou num meio termo e o nosso ficou bem abaixo daquilo. A equipe nossa era pequena tinha 6 pessoas $[\ldots]$ "

De maneira geral, esse argumento tem contraposição no discurso do implementador do sistema de gestão ISO 9001:2000 na empresa:

\footnotetext{
"[...] A interpretação que se dava num sistema de você ter um procedimento de gerenciamento de configuração o objetivo não era tolher, amarrar a criatividade ou bloquear que o produto sofresse inovações. Não existe nenhum aspecto relacionado a isso ou associado a tolher criatividade à inovação. Pelo contrário, é um apoio para que a inovação se dê de uma maneira mais tranqüila e que haja a possibilidade de você transferir todas essas informações da configuração para o ambiente produtivo[...]"
}

Considerando que os interlocutores acima trabalharam juntos nas primeiras tentativas de implantar formas mais sistemáticas de gestão no PDP da empresa, obviamente não houve 
consenso entre as possibilidades de aumento do aporte gerencial sem tolher o perfil hardwork mencionado.

Sintetizando sua percepção acerca das iniciativas de aporte gerencial na engenharia, o Diretor de P\&D enfatiza:

"[...] É que as primeiras tentativas de organizar o negócio foram extremamente burocráticas e aí criou-se anticorpos[...]"

A ISO 9001:2000 é uma importante ferramenta comercial de empresas de países que, como o Brasil, ocupam um lugar secundário no comércio internacional. Entretanto, pode-se observar pelo histórico traçado que o aporte gerencial do PDP da empresa sempre esteve baseado na necessidade de atender a requisitos normativos. Como as normas têm modelo de referência bastante limitado, quando analisado o PDP, a discussão acerca de gerenciamento de projetos passa a ter como horizonte esse tipo de padrão. Portanto, as possibilidades de melhoria relacionadas com a gestão do PDP não conseguem avançar do aspecto burocratizante das normas que a empresa é obrigada a atender.

Esse aspecto burocratizante, que de acordo com os dados de observação participante, de fato existe, é ilustrado por alguns interessantes comentários:

"[...] É muito procedimento. Assim que pelo que a gente viu como deve ser o procedimento de como a pessoa deve se vestir, que ela tem que vir limpa".

E ainda,

"[...] Porque se você chegar para o cara e der todo o processo escrito o cara não vai ler e se ele ler ele não vai entender tudo, principalmente no linguajar lá que o pessoal usa, você pega um e-mail do cara que quer que você mude a peça de cima dessa mesa para essa,[...] o cara usa uns termos, umas cinqüenta linhas para dizer: pega a caneta dessa mesa e ponha na mesa da direita. Ele usa 4 páginas e você não entende o que o cara quer."

Portanto, além do fato de a Diretoria de P\&D identificar no "perfil” de seu pessoal uma contraposição às atividades de gestão, o processo de busca das certificações necessárias 
gerou uma série de procedimentos altamente burocráticos, os quais acabam por ser considerados sinônimos de gestão.

\subsubsection{Registro do retinógrafo em órgãos reguladores}

Da mesma forma, a sistematização da concepção e da arquitetura do retinógrafo (ver quadros Quadro 8 e Quadro 9), o relatório técnico elaborado com base nesses conceitos (Figura 102), a análise de riscos implementada e reportada (Figura 91) e os testes realizados com os software desenvolvidos (Figura 93), permitiram conseguir o registro do retinógrafo junto à ANVISA.

A Figura 106 apresenta em (a) uma comunicação recebida da ANVISA na qual a agência questionava aspectos técnicos e regulatórios relacionados com o equipamento de fotografia da retina e em (b) o registro ANVISA do retinógrafo, disponível para consulta pública em (acesso em 18/12/2005):

http://www7.anvisa.gov.br/datavisa/Consulta_Produto_correlato/consulta_correlato.asp.
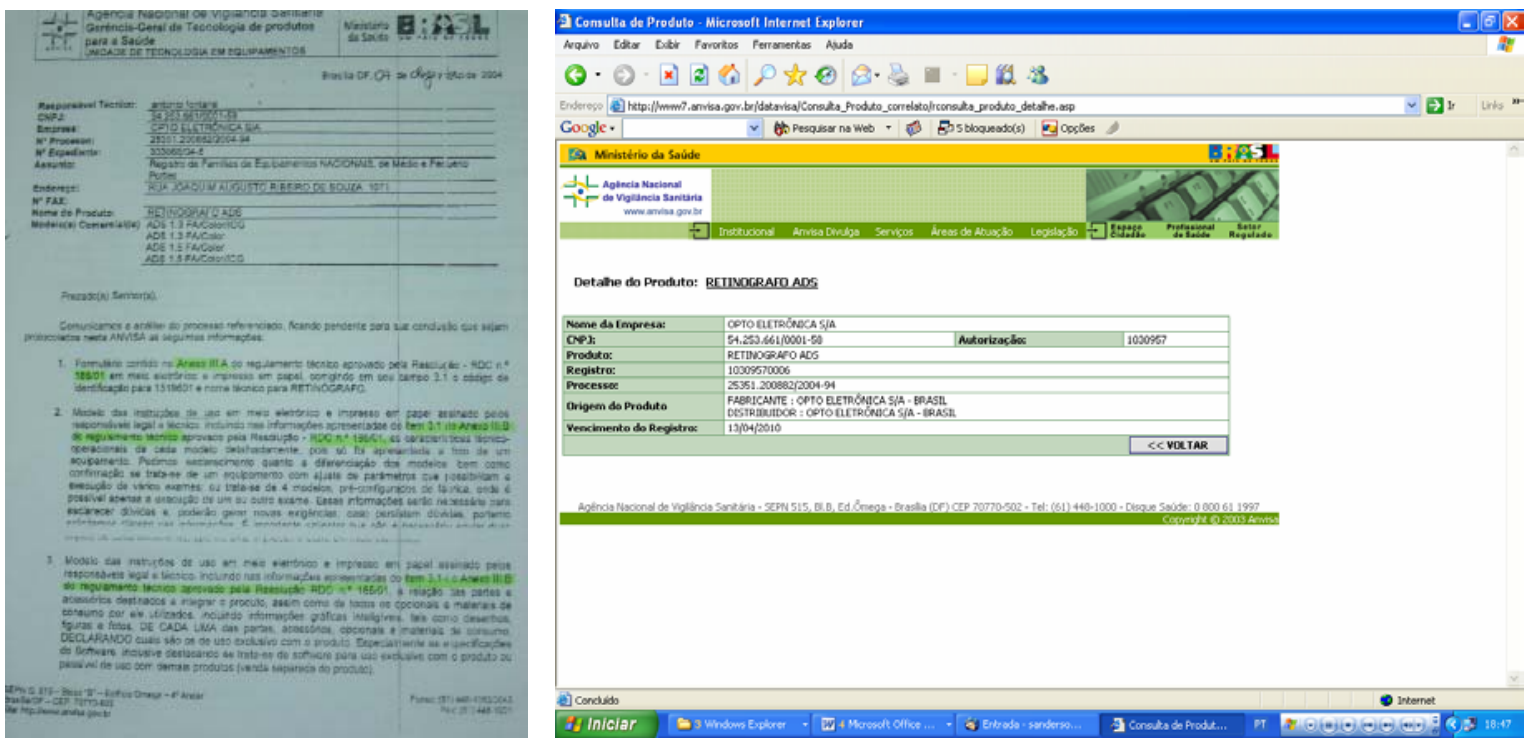

Figura 106 - Comunicação formal da ANVISA sobre a documentação gerada para o retinógrafo ADS (a) e Registro ANVISA do retinógrafo (b). 
Os documentos de validação de software foram considerados bastante pertinentes pelo pessoal de projeto:

"[...] Porque o que acontece se você tem tudo muito bem organizado, o projeto do retino, tudo extremamente organizado, alguém fala 'eu vou fazer aqui um outro equipamento'. Então, eu preciso de procedimento de validação de software, um mecanismo de movimentação de filtro. Então, o que você vai fazer? Você não vai reprojetar. Você vai pegar, vai adaptar aquele documento que você tinha anteriormente e o que você precisa agora. Você já vai adaptar a eletrônica, mas você já vai ter ela, então o projeto que você ia demorar três anos, vai demorar três meses".

Por outro lado, para o Diretor de P\&D:

"[...] quer queira quer não, o relatório técnico do retinógrafo tem 600 páginas. Legal ter feito aquilo, mas pergunto para você: precisaria ter sido feito para a gente produzir o retinógrafo? Acho que não precisaria. A gente ocupou a equipe por seis meses para gerar aquele relatório técnico que em termos do controle interno, de produção e de qualidade de projeto houve algum ganho? Houve, mas não sei se justificaria. O custo que teve para fazer aquele negócio lá, não sei se valeria a pena. Lembra, a equipe nossa ficou parada seis meses fazendo aquilo lá, não sei se se pagou”.

Entende-se, portanto, na empresa, que esse tipo de documentação permitirá abreviar o tempo necessário para desenvolver soluções para outros projetos, interessante preocupação do engenheiro entrevistado. Entretanto, o Diretor, na função de gerente, preocupa-se com o custo relacionado com esse tipo de atividade. Os dados de observação participante apontam para uma deficiência na definição do escopo da documentação do produto confeccionado.

\subsubsection{Transferência do projeto para a manufatura}

A sistemática de análise e documentação do processo de montagem (ver quadros Quadro 11, Quadro 12 e Quadro 13) permitiu que houvesse facilidade na transferência do retinógrafo para os setores de manufatura da empresa. Esse processo está em curso e não foi concluído por limitações estruturais da firma.

Os resultados parciais são satisfatórios, conforme pode ser visto no trecho abaixo, comentário de um dos integrantes do grupo de montagem especializada: 
“[...] Eu fiquei assustado com essa semana. Passei a montagem da câmera para o pessoal, fizemos a documentação do Viewfinder também e foi feito um pedido para a produção e no prazo de três dias eles fizeram meia dúzia perfeitamente e entregaram. Algo que se fosse há 5 anos atrás iria demorar de 10 a 15 dias e você ia ser bombardeado com um monte de perguntas, um monte de dúvidas e hoje em dia não. Em três dias o pessoal entregou. Significa que o nosso procedimento funciona. A documentação funciona. Que ministrando esses pequenos cursos de passagem de documentação $e$ integração de montagem funciona. E isso é super valido. Apesar de ter que melhorar a documentação, dar uma refinada nos procedimentos, rever algumas coisas, é valido. Se você for fazer um comparativo de 5 anos para cá melhorou 100\%, é muito bom. Eu fiquei contente e supreso porque você vê. Salta aos olhos a melhoria que foi assim: nenhuma reclamação, nenhuma dúvida".

Do ponto de vista do pessoal de manufatura, tem-se o seguinte:

"[...] Hoje chega bem mais mastigado para nós. Hoje tem treinamentos que são desenvolvidos. Por exemplo, está havendo integração do retinógrafo ao meu departamento hoje, então nesse meio tempo nós estamos fazendo treinamento junto ao $P \& D$ para habilitar pessoas a fazer esse serviço que é solicitado. Não é como antigamente que chegava e colocava no departamento e no fim você tinha que ficar adivinhando como funcionava. Existia essa lacuna, hoje o negócio é mais organizado".

\subsubsection{Resultados adicionais}

Adicionalmente, o retinógrafo - único dos projetos pesquisados que já chegou à fase de lançamento - tem chamado a atenção de investidores internacionais que se propõem a representar a empresa no mercado americano, maior consumidor mundial de serviços de retinografia. Obviamente, esse resultado é conseqüência de todo o trabalho realizado pelas equipes de engenharia e de montagem especializada no setor de P\&D da empresa.

A aplicação das atividades previstas no modelo de referência mecatrônico que têm relação com o planejamento de projetos permitiu o cumprimento de etapas fundamentais no projeto MUX, o que representou grande percentual do faturamento da empresa no ano corrente. Esse planejamento tem sido sistematicamente atualizado de maneira a manter o contratante (INPE) atualizado acerca de seu andamento. A estrutura de documentação representada pela árvore de produtos desenvolvidda para a MUX tem sido utilizada para confeccionar a documentação representativa da fase de projeto preliminar a ser submetida ao 
contratante do projeto e que juntamente com as etapas de planejamento, representarão cerca de $25 \%$ dos valores contratados para quatro anos de projeto.

\subsection{Situação do PDP da empresa após aplicado o MRM}

Nos itens 6.4.1 até 6.4.5 apresenta-se a situação final do PDP na empresa e uma análise dos resultados conseguidos com o MRM realizada com base nas entrevistas que permitiram cumprir as ETAPAS 2 e 3 do método de aplicação do MRM exposto na Figura 69.

\subsubsection{Nível de capabilidade das áreas de processo do PDP no final do trabalho de aplicação do modelo}

O mesmo conjunto de atividades e tarefas que no início do trabalho foram avaliadas quanto à sua capabilidade, foram novamente avaliadas ao final do trabalho de aplicação do MRM descritas nos itens 6.2.5.1 até 6.2.5.12. A avaliação utilizou o questionário que consta no APÊNDICE F.

A Figura 107 apresenta o nível de capabilidade das áreas de processo no final do trabalho.

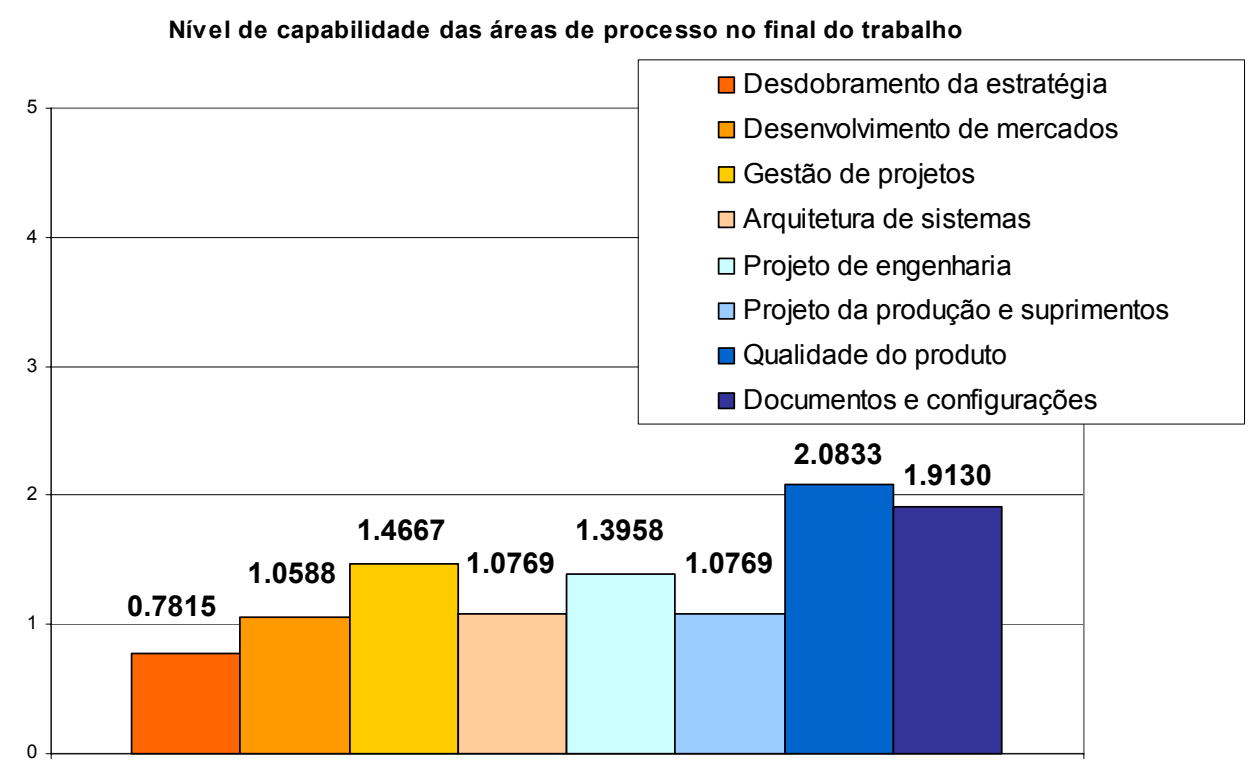

Figura 107 - Nível de capabilidade das áreas de processo no final da aplicação do $\mathrm{MRM}\left(\mathrm{N}_{\mathrm{ef}}\right)$ 
Pode-se observar que há maior dispersão entre os níveis de capabilidade no final do trabalho que no início. A área com maior capabilidade continua sendo a "qualidade do produto" seguida de perto pela área de "documentos e configurações", ambas com capabilidade de nível 2. As áreas de "gestão de projetos" e de "projeto de engenharia" têm capabilidade em torno de 1.4. Próximo a 1 estão as capabilidades das áreas de "desenvolvimento de mercados", "arquitetura de sistemas" e "produção e suprimentos".

A menor capabilidade detectada no final do trabalho foi na área de "desdobramento da estratégia".

\subsubsection{Graus de melhoria da capabilidade do PDP}

O gráfico da Figura 108 apresenta o grau de melhoria do nível de capabilidade das áreas de processo $\left(\Delta_{\mathrm{c}}\right)$. Esses graus de melhoria resultam do cálculo $\mathrm{N}_{\mathrm{cf}} / \mathrm{N}_{\mathrm{ci}}$, conforme discutido no item 6.1.

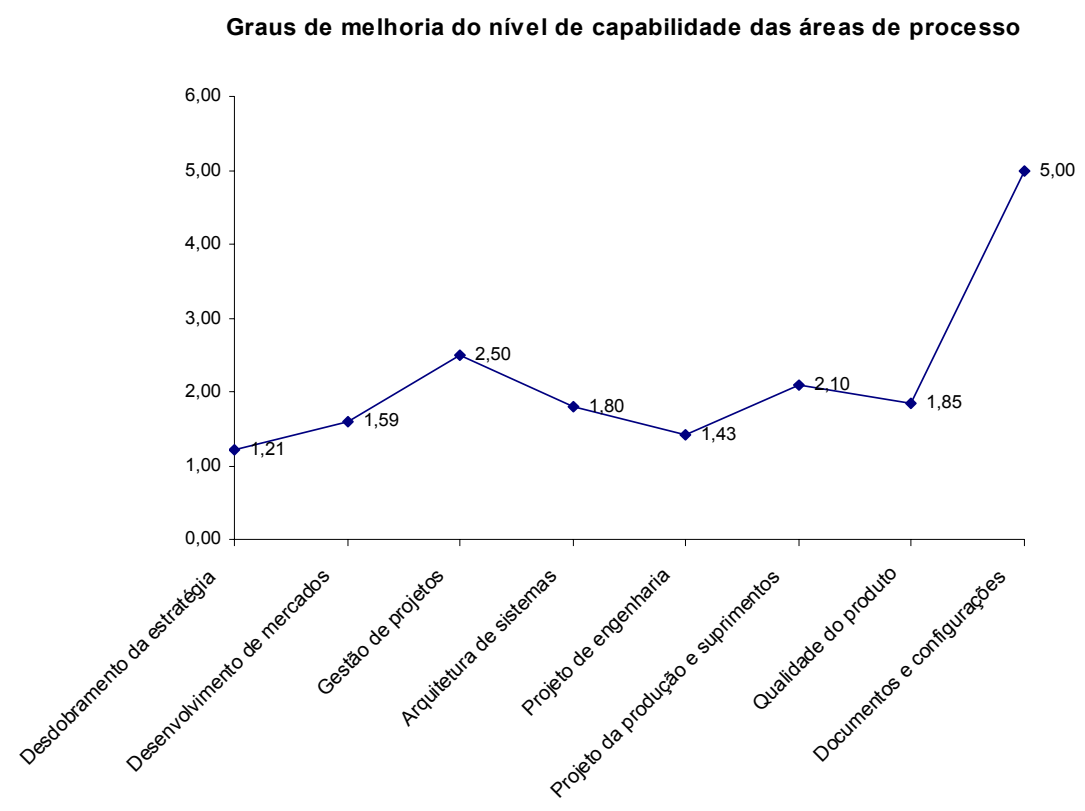

Figura 108 - Melhoria dos níveis de capabilidade das áreas de processo do MRM

Retomando os dados da Figura 77, observa-se que em todas as áreas de processo, o grau de melhoria do nível de capabilidade foi maior que "1", o que implica que o projeto das 
áreas de processo do MRM foi consistente com a teoria relacionada para a qual a melhoria no PDP tem relação direta com o aumento do grau de capabilidade das áreas de processo. Ou seja, mesmo que as aplicações do MRM não tenham sido explicitamente relacionadas com as áreas de processo projetadas quando foram implementadas, o resultado foi uma melhoria global em seu estado final comparado com o inicial.

Observa-se ainda que a área de processo com maior grau de melhoria, "documentos e configurações", é também aquela com maior número de aplicações do MRM, e que a área com menor $\Delta_{c}$ é também a com menor número de intervenções baseadas no MRM.

Esses resultados permitem verificar a validade da PROP_1 que consta no item 3.2.3.

\subsubsection{Validação da melhoria das áreas de processo do MRM}

A validação dos graus de melhoria nas áreas de processo do MRM inicia a ETAPA 2 da validação do MRM na empresa pesquisada (Figura 69). Essa ETAPA foi realizada através de entrevista com um segundo grupo de pessoas da empresa. Os dados de melhoria das áreas de processo foram submetidos a esse grupo para que fosse realizada uma análise do tipo concorda/discorda. Essa ETAPA foi realizada com base no questionário que consta no APÊNDICE G.

O Quadro 16 apresenta o perfil do grupo pesquisado quanto às áreas funcionais de origem e quanto a sua função no PDP da empresa.

Quadro 16 - Perfil dos entrevistados na segunda etapa de validação do MRM quanto à área funcional

\begin{tabular}{lllccccc}
\hline TOTAL & Engenharia & Manufatura & Vendas & Alta direção & $\begin{array}{c}\text { Gerentes } \\
\text { funcionais }\end{array}$ & $\begin{array}{c}\text { Líderes de } \\
\text { projeto }\end{array}$ & $\begin{array}{c}\text { Pessoal } \\
\text { técnico }\end{array}$ \\
\hline 20 & 14 & 4 & 2 & 3 & 7 & 5 & 5 \\
\hline
\end{tabular}

Observa-se que a maioria dos entrevistados pertenceu à engenharia uma vez que o trabalho de aplicação do MRM realizado pelo pesquisador se concentrou nessa área da empresa, conforme discutido no item 6.2.3. 
A Figura 109 apresenta um gráfico que demonstra o grau de concordância médio do grupo pesquisado. Observa-se que o grau de concordância médio é de $56 \%$ dos entrevistados, há menor concordância entre o pessoal de manufatura e as pessoas com função de execução. A maior concordância se dá entre os "líderes de projeto" e o pessoal de vendas.

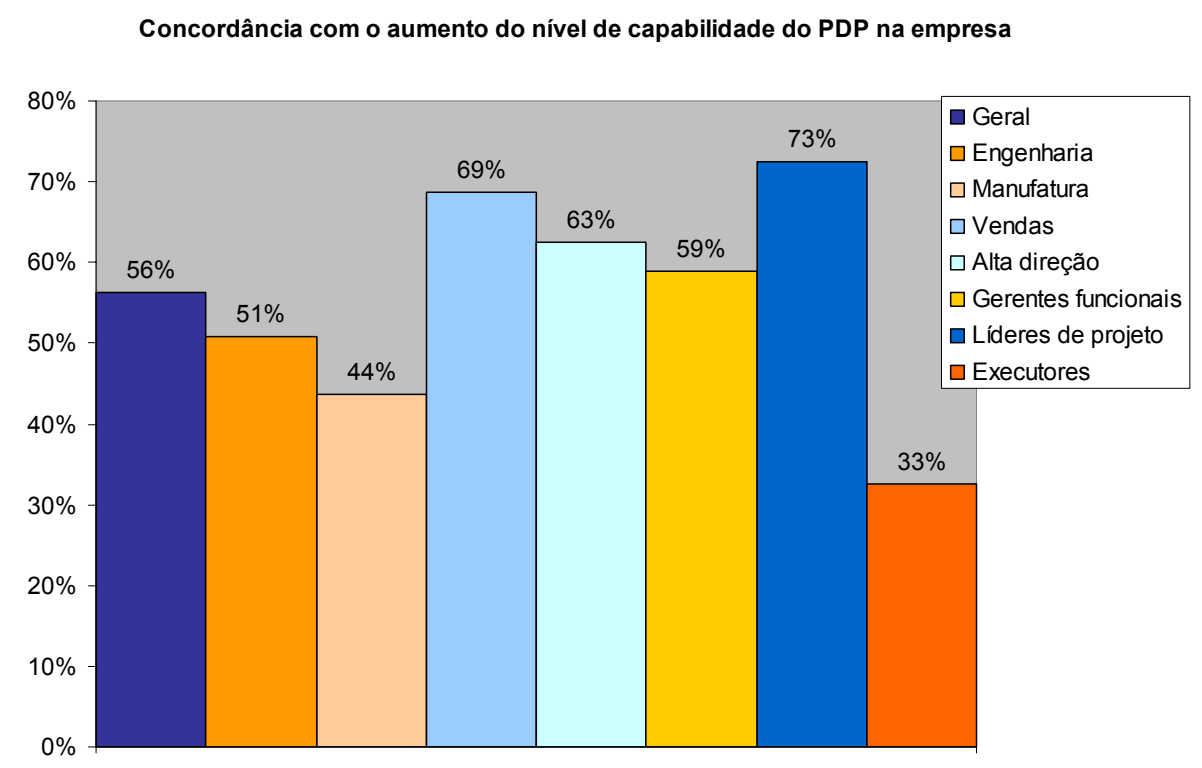

Figura 109 - Grau de concordância com o aumento do nível de capabilidade do PDP da empresa

A Figura 110 apresenta o grau de concordância médio com relação ao aumento de capabilidade de cada área de processo. Observa-se que, mesmo tendo o menor grau de melhoria, há menor concordância quanto à área de desdobramento da estratégia. No outro extremo, a área de documentos e configurações, além de ter maior grau de melhoria, tem maior concordância quanto a esse aumento. 


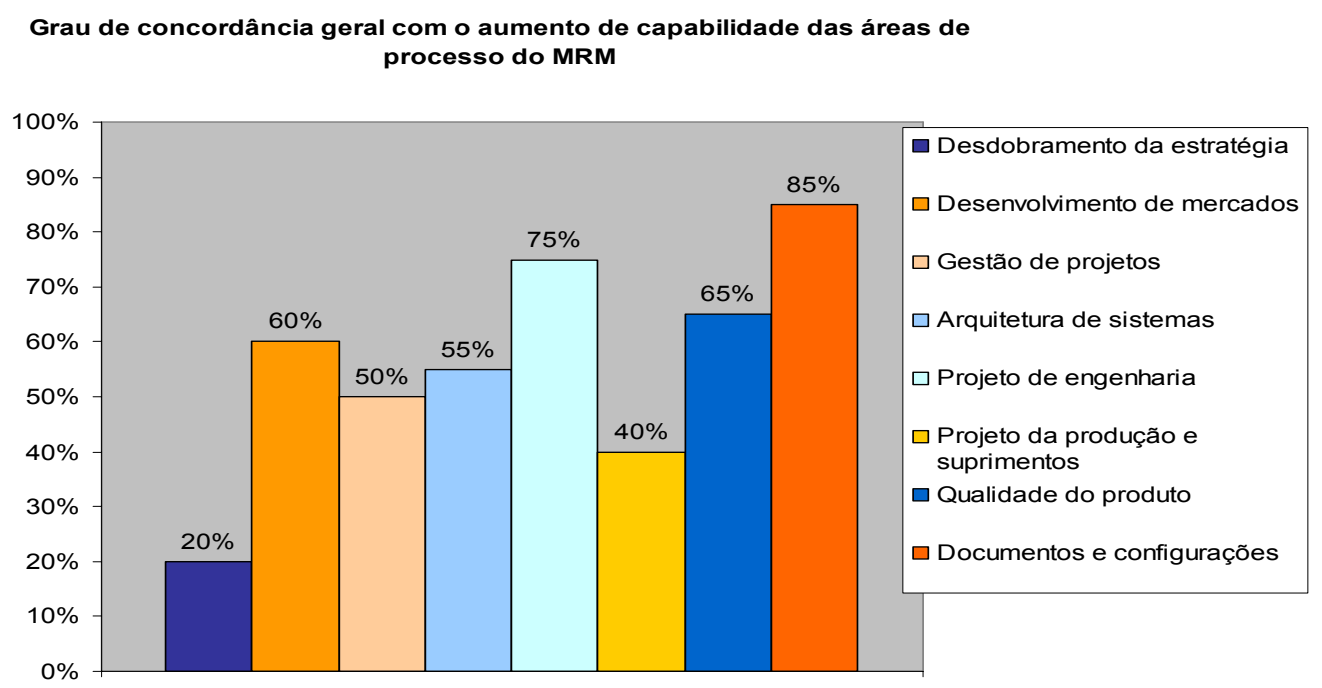

Figura 110 - Grau de concordância quanto ao aumento de capabilidade das áreas de processo do MRM

Analisado com base nas áreas funcionais pesquisadas, tem-se a distribuição de concordância ilustrada na Figura 111. Observa-se que a manufatura discorda totalmente $(\mathrm{O} \%$ de concordância) de ter havido melhoria de capabilidade nas áreas de "desdobramento da estratégia" e de "desenvolvimento de mercados"; vendas discorda totalmente quanto às melhorias em “produção e suprimentos”. A engenharia apresenta menor grau de concordância na área de "desdobramento da estratégia".

Grau de concordância das áreas funcionais com o aumento de capabilidade

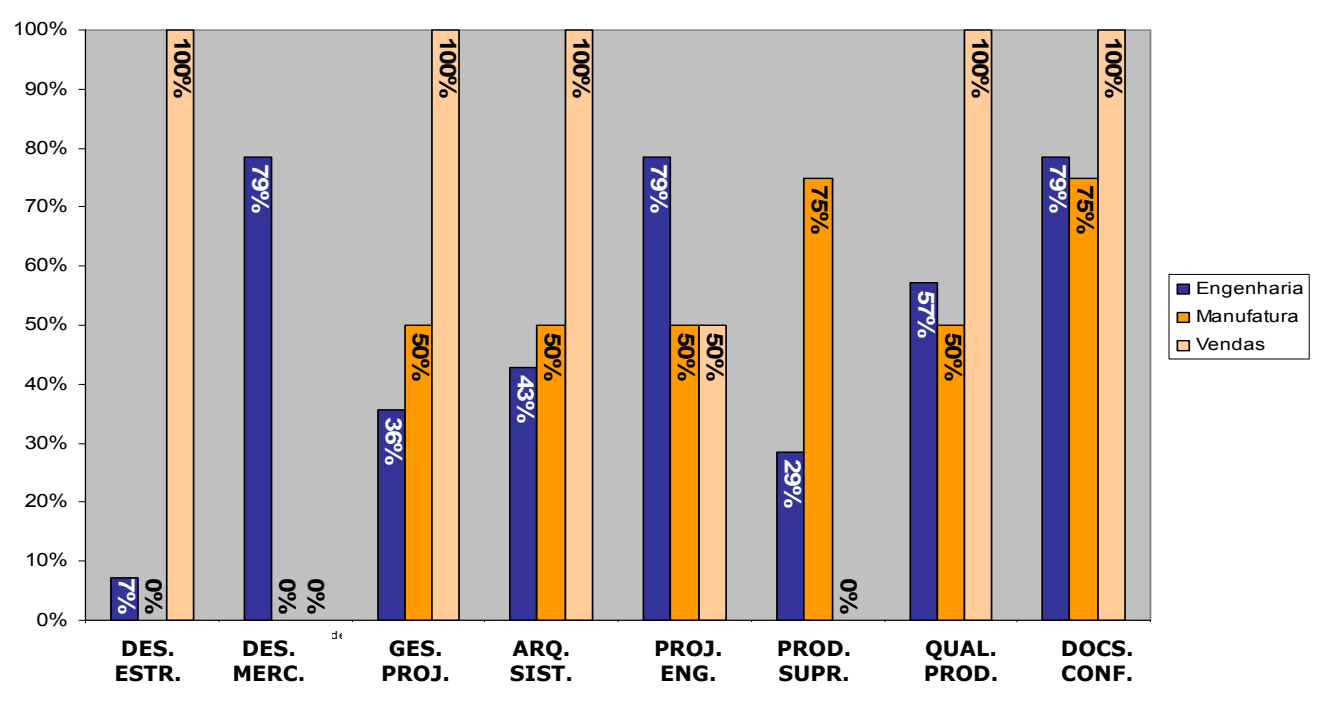

Figura 111 - Grau de concordância com o aumento de capabilidade por área funcional 
A análise baseada no papel desempenhado pelo pesquisado dentro do PDP da empresa é apresentada na Figura 111. Pode-se observar que a área de "documentos e configurações” continua a ter maior concordância quanto ao aumento de seu nível de capabilidade em todas as estratificações realizadas nos dados. Há forte discordância dos executores quanto a ter havido melhorias na área de "desdobramento da estratégia". A discordância é ainda maior quanto à melhoria da capabilidade da área de "desenvolvimento de mercados", conforme avaliado pela alta gerência.

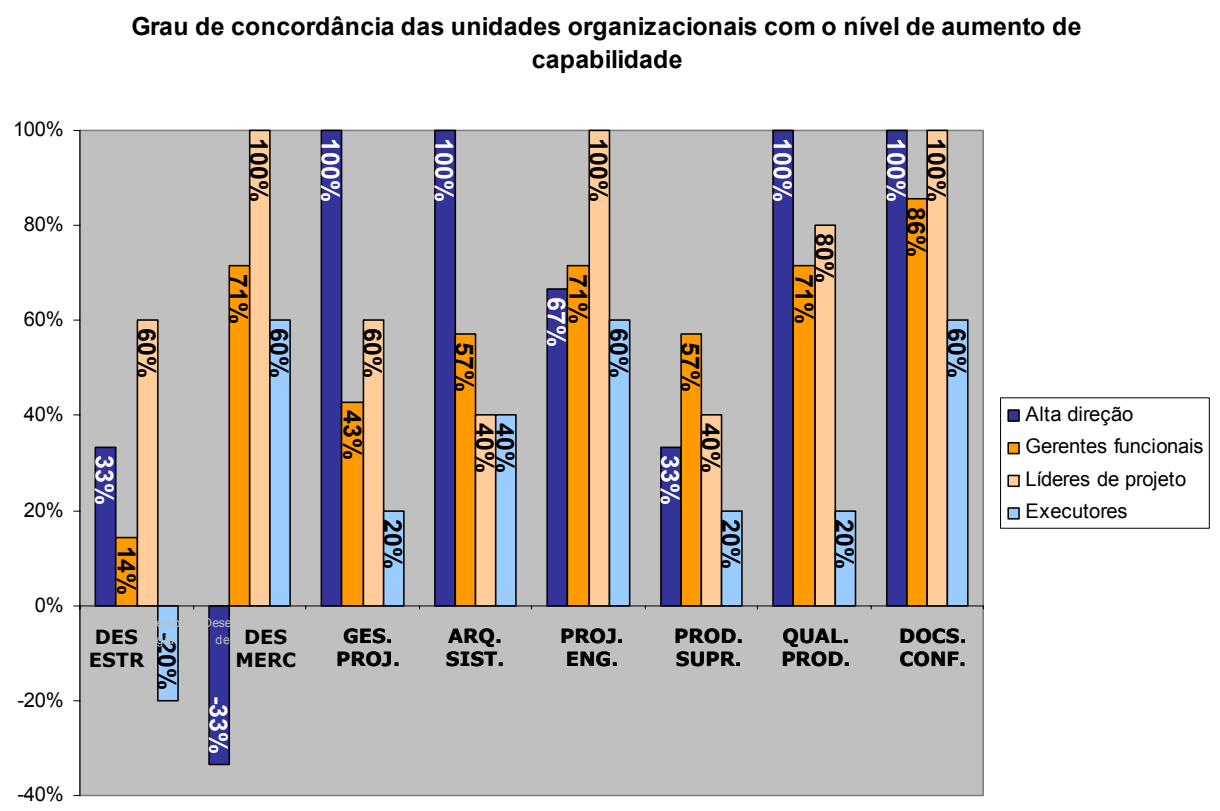

Figura 112 - Grau de concordância com aumento de capabilidade das áreas de processo por unidade organizacional participante do PDP na empresa

A análise realizada nesse tópico permite validar os dados de aumento da capabilidade das áreas de processo após a aplicação do MRM. Confirma-se que houve maior aumento na área de documentos e configurações. Por outro lado, detectou-se forte tendência funcional na análise do grau de concordância com as melhorias de capabilidade nas áreas de processo.

\subsubsection{Melhoria de indicadores de desempenho do PDP}

O grupo pesquisado na etapa 2 de validação do modelo de referência, respondeu com base em uma escala de concordância ou discordância, se houve melhoria em indicadores de 
desempenho de desenvolvimento de produtos, ainda com base no questionário apresentado no APÊNDICE G.

Os indicadores de desempenho utilizados para aferir o impacto do aumento de capabilidade do PDP na empresa foram:

- $\quad$ controle de custos dos projetos;

- $\quad$ controle de prazos dos projetos;

- $\quad$ exatidão nas estimativas de prazos;

- $\quad$ controle das informações geradas ao longo dos projetos;

- $\quad$ capacidade de integração de pessoas aos projetos;

- $\quad$ grau de mudança das especificações a serem atingidas no projeto;

- $\quad$ quantidade de reclamações de setores de manufatura e montagem; e

- $\quad$ quantidade de reclamações de clientes quanto aos produtos.

Os indicadores têm por base a proposta de CLARK e FUJIMOTO (1991), ver APÊNDICE B, complementados com indicadores sugeridos por KAPLAN e NORTON (1997) que têm forte relação com o processo de gestão de documentos ao longo do PDP.

A Figura 113 apresenta a visão geral dos entrevistados quanto ao grau de melhoria dos indicadores de desempenho do PDP. 


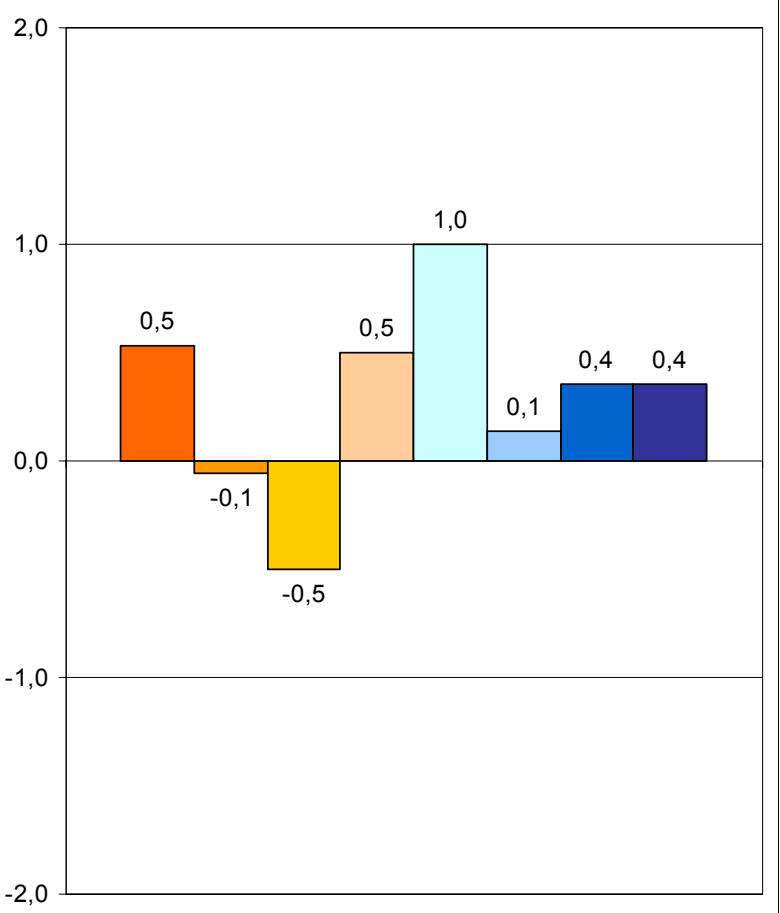

$\square$ Atualmente os projetos são mais bem controlados em termos de custos.

$\square$ Atualmente os projetos são mais bem controlados em termos de prazos.

$\square$ Atualmente se consegue estimar com exatidão os prazos necessários para realizar as atividades.

$\square$ Atualmente há um eficiente controle sobre as informações geradas ao longo do projeto.

$\square$ Atualmente há maior capacidade de integrar pessoas novas aos projetos.

$\square$ Atualmente há menos mudanças nas especificações que precisam ser atingidas pelo projeto ao longo de seu desenvolvimento.

$\square$ Atualmente há menos reclamações dos setores de manufatura e montagem quanto às informações geradas nos projetos.

$\square$ Atualmente há menos reclamações dos clientes quanto aos produtos desenvolvidos.

Figura 113 - Graus de melhorias dos indicadores de desempenho pesquisados

Observa-se que o indicador de desempenho considerado mais positivo na evolução do PDP da empresa entre os dois momentos pesquisados foi a "capacidade de integrar pessoas novas aos projetos", o que tem óbvia decorrência com relação à documentação desenvolvida ao longo dos projetos. Os indicadores nos quais houve discordância quanto à melhoria foram a "capacidade de cumprir prazos" e a "capacidade de estimar prazos", ambos relacionados com tempo e cujo vínculo com a área de gestão de projetos é claro.

Estratificando os entrevistados por área funcional, papel hierárquico dentro do PDP na empresa e função dentro do processo, tem-se a distribuição ilustrada na Figura 114. 


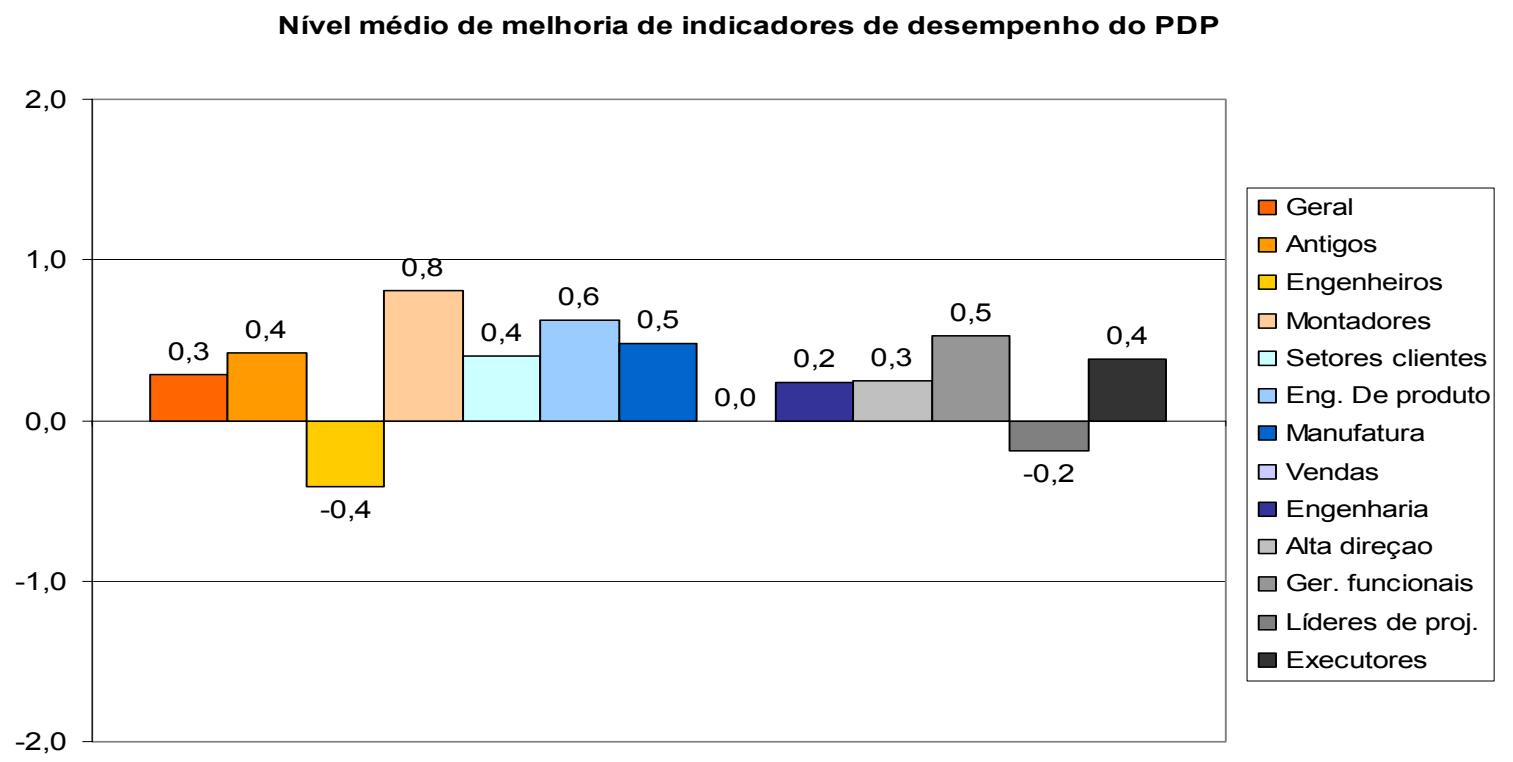

Figura 114 - Graus de melhorias dos indicadores de desempenho estratificados em função do papel do respondente no PDP

Observa-se que o grau de melhoria médio dos indicadores de desempenho analisados é de 0,3. Esse número é similar ao valor imputado pela alta direção, o que é interessante aspecto na validação dos dados, pois é a alta gerência que determina a importância de determinadas ações de melhoria.

O grau de melhoria médio cresce para o grupo de montadores.e para a engenharia de produto. Em ambos os casos, considera-se que há forte relacionamento de práticas de documentação de produto com esse grau de percepção de melhoria por parte destes atores. Para os montadores, a documentação facilita seu trabalho, pois há menor risco de erros baseados em uso de documentos antigos ou mal-elaborados. Para a engenharia de produto, a documentação do projeto facilita a sua adaptação à estrutura de produção da empresa.

Os gerentes funcionais e os setores de manufatura foram beneficiados com a aplicação do MRM, uma vez que além de receberem documentos controlados, a quantidade de especificações de manufatura e montagem, assim como de controles de qualidade de processo, contribui para reduzir a variabilidade da produção, o que implica em redução de custos e prazos. 
Por outro lado, embora a engenharia como um todo considere que houve melhoria dos indicadores de desempenho do PDP $(0,2)$, os engenheiros que participaram diretamente do processo de implementação do MRM e os líderes de projeto consideraram que houve degradação dos indicadores de desempenho. Isso pode se explicar por três motivos distintos: (1) a exigência de documentação implica em grande esforço da engenharia no sentido de sistematizar as soluções de projeto, atividade normalmente não considerada muito interessante pelos engenheiros; (2) a formalização de processos de desenvolvimento tradicionalmente é considerada impactante negativamente na satisfação dos engenheiros com o trabalho; e (3) aumentar a capabilidade da gestão de projetos implica em maior rigor nos prazos de desenvolvimento e disso normalmente resultam pressões sobre os engenheiros, especialmente os líderes do projeto.

Considerando que o grupo denominado "antigos" na empresa, i.e. as pessoas com maior tempo de empresa e que participaram efetivamente dos projetos que foram comparados com aqueles nos quais o MRM foi aplicado, independente de sua função no processo, setor no qual está alocado, ou grau de escolaridade, são as que podem realizar melhor comparação entre os indicadores de desempenho analisados nos momentos inicial e final de aplicação do MRM, conclui-se esse tópico com o detalhamento dos graus de melhoria identificados por esse grupo, o qual consta na Figura 115. 


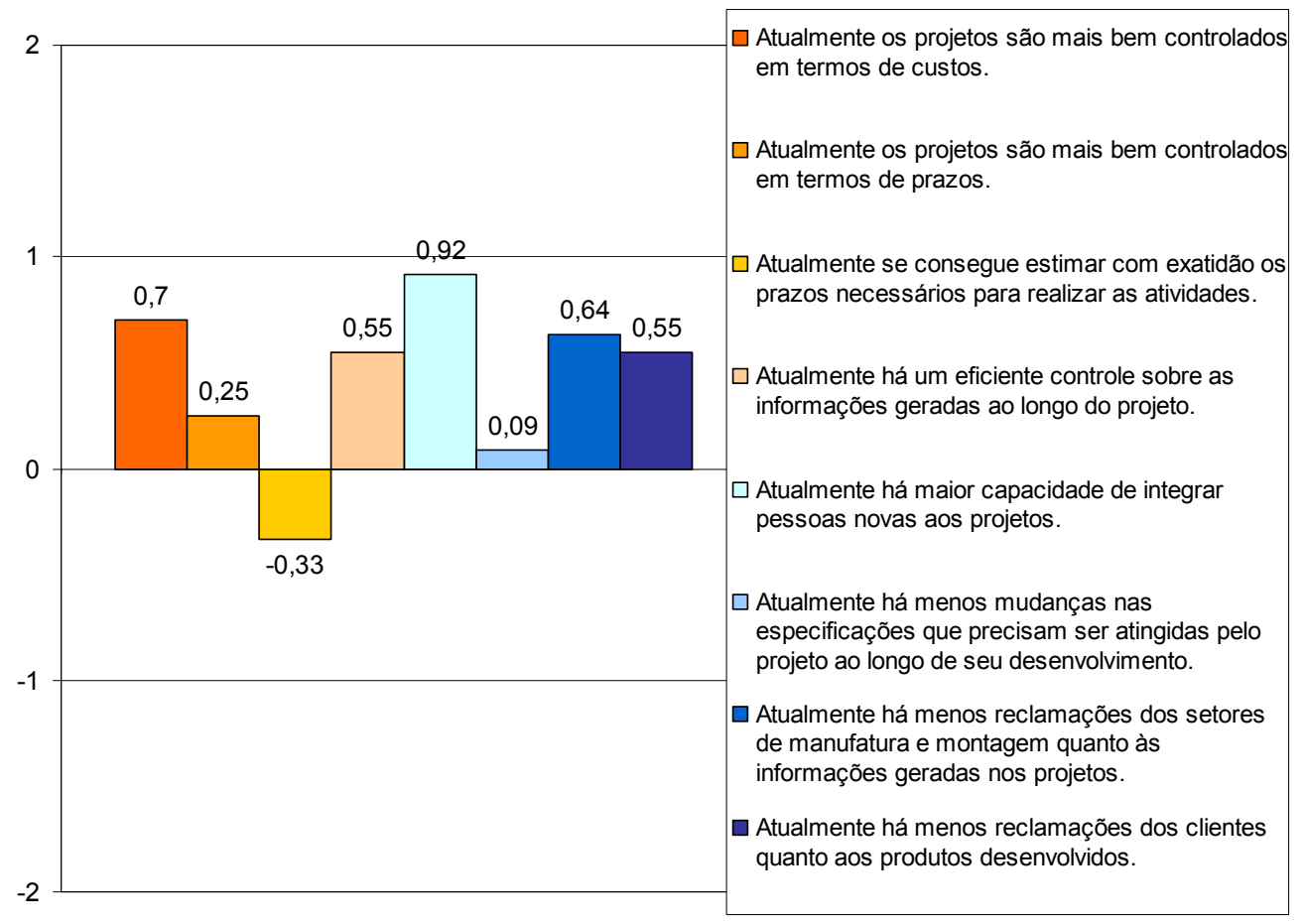

Figura 115 - Graus de melhorias dos indicadores de desempenho estratificados para os entrevistados com maior tempo de empresa

A média da melhoria dos indicadores de desempenho, conforme avaliação das pessoas com maior tempo de empresa é de 0,4 (ver Figura 114). Na Figura 115, esse grau de melhoria é detalhado, indicando que a menos do indicador de exatidão de estimativas de prazos, o MRM permitiu a melhoria dos outros indicadores de desempenho do PDP.

Portanto, além de aumentar a capabilidade das áreas de processo, o MRM permitiu melhorar indicadores, o que não consta em publicação relacionada com o PDP. Dessa forma, cumpriu-se a ETAPA 2 do método de aplicação do MRM para a validação da hipótese de pesquisa (ver item 6.1). Considera-se que a PROP_2 foi testada e validada.

\subsubsection{Discussão com os entrevistados da ETAPA 2 sobre a aplicação do MRM}

A ETAPA 3 do método introduzido na Figura 67 foi realizada através da análise das entrevistas realizadas com o grupo pesquisado na ETAPA 2 do método de validação. A descrição a seguir apresenta um debate entre as explicações que os entrevistados deram acerca de alguns dos resultados apresentados nos itens 6.3 e 6.4 e a visão do pesquisador a respeito, 
considerando sua pesquisa-ação na empresa. Os dados aqui apresentados são decorrentes do uso do procedimento de observação participante (ver item 3.3.2).

- Sobre o grande aumento de capabilidade em documentação e configurações: esse aumento resultou das imposições dos órgãos que regulam os mercados interno e externo relacionados com os produtos que a empresa desenvolve: médicos e espacial. Essa visão é compartilhada pelos entrevistados. Para o Diretor de P\&D, no passado:

"[...] Não tinha a ANVISA para pertubar. Na medida que foi entrando esses produtos médicos, órgãos reguladores começaram a pegar no pé aí a gente teve que começar certas formas de trabalho".

O representante dos sistemas de gestão, enfatiza:

"[...] A organização do projeto que existe hoje ela evolui principalmente através de necessidades regulatórias, de certificação de produtos”.

- Sobre o aumento de capabilidade em gestão de projetos: também decorre de imposições do contratante do projeto da área espacial. Entretanto há outros elementos dispersos nos diferentes discursos. Para o Diretor de P\&D, responsável direto pelo gerenciamento dos projetos de seu setor:

"[...] A equipe aumentou [...] então começa a te obrigar a usar ferramentas mais adequadas"

Essa visão é compartilhada pelos engenheiros de projeto:

"[...] do tamanho que ficou a coisa não tem como o Diretor de Engenharia ficar cuidando de tudo"

Um outro engenheiro enfatiza:

“[...] Então, cada projeto tem um gerenciamento. Isso já vinha de um certo tempo, mas hoje está mais declarado porque os projetos estão aumentando então cada um tem que cuidar do seu setor para a coisa andar. Não tem como uma pessoa cuidar de 5 projetos, então nesse sentido houve uma evolução na gestão de projetos".

Portanto, diferentemente da área de "documentos e configurações", em "gestão de projetos" há um determinante imposto pelo próprio crescimento da empresa. 
- $\quad$ Sobre os problemas relacionados com a gestão de prazos na empresa: os problemas decorrem da percepção do pessoal da área comercial de que se deixar o prazo aberto, o pessoal de projeto não consegue convergir para uma solução rapidamente, pois “[...] $o$ engenheiro tende a querer otimizar ao máximo o produto". Esse tipo de procedimento gera reações, como por exemplo, a explicitada pelo Diretor de P\&D da empresa acerca do que seria uma melhoria significativa para o PDP da firma:

\section{"[...]trabalhar independente do pessoal do comercial".}

De maneira geral há uma grande lacuna entre vendas e engenharia na empresa. Essa lacuna se estabelece inicialmente na baixa de capabilidade da área de desdobramento da estratégia de produtos, o que se reflete na fase de estratégia. As reuniões que ocorrem entre os diretores não chegam a versar sobre estratégias de produto, de mercado etc., mas principalmente sobre resultados financeiros do ano fiscal.

- $\quad$ Sobre a falta de capabilidade da área de desdobramento da estratégia: não há uma clara noção do gerenciamento das linhas de produto e dos produtos dentro dessas linhas. Embora a empresa tenha conseguido garantir um fluxo de caixa positivo, as oportunidades de negócio não são pensadas a médio e longo prazo antes de se transformarem em novos projetos. Isso faz com que da mesma forma que começaram impulsivamente, alguns projetos sejam trocados por “outras oportunidades melhores", sobre as quais, porém, pouco houve de análise.

De certa forma, há uma confusão entre "estratégia", "portifólio" e "especificações do produto", o que pode decorrer de estarem essas atividades sob responsabilidade do mesmo setor dentro da empresa: a diretoria comercial. Como o foco do comercial é o ano fiscal não se coloca em questão as LDPs e seu vínculo com a estratégia. 


\section{CONSIDERAÇÕES FINAIS E CONCLUSÕES}

Neste capítulo são apresentadas em 7.1 algumas considerações gerais que decorrem do trabalho de revisão bibliográfica, da confecção do MRM e de sua aplicação, mas não têm relação direta com as questões, hipóteses e proposições testadas ao longo da pesquisa. No item 7.2 são apresentadas as respostas conseguidas em torno das questões de pesquisa que constam no capítulo introdutório e no item 7.3 são discutidas considerações finais do trabalho e proposição de estudos futuros.

\subsection{Considerações gerais acerca das áreas teóricas do trabalho}

A análise bibliográfica realizada ao longo do trabalho permitiu chegar a alguns resultados parciais cuja relevância vale seu registro.

Inicialmente, foi desenvolvido o conceito de produto mecatrônico com base no conceito de mecatrônica discutido por diversos autores da área. No conceito desenvolvido (item 2.1.2), os elementos que compõem o produto mecatrônico foram sistematizados em função de seu papel dentro de um determinado sistema. Embora na parte de aplicação do trabalho não tenha havido a possibilidade de utilizar o conceito, as figuras Figura 13, Figura 14, Figura 15 e Figura 16 retratam o uso do conceito em produtos comerciais e científicos. Vale ressaltar, ainda, a diferenciação entre mecatrônica e sistemas de controle realizada no item 2.1.1 e exemplificada nas figuras Figura 9, Figura 10 e Figura 11.

A análise das teorias de PDP (APÊNDICES B e C) tem por base o item 2.2.1 no qual consta um sumário das abordagens que autores das diferentes áreas envolvidas com a mecatrônica têm quanto ao processo de desenvolvimento de produtos. Ter nesta discussão o ponto de partida para o entendimento do PDP foi motivado pelo fato de que o trabalho ora apresentado demanda um diálogo entre os teóricos mais voltados para as disciplinas de engenharia eletrônica, mecânica e de software com aqueles mais relacionados com 
adminstração e engenharia de produção. Esse contraponto é raramente encontrado nos autores de PDP. Esse ponto de vista permitiu elaborar o conceito de âmbito de aplicabilidade (item 5.2.2)

A utilização da teoria de modelagem de empresas (ME) para a confecção do modelo de referência mecatrônico proveu um método de análise da bibliografia que se fundamentou no conceito de tipos de conteúdo. O uso desse conceito para estabelecer as categorias da análise de conteúdo permitiu identificar os conteúdos mais pertinentes a modelos de referência em PDP e um entendimento mais sistemático sobre as diferenças entre os conceitos e propostas dos diferentes autores de desenvolvimento de produtos. Esse estudo está consolidado na Tabela 2 e está apresentado no APÊNDICE C.

Também com base nas teorias de modelagem de empresas, foi possível desenvolver o MRM de maneira a rastrear sua forma de representação e sua sintaxe às técnicas de modelagem consagradas na bibliografia de $\mathrm{ME}$, o que não consta nos modelos de referência analisados neste trabalho (APÊNDICE C).

A utilização de técnicas de ME na modelagem do PDP está, ainda, presente na representação dos tipos de conteúdo modelados no MRM, conforme apresentados no APÊNDICE A. No MRM a técnica de modelos entidade-relacionamento (MER) é utilizada para demonstrar como os tipos de conteúdo modelados se relacionam (ver item 5.1 e Figura 40). Esses relacionamentos podem ser comprovados no APÊNDICE A. PRASAD (1997) utiliza o MER para descrever os construtos utilizados em seu modelo de referência, porém o autor não utiliza os construtos identificados na descrição das fases de seu modelo.

Do ponto de vista do PDP propriamente dito, a análise da bibliografia permitiu que o MRM fosse confeccionado com base em alguns conceitos importantes acerca do desenvolvimento de produtos, quais sejam: 
- $\quad$ conceito de âmbito do PDP: esse conceito é uma contribuição desse trabalho, ele advoga que as fases do PDP ocorrem em âmbitos diferentes desse processo (ver item 5.2.2). $\mathrm{Na}$ fase de estratégia, por exemplo, a preocupação é com o conjunto das LDPs da empresa que podem ser diversas e com muitos produtos em cada uma, enquanto na fase de concepção a preocupação se volta para questões técnicas específicas de um produto e às vezes de um determinado componente dele. Pode-se construir a hipótese de que é o conceito de âmbito que está presente na dificuldade que o pessoal de eletrônica ou de mecânica tem quando estuda textos de PDP, ou que o pessoal de PDP tem quando estuda material daquelas áreas;

- $\quad$ conceito de ciclo de gestão da estratégia e do portifólio (ver item 5.2.3): esse conceito é derivado da teoria de COOPER (1998). O conceito estabelece que a interface entre os processo de gestão de portifólio e o PDP ocorre em ciclos consecutivos das fases F12-F1-F2 que são determinados pelo tempo $T_{1}$ no qual a primeira revisão da estratégia de produtos ocorre e pelo período $\boldsymbol{x}$ estabelecido entre revisões de estratégia consecutivas.

- $\quad$ conceitos de ciclos e de refinamentos (ver item 5.2.4): os ciclos do PDP são discutidos por PRASAD (1996) e são incorporados nas fases do MRM para representar os ciclos de desenvolvimento de soluções técnicas que devem integrar diferentes partes de um dado produto e devem estar respaldadas em soluções de desenvolvimento de processo e em análises de riscos e falhas. O conceito de refinamento é utilizado para implementar revisões em resultados intermediários do PDP para os quais não seria interessante criar ciclos entre fases distintas. Refinamentos são utilizados para desenvolver e revisar as especificações do produto e o plano de projeto sendo um conceito sistematizado com base no estudo de ULRICH e EPPINGER (1995).

- $\quad$ conceito de áreas de processo do PDP: embora o MRM utilize o conceito de áreas de processo desenvolvido por CHRISSIS et al. (2003), as áreas de processo projetadas são uma 
contribuição do trabalho decorrente da necessidade de agregar atividades específicas de mecatrônica no PDP genérico desenvolvido pelos autores referenciados no APÊNDICE C e de reduzir a sua quantidade e complexidade com relação à proposta original desses autores.

Enfim, o MRM busca integrar atividades de validação e certificação do produto dentro da teoria de PDP. Esse aspecto tem sido negligenciado pelos autores de desenvolvimento de produtos e de mecatrônica. A exceção é o texto de ROZENFELD et al. (2006) no qual, entretanto, o tema não é tratado com a profundidade necessária ao PDP mecatrônico.

\subsection{Conclusões}

Os resultados demonstraram que a utilização da metodologia descrita no capítulo 3 permitiu desenvolver e testar um modelo de referência que se demonstrou viável para a aplicação ao desenvolvimento de produtos mecatrônicos.

As questões de pesquisa foram respondidas da seguinte forma:

Q1) qual modelo de referência para o PDP pode ser aplicado em empresas cujos produtos são mecatrônicos?

A resposta a essa questão foi dada no capítulo 5. A íntegra do MRM consta no APÊNDICE A. Além do MRM, há um considerável conjunto de modelos de referência que podem ser aplicados ao PDP de empresas que desenvolvem produtos mecatrônicos. BUUR (1990) e BRADLEY et al. (2000) são modelos focados na especificidade da mecatrônica, enquanto ROZENFELD et al. (2006) apresenta um modelo genérico para o PDP que pode ser instanciado para os produtos mecatrônicos. O MRM é uma opção a esses modelos cujo enfoque é adaptado à bibliografia de mecatrônica pesquisada nesse trabalho e agrega contribuições de vários autores, que, como ROZENFELD et al. (op. cit.) discutem o PDP de forma genérica.

O modelo descrito no capítulo 5 visou preencher a lacuna identificada na bibliografia pesquisada: 
A inexistência de um modelo de referência que contemple as melhores práticas da teoria de PDP e que seja adaptado ao contexto tecnológico dos produtos mecatrônicos.

Q2) como o modelo de referência mecatrônico deve ser utilizado em uma empresa para o desenvolvimento de um produto real?

Foram desenvolvidas duas possíveis aplicações do MRM (itens 5.4.1 e 5.4.2 ), a saber, aplicação por "área de processo" e por "atividade". As aplicações são baseadas no conceito de “áreas de processo" tendo sido detalhado um método de uso sugerido do MRM (item 5.4.3). Esse método foi aplicado a uma empresa que desenvolve produtos mecatrônicos de maneira a validar as hipóteses de pesquisa. A aplicação foi realizada mediante o procedimento descrito no item 6.1. Essa forma de aplicação pode, a princípio, ser utilizada em outras empresas e iniciativas de desenvolvimento de produtos mecatrônicos.

Q3) quais os resultados que uma empresa pode esperar da aplicação do modelo de referência mecatrônico?

O trabalho é conclusivo nesse sentido, desde que o modelo seja aplicado da forma como previsto nos itens 5.4.3 e 6.1. A aplicação do MRM realizada validou o modelo, porém, dentro do método hipotético-dedutivo, isso significa apenas que o MRM passou por um teste de refutação com base no conceito de áreas de processo. Muitos outros conceitos utilizados para confeccionar o MRM podem ser utilizados em uma aplicação real e os resultados não podem ser previstos por esse trabalho.

Deve-se observar que a aplicação por áreas de processo, conforme o método estabelecido no já mencionado item 5.4.3 pode gerar resultados diferentes dos que estão relatados nos itens 6.3 e 6.4. De qualquer forma, os resultados descritos nos referidos itens podem ser considerados potenciais de melhoria permitidos pelo MRM. Especial atenção deve ser dada aos resultados relacionados com questões bastante concretas para as empresas que desenvolvem produtos mecatrônicos: sua certificação ISO 9001:2000 (item 6.3.1.1), o registro 
de seus produtos em agências regulatórias (item 6.3.1.2) e a transferência do projeto para os setores de manufatura e montagem (item 6.3.1.3).

A pesquisa permitiu verificar que os graus de melhoria conseguidos nas áreas de processo de "documentos e configurações" e de "gestão de projetos" foram fortemente decorrentes de demandas práticas que a empresa vivenciava. Caso houvesse necessidade premente de modificar a estratégia da firma, ou de diminuir a variabilidade da fabricação, etc. outras áreas de processo certamente seriam enfocadas no trabalho de aplicação do MRM e outros resultados seriam conseguidos. Esse tipo de variável depende de cada aplicação em específico, o que justifica a dificuldade de generalizar os resultados conseguidos nessa pesquisa.

\begin{abstract}
A hipótese de pesquisa:
HIP1) Os resultados da aplicação do modelo devem estar respaldados na bibliografia especializada em PDP. A melhoria de indicadores de desempenho no PDP da empresa na qual o MRM é aplicado determina a validade das melhores práticas contidas no modelo ou sua refutação.
\end{abstract}

Foi traduzida em duas proposições passíveis de teste:

PROP_1) as áreas de processo nas quais houve maior grau de aplicação do modelo devem ter maior aumento em seu nivel de capabilidade;

Essa proposição foi validada pelo fato de que a área de processo de "documentos e configurações" foi a mais sujeita à aplicação do MRM (Figura 77) e foi também a que apresentou maior grau de melhoria de seu nível de capabilidade (Figura 108) e maior concordância do pessoal entrevistado na ETAPA 2 da aplicação do MRM (Figura 110, Figura 111 e Figura 112). Corrobora com essa conclusão o fato da área de "desdobramento da estratégia" apresentar comportamento oposto ao da área de "documentos e configurações".

Uma vez que o MRM utiliza o conceito de áreas de processo baseado em CHRISSIS et al. (2003) o resultado acima indica que o MRM é uma ferramenta teoricamente consistente. 
PROP_2): a aplicação do modelo deve resultar em melhoria significativa em indicadores de desempenho do PDP.

Para o teste dessa proposição foram levantados dados acerca de " 8 " (oito) indicadores de desempenho do PDP. Os resultados apresentados na Figura 113, e, especialmente na Figura 115, indicam que houve melhoria no controle de custos do projeto, na capacidade de integrar novos membros ao projeto, no controle sobre as informações geradas pelo projeto, assim como redução de reclamações de clientes e dos setores de manufatura acerca das especificações finais do projeto. Houve pequena melhoria quanto à exatidão das especificações entregues para o pessoal de projeto, e considerou-se que não houve melhoria quanto à estimativa e gestão dos prazos envolvidos nos projetos.

Considera-se, portanto, que a proposição foi validada para os indicadores que apresentaram grau de concordância positivo nas figuras Figura 113 e Figura 115.

\subsection{Considerações finais}

A área de processo de "documentos e configurações" apresentou grau de melhoria de nível de capabilidade $\left(\Delta_{c}\right)$ de "5" (ver Figura 108). Pode-se relacionar esse dado com o fato de o indicador de desempenho com maior melhoria ter sido "a capacidade de integrar pessoas novas ao projeto". Considera-se que esse resultado demonstra coerência da aplicação do modelo com a teoria de PDP. Entretanto, é necessário pesquisa adicional com enfoque nessa temática para que se chegue a resultados conclusivos.

A área de gestão de projetos, que teve um aumento de capabilidade de 2.5 (ver Figura 108), teoricamente deveria puxar os indicadores de controle de prazos dos projetos para um patamar positivo considerando o perfil condordo/discordo das figuras Figura 113 e Figura 115. Os dados mostraram, entretanto, que isso não se configurou como verdadeiro. Explica-se essa discrepância pelo fato de ter havido melhoria em gestão de projetos decorrente de aspectos contratuais, de ser ainda uma iniciativa bastante recente, e principalmente, de haver 
barreiras organizacionais que impedem a eficiência das estruturas matriciais necessárias à consecução das práticas de gestão de projetos. Caberia uma estratégia de aplicação do MRM cujas hipóteses fossem derivadas dessas possíveis explicações de maneira a verificar sua propriedade na explicação da discrepância acima mencionada.

A análise final dos dados de melhoria de capabilidade e de indicadores, permitiu ainda, verificar a grande dependência entre a percepção da melhoria e a posição hierárquica do pesquisado, a unidade organizacional à qual pertence etc. Essa variação sugere, por um lado que o conceito de capabilidade precisa ser relativizado em função de variáveis organizacionais, e por outro que a aplicação do MRM por áreas de processo deve levar em consideração o aspecto "organização" como um de seus principais determinantes.

O fato da empresa analisada apresentar baixo nível de capabilidade no início da aplicação do MRM permitiu que apenas a realização per si de algumas atividades do PDP mecatrônico causassem um aumento considerável da capabilidade das áreas de processo enfocadas no trabalho de aplicação. Essa aplicação e os resultados conseguidos permitem validar o conjunto de atividades previsto no MRM. Em uma situação de maior capabilidade, seria possível validar os documentos e formulários desenvolvidos.

Como pode ser visto no item 6.2.5.8, no qual são apresentadas as aplicações realizadas na fase de otimização, foram utilizadas duas abordagens distintas quanto à consecução da atividade "analisar riscos do produto quanto às normas". Utilizou-se inicialmente o formulário FMEA para sistematizar dados de análise de riscos realizadas, o que foi bem aceito pelo pessoal de Engenharia. Em paralelo, tentou-se utilizar a FMEA como método de identificação de modos de falha de projeto. Essa aplicação foi considerada desnecessária pelo pessoal envolvido no PDP. 
Explica-se essa situação pelo seguinte: o $\mathrm{N}_{\mathrm{ci}}$ da atividade era de “1”, portanto, uma atividade já realizada na empresa. A aplicação do formulário FMEA permitiria uma padronização das análises de risco realizadas em diferentes projetos com base no resultado provido pelo formulário FMEA, sem porém uma utilização sistemática do método FMEA, conforme descrito na bibliografia de PDP (APÊNDICE B). Essa aplicação levou a capabilidade da atividade para "2", uma atividade planejada. A tentativa de aplicar o método FMEA foi frustrada por demandar um aumento da capabilidade para nível "3", quando a teoria desenvolvida por CHRISSIS et al. (2003) sugere níveis sucessivos de capabilidade, uma vez que é um método de melhoria contínua. Portanto, o resultado apresentado pela situação descrita é coerente com a teoria de PDP.

A utilização do conceito de arquitetura do produto para documentar as soluções técnicas do projeto retinógrafo no momento em que o produto foi submetido à ANVISA (ver Quadro 9) foi considerada desnecessária por parte da equipe de projeto. Entretanto, esse exercício possibilitou abreviar o tempo necessário à confecção da estrutura de documentação do projeto MUX com base na sua arquitetura que é sumariamente apresentada na Figura 73. Embora essa estrutura documental esteja baseada no conceito de árvore de produtos, a discussão realizada pela equipe do projeto MUX para confecciona-la utilizou como alicerce o conceito de arquitetura explorado quando do desenvolvimento dos documentos necessários ao registro ANVISA do retinógrafo.

A partir de então, ambos os conceitos, de árvore e de arquitetura do produto, passaram a ser utilizados no PDP da empresa. Essa situação demonstrou que o avanço da capabilidade de uma determinada atividade ocorre em função da necessidade de utilização de determinados conceitos vinculados àquela atividade e que o uso efetivo desses conceitos se dá pelo convencimento dos usuários do processo acerca dos resultados alcançados com ele. Em outras 
palavras, ter conseguido o registro ANVISA do retinógrafo com base no conceito de arquitetura permitiu a sua utilização no projeto MUX.

A relação entre aumento de capabilidade das áreas de processo e a melhoria de indicadores de desempenho do PDP é ainda uma matéria de pouco estudo teórico indexado. O uso do MRM, conforme exposto nesse trabalho, permitiu verificar que, ao implementar um modelo de referência em desenvolvimento de produtos com base no conceito de áreas de processo, é possível melhorar o desempenho do PDP na empresa. A aplicação permitiu, ainda, mapear os indicadores mais sensíveis à aplicação realizada cujo enfoque se deu em aspectos relacionados com documentação de produto e gestão de projetos.

Este resultado aponta para a eficácia do uso de modelos de referência de PDP em situações reais de projeto e com resultados de melhoria efetiva do processo. Esse é um resultado significativo dessa pesquisa uma vez que a bibliografia científica sobre a utilização de modelos de referência em um determinado processo não contempla a discussão de resultados concretos alcançados pelo uso dos modelos.

Ressalta-se, ainda, que a forma de aplicar o modelo permitiu atingir resultados práticos importantes para a empresa, o que demonstra que as melhorias de processo permitidas pelo MRM não se resumem à elocubrações científicas, mas permitem atingir objetivos bastante significativos para as empresas que desenvolvem produtos mecatrônicos. 


\section{BIBLIOGRAFIA}

AALST, W.V. (org.) Business process management: models, techniques, and empirical studies. Germany, Springer-Verlag, 2000.

ASSOCIAÇÃO BRASILEIRA DE NORMAS TÉCNICAS, NBR ISO 9000:2000, Sistemas de Gestão da Qualidade - Fundamentos e Vocabulário, Rio de Janeiro, 2000a.

Janeiro, 2000b.

NBR ISO 9001:2000 - Sistemas de Gestão da Qualidade - Requisitos, Rio de

NBR ISO 13485, Produtos para a Saúde - Sistemas de Gestão da Qualidade Requisitos Particulares para a aplicação da NBR ISO 9001, Rio de Janeiro, 2003.

ADAMSSOM, N. Mechatronics engineering: new requirements on cross-functional integration. Licentiate Thesis, Department of Machine Design, Royal Institute of Technology. Stockholm, Sweden, 2005.

AGOSTINHO, O.L. et al.. Tolerâncias, ajustes, desvios e análise de dimensões. São Paulo/SP: Editora Edgard Blücher, 1977.

AGUILAR-SAVÉN, R. S. Business process modeling: review and framework. International Journal of Production Economics, 90, p. 129-149,2004.

ALI, A. et al.. Product innovativeness and entry strategy: impact on cycle time and breakeven time. Journal of Product Innovation Mangament, 12, p. 54-69, 1995.

ALVES, R. Filosofia da ciência: introdução ao jogo e suas regras. São Paulo/SP: Editora Brasiliense, 1994.

AMARAL, D. C. Arquitetura para o Gerenciamento de Conhecimentos Explícitos sobre o Processo de Desenvolvimento de Produtos. Tese apresentada à Escola de Engenharia de São Carlos, da Universidade de São Paulo. São Carlos/SP, 2001.

AMERONGEN, J. Mechatronic design. Mechatronics, 13, p.1045-1066, 2003.

$11 / 03 / 2005$

. The role of control in Mechatronics. www.ce.utwente.nl/amn, acesso em

AGÊNCIA NACIONAL DE VIGILÂNCIA SANITÁRIA. RDC 185 - Registro, alteração, revalidação e cancelamento do registro de produtos médicos. Brasília, 2001.

AUTOMOTIVE INDUSTRY ACTION GROUP. APQP. Advanced Product Quality Planning e Control Plan, 1994.

QS-9000. Quality System Requirements. Second Edition ,1995.

BALLOU, R. Logística empresarial: transportes, administração de materiais e distribuição física. Trad. Hugo T. Yoshizaki. São Paulo: Editora Atlas S.A., 1993. 
BARBALHO, S.C.M. e ROZENFELD, H(a). Análise do processo de desenvolvimento de produtos de uma pequena empresa de alta tecnologia. In: ENCONTRO NACIONAL DE ENGENHARIA DE PRODUÇÃO, 24, 2004, Florianópolis. Anais do XXIV Encontro Nacional de Engenharia de Produção, São Paulo, ASSOCIAÇÃO BRASILEIRA DE ENGENHARIA DE PRODUÇÃO , Nov./2004,1 CD-ROM.

(b). Análise dos conteúdos necessários à confecção de modelos de referência para o processo de desenvolvimento de produtos. In: SIMPÓSIO DE GESTÃO DA INOVAÇÃO TECNOLÓGICA, 23, 2004, Curitiba. Anais do XXIII Simpósio de Gestão da Inovação Tecnológica, São Paulo, Out./2004, 1 CD-ROM.

(a). Modelo de referência para o desenvolvimento de produtos mecatrônicos. In: AMARAL. D. C. Gestão do Ciclo de Vida dos Produtos. Coleção Fábrica do Milênio Volume III. Jaboticabal: Editora Novos Talentos, 2005.

(b). Adequação da ISO 9001 ao Processo de Desenvolvimento de Produtos de Uma Empresa de Alta Tecnologia. In: CONGRESSO BRASILEIRO DE GESTÃO DO DESENVOLVIMENTO DE PRODUTOS, 5, 2005, Curitiba. Anais do V Congresso Brasileiro de Gestão do Desenvolvimento de Produtos - CBGDP, Florianópolis, INSTITUTO DE GESTÃO DO DESENVOLVIMENTO DE PRODUTOS, 2005, 1 CDROM.

BARBALHO, S.C.M. et al. Modelando processos de negócio com UML. In: In: ENCONTRO NACIONAL DE ENGENHARIA DE PRODUÇÃO, 22, 2002, Curitiba. Anais do XXII Encontro Nacional de Engenharia de Produção, São Paulo, ASSOCIAÇÃO BRASILEIRA DE ENGENHARIA DE PRODUÇÃO, Nov./2002,1 CD-ROM.

. Requisitos para a publicação na internet de um modelo de referência do processo de desenvolvimento de produtos. In: CONGRESSO BRASILEIRO DE GESTÃO DO DESENVOLVIMENTO DE PRODUTOS, 5, 2005, Curitiba. Anais do V Congresso Brasileiro de Gestão do Desenvolvimento de Produtos - CBGDP, Florianópolis, INSTITUTO DE GESTÃO DO DESENVOLVIMENTO DE PRODUTOS, 2005, 1 CDROM.

BARDIN, L. Análise de conteúdo. Tradução de Luís Antero Reto e Augusto Pinheiro. Portugal, Lisboa: Edições 70, 1979.

BAXTER, M. Projeto de produto: guia prático para o design de novos produtos. $2 \mathrm{ed}$.Rev. Tradução: Itiro Iida - São Paulo: Editora Edgard Blücher Ltda., 2000.

BENEDETTO, C.A. Identifying the key success factors in new product launch. Journal of Product Innovation Mangament, 16, p. 530-544, 1999.

BENEDICTS, C.C. et al.. Desenvolvimento de um modelo para desenvolvimento de produtos baseado em uma empresa montadora de produtos "linha branca". Revista de Iniciação Científica, n.4, 2002.

BERNARDI, M. Et al.. New approaches for developing mechatronical products in multidisciplinary teamwork. In: CIRP-INTERNATIONAL SEMINAR ON MANUFACTURING SYSTEMS, 35, 2002, Seoul. Anals of The 35th CIRP-International Seminar on Manufacturing Systems. Seoul. CIRP, 2002. 
BOOCH, G. UML: Guia do usuário. Rio de Janeiro: Ed. Campus, 2000.

BOOTHROYD et al.. Product Design for Manufacture and Assembly. New York: Marcel Dekker, Inc. 1994.

BOYER, K.K. e PAGELL, M. Measurement issues in empirical research: improving measures of operations strategy and advanced manufaturing technology. Journal of Operations Management, 18, p. 361-374, 2000.

BRABAZON, T. e MATTHEWS, R. Product architecture and product design: a complexity perspective. The Journal of American Academy of Business, v.2, n.2, p. 472-478, 1998.

BRADLEY, D.A. et al.. Mechatronics: electronics in products and processes. London, United Kingdom, Chapman and Hall, 1991.

. Mechatronics and the design of intelligent machines and systems. Cheltenham, United Kingdom, Stanley Thornes, 2000.

BRANDÃO, C.R. (org.) Pesquisa participante. São Paulo/SP: Editora Brasiliense, 1988.

(a). Repensando a pesquisa participante. São Paulo/SP: Editora Brasiliense, 1987.

(b). Participar-pesquisar. In: Repensando a pesquisa participante. São Paulo/SP: Editora Brasiliense, 1987.

BUBENKO JR.; J. A., STIRNA, J.; BRASH, D. EKD user guide, Department of computer and systems sciences. Stockholm, Royal Institute of Technology, 1998.

BUUR, J. Mechatronics design in Japan: a study of Japanese design methods and working practice in Japanese Companies. Technical Report, 1989.

A theoretical approach to mechatonical design. Institute for Engineering Design. Technical University of Denmark, Doctoral Thesis, 1990.

CALANTONE, R. et al.. Investiganting the manufacturing-marketing interface in new product development: does context affect the strenght relationships? Journal of Operations Management, 20, p. 273-287, 2002.

CALDERINI, M. e CANTAMESSA, M. Innovation paths in product development: an empirical research. International Journal of Production Economics, 51, p. 1-17, 1997.

CAMPBELL, A. J. e COOPER, R. Do customer partnerships improve new product success rates? Industrial Marketing Management, 28, p. 507-519, 1999.

CAPABILITY MATURITY MODEL INTEGRATION. Disponível em: www.sei.cmu.edu/cmmi. Acesso em 15/11/2004.

CHAPMAN, R. e HYLAND, P. Complexity and learning behaviors in product innovation. Technovation, 23. Article in press, 2003. 
CHEN, P.P. "The Entity-Relationship Model: Toward a Unified View of Data". ACM Transactions, on Database Systems, volume 1, number 1, January, 1976.

CHENG, H. Structured Database System Analysis and Design through Entity Relationship Approach. Proceedings of the Fourth International Conference on Entity-Relationship Approach, p. 56-63, 1985.

CHENG, L.C. Caracterização da gestão de desenvolvimento do produto: delineando o seu contorno e dimensões básicas. CONGRESSO BRASILEIRO DE GESTÃO DO DESENVOLVIMENTO DE PRODUTOS, 2, São Carlos. Anais do II Congresso Brasileiro de Gestão do Desenvolvimento do Produto, INSTITUTO DE GESTÃO DO DESENVOLVIMENTO DE PRODUTOS, 2000, 1 CD-ROM.

CHIESA, V. et al.. Development of a technical innovation audit. Journal of Product Innovation Mangament, 13, p. 105-136, 1996.

CHRISSIS, M. B. et al.. CMMI: Guidelines or process integration and product improvement. Boston, Massachussets, United States, Addison-Wesley,2003.

CLARK, K. B.; FUJIMOTO, T. Product development performance: strategy, organization and management in the world auto industry. Harvard Business School Press, Boston, Massachussets, United States, 1991.

CLAUSING, D. Total Quality Development: a step-by-step guide to world-class concurrent engineering. The American Society of Mechanical Engineers, New York, 1994.

CLIFT, T.B. e VANDENBOSCH M. B. Project complexity and efforts to reduce product development cycle time. Journal of Business Reseach, 45, p. 187-198, 1999.

COOPER, R. Winning at New Product: acceleranting the process from idea to launch. Reading Massachussetts, Addison-Wesley Publishing Company Inc., 1993.

. PERSPECTIVE: Third-generation new product processes. Journal of Product Innovation Mangament, 11, 3-14, 1994.

. Benchmarking new product performance: results of the best practices study. European Management Journal, v. 16, n. 1, p. 1-17, 1998.

COOPER, R. e KLEINSCHMIDT, E. J. Benchmarking the firm's critical success factors in new product development, Journal of Product Innovation Mangament, 12, p. 374-391, 1995.

. Performance typologies of new product projects. Industrial Marketing Management, 24, p. 439-456, 1995.

COOPER, R. et al.. Portifólio management in new product development: lessons from the leaders-II. Research Technology Management, 40, p. 43-52, 1997.

United States, 1998.

Portifólio Management for New Products. Perseus Books, Massachussets, 
CREVELING, C.M. et al.. Design for six-sigma in technology and product development. New Jersey, United States, Prentice Hall, 2003.

CROSBY, P. B. Qualidade é investimento. Rio de Janeiro, 1999.

CURRAN, T., KELLER, G. SAP R/3 business print: understanding the business process reference model. Upper Saddle River, N.J.: Prentice Hall PTR, 1998.

DANE, F.C. Research Methods. Brooks/Cole Publishing Company, Pacific Grove, California, United States, 1990.

DAVENPORT, T.H. Reengenharia de processos: como inovar na empresa através da tecnologia da informação. Rio de Janeiro/RJ: Editora Campus, 1994.

DEMMOU, H. et al. Critical scenarios derivation methodology for mechatronic systems. In: Reliability Engineering and System Safety, 84, p. 33-44, 2004.

DEMO, P. Elementos metodológicos da pesquisa participante. In: Repensando a pesquisa participante. São Paulo/SP: Editora Brasiliense, 1987.

Avaliação qualitativa. Campinas/SP: Editora Autores Associados, 1995.

. Metodologia científica em ciências sociais. São Paulo/SP: Atlas, 1995.

DESCHAMPS, J. e NAYAK, P. Produtos irresistíveis. Trad. James F. Sunderland Cook; Rev. Myses Gedanke. São Paulo/SP: Makron Books, 1996.

DE TONI, A. et al.. Innovation in product development within the electronics industry. Technovation, 19, p. 71-80, 1999.

DORF, R. e BISHOP, R. Modern Controle Systems. New Jersey, Prentice Hall Inc., 2001.

DOUGLAS, F. Lean Principles Implementation in the Program Preparation Phase. Thesis of master of science in enginnering and business management. Massachusetts Institute of Technology, 2002.

DRIVA, H. et al.. Measuring product development performance in manufacturing organisations. International Journal of Production Economics, 63, 147-159, 2000.

ELECTROLUX HOME PRODUCT EUROPE. GSQA. The Global Supplier Quality Assurance System. Supplier Pre-production quality (EL 29003). Revision A, 2002.

EUROPEAN COMMISSION FOR SPACE STANDARDIZATION. ECSS-E-10A. Space engineering - system engineering. Noordwijk, The Netherlands, 1996a.

. ECSS-M-40A. Space project management - configuration management. Noordwijk, The Netherlands, $1996 \mathrm{~b}$.

. ECSS-M-10B. Space project management - project breakdown structures. Noordwijk, The Netherlands, 2003.

EVERSHEIM, W. et al.. Simultaneous engineering approach to an integrated design and process planning. European Journal of Operational Research, 100, p. 327-337, 1997. 
GIURGIUTIU et al.. Mechatronics and smart structures: emerging engineering disciplines for the third millenium. Mechatronics, 12, p. 169-181, 2002.

GODOY, A.S. Pesquisa qualitativa: tipos fundamentais. Revista de Administração de Empresas, São Paulo, v.35, n.3, p. 20-29, 1995.

GONÇALVES, J. E. L (a). As empresas são grandes coleções de processos. RAE - Revista de Administração de Empresas, São Paulo, v.40, n.1, Jan./Mar 2000.

. (b) Processo, que processo?. RAE - Revista de Administração de Empresas, São Paulo, v.40, n.4, Out./Dez. 2000.

GREEN, P. e ROSEMANN, M. Integrated process modeling: an ontological evaluation. Information Systems, Vol. 25, N. 2, p. 73-87, 2000

GRIFFIN, A. PDMA reseach on new product development practices: updating trends and benchmarking best practices. Journal of Product Innovation Mangament, 14, p. 429-458, 1997.

GRIFFIN, A e PAGE, A. L. PDMA success measurement project: recommended measures for product development success and failure. Journal of Product Innovation Mangament, 13, p. 478-494, 1996.

GRIMHEDEN, M e HANSON, M. Mechatronics - the evolution of an academic discipline in engineering education. Mechatronics, 15, p. 179-192, 2005.

GRYNA, F. Quality planning and analysis: from product development through use. New York, NY, United States, McGraw-Hill Education, 2001.

GROVE, D. The Vertical Integration of Mechatronics at Virginia Tech. Thesis Submitted to the Faculty of Virginia Polytechnic Institute and State University. Blacksburg, Virginia, 2001 .

GROVER, V. Business process change: concepts, methods and technologies. Harrisburg, PA, United States, Idea Group Publishing, 1995.

HAMMER, M. e CHAMPY, J. Reengenharia: revolucionando a empresa em função dos clientes, da concorrência e das grandes mudanças da gerência. Rio de Janeiro: Campus, 1994.

HARMSEN, H. et al. . Company competencies as a network: the role of product development. Journal of Product Innovation Mangament, 17, p. 194-207, 2000.

HILLER, M. H. e HIRSCH, K. Multybody system dynamics and mechatronics. In: Z. Angew. Math. Mech, 86, No. 2, p. 87-109, 2006.

HISTAND, M. e ALCIATORE, D. Introduction to Mechatronics and Measurement Systems. Colorado: McGraw-Hill, 3 edition, 2006.

HÖHNE, G. Projeto de componentes mecânicos para produtos mecatrônicos. In: CONGRESSO BRASILEIRO DE GESTÃO DO DESENVOLVIMENTO DE PRODUTOS, 3, Florianópolis. Anais do III Congresso Brasileiro de Gestão de Desenvolvimento de 
Produtos. INSTITUTO DE GESTÃO DO DESENVOLVIMENTO DE PRODUTOS, Florianópolis/SC, 2001, 1 CD-ROM.

HORIKAWA, O. Características de projeto de sistemas mecatrônicos. Tese de Livre Docência. São Paulo: Universidade de São Paulo, Escola Politécnica, 2000.

HOROWITZ, P. e HILL, W. The art of electronics. Cambridge, United Kingdom, Cambridge University Press, 1999.

HUNT, V.D. Mechatronics: Japan's Newest Threat. New York, United States, Chapman and Hall, 1988.

INTERNATIONAL ELECTROTECHNICAL COMMISSION. IEC 60601-1:1988, Medical electrical equipment: Part 1-2: General requirements for safety. Second Edition. Suíça (Genébra): IEC, 1988, 351p.

IEC 60825:1994, Safety of laser products: Part 1. Equipment classification, requirements and user's guide, Bélgica (Bruxelas): IEC, 1994, 112p.

IEC 60601-1-2:2003, Medical electrical equipment: Part 1-2: General

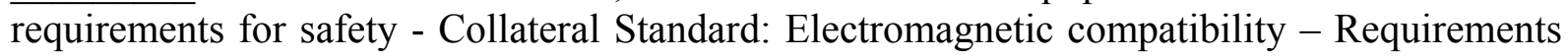
and tests . Second Edition. Suíça (Genébra): IEC, 1988, 83p.

INSTITUTE OF ELECTRICAL AND ELECTRONICS ENGINEERS. IEEE STD 1220, Standard for application and management of the systems engineering process. Software Engineering Standard Committee, 1998a.

IEEE STD. 1320.1, Standard for functional modeling language - syntax and semantics for IDEF0. Software Engineering Standard Committee of the IEEE Computer Society, $1998 b$.

JAMES, P. Mechatronics and automotive systems design. In: International Journal of Electrical Engineering Education, 41 (4), p. 307-312, 2004.

JET PROPULSION LABORATORY. Disponível http://mars.jpl.nasa.gov/mer/mission/spacecraft_rover_antennas.html. Acesso em 22/11/2005.

JÚNIOR, P.J. Etnografia, antropologia e o universo organizacional. Revista de Administração Pública, Rio de Janeiro, v.30, n.6, p. 105-121, 1996.

Ligações perigosas: breves reflexões sobre as relações entre antropologia e administração. Revista de Administração Pública, Rio de Janeiro, v.30, n.4, p. 108-137, 1996.

KAPLAN, R.S. e NORTON, D.P. A Estratégia em ação: balanced scorecard. Tradução: Luiz Euclides Trindade Frazão Filho. Rio de Janeiro/RJ: Editora Campus, 1997.

Mapas estratégicos: convertendo ativos intangíveis em resultados tangíveis. Tradução de Afonso Celso da Cunha Serra. Rio de Janeiro/RJ: Editora Campus, 2004.

KHAN, M. R. R. Business process reengineering of an air cargo handling process. International Journal of Production Economics, 63, p. 99-108, 2000. 
KIM et al.. The complementary use of IDEF and UML modelling approaches. Computers in industry, 50, p. 35-56, 2003.

KOSANKE, K. CIMOSA: overview and status. Computers in Industry, 27, p. 101-109, 1995.

KOTLER, P. Administração de marketing: análise, planejamento, implementação e controle. São Paulo/SP: Editora Atlas, 2000.

KOTTEAKU, A.G. et al.. The influence of product complexity on the purchasing structure. Omega International Journal of Management Science, v. 23, n.1, p. 27-39, 1995.

KUNH, T.S. A estrutura das revolucoes cientificas. São Paulo/SP: Editora Perspectiva, 1995.

LAKATOS, E. M.; MARCONI, M. A. Fundamentos de Metodologia Científica. São Paulo, Atlas, 1991.

LEAN PRODUCT DEVELOPMENT GROUP. Disponível em: http://www.lean-productdevelopment.com. Acesso em 12/12/2004.

LETTY, R. et al. Actuators in adaptronics: piezoelectric actuators. THEMATIC CONFERENCE ON SMART STRUCTURES AND MATERIALS, 2, Lisboa. Anals of II ECCOMAS Thematic conference on smart structures and materials, Lisboa, Portugal, July, p. 18-21, 2005.

MAGEE, B. Idéias de Popper. São Paulo, Cultrix, 1979.

McMANUS, H. Product development value stream analysis and mapping manual (PDVSM) - Alpha draft. Lean Aerospace Initiative, Center for Technology, Policy, and Industrial Development. Cambridge, Massachusetts, Massachusetts Institute of Technology, 2003.

MECHATRONICS AT RENSSELAER. Disponível em: www.rpi.edu/ craigk. Acesso em 21/05/2005.

MIL-HDBK-217F (2). MILITARY HANDBOOK. Reliability Prediction of Electronic Equipment. Department of Defense, Washington DC, USA, 1995.

MIL-STD-881. MILITARY HANDBOOK. Work Breakdown Structure for Defense Materiel Items, Military Standard/ Department of Defense, Washington DC, USA,1998.

MOORE, G. The Future of the European MicroElectronics Industry. MEDEA+Board, 2003.

MOTOROLA. High Data Rate Wireless USB Optical Mouse Solution Using the MC68HC908QY4 and MC68HC908JB12 - Designer Reference Manual, 2004.

MOULIANITIS et al.. A model for concept evaluation in design - an application to mechatronics design of robot grippers. Mechatronics, 14, p. 599-622, 2004.

MUNDIN, A. P. F. Desenvolvimento de produtos e educação corporativa. São Paulo: Ed. Atlas, 2002. 
MIYAGI et al. Petri Net approach for modelling system integration in intelligent buildings. In: Journal of the Brazilian Society of Mechanical Sciences, vol. 24, no. 4, Rio de Janeiro, Nov. 2002.

MULTIDIMENSIONAL MATURITY. Disponível em: http://www.mdmaturity.com. Acesso em 02/02/2005.

NASCIMENTO, P.T.S. Desenvolvimento de produto: o foco da administração estratégica da tecnologia na indústria eletrônica brasileira. Tese de doutorado - Faculdade de Economia, Administração e Contabilidade, Departamento de Administração, Universidade de São Paulo, São Paulo/SP, 1995.

NEW PRODUCT DEVELOPMENT SOLUTIONS. Disponível em: http://www.npdsolutions.com. Acesso em 11/11/2004.

NONAKA, I. e TAKEUSCHI, H. Criação de conhecimento na empresa. Trad. Ana Beatriz Rodrigues, Priscilla Martins Celeste - Rio de Janeiro: Campus, 1997.

OPTO ELETRÔNICA S.A. Procedimento 7.3-PRO-01, projeto do produto, São Carlos, 2006.

Relatório técnico do OPTO ADS, São Carlos, 2005a.

. Manual do usuário do OPTO ADS, São Carlos, 2005b.

. Relatório de análise de riscos do OPTO ADS, São Carlos, 2005c.

2005 d.

. Procedimento de montagem da fonte de alimentação do OPTO ADS, São Carlos,

2004a.

Procedimento de montagem da mesa elevatória do OPTO ADS, São Carlos, . Validação do software CONRET01 do OPTO ADS, São Carlos, 2004b.

PÁDUA, S.I.D. Investigação do processo de desenvolvimento de Software a partir da Modelagem Organizacional, enfatizando regras do negócio. São Carlos. 144 p. Dissertação (Mestrado) - Escola de Engenharia de São Carlos, Universidade de São Paulo, 2000.

PAHL, G. e BEITZ, W. Engineering design: a systematic approach - 2Rev.ed. SpringerVerlag London Limited, London, Great Britain, 1996.

PAULA FILHO, W. P. Engenharia de software: fundamentos, métodos e padrões. Rio de Janeiro, LTC - Livros Técnicos e Científicos Editora S.A., 2001.

PAWAR, K.S. e DRIVA, H. Performance measurement for product design and development in a manufacturing environment. International Journal of Production Economics, 60-61, 61-68, 1999.

PIDD, M. Modelagem empresarial: ferramentas para a tomada de decisão. Trad. Gustavo Severo de Borba. Porto Alegre, Bookman, 1998. 
PIRES, S. R. I. Gestão estratégica da produção. Piracicaba/SP: Unimep, 1995.

PORTER, M.E. Estratégia competitiva: técnicas para análise de indústria e da concorrência. Tradução: Elizabeth Maria de Pinto Braga. Rio de Janeiro/RJ: Editora Campus, 1991.

A vantagem competitiva das nações. Tradução: Waltensir Dutra. Rio de Janeiro/RJ: Editora Campus, 1993.

PRASAD, B. Concurrent engineering fundamentals: integrated product and process organization. New Jersey, United States, Prentice Hall, 1996.

. Concurrent engineering fundamentals - volume II: integrated product development. Nex Jersey, United States, Prentice Hall, 1997.

PRESSMAN, R. Sotware engineering: a practitioner's approach. 5th ed. New York, McGraw-Hill Higher Education, 2001.

PROJECT MANAGEMENT INSTITUTE (PMI). Project Management Body of Knowledge - PMBOK (Tradução Livre), Capítulo de Minas Gerais do PMI, 2005.

PUGH, S. Total design: integrated methods for successful product engineering. Addison Wesley, London, United Kingdom, 1990.

REINHART, G. e HAGEN, F. Integrated and Distributed Product Development Through Paralleled Mechanical and Electrical. In: Anals of CIRP-Seminar "Design in the new Economy". Stockholm: KTH (Eigenverlag), S. 115-120, 2001.

RIBENS, J. Simultaneous Engineering for New Product Development: Manufacturing Applications. New York, John Wiley e Sons Inc. 2000.

ROBERTSON, D. e ULRICH, K. Planning for product platforms. Sloan Management Review, 19-31, Summer, 1998.

ROBERTS, G. e KING. T. Twelve Years of the Mechatronics Journal. Mechatronics, 13, pp. 1025-1028, 2003.

ROUSSEL, P.A. et al.. Pesquisa e desenvolvimento: como integrar P\&D ao plano estratégico e operacional das empresas como fator de produtividade e competitividade. Tradução José Carlos Barbosa dos Santos. São Paulo/SP, Editora Makron Books, 1992.

ROZENFELD, H. Reflexões sobre a Manufatura Integrada por Computador. In: AMATO, J. (org) Manufatura de Classe Mundial: mitos e realidade, São Paulo/SP: Editora Atlas, 1996.

ROZENFELD, H. et al.. Gestão de Desenvolvimento de Produtos. São Paulo/SP: Editora Saraiva, 2006.

RZEVSKI, G. On Conceptual Design of Intelligent Mechatronic Systems. Mechatronic $s, 13$, pp. 1029-1044, 2003.

SADAUNE, V. e PHILIPPE, B. La mécatronique dans la formation d'ingénieurs généralistes. Mécanique e Industries, 3, pp. 99-106, 2002. 
SALERNO, M.S. Projeto de organizações integradas e flexíveis: processos, grupos e gestão democrática via espaços de comunicação-negociação. São Paulo: Editora Atlas S.A., 1999.

SANTOS, R.P.C. Engenharia de processos: análise do referencial teórico-conceitual, instrumentos, aplicações e casos. Dissertação (mestrado), Universidade Federal do Rio de Janeiro - COPPE, Rio de Janeiro, 2002.

SCHEER, A.W. ARIS - Business process framework, completely revised and enlarged. Ed. Berlin, Springer-Berlag, 1998.

ARIS - Business process modeling, completely revised and enlarged. Ed. Berlin, Springer-Berlag, 1999.

SERVA, M. e JÚNIOR, P.J. Observação participante e pesquisa em administração: uma postura antropológica. Revista de Administração de Empresas, São Paulo, v.35, n.1, 64-79, 1995.

SLACK et al. Administração da Produção. Trad. Maria Teresa Corrêa de Oliveira, Fábio Alher; Rev. Henrique Luiz Corrêa. 2 ed. São Paulo, Atlas, 2002.

SPINK, P. Pesquisa-ação e a análise de problemas sociais e organizacionais complexos. Psicologia, v.5, n.1, 31-44, 1979.

STAGE-GATE. Disponível em: http://www.prod-dev.com/stage-gate.shtml. Acesso em $25 / 10 / 2004$

STRUSS, P. et al. Model-based Tools for The Integration and Design and Diagnosis into a Commom Process - A Project Report. www.tuv.de, acesso em 13/03/2005.

SYAN, C. S. e MENON, U. (1994). Concurrent engineering: concepts, implementation and practice. London, Chapman \& Hall, 1992.

TATIKONDA, M.V. An empirical study of Platform and Derivative product development projects. Journal of Product Innovation Mangament, 16, p. 3-26, 1999.

TECHNICAL SUPPORT ARTICLES. Disponível em: http://www.autoshop101.com/autoshop15.html. Acesso em 23/12/2005.

TERRA, J. R. et al., 2005, Taxonomia: alguns conceitos e algumas confusões. www.terraforum.com.br, acesso em 25/11/2005

TERWIESCH, C. et al. When product development performance makes a difference: a statistical analysis in the electronics industry. Journal of Product Innovation Mangament, 15, p. 3-15, 1998.

THE D-JETRONIC ELECTRONIC CONTROL UNIT. Disponível em: http://members.rennlist.com/pbanders/ecu.htm. Acesso em 21/11/2005

THIOLlENT, M. Metodologia da pesquisa-ação. São Paulo/SP: Editora Cortez, 1994. Pesquisa-ação nas organizações. São Paulo/SP: Editora Atlas, 1997. 
THÖLKE, J.M. et al.. Lauching new product features: a multiple case examination. Journal of Product Innovation Mangament, 18, 3-14, 2001.

TOMATIS et al.. A Complex Mechatronic System: from Design to Application. INTERNATIONAL CONFERENCE ON ADVANCED INTELLINGENT MECHATRONICS, 4, 2001, Como. IEEE/ASME International Conference on Advanced Intelligent Mechatronics Proceedings. IEEE/ASME, Como, 2001.

THE FEDERAL AVIATION ADMINISTRATION. Disponível em: http://www.faa.gov/aio. Acesso em 17/11/2004.

UNIQUE Ics. Disponível em: http://www.uniqueics.com/htmls/od optical mouse.htm. Acesso em 23/11/2005.

ULRICH, K.T., EPPINGER, S.D. Product design and development. McGraw-Hill Inc. United States, 1995.

VALERIANO, D.L. Gerenciamento estratégico e administração por projetos. São Paulo/SP: Editora Makron Books, 2001.

VERNADAT, F. B. Enterprise modelling and integration: principles and applications. Chapman e Hall, London, United Kingdom, 1996.

VERZUH, E. MBA Compacto: gestão de projetos. Tradução de André de L. Cardoso. Rio de Janeiro/RJ: Campus, 2000.

WALTERS et al.. (2000). A conceptual study for a computer-based tool to support electronics design in a mechatronic environment. Microprocessors and Microsystems, 24, p. 51-61, 2000 .

WHEELWRIGHT, S. C. e CLARK, K. B. Revolutionizing product development process: quantum leaps in speed, efficiency, and quality. New York, United States, The Free Press, 1992.

Leading product development: the senior manager's guido to creating and shaping the enterprise. New York, United States, The Free Press, 1995.

WRIGHT, I.C. et al. A survey of methods utilisation during the product design process in UK industry. Training Resource, Loughborough University of Technology, 1995. (Research Report).

YIN, R. Estudo de caso: planejamento e métodos. Trad. Daniel Grassi. Rev. Cláudio Damacena. 2 ed. Porto Alegre: Bookman, 2001. 